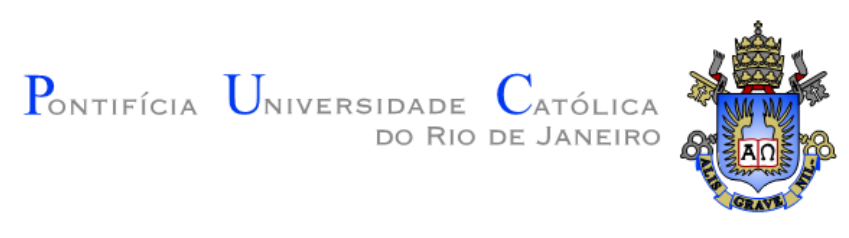

Pollyana de Lima Massari

Estudo Experimental em Túnel de Vento da Dispersão de Plumas em Escoamentos Turbulentos Atmosféricos

Dissertação de Mestrado

Dissertação apresentada como requisito parcial para obtenção do grau de Mestre pelo Programa de PósGraduação em Engenharia Mecânica da PUC-Rio.

Orientador: Prof. Marcos Sebastião de Paula Gomes 


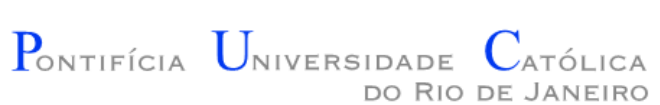

Pollyana de Lima Massari

\section{Estudo Experimental em Túnel de Vento da Dispersão de Plumas em Escoamentos Turbulentos Atmosféricos}

Dissertação apresentada como requisito parcial para obtenção do grau de Mestre pelo Programa de PósGraduação em Engenharia Mecânica da PUC-Rio. Aprovada pela Comissão Examinadora abaixo assinada.

Prof. Marcos Sebastião de Paula Gomes

Orientador Departamento de Engenharia Mecânica - PUC-Rio

Prof. Igor Braga de Paula Departamento de Engenharia Mecânica - PUC-Rio

Maria Helena Farias Inmetro

Prof. Márcio da Silveira Carvalho Coordenador Setorial do Centro Técnico Científico - PUC-Rio 
Todos os direitos reservados. É proibida a reprodução total ou parcial do trabalho sem autorização da universidade, da autora e do orientador.

\section{Pollyana de Lima Massari}

Graduou-se em Engenharia Mecânica na UCP (Universidade Católica de Petrópolis) em 2014. Possui experiência na área de pesquisa, como colaborador do Inmetro (Instituto Nacional de Metrologia, Qualidade e Tecnologia). Participou de diversos congressos internacionais de engenharia mecânica.

Ficha Catalográfica

Massari, Pollyana de Lima

Estudo experimental em túnel de vento da dispersão de plumas em escoamentos turbulentos atmosféricos / Pollyana de Lima Massari ; orientador: Marcos Sebastião de Paula Gomes. - 2017.

148 f. : il. color. ; $30 \mathrm{~cm}$

Dissertação (mestrado)-Pontifícia Universidade

Católica do Rio de Janeiro, Departamento de Engenharia Mecânica, 2017.

Inclui bibliografia

1. Engenharia Mecânica - Teses. 2. Túnel de vento. 3. Camada limite atmosférica. 4. Pluma. 5. Dispersão de poluentes. I. Gomes, Marcos Sebastião de Paula. II. Pontifícia Universidade Católica do Rio de Janeiro. Departamento de Engenharia Mecânica. III. Título. 


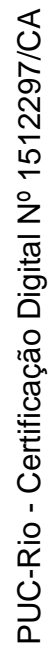

À minha família, pelo incentivo e contribuição, dedico-lhes essa conquista como gratidão. 


\section{Agradecimentos}

Agradeço primeiramente a Deus, por ter guiado meus passos até aqui e por permitir que tudo isso acontecesse.

Aos meus pais que com muito carinho, apoio e incentivo, não mediram esforços para que eu chegasse até esta etapa da minha vida.

Ao meu irmão pelo companheirismo e ajuda prestada em diversos momentos.

A minha querida avó pelas orações, paciência e incentivo constante durante toda essa jornada.

Agradeço ao meu orientador Marcos Sebastião, por ter me passado seu conhecimento e pela orientação proporcionada durante todo este trabalho.

Agradeço ao meu amigo Fábio Ouverney por todo o apoio, auxilio e incentivo prestados que foram indispensáveis.

Agradeço aos professores Igor Braga de Paula e Maria Helena Farias por terem aceitado fazer parte da banca avaliadora e por toda ajuda prestada. E ao Inmetro por disponibilizar toda infraestrutura necessária para realização deste trabalho. 


\section{Resumo}

Massari, Pollyana de Lima; Gomes, Marcos Sebastião de Paula. Estudo Experimental em Túnel de Vento da Dispersão de Plumas em Escoamentos Turbulentos Atmosféricos. Rio de Janeiro, 2017. 148p. Dissertação de Mestrado - Departamento de Engenharia Mecânica, Pontifícia Universidade Católica do Rio de Janeiro.

A questão da poluição ambiental está recebendo cada vez mais importância. Por esse motivo, os estudos relacionados a processos de dispersão de poluentes estão ganhando cada vez mais destaques. Como estudos em campo são mais custosos, os estudos realizados em laboratório, com modelos reduzidos, estão sendo mais aplicáveis, uma vez que permitem análises de problemas específicos. Este trabalho tem como objetivo realizar um estudo exploratório em um túnel de vento do comportamento de uma pluma emitida por uma chaminé, que permita modificações nas condições de velocidade e temperatura da pluma. Para isso, foi realizada a reprodução da camada limite atmosférica, através do Método de Irwin, simulando um ambiente suburbano, em que o perfil de velocidades média foi medido com a técnica de Anemometria de Fio Quente. Foram realizados ensaios para três condições do escoamento principal e levantados os perfis de velocidade e intensidade turbulenta à jusante da chaminé. Foi realizado um estudo da inclinação da pluma, tanto pela influência da velocidade, quanto pela diferença de temperatura da pluma em relação à do escoamento principal, que foi variada em 10 e $20^{\circ} \mathrm{C}$. As análises de concentração foram possíveis através das imagens obtidas com a técnica de Velocimetria por Imagem de Partículas. Foram feitas análises do perfil de concentração a diferentes posições a sotavento da chaminé e o coeficiente de dispersão vertical $\left(\sigma_{z}\right)$ obtido foi comparado com diversas literaturas conhecidas.

\section{Palavras-chave}

Túnel de vento; camada limite atmosférica; pluma; dispersão de poluentes 


\section{Abstract}

Massari, Pollyana de Lima; Gomes, Marcos Sebastião de Paula (Advisor). Experimental study in wind tunnel of the plumes dispersion in turbulent atmospheric flows. Rio de Janeiro, 2017. 148p. Dissertação de Mestrado - Departamento de Engenharia Mecânica, Pontifícia Universidade Católica do Rio de Janeiro.

Environmental pollution issue is becoming increasingly important. For this reason, studies related to processes of atmospheric dispersion of pollutants are gaining prominence. Since studies in situ are expensive, laboratory studies with reduced models are useful, since specific problem can be investigated. The present work performs an experimental study, in a wind tunnel, evaluating the behavior of a plume generated by a chimney. For this, the reproduction of the atmospheric boundary layer was made, using the Irwin method, simulating a suburban environment, in which the mean velocity profile was measured with the Hot Wire Anemometry technique. Tests were performed for three main flow conditions and the profiles of velocity and turbulent intensity were made upstream of the stack. A study of the bent of the plume was made, both by the influence of the velocity, and by the temperature difference between the plume and the main flow, that was varied at 10 and $20^{\circ} \mathrm{C}$. The concentration analyzes were possible through the images obtained with the Particle Image Velocimetry technique. Concentration profile analyzes were performed at different leeward positions of the chimney and the vertical dispersion coefficient $\left(\sigma_{z}\right)$ obtained was compared with several known literatures.

\section{Palavras-chave}

Wind tunnel; Atmospheric boundary layer; Plumes; Pollutant dispersion 


\section{Sumário}

1 Introdução

2 Revisão bibliográfica 13

2.1.Experimentos com camada limite atmosférica 13

2.2. Estudos de dispersão de plumas 20

3 Conceitos Fundamentais $\quad 27$

3.1. Camada limite atmosférica 27

3.2. Estabilidade atmosférica 29

3.2.1. Atmosfera neutra, instável e estável 30

3.3. Turbulência e intensidade turbulenta 32

3.4. Perfil de velocidades do vento 33

4 Dispersão atmosférica $\quad 35$

4.1. Modelos de dispersão de poluentes 36

4.1.1. Modelo gaussiano 37

4.1.2. Parâmetros de dispersão no modelo gaussiano 38

4.1.3. Crescimento da pluma 42

4.2. Análise de concentração 43

5 Metodologia experimental e instrumentação 45

5.1.Túnel de vento atmosférico do Inmetro 45

5.1.1.Técnica experimental para simulação da camada limite $\begin{array}{ll}\text { atmosférica no túnel de vento } & 47\end{array}$

5.1.2. Simulação computacional para reprodução da camada limite atmosférica no túnel de vento 50

5.2. Instrumentação para análise de escoamentos 52

5.2.1. Anemometria de fio quente 52

5.3.Instrumentação para análise de processos de dispersão

de plumas $\quad 54$ 
5.3.1.Velocimetria por Imagem de Partículas

5.3.1.1. Montagem do sistema PIV no túnel de vento 56

5.3.2. Sistema de injeção de partículas na chaminé

6 Estratificação térmica do túnel de vento atmosférico 60

6.1. Camada limite convectiva 60

6.2. Estratificação térmica em túneis de vento 61

6.3. Montagem para realizar o aquecimento do túnel de vento 63

6.3.1. Calibração dos termopares 65

6.3.2. Incerteza dos Termopares 66

7 Resultados e discussões 69

7.1. Planejamento dos experimentos 69

ङ 7.2. Caracterização do túnel de vento 70

7.3. Verificação da camada limite atmosférica gerada 72

7.3.1. Análise em frequência do túnel de vento 81

7.3.2. Medições do perfil de temperatura no túnel de vento atmosférico 83

7.4. Resultados do estudo do processo de dispersão da pluma $\quad 90$

7.4.1. Análises do perfil do escoamento 90

7.5. Análise de concentração da pluma 121

7.5.1. Flutuações de concentração da pluma 128

7.6. Análise da dispersão vertical $\left(\sigma_{z}\right)$ da pluma 131

8 Conclusões 135

9 Referências bibliográficas 137 


\section{1 \\ Introdução}

A poluição do ar é um problema bem conhecido mundialmente. É de grande preocupação a pureza do ar que inalamos e o impacto dos poluentes dispersados por chaminés industriais, uma vez que estes têm amplo impacto na natureza e na saúde dos seres vivos. Em relação à saúde pública, a poluição do ar associada a zonas urbanas ou industriais, nas quais o ambiente exterior é contaminado por emissões de indústrias e de automóveis, está ganhando uma importância cada vez maior em relações a estudos para se avaliar e minimizar o impacto da poluição.

Atualmente, existem leis para regulamentação de emissões industriais lançadas na atmosfera e, devido a essas exigências, o estudo relacionado à dispersão e concentração de poluentes tornou-se imprescindível para atender tais regulamentações e avaliar o perigo potencial para os seres humanos e o meio ambiente. A poluição tornou-se assim, um problema mundial, influenciando todos os aspectos do desenvolvimento.

As escalas de movimento atmosférico desempenham um importante papel na poluição do ar, embora em diferentes magnitudes de tempo. Os efeitos meteorológicos de micro escala, por exemplo, que tem escalas de tempo na ordem de minutos a algumas horas, determinam a dispersão de uma pluma emitida por uma chaminé industrial. Por outro lado, os fenômenos de meso escala que ocorrem ao longo de horas ou dias, influenciam o transporte e a dispersão de poluentes para áreas que estão a centenas de quilômetros de suas fontes. A maior parte das emissões de gases e vapores, seja por atividades antropogênicas ou pela própria natureza, entram na atmosfera pelo nível inferior da troposfera, que corresponde a região da camada limite atmosférica.

Os processos de difusão e transporte dos poluentes dependem de diversos fatores. O grau de mistura, tempo de vida, distância que podem atingir e concentração dos poluentes, estão diretamente ligados a fatores como: condições 
meteorológicas, natureza do contaminante, características da chaminé, características do terreno, entre outros.

Os gases poluentes podem ser espalhados por vários quilômetros (Figura 1), devido à característica dinâmica da atmosfera, prejudicando a fauna, flora e a saúde da população. Ficam cada vez mais aparentes as mudanças climáticas e os danos que os poluentes atmosféricos causam à população. Portanto, é necessário pesquisar, conhecer e analisar o comportamento desse efeito na atmosfera.

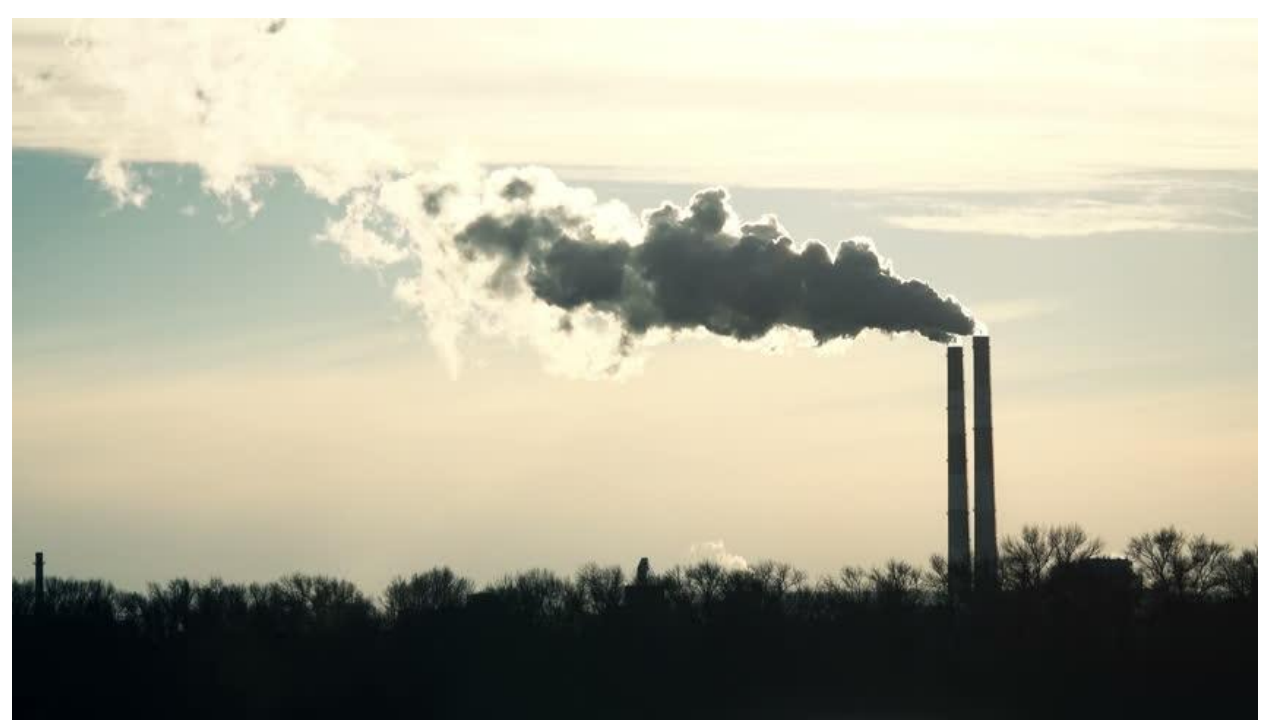

Figura 1. Emissão de poluentes a partir de chaminés de uma usina (Shutterstock, 2017)

O grau de mistura de poluentes nos primeiros quilômetros da fonte de emissão é determinado, em grande parte, pelo perfil de temperatura da atmosfera e pela velocidade e perfil do vento.

A dispersão das chaminés das fábricas é um problema de importância considerável, tanto no que diz respeito à saúde da população quanto por razões econômicas. Desta forma, atualmente estão sendo desenvolvidos diversos trabalhos, tanto experimentais quanto computacionais, relacionados a esse fenômeno. Estes últimos, muitas vezes, necessitam ser validados com resultados experimentais. O túnel de vento se torna, então, indispensável para tal estudo. Para que um ambiente em laboratório se torne viável para tais pesquisas, é necessário que esta bancada reproduza as características da camada limite atmosférica, turbulência, estabilidade térmica para que se possa simular processos de dispersão 
da forma mais realista possível. Os estudos deste tipo, além de permitirem a validação dos modelos numéricos, servem para analisar problemas específicos de dispersão de poluentes atmosféricos.

Conhecendo o problema e a necessidade de se pesquisar a dispersão de poluentes, o presente trabalho tem como objetivo adequar o túnel de vento do Instituto Nacional de Metrologia, Qualidade e Tecnologia (Inmetro) para simular condições atmosféricas. A técnica proposta pro Irwin (1981) foi utilizada para simular uma camada limite atmosférica no túnel de vento. Para o ajuste da camada limite é necessário um conhecimento prévio do perfil de escoamento que reproduz a camada limite atmosférica. A condição simulada neste trabalho foi um ambiente suburbano, onde tipicamente estão localizadas as regiões industriais. O objetivo é realizar estudos de dispersão de uma pluma emitida por uma chaminé nesse ambiente, modelando uma fonte de emissão pontual de uma chaminé, permitindo modificações tanto na velocidade do escoamento principal quanto na velocidade e temperatura do escoamento emitido pela chaminé.

A estrutura deste trabalho possui 8 capítulos. No Capítulo 2 é apresentada uma revisão bibliográfica, dividida em duas partes: simulações em túnel de vento para geração da camada limite atmosférica e experimentos envolvendo a dispersão da pluma de uma chaminé. No Capítulo 3 apresentados conceitos fundamentais para entendimento do trabalho, envolvendo características dinâmicas da atmosfera, conceitos de turbulência e de camada limite. No Capítulo 4 são apresentados conceitos relacionados ao processo de dispersão de poluentes e modelos analíticos utilizados para a simulação do processo de dispersão de uma pluma de contaminantes. O Capítulo 5 apresenta a metodologia experimental, mostrando os equipamentos e as técnicas de medição utilizadas para realização do trabalho. No Capítulo 6 é abordada a instalação da estratificação térmica do túnel de vento e no Capítulo 7 são apresentados os resultados e feitas as discussões. Por fim, as conclusões da pesquisa e sugestões para futuros trabalhos são apresentadas no Capítulo 8 . 


\section{2 Revisão bibliográfica}

\section{1. Experimentos com camada limite atmosférica}

Antigamente, a maioria dos túneis de vento eram construídos para fins aeronáuticos, possuindo seções de teste com um comprimento relativamente curto para que uma camada limite atmosférica se desenvolvesse. Os laboratórios não possuíam recursos para construir túneis com longas seções de testes, e, portanto, iniciou-se uma série de tentativas para tentar simular, com métodos artificiais, as características de uma camada limite atmosférica. A base da metodologia para reproduzir uma camada limite atmosférica utiliza-se de elementos de rugosidade dimensionados de acordo com parâmetros descritivos da camada limite atmosférica real. Assim, quando o escoamento, no interior do túnel de vento, atinge esses elementos de rugosidade, causa uma mudança no seu perfil de velocidade e gera fenômenos de turbulência. Deste modo, diversas pesquisas foram realizadas a fim de se obter uma correlação entre o dimensionamento dos elementos de rugosidade e o perfil de velocidades médias do escoamento.

Inicialmente, esses métodos artificiais, como barras transversais e telas dobradas (Owen e Zienkiewicz, 1957 e Elder, 1957), conseguiam reproduzir somente as características do perfil de velocidade, sendo incapazes de reproduzir as propriedades de turbulência (Lawson, 1968).

O primeiro túnel de vento com camada limite foi construído em 1965 pelo Prof. Davenport, na Universidade de Western Ontario, Canadá (Souza, 2004). O desenvolvimento da camada limite atmosférica foi gerado a partir de rugosidades acopladas ao chão do túnel. Posteriormente, começaram a surgir novos túneis, projetados especificamente para este fim (Cermak, 1977; Davenport; Cook, 1978; Blessmann, 1982; Hertig, 1984; Stathopoulos, 1984; Hansen, 1985).

No trabalho de Counihan, (1969), foram sugeridos diversos métodos para melhorar as características da camada limite atmosférica gerada, modificando por exemplo, a forma dos spires (triângulos) em elipses. O autor acrescentou também 
uma barreira na entrada do túnel de vento. Assim, Counihan (1969) concluiu que os métodos melhoraram os parâmetros da camada limite alcançada. Porém, esses métodos foram obtidos praticamente por tentativa e erro, dificultando a formulação de equações simples para o dimensionamento de elementos de rugosidade (Hunt e Fernholz, 1975).

No trabalho de (Schon e Mery, 1971), foi utilizado um método de injeção de ar no início do túnel de vento para que obtivessem um aumento significativo na espessura da camada limite do túnel. Esse experimento foi realizado num túnel de vento com uma seção transversal de $1,20 \times 1,00 \mathrm{~m}^{2}$, do tipo circuito aberto e os dados de velocidade, medidos com o tubo de pitot, foram comparados com dados atmosféricos reais. A intensidade turbulenta obtida foi em torno de $3 \%$.

Segundo (Plate, 1971) há duas principais razões para simular a camada limite atmosférica em um túnel de vento. A primeira é ajudar a compreender os escoamentos de ar na atmosfera, o que requer colaboração entre engenheiros e meteorologistas. A segunda é ajudar a resolver problemas de engenharia, tais como (i) prever as forças do vento sobre as estruturas, tanto as forças globais como as pressões locais flutuantes sobre a estrutura; (ii) prever a forma como as estruturas afetam o vento, por exemplo, a perturbação que causam às pessoas que caminham perto dos edifícios; e (iii) estudar a dispersão de plumas de chaminés e outras fontes de poluição atmosférica. Ele examinou os vários meios artificiais de se desenvolver uma camada limite com espessura considerável em uma curta distância ao longo de um túnel de vento e de simular as variações de temperatura na camada limite atmosférica. Plate concluiu que estudos de difusão da pluma na atmosfera só pode ser feita com extidão perto da fonte, principalmente porque a guinada do vento na direção vertical, que não é simulada em um túnel de vento, afeta a difusão a poucos quilômetros da fonte.

Robins (1975) apresentou uma investigação detalhada do desenvolvimento de uma camada limite para o estudo de emissões de chaminé em um escoamento neutralmente estável. Ao espessar artificialmente a camada limite com uma combinação de uma cerca, geradores de vorticidade (Counihan, 1969) e uma superfície áspera, Robins descobriu que a turbulência na camada limite atingiu um estado de equilíbrio de cerca de 7 vezes a espessura de camada limite na direção do vento. Gandemer (1979) desenvolveu um novo túnel de vento semelhante ao da Universidade de Western Ontario, no Canadá (Souza, 2004). A seção de trabalho 
tem um teto ajustável e a camada limite é formada por jatos direcionais posicionados no assoalho e por diferentes graus de rugosidade do piso, na entrada da seção de trabalho.

O túnel de vento da Universidade de Bristol foi projetado principalmente para estudar cargas de vento em edifícios em áreas urbanas. E no trabalho de Bray apenas o terço inferior da camada limite atmosférica foi simulado, sendo os métodos de espessamento artificiais uma grade (malha de 0,3 m), uma barreira e elementos de rugosidade. As medições realizadas no túnel de vento de perfil médio de velocidade e intensidade turbulenta foram comparadas com medições em escala real.

Dye demostrou como um túnel de vento curto, de 1,5 m de comprimento, pode ser usado para simular o escoamento do vento ao redor de edifícios. Para simular velocidade média do vento em torno de edifícios altos, é importante simular o perfil de velocidade do vento natural, mesmo se a turbulência não for bem modelada (Wise, 1971). Neste caso, foi utilizada uma grade como elemento de rugosidade e foi descrita uma investigação específica sobre o escoamento em torno dos edifícios da Universidade de Manchester.

Posteriormente, Irwin (1981) propôs algumas equações empíricas para desenvolver uma camada limite em túneis de vento de curto comprimento. Esse método propõe que spires, elementos de rugosidade triangulares, sejam instalados na seção de entrada do túnel de vento, e que o escoamento anterior a esses elementos seja uniforme. $\mathrm{O}$ dimensionamento desses spires está ligado diretamente à lei da potência e é necessário inserir parâmetros da camada limite que se quer obter, tais como expoente $\alpha$ da lei da potência e espessura $\delta$ da camada limite. Por ser um método relativamente simples, atualmente este é um dos mais utilizados para ajudar na formação da camada limite atmosférica. Por esse motivo é o método utilizado nesse trabalho. No trabalho de Guimarães et al. (1999), foram testados três tipos de elementos geométricos para o desenvolvimento da camada limite requerida. Seguindo o trabalho de Counihan (1969), o autor utilizou-se de grelhas, geradores elípticos, varetas cilíndricas e barras retangulares, mostrados na Figura 2.
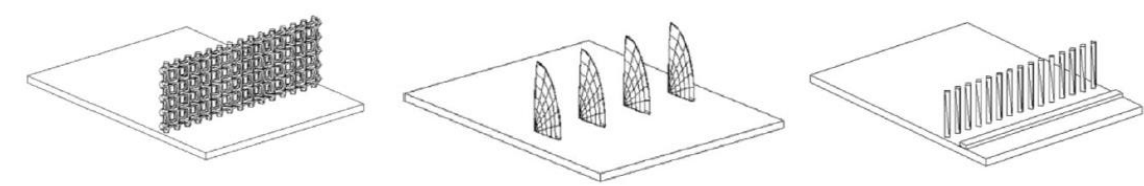

Figura 2. Grade, geradores elípticos e hastes (Guimarães, et al., 1999) 
No trabalho de Girardi e Catarina (2000), o objetivo era simular uma camada limite atmosférica de cerca de $30 \mathrm{~cm}$ de espessura, porém, o túnel de vento disponível tinha pouco menos de 3 metros de comprimento. O método que se mostrou mais adequado para simular uma região com vento marítimo, foi o Método de Irwin (Irwin, 1981), utilizando spires na entrada da seção de testes. Para o túnel de vento do trabalho de Girardi, com seção transversal quadrada de $460 \mathrm{~mm}$, utilizando as fórmulas empíricas de Irwin, a dimensão dos spires é de 32,6 mm (base) e 307,7 mm (altura).

Al-Nehari et al. (2009) realizaram uma série de experimentos no túnel de vento da Universidade de Assiut, Egito, a fim de avaliar as características do túnel, uniformidade do escoamento e verificar a sua adequação para simular a camada limite atmosférica. O objetivo de simular essa camada limite foi para posteriormente realizar estudos ambientais e avaliar a dispersão de poluentes em ambientes urbanos. O túnel de vento deste trabalho possui uma contração anterior à seção de testes, circuito aberto, ventilador axial com velocidade máxima de $2 \mathrm{~m} / \mathrm{s}$, uma unidade de aquecimento do escoamento e uma seção de testes quadrada de 1 $\mathrm{m}^{2}$. Foram confeccionados três spires, baseados no método de Irwin (Irwin, 1981) e colocados na entrada da seção de ensaio para o desenvolvimento da camada limite atmosférica. Elementos de rugosidade também foram concebidos de forma que simulassem locais urbanos e industriais reais, que podem ser simplesmente modelados como a forma de cubos. A camada limite gerada foi de cerca de $0,5 \mathrm{~m}$ de espessura e a distribuição de velocidade vertical na seção de ensaio pode ser descrita por uma lei de potência, utilizando $\alpha=0,28$, o que corresponde a um ambiente urbano (Al-Nehari et al., 2009). Com um anemômetro, foi plotado o perfil de velocidade para diferentes velocidades do ventilador, nas condições de túnel vazio, somente com os spires, e com os spires e elementos de rugosidade. Para a condição de túnel vazio, logo no início da seção de testes, observou-se uma uniformidade no perfil, com uma pequena camada limite próxima ao chão do túnel. A intensidade turbulenta, também uniforme ao longo do perfil, ficou em torno de 0,01. Ao longo da seção de testes, essa camada limite vai aumentando e foi plotado o perfil de velocidade para diferentes velocidades do ventilador a 3 metros e meio da entrada do túnel, onde observou-se uma camada limite com $31 \mathrm{~cm}$ de espessura. Os valores do coeficiente $\alpha$ da lei da potência e da espessura $\delta$ da camada limite variam de acordo com a velocidade do ventilador, dependendo do Número de 
Reynolds. A espessura da camada limite diminui e o coeficiente $\alpha$ aumenta à medida que a velocidade aumenta, de acordo com a Figura 3. A intensidade turbulenta se manteve em 0,01 .
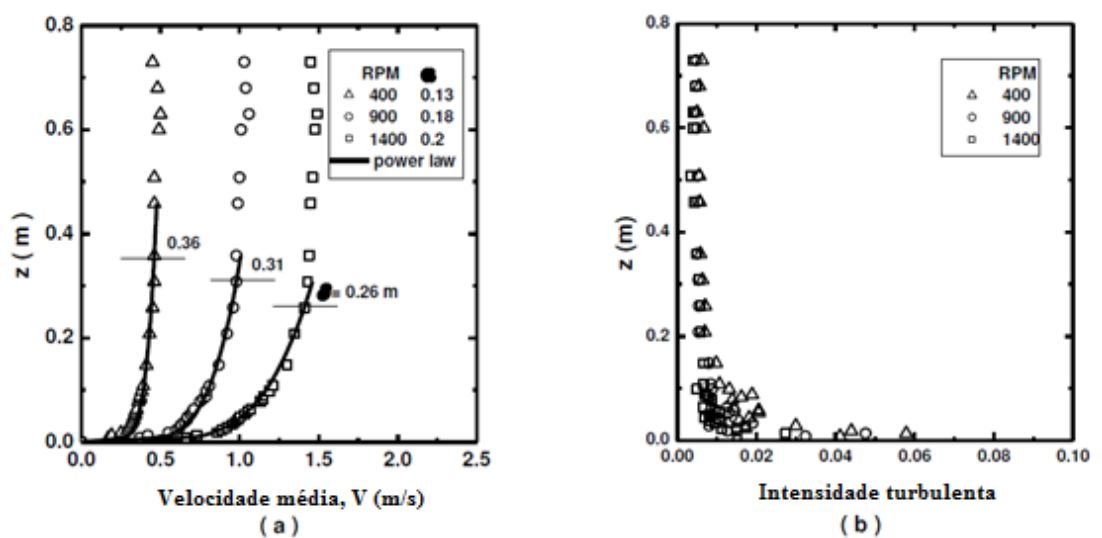

Figura 3. (a) Perfil de velocidade e (b) intensidade turbulenta para a condição do túnel vazio a 3 metros e meio da entrada da seção de testes (Al-

Nehari et al., 2009)

Nos experimentos posteriores, com os spires, foi observado um crescimento da espessura da camada limite de $31 \mathrm{~cm}$ para $46 \mathrm{~cm}$ e o valor de $\alpha$ foi de 0,12 para todas as velocidades. A intensidade turbulenta também teve um aumento considerável, como pode ser observado na Figura 4.

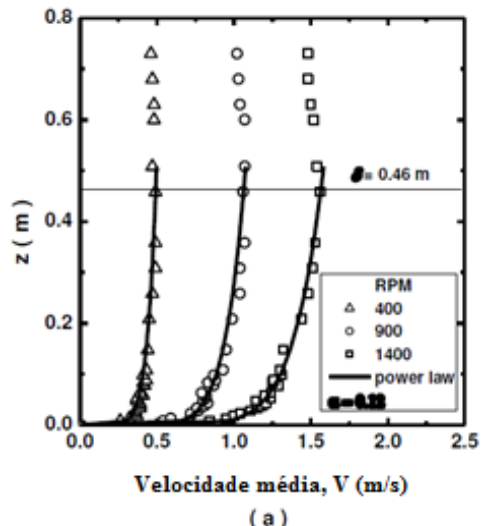

(a)

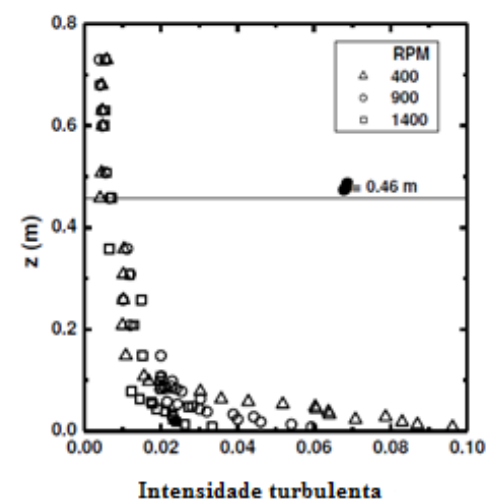

(b)

Figura 4. (a) Perfil de velocidade e (b) intensidade turbulenta para a condição do túnel somente com os spires a 3 metros e meio da entrada da seção de testes (Al-Nehari et al., 2009) 
Em seguida, medições com spires e elementos de rugosidade (cubos) foram feitos e comparados com as condições de túnel vazio e somente com spires. Nesta configuração, foi notado um crescimento da espessura da camada limite de $46 \mathrm{~cm}$ (condição somente com spires) para $51 \mathrm{~cm}$, mostrado na Figura 5 (a). Utilizando a lei de potência para ajustar os dados, o valor do coeficiente $\alpha$ fica em 0,28 , correspondendo à condição de área urbana (Al-Nehari et al., 2009).

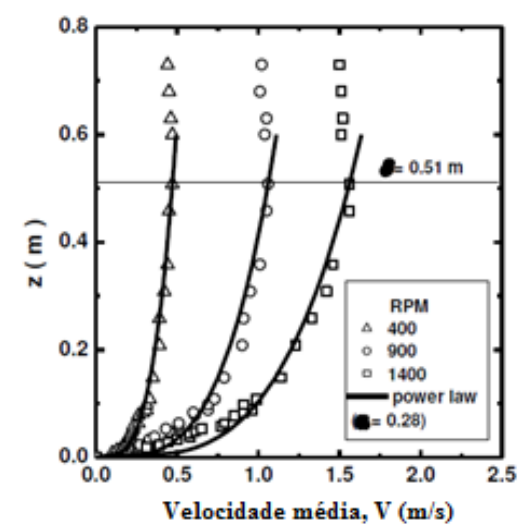

(a)

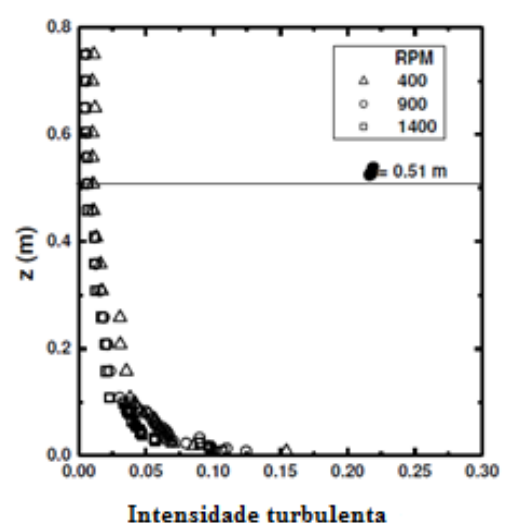

(b)

Figura 5. (a) Perfil de velocidade e (b) intensidade turbulenta para a condição do túnel com os spires e elementos de rugosidade (cubos) à 3 metros e meio da entrada da seção de testes (Al-Nehari et al., 2009)

A Figura 5 (b) mostra que as distribuições de intensidade de turbulência são uniformes fora da camada limite para todas as velocidades e os seus valores normalizados são em torno de 0,01 . Perto da parede, os valores normalizados de intensidade de turbulência são mais elevados em comparação com os da Figura 4 (b), quando o valor máximo perto do chão é de 0,15 . Os dados experimentais foram comparados com dados numéricos de CFD (Computacional Fluid Dynamics) obtidos através do software Fluent, empregando modelo de turbulência $\kappa-\varepsilon$ e apresentaram uma boa concordância.

No trabalho de Shojaee et al. (2013), é apresentado uma análise computacional e um estudo experimental de configurações de dispositivos passivos utilizados em um túnel de vento para simular a camada limite atmosférica no interior da seção de ensaio. Uma análise computacional preliminar, mostrou que o design do túnel poderia fornecer a espessura da camada limite desejada, em cerca de 4 metros a jusante da entrada do túnel, o que deixa espaço suficiente para que os 
modelos de construção possam ser colocados na seção de ensaio. Neste trabalho, foi utilizada uma técnica proposta por Simiu e Scanlan (1986), em que spires e elementos de rugosidade são colocados na entrada de testes, a fim de criar as propriedades da camada limite a montante da entrada do túnel.

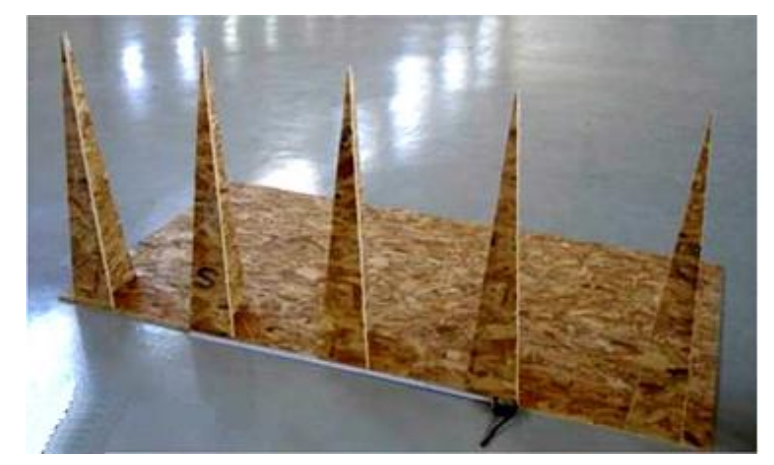

Figura 6. Disposição dos spires (Shojaee et al., 2013)

A análise computacional, utilizando o software comercial Fluent para CFD, foi realizada resolvendo as equações de equações de Navier Stokes com média de Reynolds, utilizando um modelo de turbulência $\kappa-\varepsilon$, pressão padrão, utilizando segunda ordem de precisão para equações de momento, e o cálculo da energia cinética e a taxa de dissipação turbulentas. Os efeitos dos spires são visíveis nos contornos de magnitude de velocidade da Figura 7 e é mostrado também um gráfico do perfil de velocidade comparando os dados da lei de potência, com os dados numéricos e o experimental, medido com um anemômetro de fio quente.
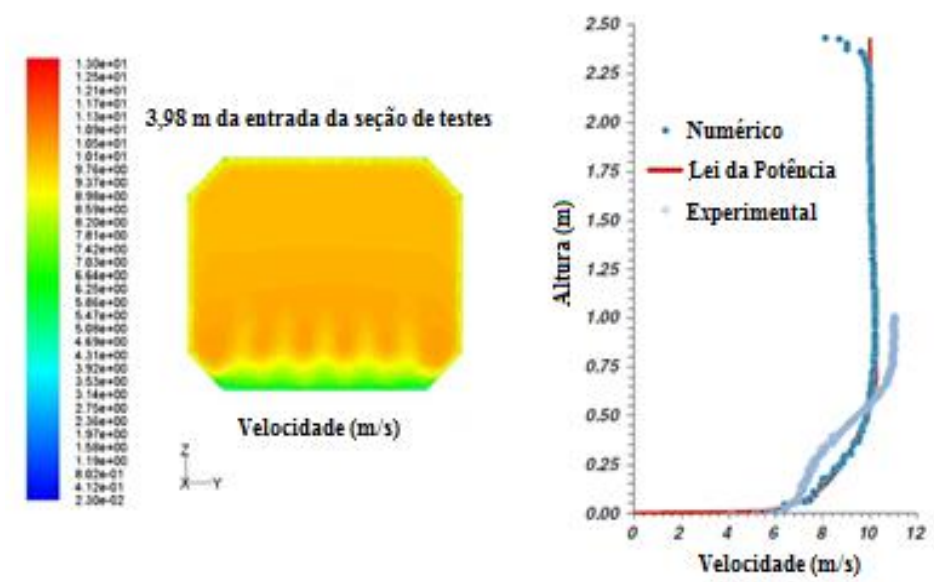

Figura 7. Contornos de magnitude de velocidade (à esquerda) e perfil de velocidade experimental, numérico e lei da potência (à direita) (Shojaee et al., 


\section{2. \\ Estudos de dispersão de plumas}

Por muito tempo, os estudos para descrever o crescimento de uma pluma foram feitos de maneira arcaica, com medições em campo. Bringfelt (1968) apresentou 70 medições de crescimento de pluma em chaminés industriais, em que a fumaça da pluma foi fotografada repetidamente por uma pequena aeronave durante uma hora. A aeronave mediu também a temperatura em diferentes altitudes, assim foi possível plotar o perfil de temperatura. Posteriormente, Carras e Williams (1986) realizaram medições da dispersão vertical de quatro diferentes plumas em quatro diferentes lugares da Austrália. As plumas foram emitidas por torres altas, os valores do coeficiente de dispersão foram obtidos por fotografia aérea de diferentes ângulos ao longo da pluma e foram realizadas leituras de temperatura da atmosfera. As fotografias foram tiradas a cada 2 - 5 segundos com a aeronave passando acima e ao longo do eixo da pluma. A forma da pluma foi reconstruída a partir de um mosaico de fotografias. Medições da velocidade horizontal do vento foram adquiridas por anemômetros situados perto das torres, com distâncias de 80 $\mathrm{m}, 50 \mathrm{~m}, 40 \mathrm{~m}$ e $30 \mathrm{~m}$. Os autores observaram que as taxas de lapso foram normalmente determinadas no início e no final dos voos da aeronave, durante o qual foram feitas sequências de medidas de dispersão horizontal da pluma. Em todos os casos, e em todos os quatro locais, as taxas de lapso adiabático determinados por uma inversão na altura de mistura foram observados, sempre que a pluma exibiu o comportamento característico de looping de condições convectivas. As condições de voo durante estes períodos foram caracterizadas por forte turbulência que se estende ao longo da camada de mistura. Dois anos depois, Templeman et al. (1989), realizaram um estudo com o objetivo de estimar parâmetros de dispersão vertical e concentração relativa na linha de centro de uma pluma, em uma usina de energia em Nova Delhi, na Índia. Para isso, realizaram uma análise digital de uma imagem de fumaça de uma pluma, como mostrado na Figura 8.

Usando um digitalizador de vídeo, as fotografias foram digitalizadas e analisadas para produzir uma imagem média da pluma e então as estimativas são utilizadas para avaliar os parâmetros de dispersão vertical e concentração. Os valores obtidos de dispersão vertical são comparados com os da literatura de Briggs 
para classe $C$ de estabilidade. E os valores de concentração relativa são comparados com as concentrações relativas obtidas utilizando a equação de difusão de Gauss.

(a)

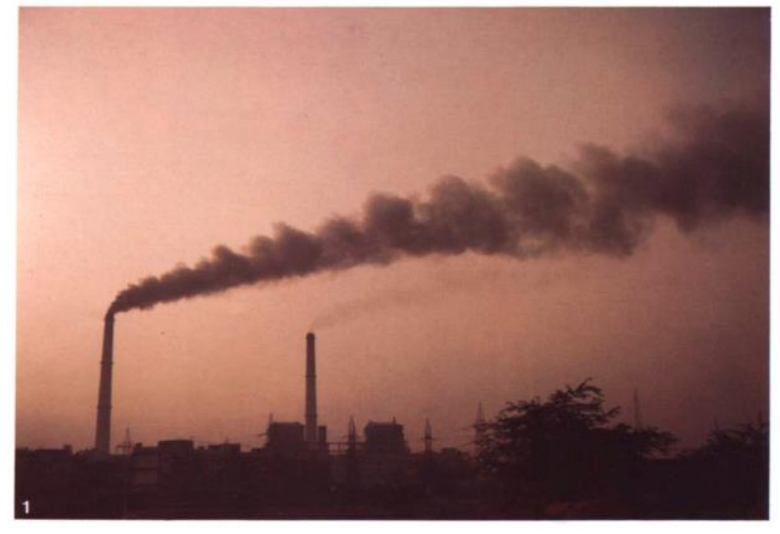

(b)

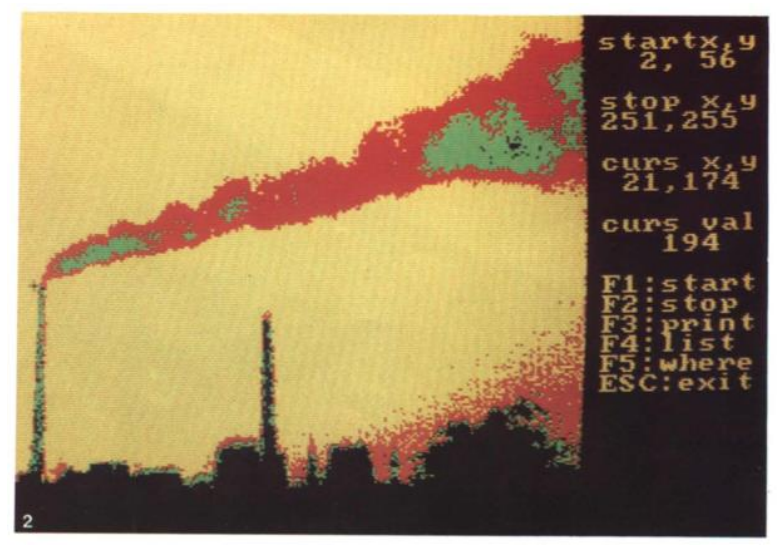

Figura 8. (a) Fotografia da chaminé de uma fábrica localizada no sul de Nova Delhi, na Índia e (b) Imagem digitalizada da pluma de fumaça (Templeman et al., 1989)

Lord e Leutheusser (1970), iniciaram os primeiros estudos em túnel de vento, a fim de se avaliar a emissão de gases. As medições em túnel de vento, ou seja, num ambiente mais controlado, tem como vantagem possibilitar a escolha das condições mais apropriadas para analisar um problema específico. Além disto, para determinar a variabilidade inerente ao processo de dispersão, podem ser realizadas numerosas repetições de um mesmo caso (Wittwer, 2006).

Huber e Snyder (1976) relataram medições de concentração de uma fonte pontual elevada colocada a sotavento de uma região de serra, cuja altura era cerca de um terço da espessura da camada limite. Seus resultados mostram concentrações significativas no nível do solo que ocorrem a montante da chaminé.

Huber (1989) examinou, em um túnel de vento, a influência da largura e orientação do edifício em relação ao vento, através de perfis de concentração na 
vizinhança do edifício. Os efeitos da largura do edifício foram examinados para edifícios com relações largura/altura variando de 2 a 22 .

White (1987) estudou experimentalmente a dispersão de um escoamento bidimensional uniforme de dióxido de carbono no ar sobre um obstáculo bidimensional quadrado em um túnel atmosférico que reproduzia a camada limite atmosférica. O número de Reynolds do obstáculo era cerca de 6000 , com base na velocidade no topo do obstáculo. A concentração de gás foi medida utilizando várias técnicas, incluindo dois métodos comumente usados: análise de hidrocarbonetos e anemometria de fio quente. O estudo demonstrou que as concentrações máximas de dióxido de carbono ocorreram na fina zona de recirculação acima do obstáculo. Imediatamente atrás do obstáculo, os níveis de concentração diminuíram significativamente e a zona de recirculação tornou-se maior.

A aerodinâmica o entorno de um edifício pode influenciar fortemente a dispersão de poluentes lançados a partir de fontes próximas. Seguindo essa ideia, diversos trabalhos foram feitos a fim de averiguar a dispersão e a concentração de poluentes lançados próximos a edifícios. Adair (1990) realizou experimentos em um túnel de vento a fim de estudar a dispersão de uma chaminé isolada interagindo com um edifício a jusante da chaminé. Para esse trabalho, a camada limite atmosférica foi gerada utilizando-se de elementos de rugosidade, na superfície do túnel, ao longo de todo comprimento da seção de trabalho. Uma imagem ilustrativa do experimento é mostrada na Figura 9.

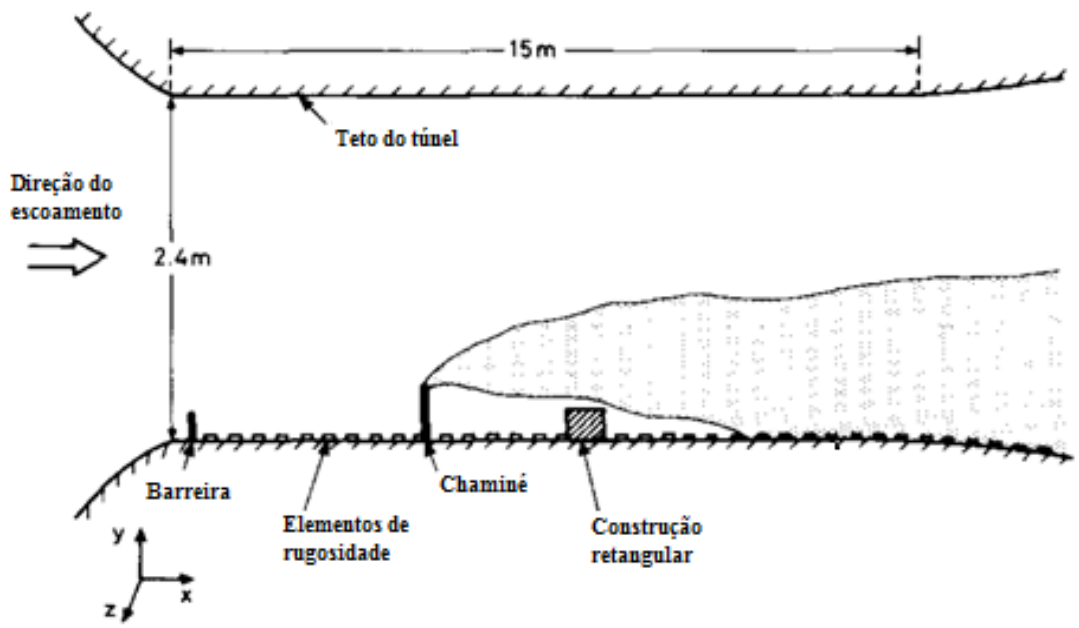

Figura 9. Montagem do experimento de Adair (1990) 
Os resultados experimentais no túnel de vento foram comparados com uma simulação numérica utilizando o método de cálculo de Reynolds-averaged NavierStokes (RANS) em um domínio de computação tridimensional. A altura da chaminé foi variada e as concentrações da pluma ao nível do solo obtiveram boa concordância tanto no experimento quanto na simulação.

Huber (1991) utilizou resultados de estudos experimentais em túneis de vento para caracterizar a dispersão de uma pluma com um marcador flutuante liberado na esteira de um edifício retangular. Os resultados mostraram que, além da região de esteira, o valor da concentração começou a aproximar-se do valor que seria obtido se não houvesse edificação. A distância onde o efeito do edifício se tornou insignificante foi influenciada pelas características da camada limite e pelo tamanho do edifício.

Investigações experimentais em um túnel de vento foram conduzidas por Mirzai et al. (1994) sobre o escoamento e a dispersão de poluentes em torno de um edifício isolado. Foi simulada uma atmosfera neutralmente estável com uma escala de 1:75. Foram coletados dados experimentais para produzir imagens mostrando a concentração média de poluição em um plano predeterminado atrás dos prédios. Os resultados mostraram que as concentrações de poluentes são afetadas pela forma e orientação do edifício, bem como pela natureza e escala do escoamento dentro da camada limite.

Thompson (1993) utilizou um túnel de vento com reprodução da camada limite atmosférica para analisar a dispersão de uma pluma sobre quatro edifícios diferentes. Ele observou que a aerodinâmica de um edifício pode influenciar fortemente a dispersão de poluentes liberados de fontes próximas. E que poluentes lançados de fontes mais baixas podem ser arrastados para regiões altamente turbulentas próximas ao edifício e resultar em concentrações elevadas de poluentes na superfície do edifício, onde as de entradas de ar estão localizadas.

A interação de fontes contínuas de pluma com estruturas é o principal fator que influencia a dispersão de poluentes em curtas distâncias em áreas urbanas. Pensando nisso, Mavroidis et al. (2003), compararam medições em campo e em laboratório da interação de uma pluma emitida por uma chaminé, com uma série de obstáculos isolados e diferentes orientações em relação à direção do vento, como mostrado na Figura 10. A pluma, localizada à montante dos obstáculos, foi emitida de forma contínua e a estabilidade atmosférica do escoamento, correspondente de 
uma atmosfera instável até neutra, representa as classes C e D de Pasquill. Os resultados em túnel de vento foram comparados com dados em campo. As medições de concentração em campo foram obtidas por dados meteorológicos coletados por um anemômetro ultrassônico. Esses experimentos mostraram a mesma tendência geral quando diferentes parâmetros, como a forma do obstáculo ou localização da fonte, foram alterados.
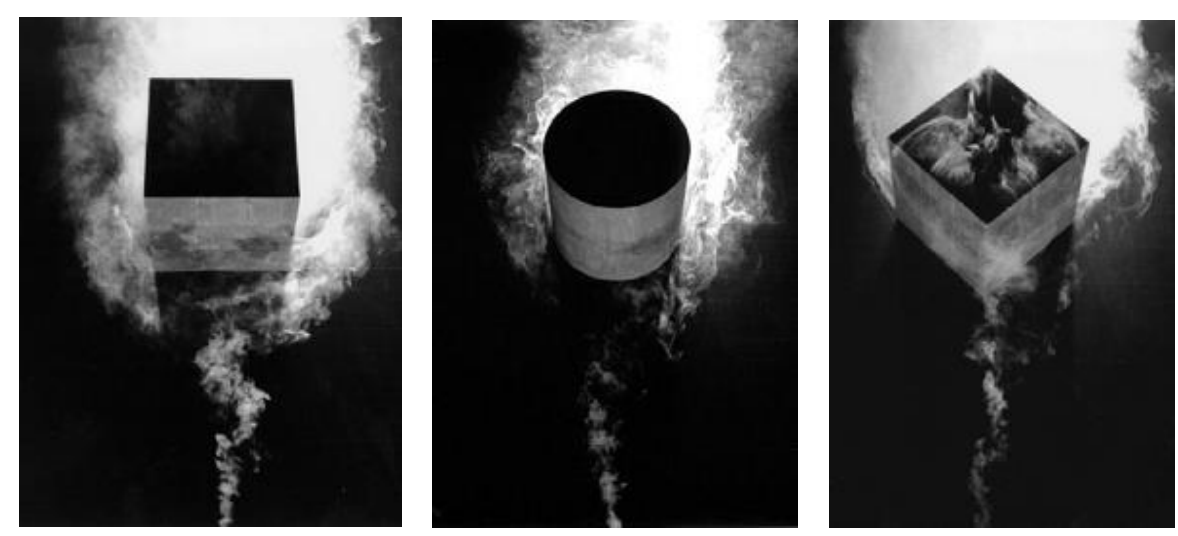

Figura 10. Escoamento da pluma ao redor de obstáculos (Mavroidis et al., 2003)

O experimento mostrou que a concentração de poluentes na região posterior ao obstáculo depende principalmente da proporção da pluma e das dimensões das regiões de recirculação do escoamento, e que a presença de obstáculos mais altos resulta na redução das concentrações ao nível do solo. No entanto, na linha central do túnel de vento as concentrações foram maiores, o que está de acordo com a observação de Higson et al. (1994), que afirmou que as maiores concentrações médias próximas a um edifício retangular são superestimadas em um túnel de vento, o que é atribuível às diferentes escalas de turbulência observadas no campo.

No trabalho de Saïd et al. (2004) foi realizado um estudo da emissão de uma pluma a partir de uma chaminé com um escoamento cruzado, como mostrado na Figura 11. Foi utilizada a técnica PIV (Velocimetria por Imagem de Partículas) para investigar as regiões de crescimento da pluma, próxima à chaminé. Foram observados também as estruturas de vórtices de Kelvin-Helmholtz e os fenômenos de Downwash. 


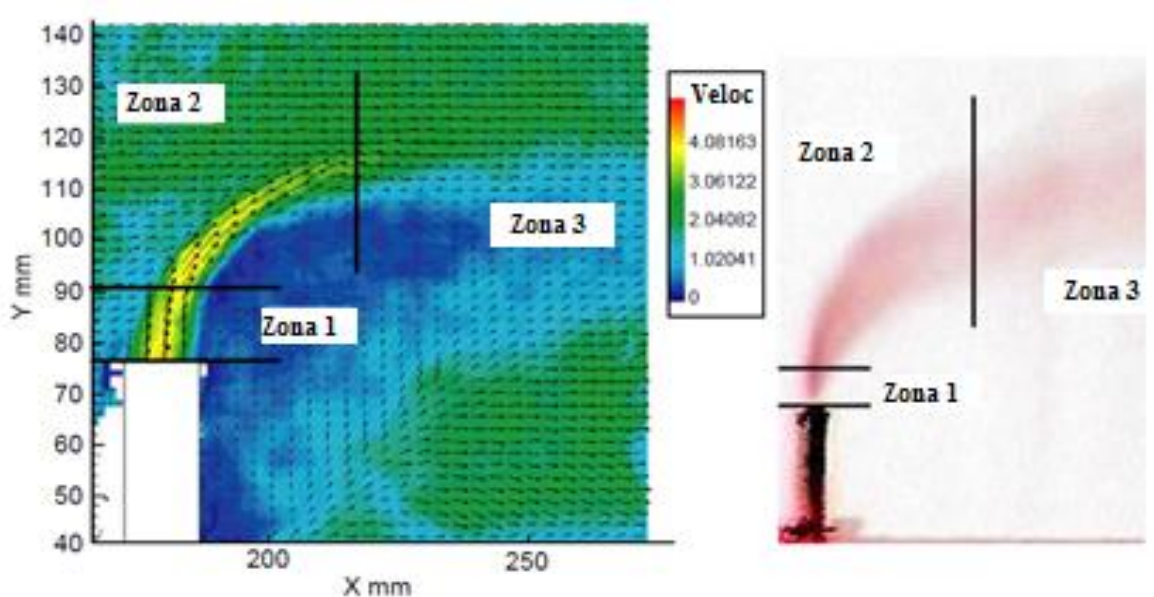

Figura 11. Diferentes regiões de evolução da pluma (Saïd et al., 2004)

A chaminé utilizada no trabalho de Saïd et al. (2004), possui 0,1 m de altura e $10 \mathrm{~mm}$ de diâmetro interno e o escoamento da pluma é composto por partículas traçadoras de glicerina. $\mathrm{O}$ escoamento principal varia de 0 a $16 \mathrm{~m} / \mathrm{s}$, a intensidade turbulenta é menor que $0,2 \%$ e o número de Reynolds varia de $2,7 \times 10^{4}$ até $2 \times 10^{5}$. Já o número de Reynolds relacionado ao escoamento da pluma varia de $3 \times 10^{3}$ até $8 \times 10^{3}$. Os autores variaram a velocidade do escoamento principal, para examinarem as mudanças na dispersão da pluma, como pode ser visto na Figura 12.
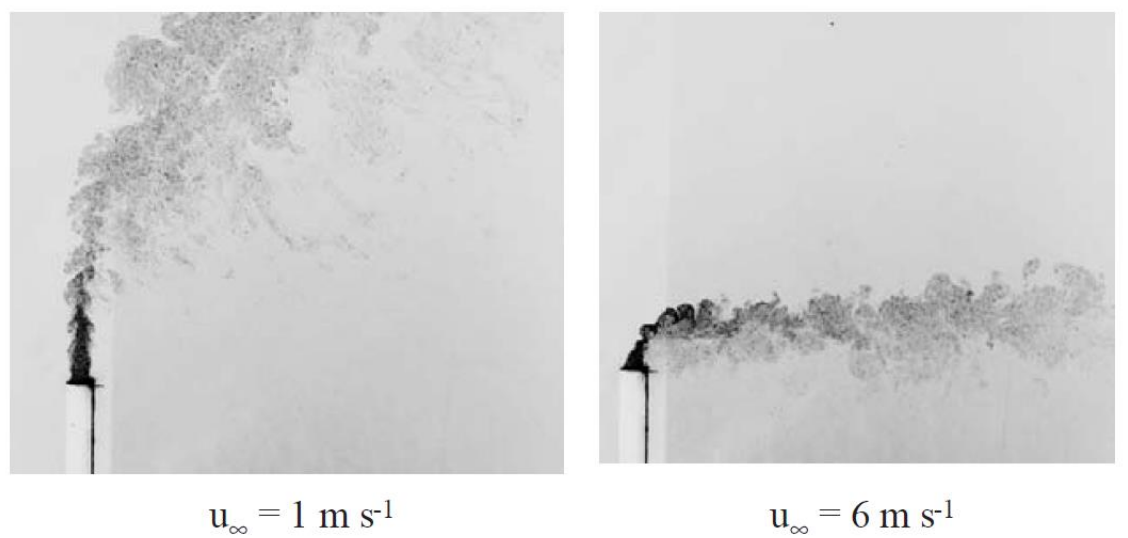

Figura 12. Efeito da velocidade do escoamento principal sobre a pluma (Saïd et al., 2004)

Seis anos depois esses mesmos autores reproduziram esse mesmo tipo de estudo, porém com algumas modificações. Foram realizados experimentos em túnel de vento e comparados com dados numéricos. Agora, uma chaminé possui um 
ângulo reto na sua saída, como mostrado na Figura 13. Os experimentos consistiram em avaliar o efeito da presença de obstáculos, a forma do obstáculo (cilíndrica ou paralelepípedo) e a configuração da chaminé (reta ou curvada).

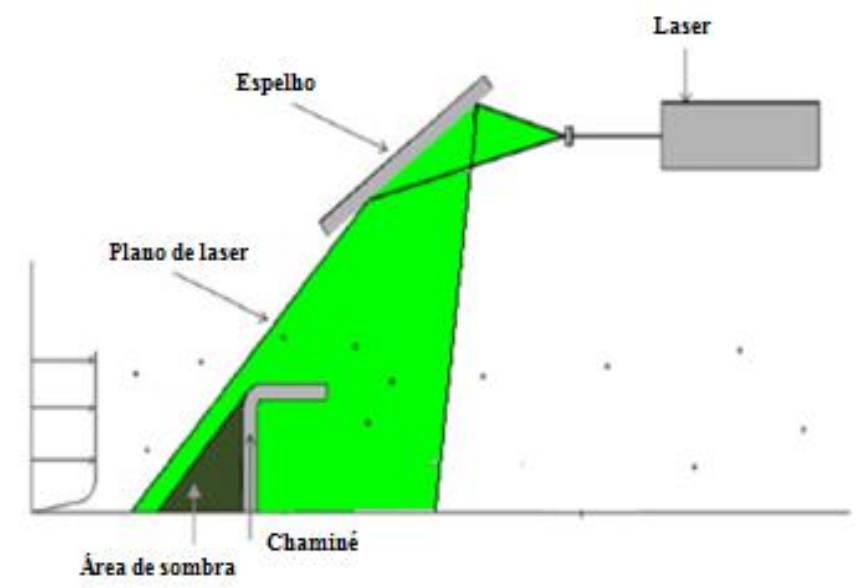

Figura 13. Montagem do sistema PIV no trabalho de Saïd et al. (2010)

A técnica PIV também foi utilizada para visualização da dispersão do fluido da chaminé sobre os obstáculos. O principal objetivo foi avaliar o impacto da pluma sobre a dinâmica e as características turbulentas do escoamento principal. Os autores observaram também que a velocidade de entrada é um fator importante para determinar a existência de uma zona de recirculação atrás do obstáculo, sendo que à medida que a velocidade diminui, a zona de recirculação aumenta.

Sendo assim, este trabalho pretende contribuir com novos dados experimentais relacionados a estudos de dispersão de poluentes emitidos através de uma fonte pontual e contínua. 


\section{3 \\ Conceitos Fundamentais}

\section{1. Camada limite atmosférica}

A camada limite atmosférica (CLA) é importante para a vida humana e isso pode ser concluído a partir dos vários fenômenos que ocorrem nessa camada (Stull, 1997). A vida se origina e se desenvolve dentro da camada limite atmosférica, bem como os processos meteorológicos e as mudanças que afetam a vida humana e o meio ambiente. Dentro desta camada, a absorção do calor proveniente do sol e da poluição do ar afetam a saúde humana e os ecossistemas. Ocorre também a maioria das variações diárias da circulação atmosférica, que é afetada pela topografia da superfície da Terra.

Assim, a camada limite atmosférica pode ser definida como a camada inferior da troposfera, em que ventos, umidade e temperatura são afetados pela superfície da Terra (Hartmann, 1994). A espessura da CLA pode chegar até um quilometro de altura, altura esta, que é variável durante o dia e afetada também por condições meteorológicas. Essa camada reage a alterações na superfície e as mudanças que ocorrem no seu interior são causadas por turbulência, evaporação, transferência de calor, topografia e as emissões de poluentes atmosféricos (Stull, 1988). A parte superior da troposfera também é afetada por mudanças na superfície da Terra, mas em um período de tempo maior. A variação de temperatura diária perto da superfície da Terra não é observada em altitudes mais elevadas. Portanto, a variação diária da temperatura é uma das principais características para a determinação da camada limite atmosférica.

Devido à influência da superfície, o vento circula das zonas de alta pressão para as zonas de baixa pressão, porém a rotação terrestre modifica essa direção pelo surgimento das forças de Coriolis (Wittwer, 2006), enquanto que, acima da CLA, o vento é dirigido paralelamente às linhas isobáricas (linhas de pressão constante).

Acima dos oceanos a altura da camada limite muda lentamente em relação ao tempo e localização. Isto é devido a uma mudança lenta da temperatura da 
superfície do mar, pois a água tem grande capacidade de absorver calor e pode absorver grandes quantidades de calor sem uma mudança considerável de sua temperatura. A camada limite, tanto acima do mar quanto acima da terra, tende a ser mais fina nas áreas de alta pressão e o ar é transportado para zonas de baixa pressão. Em áreas de baixa pressão, há uma ascensão do ar em níveis superiores da troposfera e nessas condições, é difícil determinar o limite superior da camada limite. A base de nuvens é considerada como o limite superior da CLA e, portanto, acima de um sistema de baixa pressão, onde as nuvens estão próximas ao solo, a altura da camada limite é baixa.

De acordo com Stull (998), a altura e a estrutura da CLA são bem estabelecidas como resultado da sua evolução do ciclo diário. As três partes principais da camada limite, que são observadas durante o seu desenvolvimento diário, são a camada de mistura, a camada residual e a camada limite estável, como pode ser observado na Figura 14. Perto da superfície da Terra há uma fina camada de ar, chamada de camada superficial, que é formada em consequências de mudanças abruptas na superfície, como por exemplo, a rugosidade do terreno, temperatura e umidade (Jegede e Foken, 1998). Durante o período diurno, pode-se observar a camada de mistura, formada devido à resposta ao aquecimento da superfície, onde a turbulência independe da altura e da tensão de cisalhamento. A camada limite estável noturna é formada pelo resfriamento radiativo da superfície durante a noite.

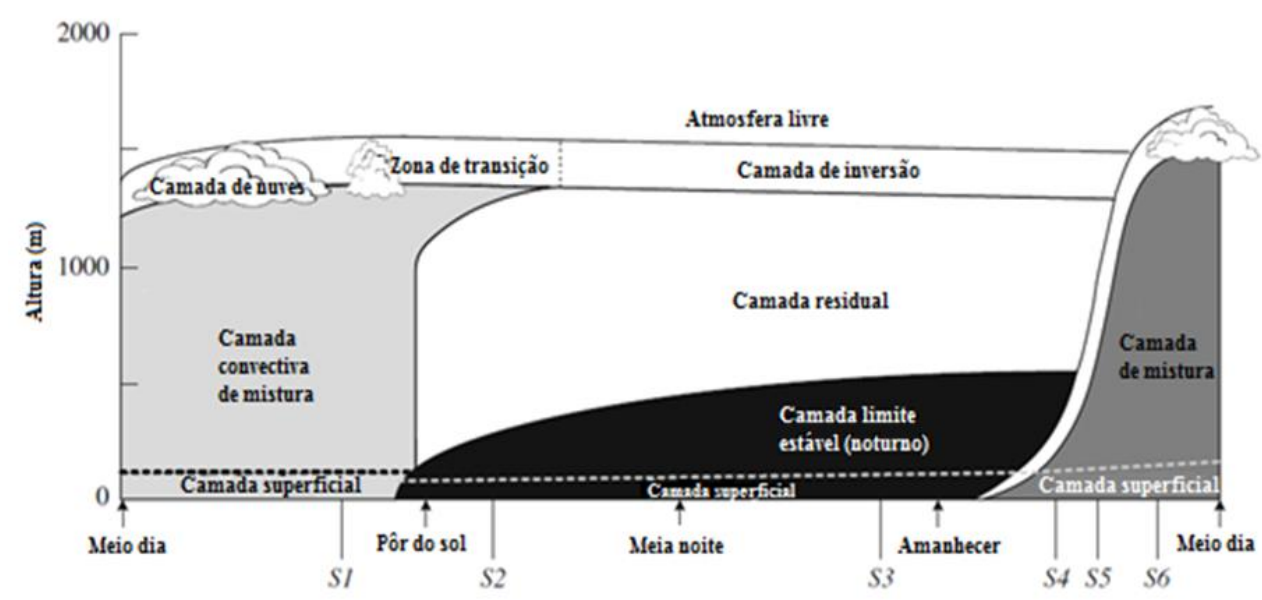

Figura 14. Variação diurna da camada limite atmosférica em boas condições de tempo (Stull, 1998) 


\section{2. \\ Estabilidade atmosférica}

A variação da temperatura com a altitude na atmosfera é um parâmetro chave para determinar o grau em que o material vai se misturar verticalmente. Além da variação da temperatura, a estabilidade atmosférica está correlacionada com a velocidade do vento e com a umidade. O estudo do perfil de temperatura atmosférica é facilitado pelo conceito de uma parcela de ar: uma massa hipotética de ar que pode deformar-se à medida que se move na atmosfera, mas permanece como uma única unidade, sem troca de massa ou propriedades com o seu ambiente. Se esse pacote de ar não trocar o calor com seu entorno, pode-se denominar um pacote de ar adiabático (Seinfeld e Pandis, 1998).

Se um pacote de ar adiabático sobe na atmosfera, ele entrará numa região onde a pressão do ar circundante é inferior, então irá ocorrer uma expansão desse pacote e uma redução da sua pressão. A expansão da parcela de ar irá consumir energia das moléculas de ar dentro do pacote, fazendo com que ele desacelere e diminua a temperatura. Como resultado, o ar que sobe expande e esfria. O oposto irá acontecer, se uma parcela de ar desce, sua temperatura aumenta e o seu volume diminui. A diferença de temperatura de uma parcela de ar e seu entorno que irá determinar se um pacote de ar em movimento continuará se movendo na mesma direção ou se ele vai atingir o equilíbrio e parar (Seinfeld e Pandis, 1998).

O processo de mistura vertical na atmosfera pode ser aproximado como um processo que envolve um grande número de parcelas de ar ascendente e descendente. As condições de estabilidade na atmosfera estão relacionadas com a capacidade da atmosfera para misturar e espalhar poluentes. Estas condições também determinam os níveis de turbulência na atmosfera e a formação de nuvens. De acordo com Davis e Cornwell (1998), a estabilidade atmosférica determinará o processo de elevação vertical da pluma, pois é a tendência da atmosfera de acelerar ou impedir o movimento vertical de um pacote de ar.

$\mathrm{Na}$ troposfera a temperatura normalmente diminui com o aumento da altitude, devido à diminuição da pressão com a altura. Se a atmosfera está em seu estado de equilíbrio, uma parcela de ar não terá tendência para subir ou descer. A temperatura durante este estado neutro diminui lentamente com altura e é considerado o perfil de temperatura de referência para a atmosfera. Assim, pode-se definir gradiente 
térmico adiabático seco $(\Gamma)$ como sendo a taxa de resfriamento do pacote de ar com a sua elevação e seu valor médio é de aproximadamente $10^{\circ} \mathrm{C} / \mathrm{km}$.

No entanto, raramente a atmosfera se mantém nesse estado de equilíbrio, devido à influência de aquecimento da superfície e fenômenos em escalas maiores. Se a temperatura atmosférica diminui mais rapidamente com a altura do que o perfil de referência, então a atmosfera é considerada instável. Se um pacote de ar é deslocado para cima ou para baixo, ele vai continuar se movendo nesta direção. Uma atmosfera instável é, portanto, caracterizada por fortes correntes verticais em ambos os sentidos ascendente e descendente, o que leva a uma mistura rápida dos poluentes emitidos. Por outro lado, se a temperatura diminui ou aumenta mais lentamente com a altura do que o perfil de referência, a atmosfera é estável. Em atmosferas estáveis parcelas de ar são inibidas de movimento para cima ou para baixo, resultando em uma mistura fraca de poluentes emitidos. Se a temperatura de uma camada atmosférica aumenta com a altitude, chama-se de uma camada de inversão, que ocorre quando o ar quente se encontra acima de ar frio, e esta condição é extremamente estável.

A existência de nuvens na atmosfera pode alterar significativamente o perfil de temperatura. Como um pacote de ar contendo vapor de água sobe, a sua temperatura diminui e aumenta-se a umidade relativa. Se a umidade relativa é superior a 100\%, a água começará a se condensar sobre as partículas disponíveis, e ocorre a liberação de calor latente de condensação de água. Assim, o ar não esfria à mesma taxa do gradiente térmico adiabático seco, mas a uma taxa inferior chamada de gradiente térmico adiabático úmido, $\Gamma s$. Esse valor depende da pressão atmosférica, da temperatura do ar e da pressão de saturação do vapor de água, ficando próximo de $6{ }^{\circ} \mathrm{C} / \mathrm{km}$.

\subsection{1.}

\section{Atmosfera neutra, instável e estável}

Como mencionado anteriormente, o aspecto da estabilidade atmosférica é indicado pelos gradientes térmicos e, dependendo das curvas apresentadas pelos gradientes térmicos na atmosfera, pode-se dividir a estabilidade atmosférica em neutra, instável e estável. Porém, um parâmetro muito utilizado juntamente com essas curvas é o gradiente térmico ambiental (1), que é a taxa de decréscimo da 
temperatura da atmosfera com a altitude, sendo esse gradiente responsável pela ascensão ou decréscimo da parcela de ar.

Comparando o gradiente térmico ambiental $\Lambda$, com o gradiente térmico adiabático seco $\Gamma$, tem-se três situações definidas:

$$
\begin{array}{cc}
\Lambda=\Gamma & \text { atmosfera neutra } \\
\Lambda>\Gamma & \text { atmosfera instável } \\
\Lambda<\Gamma & \text { atmosfera estável }
\end{array}
$$

Se o gradiente térmico da atmosférica é adiabático, uma parcela de ar deslocada verticalmente está sempre em equilíbrio com o seu entorno. Isso caracteriza a condição neutra, em que a taxa de diminuição da temperatura da parcela de ar é igual à taxa de diminuição da temperatura da atmosfera. Atmosfera instável ocorre quando $\Lambda>\Gamma$, assim, o gradiente térmico ambiental é dito como superadiabático (Figura 15 (a)). Uma parcela de ar subindo terá uma temperatura maior do que o ambiente e continuará a subir. E se uma parcela de ar tiver uma temperatura menor do que seus arredores, esta tenderá a descer, e os poluentes são misturados mais rapidamente em um ambiente instável.

Finalmente, quando uma parcela de ar subindo esfria mais rapidamente com a altura do que seus arredores, é dito que a atmosfera é estável (Figura 15 (b)). Essa situação $\Lambda<\Gamma$, é chamada de subadiabática. Em um ambiente estável há pouca ou não há nenhuma elevação de pluma de contaminantes na atmosfera e o ar estável resiste fortemente ao movimento vertical, espalhando os poluentes horizontalmente. A atmosfera é estável quando o gradiente térmico é pequeno, isto é, quando a diferença de temperatura entre a superfície e a uma certa altura é relativamente pequena. Como resultado, a atmosfera tende a tornar-se mais estável, devido a processos que causam tanto arrefecimento do ar perto do solo quanto aquecimento do ar em determinada altura. Se a temperatura da atmosfera aumenta com a altitude, numa camada na atmosfera, então esta camada é muito estável e é chamada de camada de inversão. 
(a) Unstable

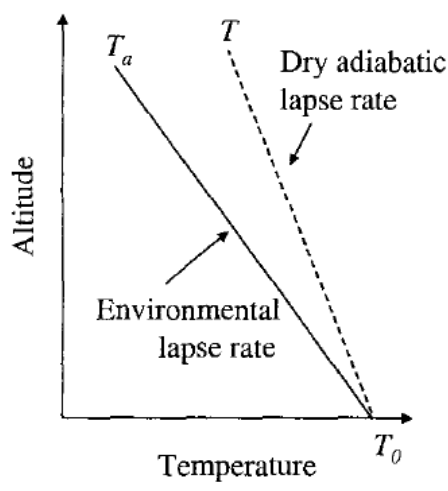

(b) Stable

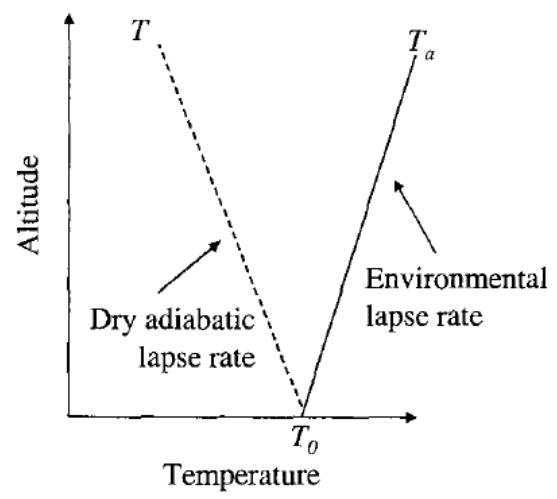

Figura 15. Perfis de temperatura para (a) uma atmosfera instável e (b) uma atmosfera estável (Seinfeld e Pandis, 1963)

\section{3.}

\section{Turbulência e intensidade turbulenta}

Através do Número de Reynolds, pode-se classificar o tipo de escoamento em laminar, transição ou turbulento. E a mudança de regime no escoamento pode ocorrer quando o número de Reynolds característico de um escoamento excede certo valor crítico. E esta condição praticamente predomina na CLA, ou seja, atmosfera possui um escoamento turbulento e embora não haja uma definição exata para turbulência, existem diversas propriedades que ajudam sua caracterização (Tennekees e Lumley, 1994 e Silveira, 2002). Algumas dessas propriedades são:

- Escoamentos turbulentos são irregulares, de modo que as componentes de velocidade em qualquer localização variam quase que aleatoriamente com o tempo. Uma vez que as velocidades não são variáveis determinísticas, os valores não podem ser previstos com exatidão.

- Difusividade: Origina mistura rápida e incremento da transferência de quantidade de movimento, calor e massa.

- Flutuações de velocidade tridimensionais: A turbulência é rotacional e tridimensional.

- Escoamentos turbulentos são dissipativos no sentido de que há uma conversão contínua de energia cinética em energia interna. 
Assim, a menos que a energia seja continuamente fornecida, a turbulência irá decair.

Devido à turbulência presente no escoamento de ar, a direção e velocidade do vento variam em cada ponto com o tempo. Assim, num determinado instante de tempo, o escoamento pode ser caracterizado por um campo de velocidade $U(x, y$, z), em que a velocidade é considerada dependente do tempo. Pode-se descrever a velocidade em um ponto qualquer, como sendo:

$$
U(t)=\bar{U}+u^{\prime}(t)
$$

Em que $\bar{U}$ é a velocidade média e $u^{\prime}(t)$ é a flutuação em relação à velocidade média para cada instante $t$.

A intensidade turbulenta é uma medida adimensional da energia cinética existente em cada componente das flutuações de velocidade (Blessmann, 1995). Assim, a intensidade turbulenta, normalmente apresentada em porcentagem, está associada às flutuações dos três componentes do campo de velocidade $(x, y, z) \mathrm{e}$ pode ser definida por:

$$
I=\frac{1}{\bar{U}}\left(\sqrt{\frac{\sum_{i=1}^{N}\left(U_{i}-\bar{U}\right)^{2}}{N}}\right)
$$

Em que $N$ é o número de amostras. Em experimentos realizados em túnel de vento, existe praticamente só um componente de flutuação, uma vez que o escoamento é induzido somente em uma direção.

\section{4 .}

\section{Perfil de velocidades do vento}

Perfis de velocidade do vento são frequentemente utilizados em uma série de modelos de dispersão de poluentes (Beychok, 2005), em avaliações para construções civis e parques eólicos.

O perfil de velocidades do vento é uma função da altura acima da superfície e é alterado basicamente pela rugosidade do terreno. Esta pode ser a rugosidade 
natural, como regiões de florestas, ou rugosidades artificiais, como regiões urbanas, com edifícios e outras construções.

O perfil de velocidades médias do vento através da Lei da Potência é apresentado na equação (3-3).

$$
\frac{U}{U_{\delta}}=\left(\frac{Z}{\delta}\right)^{\alpha}
$$

Onde $U$ é a velocidade do vento a uma altura $z ; \delta$ é a espessura da camada limite atmosférica; $U_{\delta}$ é a velocidade para $z>\delta$ e $\alpha$ é o expoente da lei da potência. Como pode ser visto na Figura 16, o expoente $\alpha$ representa o tipo de terreno que se quer estudar. $\mathrm{O}$ valor de $\alpha$ igual a 0,16 simula superfícies lisas como oceanos e campos, o valor de $\alpha$ igual a 0,28 representa uma zona suburbana, e $\alpha$ igual a 0,40 representa zonas urbanas densas.

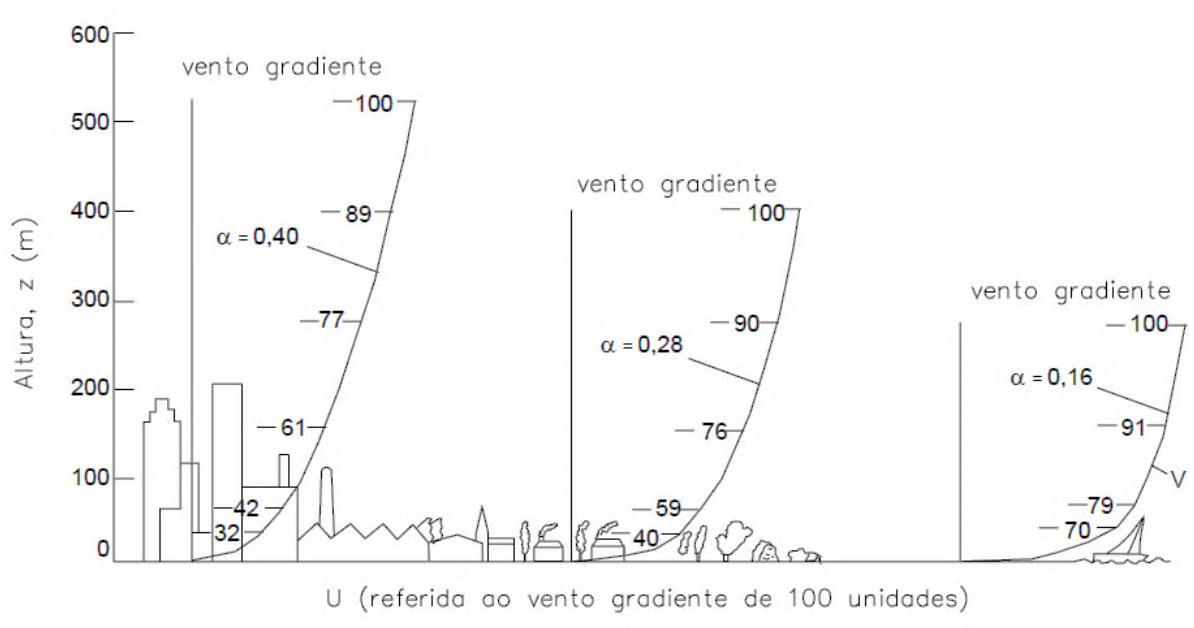

Figura 16. Perfil de velocidade média do vento sobre terrenos de diferentes rugosidades (Parker, 1977) 


\section{4 \\ Dispersão atmosférica}

O processo de dispersão e transporte de poluentes descarregados na atmosfera está fortemente ligado à natureza dos contaminantes, características da fonte de emissão, efeitos do terreno e do seu entorno, condições meteorológicas, estabilidade atmosférica, dentre outros fatores.

Nas plantas industriais, onde existem chaminés de descargas de efluentes industriais, os gases gerados são descarregados diretamente para a atmosfera. O comportamento e a elevação da pluma dependem do dimensionamento da chaminé, da quantidade de movimento da emissão e de seu empuxo e das características ambientais e de topografia. O aumento da velocidade de saída ou da temperatura do gás da pluma implicará no aumento da elevação, fazendo com que os gases não se concentrem na região da esteira da pluma ou de algum edifício próximo. E através dos conhecimentos de efeitos de turbulência e mistura de poluentes, deve-se conseguir uma elevação da pluma apropriada para que os gases atinjam o solo com uma concentração adequada.

A forma que uma pluma emitida por uma chaminé adquire, também influencia sua característica de dispersão, e depende das condições de estabilidade atmosférica, como pode ser visto na Figura 17. 


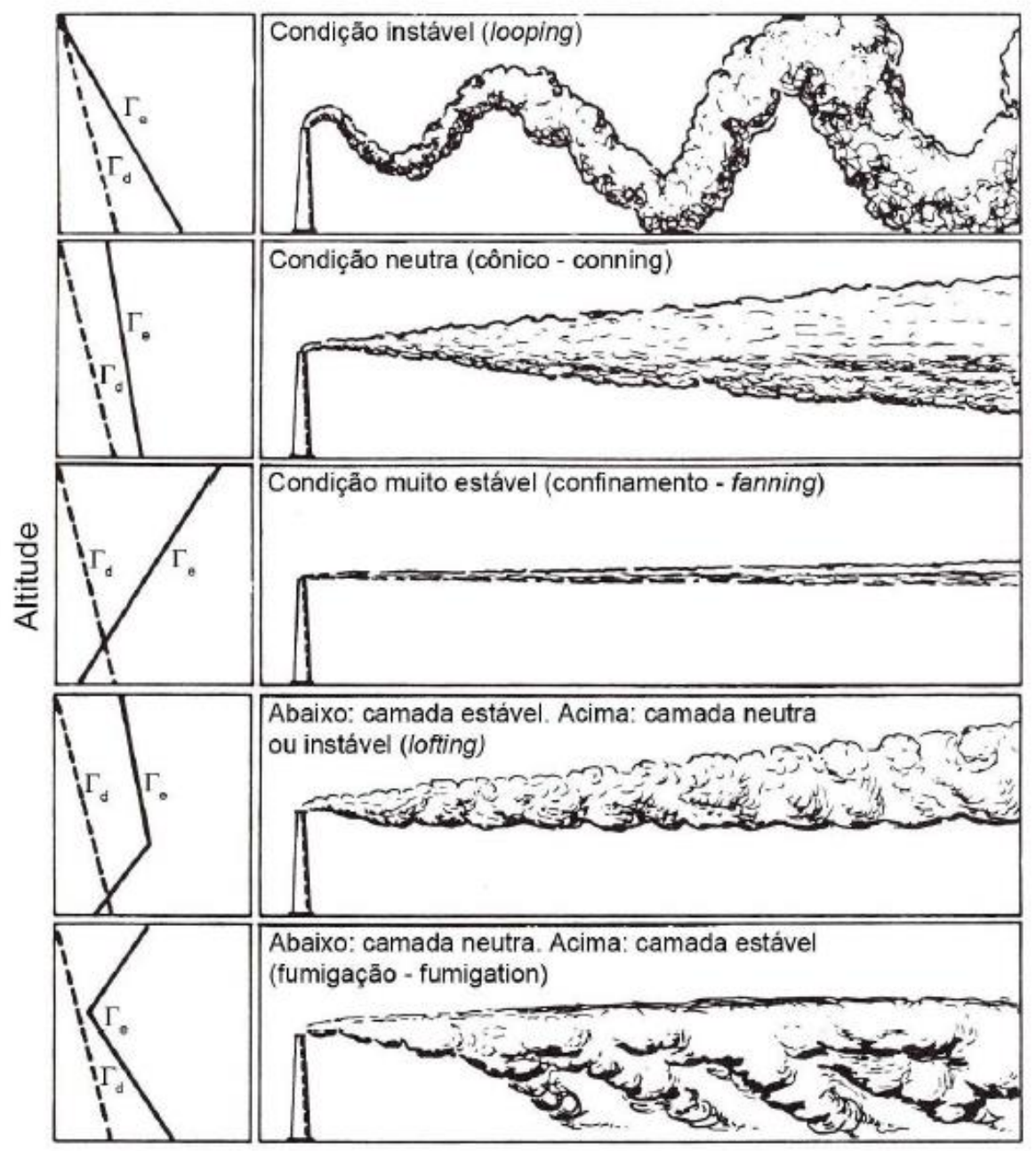

Temperatura

Formato da Pluma

Figura 17. Comportamento dos tipos de pluma de acordo com a estabilidade atmosférica (Zannetti, 1990)

\section{1. Modelos de dispersão de poluentes}

Os modelos de dispersão constituem uma descrição matemática do perfil de concentração de diferentes compostos químicos na atmosfera. Um dos principais objetivos é ser capaz de descrever matematicamente a distribuição espacial e temporal de contaminantes lançados na atmosfera. Para isso, é necessário dispor de uma descrição detalhada das emissões dos poluentes, da topografia do terreno, da reatividade dos poluentes e das condições de transporte na atmosfera. A determinação exata dos fatores que controlam a concentração de poluentes, como as fontes de emissão, o transporte de poluentes, condições meteorológicas e a 
topografia da superfície definem o quão realista é a solução do problema (Seinfeld e Pandis, 1963).

\subsection{1.}

\section{Modelo gaussiano}

Os modelos gaussianos são amplamente utilizados para descrição de poluentes na atmosfera, uma vez que descrevem realisticamente, com base na comparação com dados de campo, a dispersão de poluentes para uma atmosfera estacionária (Lazaridis, 2010).

Algumas considerações, que esse modelo, demonstrado na Figura 18, assume são: (i) O gás poluente é liberado na atmosfera em uma altura correspondente a altura física da chaminé mais a elevação da pluma; (ii) O grau de diluição do gás contaminante é inversamente proporcional à velocidade do vento; (iii) Os poluentes não estão reagindo quimicamente na atmosfera, uma vez que o modelo gaussiano não inclui reações químicas e (iv) Na direção do vento, o processo de transporte é dominante para a dispersão turbulenta.

O foco destas fórmulas é expressar a concentração média de uma espécie emitida a partir de uma fonte pontual elevada e contínua, chamada equação de pluma gaussiana, representada por:

$$
c(x, y, z)=\frac{Q}{2 \pi \sigma_{y} \sigma_{z} u} \exp \left[-\frac{y^{2}}{2 \sigma_{y}^{2}}\right] \exp \left[-\frac{(H-z)^{2}}{2 \sigma_{z}^{2}}\right]
$$

Em que $c(x, y, z)$ é a concentração de um poluente no ponto $(x, y, z)$ expresso em $\mathrm{g} / \mathrm{m}^{3} ; Q$ é a taxa de emissão expressa em $\mathrm{g} / \mathrm{s} ; u$ é a velocidade do vento em $\mathrm{m} / \mathrm{s}$; $\sigma_{y}$ e $\sigma_{z}$ são os desvios - padrão horizontal e vertical respectivamente e $H$ é a altura total da chaminé em $\mathrm{m}$. 


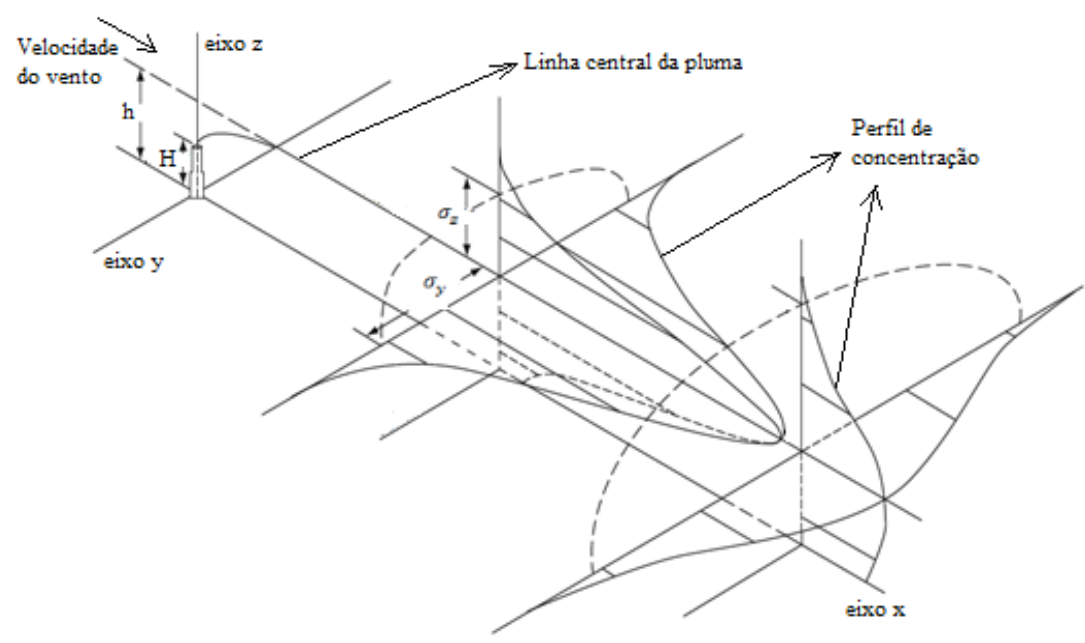

Figura 18. Perfil de concentração tridimensional de uma pluma Gaussiana (Zannetti, 1990)

\subsection{2.}

\section{Parâmetros de dispersão no modelo gaussiano}

Em muitos problemas envolvendo dispersão de poluentes, é essencial determinar a concentração de poluentes lançados a partir de uma fonte de emissão contínua. A utilização do modelo gaussiano requer a estimativa de coeficientes de dispersão vertical $\left(\sigma_{z}\right)$ e horizontal $\left(\sigma_{y}\right)$ da pluma. Esses coeficientes são determinados a partir de medições em campo e dependem da topografia da área de interesse, da estabilidade atmosférica, condições de turbulência e da distância e tempo desde o início da dispersão. Os valores existentes na literaura para esses coeficientes foram obtidos durante experimentos na década de 50 e 60 (Hanna et al., 1981). Em 1961, Pasquill propôs um esquema para determinar a dispersão vertical e horizontal de poluentes conhecido como metodologia de Pasquill-Gifford (P-G). Nesse método, $\sigma_{y}$ e $\sigma_{z}$ são determinados em relação às classes de estabilidade da atmosfera, que variam de A (extremamente instável) até F (moderadamente estável). A representação gráfica dessas curvas de P-G, indicadas na Figura 19, mostram valores de $\sigma_{y}$ e $\sigma_{z}$ em função da distância da emissão da pluma, para diversas condições atmosféricas. 

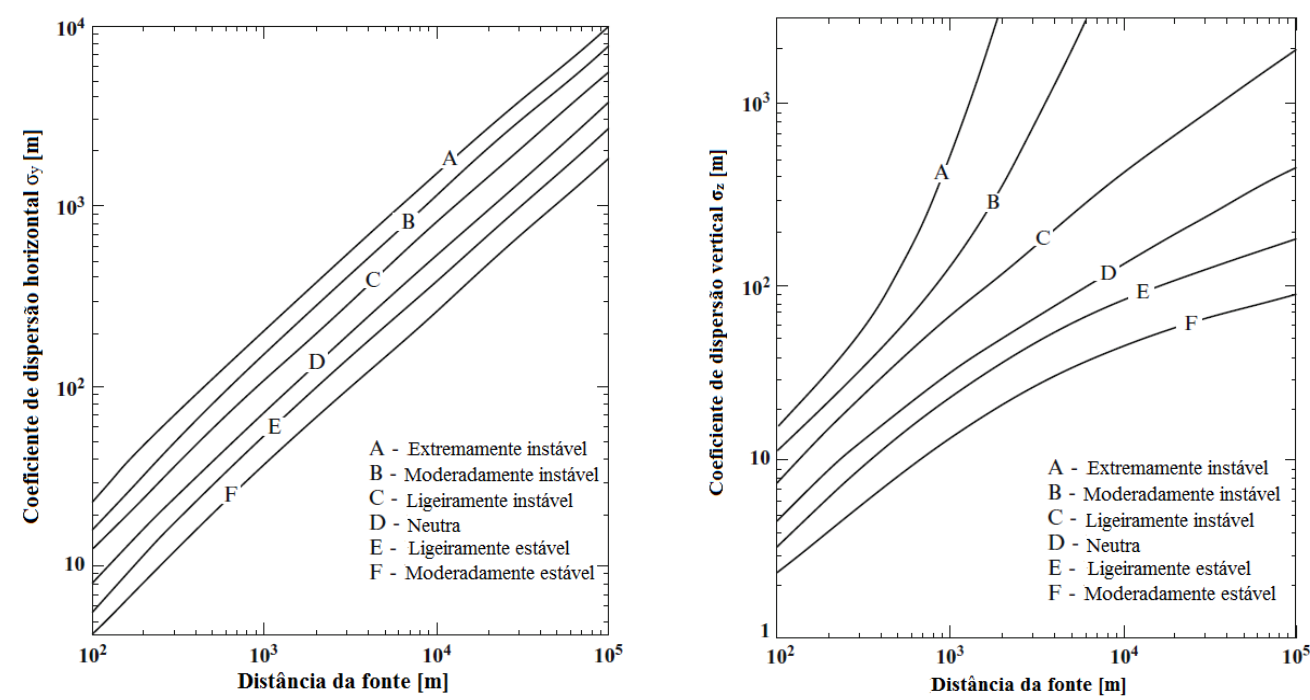

Figura 19. Curvas dos coeficientes de dispersão $\sigma_{y}$ e $\sigma_{z}$ com base na formulação de Pasquill-Gifford (adaptado de Lazaridis, 2010)

Através dos gráficos é possível observar que a dispersão horizontal não depende tanto da classe de estabilidade da atmosfera, que é uma característica quase que totalmente do perfil vertical. As linhas de dispersão horizontal são paralelas, seguindo a mesma tendência, enquanto que na dispersão vertical, o perfil vertical de temperatura afeta significativamente a dispersão. Na condição A, extremamente instável, a velocidade na componente vertical é maior, por isso a dispersão vertical aumenta em relação à condição F, moderadamente estável, em que se tem menos dispersão vertical. Para uso em fórmulas de dispersão é conveniente ter expressões analíticas para $\sigma_{y}$ e $\sigma_{z}$, que são representadas por:

$$
\sigma_{y}=R_{y} x^{r_{y}} \quad e \quad \sigma_{z}=R_{z} x^{r_{z}}
$$

Em que $R_{y}, R_{z}, r_{y}$ e $r_{z}$ dependem da classe de estabilidade da atmosfera e do tempo médio de medição. Existem incertezas nesses coeficientes devido, por exemplo, à altura da chaminé ou à distância que o poluente se extende. Portanto, existe uma outra expressão para determinar os coeficientes de dispersão, na forma:

$$
\sigma_{z}=\exp \left[I_{z}+J_{z} \ln x+K_{z}(\ln x)^{2}\right]
$$

Em que $I_{z}, J_{z}$, e $K_{z}$ são os novos coeficientes, mostrados na Tabela 1. 
Tabela 1. Coeficientes de dispersão no modelo de pluma gaussiana (Seinfeld e Pandis, 1998)

\begin{tabular}{|c|c|c|c|c|c|c|c|c|}
\hline \multirow[b]{2}{*}{ Fonte } & \multirow[b]{2}{*}{ Tempo médio (min) } & \multirow[b]{2}{*}{ Coeficiente } & \multicolumn{6}{|c|}{ Classe de estabilidade } \\
\hline & & & A & $\mathrm{B}$ & $\mathrm{C}$ & $\mathrm{D}$ & $\mathrm{E}$ & $\mathrm{F}$ \\
\hline $\begin{array}{l}\text { Pasquill-Gifford } \\
\text { (Turner 1969; }\end{array}$ & 10 & $R_{y}$ & 0.443 & 0.324 & 0.216 & 0.141 & 0.105 & 0.071 \\
\hline Martin 1976) & & $r_{y}$ & 0.894 & 0.894 & 0.894 & 0.894 & 0.894 & 0.894 \\
\hline \multirow[t]{4}{*}{ ASME (1973) } & 60 & $R_{y}$ & 0.40 & 0.36 & & 0.32 & & 0.31 \\
\hline & & $r_{y}$ & 0.91 & 0.86 & & 0.78 & & 0.71 \\
\hline & & $R_{z}$ & 0.40 & 0.33 & & 0.22 & & 0.06 \\
\hline & & $r_{z}$ & 0.91 & 0.86 & & 0.78 & & 0.71 \\
\hline \multirow[t]{4}{*}{ Klug (1969) } & 10 & $R_{y}$ & 0.469 & 0.306 & 0.230 & 0.219 & 0.237 & 0.273 \\
\hline & & $r_{y}$ & 0.903 & 0.885 & 0.855 & 0.764 & 0.691 & 0.594 \\
\hline & & $R_{z}$ & 0.017 & 0.072 & 0.076 & 0.140 & 0.217 & 0.262 \\
\hline & & $r_{z}$ & 1.380 & 1.021 & 0.879 & 0.727 & 0.610 & 0.500 \\
\hline Pasquill-Gifford & 10 & $I_{y}$ & -1.104 & -1.634 & -2.054 & -2.555 & -2.754 & -3.143 \\
\hline \multirow[t]{5}{*}{ (Turner 1969) } & & $J_{y}$ & 0.9878 & 1.0350 & 1.0231 & 1.0423 & 1.0106 & 1.0148 \\
\hline & & $K_{y}$ & -0.0076 & -0.0096 & -0.0076 & -0.0087 & -0.0064 & -0.0070 \\
\hline & & $I_{z}$ & 4.679 & -1.999 & -2.341 & -3.186 & -3.783 & -4.490 \\
\hline & & $J_{z}$ & -1.7172 & 0.8752 & 0.9477 & 1.1737 & 1.3010 & 1.4024 \\
\hline & & $K_{z}$ & 0.2770 & 0.0136 & -0.0020 & -0.0316 & -0.0450 & -0.0540 \\
\hline
\end{tabular}

Smith (1990), propôs uma expressão matemática que mostrou medidas a distâncias de até $10 \mathrm{~km}$ de uma fonte com altura de 108 metros. De acordo com as medições de Smith, são válidas as seguintes expressões para $\sigma_{y}$ e $\sigma_{z}$ :

$$
\sigma_{y}=a x^{b} \quad e \quad \sigma_{z}=c x^{d}
$$

Em que $x$ é a distância em quilometros. Os valores para os coeficientes $a, b, c$ e $d$ podem ser obtidos a partir de valores dados pelo laboratório nacional em Brookhaven, EUA (Tabela 2).

Tabela 2. Parâmetros propostos para as relações $\sigma_{y}=a x^{b}$ e $\sigma_{z}=c x^{d}$ (adaptado de Lazaridis, 2010)

\begin{tabular}{lllll}
\hline \multirow{2}{*}{ Classe de estabilidade } & \multicolumn{2}{l}{ Parâmetros } & c & d \\
\cline { 2 - 5 } & $\mathrm{a}$ & $\mathrm{b}$ & 0.41 & 0.91 \\
$\mathrm{~B}_{2}$ & 0.40 & 0.91 & 0.33 & 0.86 \\
$\mathrm{~B}_{1}$ & 0.36 & 0.86 & 0.22 & 0.78 \\
$\mathrm{C}$ & 0.32 & 0.78 & 0.06 & 0.71 \\
$\mathrm{D}$ & 0.31 & 0.71 &
\end{tabular}

Dados mais recentes foram apresentados por Briggs (Hanna et al., 1981), e ajustados por expressões numéricas que incluem a diferença de rugosidade do terreno e são dadas na Tabela 3. 
Tabela 3. Relações propostas por Briggs para os parâmetros de dispersão $\sigma_{y}$ e $\sigma_{z}\left(10^{2}<\mathrm{X}<10^{4} \mathrm{~m}\right)$ (adaptado de Lazaridis, 2010)

\begin{tabular}{|c|c|c|}
\hline $\begin{array}{l}\text { Classe de } \\
\text { estabilidade }\end{array}$ & $\sigma_{y}(\mathrm{~m})$ & $\sigma_{z}(\mathrm{~m})$ \\
\hline \multicolumn{3}{|c|}{ Condição de campo aberto } \\
\hline $\mathrm{A}$ & $0.22 \mathrm{X}(1+0.0001 X)^{-1 / 2}$ & $0.20 X$ \\
\hline B & $0.16 \mathrm{X}(1+0.0001 X)^{-1 / 2}$ & $0.12 X$ \\
\hline $\mathrm{C}$ & $0.11 \times(1+0.0001 X)^{-1 / 2}$ & $0.08 X(1+0.0002 X)^{-1 / 2}$ \\
\hline $\mathrm{D}$ & $0.08 \mathrm{X}(1+0.0001 X)^{-1 / 2}$ & $0.06 X(1+0.0015 X)^{-1 / 2}$ \\
\hline $\mathrm{E}$ & $0.06 \mathrm{X}(1+0.0001 X)^{-1 / 2}$ & $0.03 X(1+0.0003 X)^{-1}$ \\
\hline $\mathrm{F}$ & $0.04 \mathrm{X}(1+0.0001 X)^{-1 / 2}$ & $0.016 X(1+0.0003 X)^{-1}$ \\
\hline \multicolumn{3}{|c|}{ Condição de ambiente urbano } \\
\hline $\mathrm{A}-\mathrm{B}$ & $0.32 X(1+0.0004 X)^{-1 / 2}$ & $0.24 X(1+0.001 X)^{1 / 2}$ \\
\hline $\mathrm{C}$ & $0.22 X(1+0.0004 X)^{-1 / 2}$ & $0.20 X$ \\
\hline $\mathrm{D}$ & $0.16 X(1+0.0004 X)^{-1 / 2}$ & $0.14 X(1+0.0003 X)^{-1 / 2}$ \\
\hline E-F & $0.11 X(1+0.0004 X)^{-1 / 2}$ & $0.08 X(1+.00015 X)^{-1 / 2}$ \\
\hline
\end{tabular}

Métodos mais sofisticados para determinar os coeficientes de dispersão são baseados na Teoria de Taylor (Taylor, 1921). Baseado nessa teoria, Pasquill sugeriu uma definição alternativa, adotado por Draxler (1976), a Sociedade Americana de Meteorologia e Irwin (1979), a representação de Pasquill conduz a:

$$
\sigma_{y}=\sigma_{v} t F_{y} \quad \sigma_{z}=\sigma_{w} t F_{z}
$$

Onde $\sigma_{v}$ e $\sigma_{w}$ são os devios padrão de flutuações de velocidade do vento nas direções x e y respectivamente e $F_{y}$ e $F_{z}$ são funções universais de um conjunto de parâmetros que especificam as caracteristicas da camada limite atmosférica. Irwin (1979), Deardorff and Willis (1975), Draxler (1976), Nieuwstadt and van Duuren (1979) Panofsky et al. (1977) desenvolveram trabalhos para determinação desses parâmetros, que são dependentes de velocidade de fricção, comprimento de MoninObukhov, força de Coriolis, profundidade da camada de mistrura, rugosidade na superfície, altura da chaminé, entre outros.

Dos dois desvios-padrão, $\sigma_{y}$ e $\sigma_{z}$, a literatura aborda mais sobre $\sigma_{y}$. Primeiramente, porque a maioria dos experimentos dos quais os valores de $\sigma_{y}$ e $\sigma_{Z}$ são inferidos, envolvem medições no nível do solo. Tais medições fornecem uma indicação adequada de $\sigma_{y}$, enquanto que, para determinar $\sigma_{Z}$, as distribuições de 
concentração verticais são necessárias. Além disso, a expressão gaussiana para distribuição de concentração vertical é conhecida por não ser obedecida para emissões ao nível do solo, de modo que a montagem de uma distribuição vertical medida para uma forma gaussiana é consideravelmente mais difícil do que a distribuição horizontal onde a simetria lateral e uma aproximação gaussiana são boas suposições (Seinfeld e Pandis, 1963).

\subsection{3.}

\section{Crescimento da pluma}

Uma série de parâmetros afeta o crescimento de uma pluma, como a velocidade de saída da chaminé, a diferença da temperatura da pluma e do ar, a estratificação térmica da atmosfera e a velocidade do vento (Seinfeld e Pandis, 1963). Com base nas condições iniciais da fonte, as plumas podem ser categorizadas da seguinte maneira:

- Pluma flutuante: Empuxo inicial >> Momentum inicial

- Pluma forçada: Empuxo inicial $\cong$ Momentum inicial

- Jato: Empuxo inicial $<<$ Momentum inicial

Quando as emissões da fonte possuem uma temperatura mais alta do que a temperatura ambiente, a pluma está se elevando devido à correntes convectivas. As características dos poluentes, como densidade e composição, também provocam maior elevação da pluma. Lazaridis (2010) equaciona a altura efetiva da chaminé (h) como a soma da altura normal da chaminé $(H)$ e do crescimento da pluma $(\Delta h)$, como mostrado na equação a seguir:

$$
h=H+\Delta h
$$

$\mathrm{e}$

$$
\Delta h=\frac{E x^{b}}{\bar{u}^{a}}
$$

Em que $E, a, b$ são parâmetros tabelados, $x$ é a distância em metros e $\bar{u}$ é a velocidade média. 
4.2.

\section{Análise de concentração}

$\mathrm{Na}$ década de 70 foram iniciados os primeiros estudos sobre fenômenos de dispersão em túnel de vento. Esses estudos tinham como objetivo prevenir que poluentes emitidos por chaminés chegassem ao nível do solo. Os trabalhos de Chatzipanagiotidis e Olivari (1996), relatam que para obter informações quantitativas a partir de ensaios de visualização com traçadores de fumaça é necessária a utilização de técnicas que incluem laser, vídeo-câmeras e sistemas de processamento digital de imagens.

Para análises de dispersão de plumas em túnel de vento é preciso se utilizar de testes quantitativos e de visualização, nos quais se mede a concentração nas zonas de interesse.

As análises de concentração geralmente são feitas de forma adimensional, sendo o coeficiente de concentração $K$ definido como:

$$
K=\frac{C U_{r e f} L_{r e f}^{2}}{Q_{0}}
$$

Onde $C$ é a concentração medida, $U_{r e f}$ é a velocidade de referência, $L r e f$ é um comprimento de referência e $Q_{0}$ é a vazão de emissão. A relação de Petersen (1990), é utilizada para converter os valores medidos no túnel em valores de escala real:

$$
\left(\frac{C U_{\text {ref }}}{Q_{0}}\right)_{\text {real }}=\left(\frac{C U_{r e f} S_{F}^{2}}{Q_{0}}\right)_{\text {modelo }}
$$

Sendo $S_{F}$ o fator de escala do modelo. Outro fator utilizado é o fator de diluição $D_{n}$, definido pela relação:

$$
D_{n}=\frac{C_{0}}{C}
$$

Sendo $C_{0}$ a concentração de contaminantes na saída da emissão e $C$, a concentração no ponto de medição. 
Para a análise das flutuações de concentração, são utilizados a variância, os valores de pico, as funções de densidade de probabilidade, as funções de autocorrelação e os espectros das flutuações (Wittwer, 2006). $I_{c}$ é a intensidade turbulenta das flutuações de concentração e pode ser obtida pela seguinte equação:

$$
I_{c}=\frac{{\overline{\left(K^{\prime 2}\right)}}^{1 / 2}}{\bar{K}}
$$

Sendo $\bar{K}$, o coeficiente de concentração média e $K^{\prime 2}$, o coeficiente da flutuação de concentração quadrático médio, que são obtidos substituindo a concentração média e a flutuação quadrática média na equação (4-8). 


\section{5 Metodologia experimental e instrumentação}

Os estudos realizados neste trabalho, para análise da dispersão de uma pluma emitida por uma chaminé, são de carácter experimental, englobando a simulação da camada limite atmosférica no túnel de vento. Os experimentos foram realizados para três velocidades de escoamento principal e para três velocidades de emissão da pluma. Foi simulado um tipo de escoamento para camada limite atmosférica, representando um terreno de uma área suburbana. O escoamento no túnel de vento comtemplou somente baixas velocidades, representando um ambiente ideal para a simulação atmosférica. O perfil de velocidades médias no túnel de vento foi obtido utilizando a técnica de anemometria a fio quente. Já o cálculo dos campos de velocidade na região da pluma foram feitos utilizando a técnica de velocimetria por imagem de partículas. Por último, o mapeamento do perfil vertical de concentrações em um único plano, no eixo da chaminé, para diferentes posições a sotavento, foi feito por análise de intensidade luminosa. Todos os experimentos foram realizados no Laboratório de Caracterização da Dinâmica de Escoamentos de Fluidos (LACAD) pertencente à Divisão de Metrologia em Dinâmica de Fluidos na Diretoria de Metrologia Cientifica do Inmetro.

\section{1.}

\section{Túnel de vento atmosférico do Inmetro}

O túnel de vento é uma importante bancada experimental, capaz de prover diretrizes para estudos ambientais, estruturais, aeronáuticos, entre outros. Com um túnel de vento que promove a camada limite atmosférica é possível analisar o efeito do vento sobre estruturas e estudar como poluentes se dispersam na atmosfera.

O túnel de vento utilizado foi projetado no Inmetro e confeccionado em madeira naval e estruturas de metal. O equipamento possui janelas de policarbonato transparentes, para acesso óptico e visualização, como pode ser observado na Figura 20. Ele opera a baixas velocidades e alto nível de intensidade turbulenta, a fim de simular condições de escoamentos ambientais (Farias et al., 2014). A seção de testes 
interna possui 1 metro de largura e 1 metro de altura e tem comprimento total de 10 metros, sendo composto por 5 seções móveis de 2 metros cada. A velocidade do escoamento é controlada manualmente por um inversor de frequências que varia de $5 \mathrm{~Hz}$ até $60 \mathrm{~Hz}$. Um motor elétrico de 12,50 cv, com velocidade nominal de 1755 rpm, aciona um ventilador centrífugo, fazendo com que o escoamento alcance velocidade máxima de $10 \mathrm{~m} / \mathrm{s}$, sendo o túnel classificado como subsônico. Trata-se de um túnel de circuito aberto, ou seja, o escoamento não permanece recirculando. Anterior à seção de ensaios, existe um difusor (razão de 1:2), um conjunto de telas e uma colmeia para retificação do escoamento (Massari, P. de L et al., 2016).

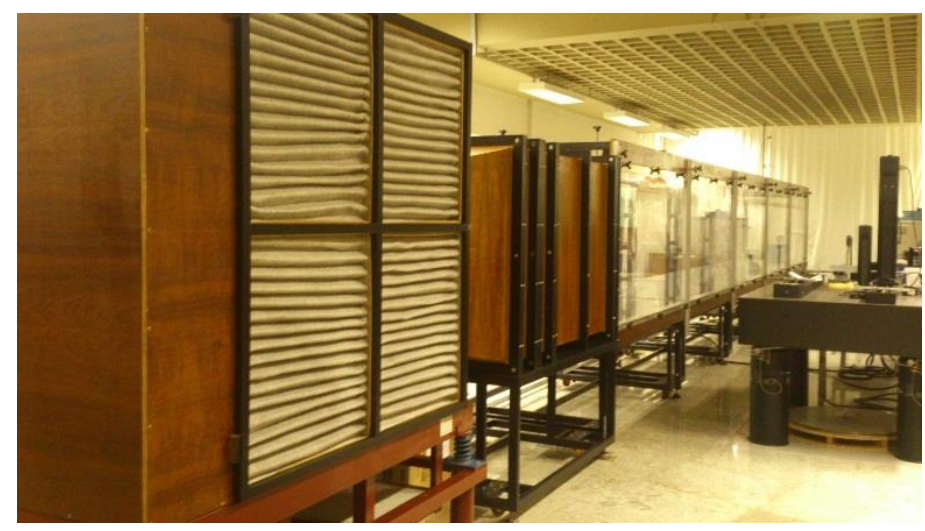

Figura 20. Túnel de Vento Atmosférico do Inmetro

A Figura 21 mostra um desenho esquemático do túnel de vento do Inmetro, composto pelos seguintes componentes (da esquerda para direita): (1) uma caixa com o motor e o ventilador centrífugo, revestida com filtros para impedir que impurezas entrem, (2) uma colmeia e telas para uniformização do escoamento, (3) spires dispostos na seção de entrada, (4) seção de testes composta de 5 módulos. Nos experimentos, a chaminé foi colocada a 7 metros da entrada.

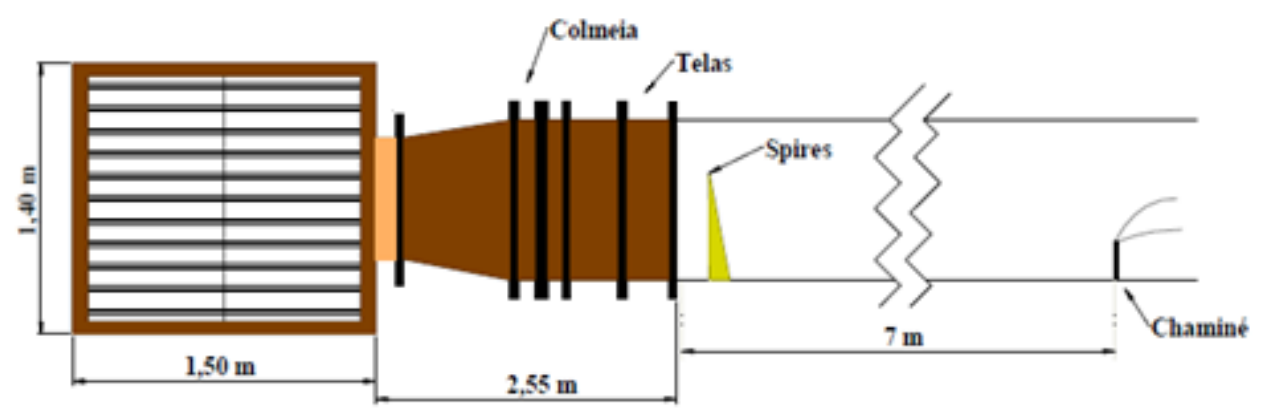

Figura 21. Desenho esquemático do Túnel de Vento Atmosférico do Inmetro 


\subsection{1. \\ Técnica experimental para simulação da camada limite atmosférica no túnel de vento}

Para o presente trabalho, que envolve o estudo de dispersão de uma pluma, surge a necessidade de simular as condições de uma camada limite atmosférica no túnel de vento, a fim de se reproduzir um ambiente realista. A camada limite atmosférica real é obtida no túnel de vento por meio de uma camada limite que se desenvolve sobre uma superfície plana com determinada rugosidade. Esta rugosidade tem efeito semelhante à orografia do terreno real, como uma região oceânica, montanhosa ou urbana por exemplo, estabelecendo um perfil de velocidades médias com determinadas características.

Entre os diversos métodos de simulação, centrou-se especial atenção no método de Irwin (Irwin, 1981), que é um método simples de desenvolver a camada limite atmosférica em túneis curtos. Essa metodologia consiste em dispor elementos passivos, conhecidos como spires, no início da seção de testes, para que, a uma determinada distância destes elementos, o perfil da camada limite atmosférica esteja desenvolvido, como pode ser observado na Figura 22. Os spires são placas triangulares, que devido a esse formato causam uma maior perda de carga na parte inferior do canal e induzem turbulência similar àquela observada na camada limite atmosférica.

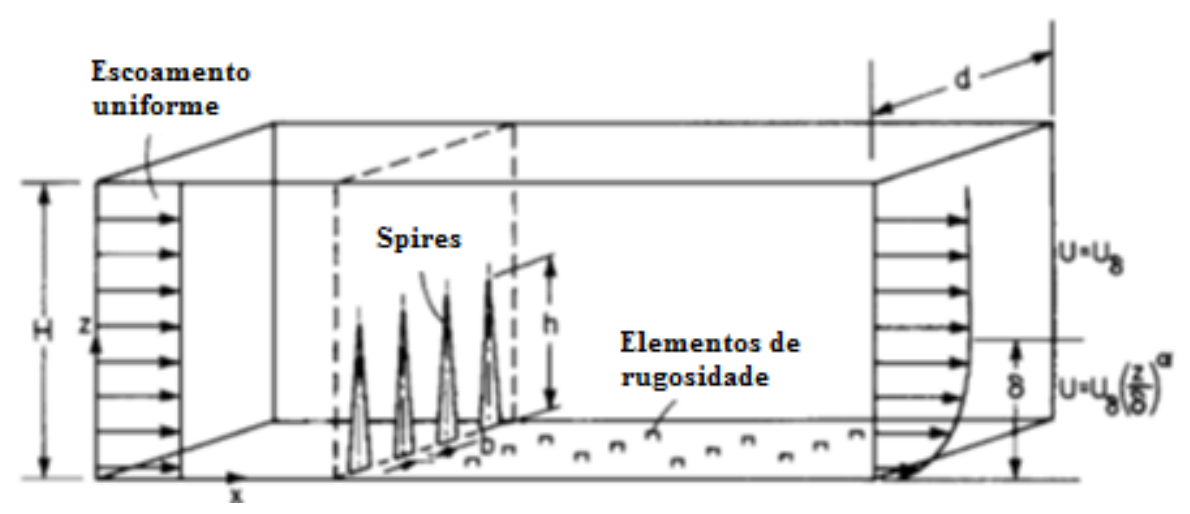

Figura 22. Spires posicionados na seção de testes (Irwin, 1981)

Irwin propôs um conjunto de equações para dimensionamento dos spires em função do tipo de terreno requerido, ou seja, de acordo com parâmetros descritivos da CLA real. Para isso é necessário estabelecer duas características essenciais do escoamento atmosférico: a rugosidade do terreno, representada pelo fator 
exponencial $(\alpha)$ e a altura da camada limite $(\delta)$. Para obter o perfil vertical da velocidade até a altura da CLA é necessário a utilização desses dois parâmetros na lei de potência, definida pela equação (3-3).

Sendo $h_{s}$ a altura dos spires, na técnica de Irwin, estes devem ser espaçados a uma distância de $h_{s} / 2$ em relação aos seus próprios eixos. Assim, a equação abaixo deve ser levada em consideração para a formação da CLA:

$$
h_{s}=\frac{2 E}{n}
$$

Em que $E$ é a largura do túnel de vento e $n$ é o número de spires necessários. Existe ainda a restrição de que a altura dos spires deve ser menor do que a altura do túnel de vento $\left(H_{t}\right)$, portanto:

$$
\frac{2 E}{n}<H_{t} \quad e \quad n>\frac{2 E}{H_{t}}
$$

Para calcular a altura dos spires é necessária a utilização da equação:

$$
h_{s}=1.39 \delta /\left(1+\frac{\alpha}{2}\right)
$$

A largura da base dos spires (b) é obtida agregando as seguintes equações:

$$
\frac{b}{h_{s}}=0.5\left[\psi\left(\frac{H_{t}}{\delta}\right) /(1+\psi)\right]\left(1+\frac{\alpha}{2}\right)
$$

Sendo que $\psi$ é determinado por:

$$
\begin{gathered}
\psi=\beta\left\{[2 /(1+2 \alpha)]+\beta-\left[1.13 \alpha /(1+\alpha)\left(1+\frac{\alpha}{2}\right)\right]\right\} /(1-\beta)^{2} \\
\beta=\left(\frac{\delta}{H_{t}}\right) \alpha /(1+\alpha)
\end{gathered}
$$


Objetivando simular um ambiente suburbano, o correspondente valor de $\alpha$ é de 0,28 e o valor de $\delta$ que se pretende simular no túnel é de $500 \mathrm{~mm}$. Sabendo que a altura da CLA para uma área suburbana pode chegar em torno de $400 \mathrm{~m}$ de extensão, como visto na seção 3.4, neste trabalho, a redução de escala da CLA em relação ao tamanho real foi de 1:800. Assim, considerando esses parâmetros e com as equações apresentadas anteriormente calcula-se a altura $\left(h_{s}\right)$ e a base $(b)$ dos spires em 609 mm e 92 mm, respectivamente. Através das equações (5-1) e (5-2), verifica-se que o número de spires (n) necessários é de 3,28. Deste modo, foram feitos experimentos com 3 e 4 spires e comparou-se os resultados. A Figura 23 mostra as configurações de 3 e 4 spires instalados no túnel de vento.

Segundo Irwin, a uniformidade transversal da camada limite é garantida a uma distância de cerca de 6 vezes a altura dos spires $\left(6 h_{s}\right)$. Dos valores calculados, chega-se à distância de 3,65 m a partir da entrada do túnel.

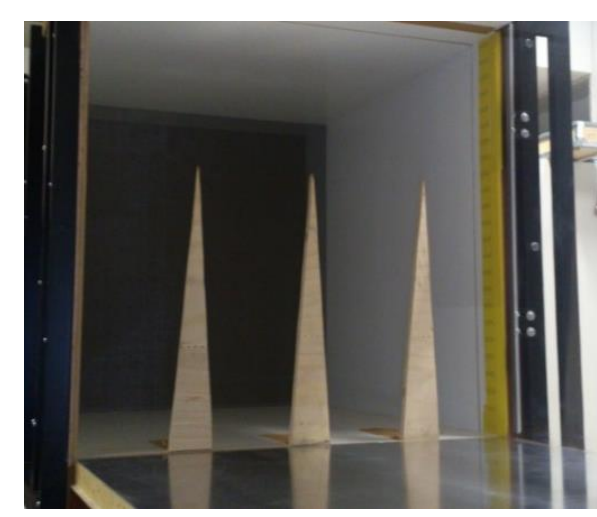

(a)

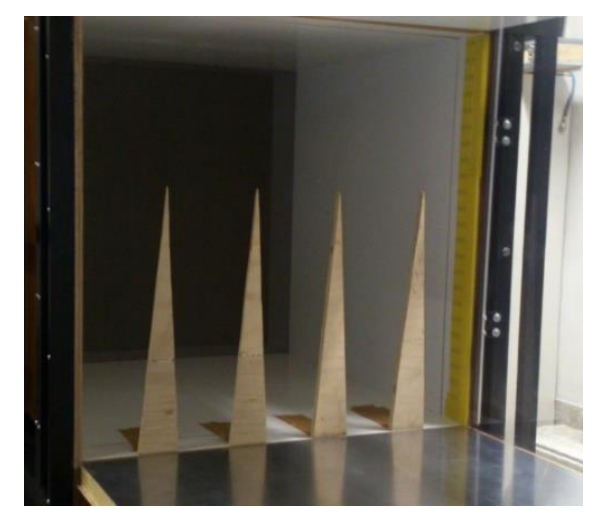

(b)

Figura 23. (a) Arranjo de 3 spires no túnel de vento e (b) Arranjo de 4 spires no túnel de vento

Os spires foram confeccionados em madeira de compensado naval e foi fixado na parte traseira de cada um deles um perfil de alumínio na forma de L, para de eles fossem presos ao chão do túnel. Um resumo de todos os parâmetros calculados para formação da CLA está apresentado na Tabela 4. 
Tabela 4. Parâmetros calculados para formação da camada limite atmosférica em relação a $\alpha=0,28$ e $\delta=500 \mathrm{~mm}$

\begin{tabular}{|c|c|c|}
\hline Parâmetros & 3 Spires & 4 Spires \\
\hline Altura do spire $\left(\boldsymbol{h}_{s}\right)(\mathrm{mm})$ & 609,65 & 609,65 \\
\hline Base do spire (b) (mm) & 92,53 & 92,53 \\
\hline$b / h_{s}$ & 0,1518 & 0,1518 \\
\hline $\begin{array}{c}\text { CLA formada a distância de } \\
6 h_{s}(\mathrm{~mm})\end{array}$ & 3657,89 & 3657,89 \\
\hline $\begin{array}{c}\text { Distância entre os eixos dos } \\
\text { spires }(\mathrm{mm})\end{array}$ & 273,13 & 218,51 \\
\hline$\psi$ & 0,1536 & 0,1536 \\
\hline 8 & 0,1094 & 0,1094 \\
\hline
\end{tabular}

\subsection{2.}

\section{Simulação computacional para reprodução da camada limite atmosférica no túnel de vento}

Para efeito de comparação, foi realizado um estudo computacional para analisar a camada limite gerada pelos spires. O escoamento no túnel de vento foi discretizado por equações diferenciais parciais descrevendo a conservação da massa e do momento no sistema de coordenadas cartesianas 3D para escoamento estável e incompressível. O estudo computacional foi realizado através do software OpenFOAM versão 3.0.1, baseado em um método de discretização de volume finito, e a geometria foi construída com o software Gmsh-2.11.0, como mostrado na Figura 24.

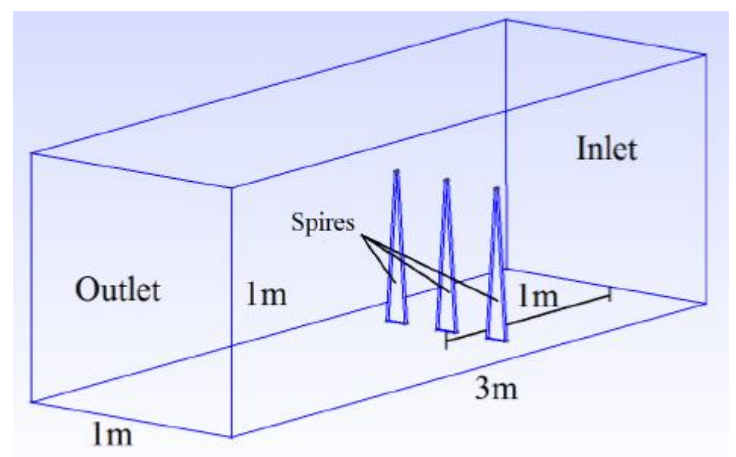

Figura 24. Geometria do túnel de vento com os spires criada no Gmsh 
As equações que governam o escoamento, baseadas em Reynolds-Averaged Navier-Stokes (RANS) são:

- Equação da continuidade:

$$
\frac{\partial u_{j}}{\partial x_{j}}=0
$$

- Equação de momentum:

$$
\frac{\partial}{\partial x_{j}}\left(u_{i} u_{j}\right)=-\frac{1}{\rho} \frac{\partial p}{\partial x_{i}}+\frac{\partial}{\partial x_{j}}\left\{v\left(\frac{\partial u_{i}}{\partial x_{j}}+\frac{\partial u_{j}}{\partial x_{i}}\right)-\overline{u_{\imath}^{\prime} u_{j}^{\prime}}\right\}
$$

Onde $x_{i}$ são as coordenadas cartesianas, $\rho$ é a densidade do ar e $u_{i}$ é a i-ésima componente da velocidade média e $p$ é a pressão estática média. Os termos $u_{i}^{\prime} u_{j}^{\prime}$ são as flutuações das componentes da velocidade, $\overline{u_{\imath}^{\prime} u_{\jmath}^{\prime}}$ são as tensões de Reynolds. As tensões de Reynolds são parametrizadas como:

$$
-\overline{u_{\imath}^{\prime} u_{\jmath}^{\prime}}=v_{t}\left(\frac{\partial u_{i}}{\partial x_{j}}+\frac{\partial u_{j}}{\partial x_{i}}\right)-\frac{3}{2} k \delta_{i j}
$$

Sendo que:

$$
v_{t}=B_{\mu} \frac{k_{c}^{2}}{\varepsilon}
$$

Onde $v_{t}$ é a viscosidade cinemática turbulenta de momentum, $\delta_{i j}$ é o delta kronecker ( $\delta_{i j}=1$, se $i=j$, caso contrário é 0$), k_{c}$ é a energia cinética turbulenta, $\varepsilon$ é a taxa de dissipação da energia cinética e $B_{\mu}$ é uma constante com um valor de 0,09. A energia cinética turbulenta, $k_{c}$, e a sua taxa de dissipação, $\varepsilon$, são obtidas a partir das seguintes equações de transporte:

$$
\frac{\partial}{\partial x_{j}}\left(k_{c} u_{j}\right)=\frac{\partial}{\partial x_{j}}\left(\frac{v_{t}}{\sigma_{k}} \frac{\partial k_{c}}{\partial x_{j}}\right)+v_{t}\left(\frac{\partial u_{i}}{\partial x_{j}}+\frac{\partial u_{j}}{\partial x_{i}}\right) \frac{\partial u_{i}}{\partial x_{j}}-\varepsilon
$$




$$
\frac{\partial}{\partial x_{j}}\left(\varepsilon u_{j}\right)=\frac{\partial}{\partial x_{j}}\left(\frac{v_{t}}{\sigma_{\varepsilon}} \frac{\partial \varepsilon}{\partial x_{j}}\right)+B_{1 \varepsilon} \frac{\varepsilon}{k_{c}} v_{t}\left(\frac{\partial u_{i}}{\partial x_{j}}+\frac{\partial u_{j}}{\partial x_{i}}\right) \frac{\partial u_{i}}{\partial x_{j}}-B_{2 \varepsilon} \frac{\varepsilon^{2}}{k_{c}}
$$

Onde $\sigma_{k}=1,0$ e $\sigma_{\varepsilon}=1,3$ são números de Prandtl turbulentos para $k_{c}$ e $\varepsilon$, respectivamente, e $B_{1 \varepsilon}=1,44$ e $B_{2 \varepsilon}=1,92$ são constantes.

O perfil de velocidade de entrada para a simulação é aplicado com base nas medições experimentais da entrada do túnel de vento. Foi empregada uma velocidade de escoamento uniforme, a energia cinética turbulenta e a taxa de dissipação turbulenta são:

$$
\begin{gathered}
k_{c}=1.5(I U)^{2} \\
\varepsilon=\frac{B_{\mu}^{3 / 4} k_{c}{ }^{3 / 2}}{0.07 L}
\end{gathered}
$$

Onde $I$ é a intensidade turbulenta do escoamento na entrada da seção de teste, $L$ é o comprimento característico e $B_{\mu}$ é uma constante igual a 0,09 . As condições de contorno foram usadas para a parede do túnel e para os spires. A condição de contorno de escoamento é definida como gradiente zero, como padrão do OpenFOAM.

\section{2. \\ Instrumentação para análise de escoamentos}

O Laboratório de Caracterização da Dinâmica de Escoamentos de Fluidos, onde foi realizado este trabalho possui uma extensa gama de instrumentos adequados à investigação de escoamentos de fluidos. Nos experimentos realizados neste trabalho foram utilizados anemômetro de fio quente, velocimetria por imagem de partículas, tubo de pitot, anemômetro de hélice e anemômetro ultrassônico.

\subsection{1.}

\section{Anemometria de fio quente}

A anemometria de fio quente (AFQ) é uma técnica amplamente utilizada na investigação de escoamentos, seja em líquidos ou gases. É considerado um método 
intrusivo, pois deve-se inserir no escoamento uma sonda com um filamento composto por um fio de tungstênio. Com essa sonda é possível realizar a medição instantânea do vetor velocidade em um ponto do escoamento com elevadas frequências de resposta, podendo atingir a ordem de centenas de $\mathrm{kHz}$.

O princípio de funcionamento dessa técnica é baseado na transferência de calor por convecção de um elemento sensor aquecido (Bruun, 1995; Goldstein, 1996). Esse filamento aquecido está ligado a um circuito eletrônico composto por um circuito de amplificação e por uma Ponte de Wheatstone, responsável pela manutenção da resistência do fio, que é um dos resistores integrantes da Ponte. Desse modo, quando o escoamento passa pelo fio quente, exerce uma influência sobre as propriedades do fio e esta influência está inteiramente ligada à velocidade do escoamento (Dantec Dynamics, 2013). Assim, na condição da Ponte balanceada, um pequeno aumento da velocidade do escoamento modifica essa temperatura préestabelecida, causando um desbalanceamento na Ponte de Wheastone e o sistema, para manter essa temperatura constante, aplica uma nova tensão no filamento. Portanto, a potência dissipada no fio quente aumenta, restaurando a temperatura estabelecida e fazendo com que a Ponte de Wheastone volte à condição de equilíbrio.

Para medições do perfil de velocidade do escoamento no túnel de vento, utilizou-se o sistema de anemometria StreamLine da Dantec Dynamics, do tipo CTA (Constant Temperature Anemometry), bidimensional (2D), com filamento de tungstênio e diâmetro de $5 \mu \mathrm{m}$. A sonda utilizada foi o modelo 55P11 1-D com resistência de $3,49 \mathrm{ohms}$ a $20^{\circ} \mathrm{C}$. A aquisição de dados e calibração do fio quente foi feita através do software StreamWare da Dantec Dynamics. O número de amostras em cada ponto de medição foi de 32768 e a taxa de aquisição foi de 1 KHz.

A velocidade do escoamento é determinada a partir da tensão de saída da Ponte de Wheatstone, baseada em uma curva de calibração feita previamente. Essa calibração foi feita no calibrador StreamLine, modelo 90H02 Flow Unit acoplado ao sistema da Dantec Dynamics. O calibrador consiste de uma câmara de estagnação onde existe uma entrada de ar, uma tomada de pressão e uma saída de ar, em formato circular, em que o escoamento é gerado por uma fonte de ar comprimido. $\mathrm{O}$ ar que vem do compressor passa antes por uma válvula reguladora 
de pressão. Para uma vazão constante, a pressão na câmara e a velocidade pelo orifício de saída também são constantes.

A calibração consiste em uma comparação entre os valores de velocidade na saída do bocal, medidas através da pressão na câmara do calibrador, e a tensão de saída da Ponte de Wheatstone. A sonda do AFQ é então alinhada ao bocal e a calibração realizada. Os pares de valores obtidos podem, então, ser correlacionados a partir da equação da lei de king (Möller, 2004) ou com um ajuste polinomial. Para o trabalho, foi utilizado um ajuste polinomial de $4^{\circ}$ ordem.

\section{3.}

\section{Instrumentação para análise de processos de dispersão de plumas}

Para analisar processos de dispersão de plumas no laboratório, a técnica escolhida para visualização e medição do campo de velocidades da região de interesse foi a técnica de Velocimetria por Imagem de Partículas. Através das imagens aquisitadas foi possível realizar também análises de concentração.

\subsection{1. Velocimetria por Imagem de Partículas}

A técnica de velocimetria por imagens de partículas (VIP), mais conhecida como PIV (Particle Image Velocimetry) surgiu na década de 80 e está sendo cada vez mais utilizada e aprimorada. É considerada uma técnica não intrusiva e utilizada na medição de campos de velocidades, ao invés de somente um ponto, como nas técnicas de anemometria de fio quente e anemometria a laser Doppler. Um requisito prévio para utilização do PIV é que as paredes da região de medição sejam transparentes e que no meio sejam inseridas partículas traçadoras. O sistema PIV 2D é montado com um plano de laser alinhado perpendicularmente com uma câmera de alta resolução. As partículas traçadoras inseridas no escoamento são iluminadas consecutivamente por dois planos de laser sincronizados com a câmera CCD (charge couple device) que captura essas imagens em um tempo $t$ e outro $t$, com uma defasagem de alguns $\mu \mathrm{s}$. Previamente, é feita uma calibração relacionando o número de pixels da imagem em milímetros, tornando possível determinar o deslocamento das partículas na imagem. Com o deslocamento das partículas e o tempo decorrido entre as duas imagens consecutivas, é possível então definir a 
velocidade do escoamento. Um desenho esquemático da técnica PIV é apresentado na Figura 25.

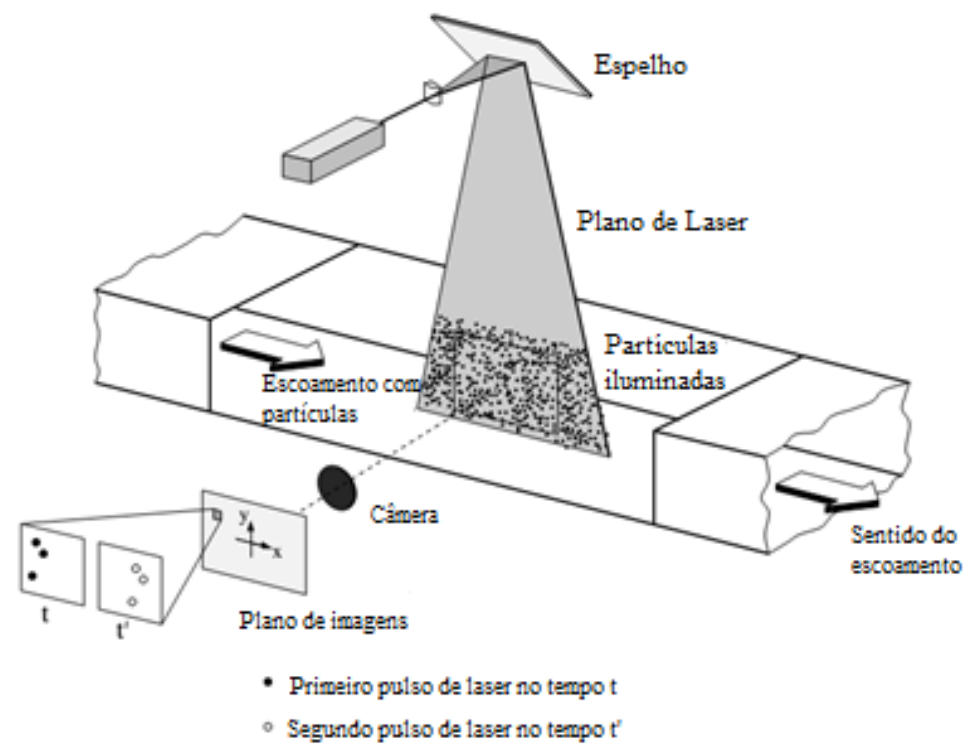

Figura 25. Princípio de funcionamento da técnica PIV (Flow Manager, 2000)

O sistema PIV empregado no trabalho utiliza um laser pulsado de dupla cavidade $N d Y A G$, que reproduz uma luz verde com comprimento de onda de 532 nm. O laser usado, Big Sky Ultra PIV 120,2 x $120 \mathrm{~mJ}$ por pulso, é fornecido pela Dantec Dynamics e possui frequência de pulsação de $15 \mathrm{~Hz}$. As partículas são iluminadas pelo plano de luz enquanto uma câmera CCD Flow Sence 4M Mk2 captura as imagens com resolução de $2048 \times 2048$ pixels. O sistema PIV é sincronizado e controlado através do software DynamicStudio da Dantec Dynamics.

Foi realizada uma calibração, ajustando um alvo de calibração com o laser, e a câmera perpendicular a esse alvo, como pode ser visto na Figura 26 . O alvo de calibração possui marcações bem delimitadas e espaçadas igualmente, e é posicionado na região de interesse do escoamento. No software do PIV insere-se a distância real entre os pontos do alvo de calibração. Assim, a câmera aquista uma imagem e o software realiza a conversão da distância em pixels entre os pontos, para milímetros. 


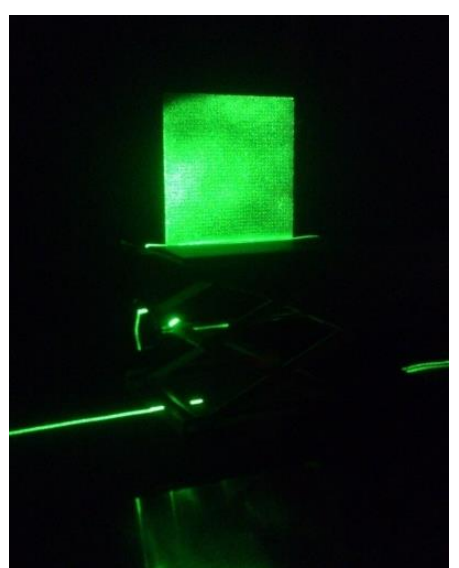

(a)

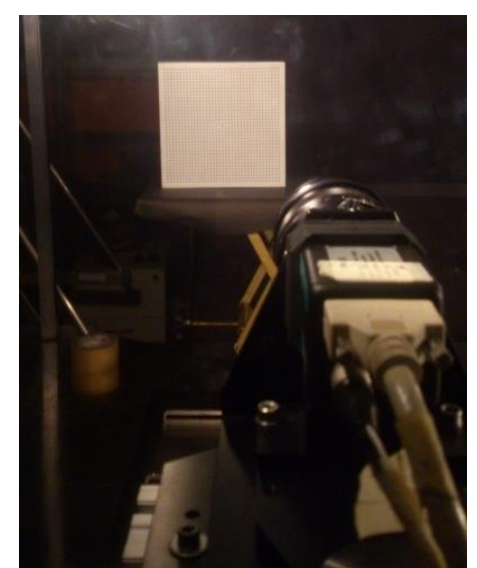

(b)

Figura 26. (a) Alvo de calibração iluminada pelo plano e laser e (b) Câmera CCD alinhada com plano de laser

\subsubsection{1.}

\section{Montagem do sistema PIV no túnel de vento}

O sistema PIV foi montado no túnel de vento e diversos testes foram realizados para que o plano de laser abrangesse toda região de interesse da pluma. O emissor de laser foi então colocado, com uma inclinação de $65,6^{\circ}$, sobre o teto do túnel de vento, de modo que sua lente ficasse alinhada a um rasgo central do teto do túnel, como mostrado na Figura 27.

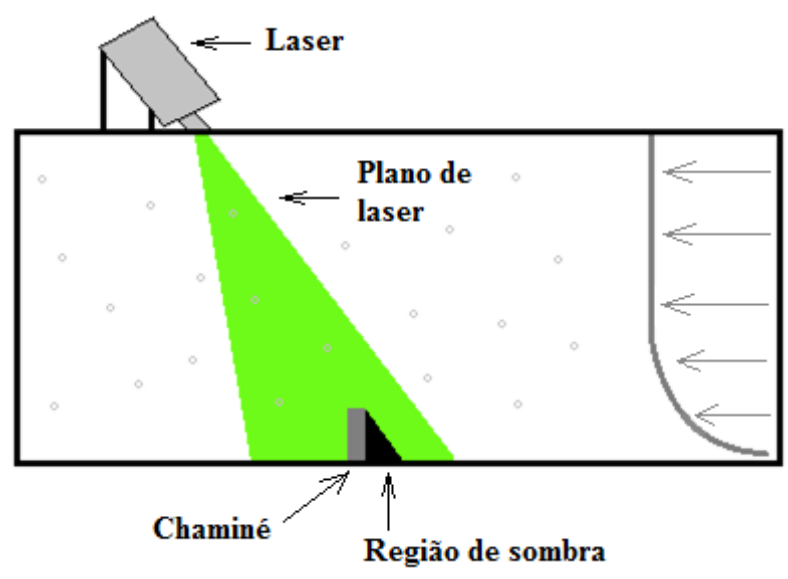

Figura 27. Disposição do laser do PIV com a chaminé

As janelas de visualização da câmera do PIV foram escolhidas depois de diversos testes realizados. Para determinar os limites inferior e superior da pluma, foram realizadas medições em diversas condições de velocidade tanto da pluma quanto do escoamento principal. As configurações escolhidas para realização dos 
experimentos atenderam à condição de que toda a pluma dispersada pela chaminé deve-se encontrar dentro da CLA reproduzida. Feitos os testes, as janelas de visualização foram definidas com dimensões expostas na Figura 28. Todos os experimentos foram realizados com duas janelas de visualização quadradas, de dimensões 23,6 cm. A janela 1 abrangeu $4,3 \mathrm{~cm}$ da chaminé para condições de velocidade mais baixa do escoamento principal do túnel (condição da linha contínua na Figura 28) e 11,1 cm de chaminé para a condição de velocidade mais alta do escoamento principal (condição da linha pontilhada na Figura 28).

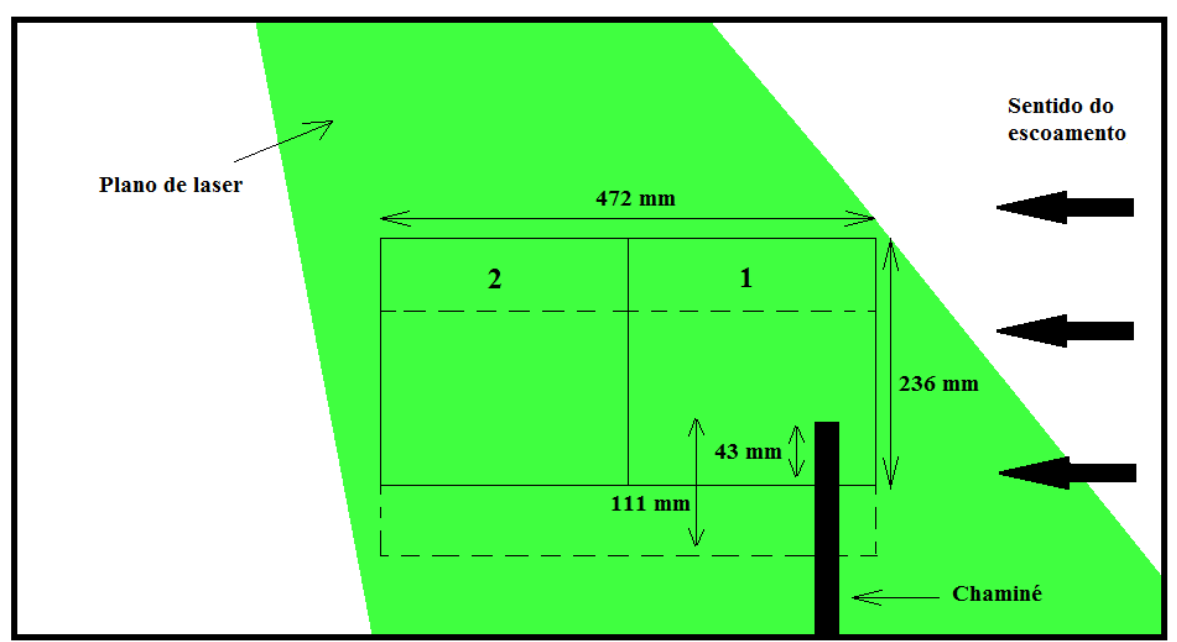

Figura 28. Posição da chaminé e das janelas de visualização da câmera do PIV

Para utilização do PIV foi necessário inserir partículas traçadoras no escoamento principal do túnel de vento e para isso o fluido empregado foi uma solução de glicerina da marca Rosco FX. O equipamento utilizado para esta finalidade foi um sistema de geração de fumaça Antari, modelo Z-1500 II, que foi posicionado dentro da caixa de entrada do túnel de vento, onde se encontra o ventilador. Desse modo, toda fumaça produzida é aproveitada para o experimento. A Figura 29 mostra a montagem do sistema PIV no túnel de vento. 


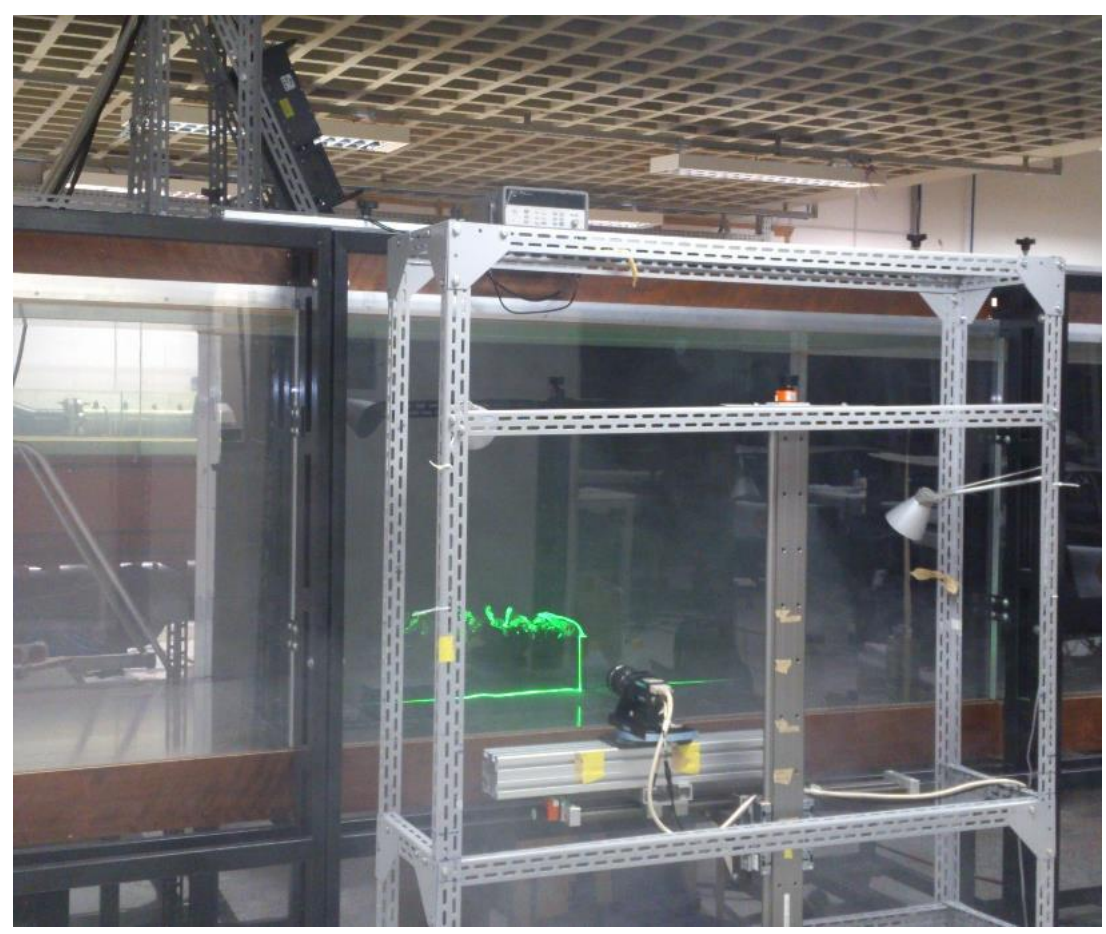

Figura 29. Montagem do sistema PIV no túnel de vento

\subsection{2. \\ Sistema de injeção do partículas na chaminé}

Para a realização dos estudos de dispersão de plumas, foi feita um modelo em escala de uma chaminé. Foi usado um tubo de PVC de 12,7 mm de diâmetro cortado com dimensões adequadas e tingido de preto, para evitar reflexos indesejados do laser do sistema PIV, e posicionado na linha central do túnel de vento, com saída a uma altura de $15 \mathrm{~cm}$.

O fluido utilizado para gerar a pluma foi uma solução de glicerina da marca Rosco FX. Um equipamento de geração de fumaça (Safex Controller NS3) foi utilizado para sublimar a glicerina. Uma caixa de $94 \mathrm{dm} 3$ de volume para estabilização da fumaça gerada foi utilizada a fim de manter a concentração adequada e constante na saída da chaminé. O equipamento de geração de fumaça foi embutido na caixa através de uma ponteira (Fog Line), pela qual saia a fumaça.

Um soprador térmico da marca Bosh, resistência para aquecimento de até $600^{\circ} \mathrm{C}$ foi posicionado na caixa, alinhado à entrada da chaminé, permitindo controle da velocidade e temperatura de saída da pluma (Figura 30). Um regulador de tensão Variac VM 10140 de $2100 \mathrm{~W}$ foi utilizado para controlar a velocidade do motor do soprador, possibilitando controle fino de velocidades, enquanto a temperatura de emissão foi ajustada manualmente no soprador térmico. Para se obter exatamente a 
temperatura na saída da chaminé, um termopar do tipo $\mathbf{J}$ foi instalado dentro da chaminé, paralelo às suas paredes, de modo que a perturbação no escoamento foi considerada desprezível.

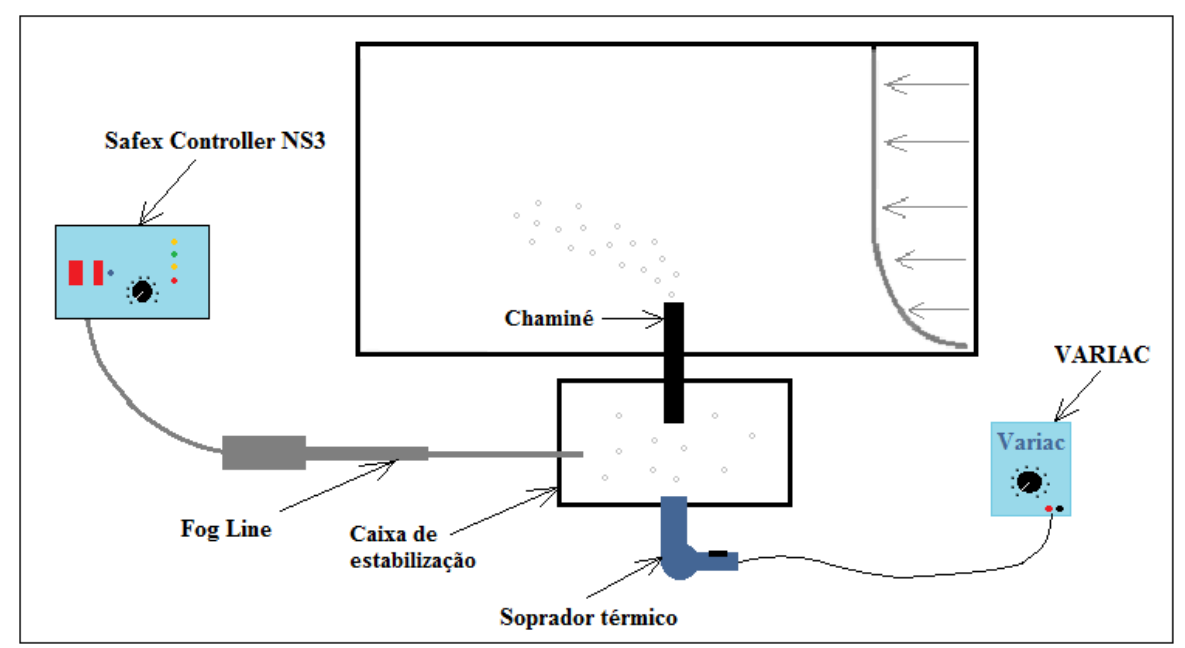

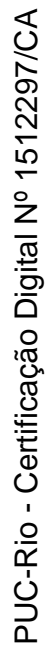

Figura 30. Desenho esquemático do sistema de injeção de FOG 


\section{6 Estratificação térmica do túnel de vento atmosférico}

\section{1. Camada limite convectiva}

A camada limite térmica se desenvolve devido à diferença de temperatura entre o fluido na corrente livre e a superfície. As partículas do fluido, quando entram em contato com a superfície, entram em equilíbrio térmico e essas partículas trocam energia com outras partículas do fluido adjacente, desenvolvendo assim um gradiente de temperatura no fluido. Esse gradiente de temperatura é a camada limite térmica.

$\mathrm{Na}$ atmosfera, a camada limite convectiva (CLC) é a parte da atmosfera mais diretamente afetada pela irradiação solar na superfície da Terra. O conhecimento da altura e estrutura da CLC é necessário em muitas aplicações, tais como estudos de qualidade do ar, operações de pulverização, investigações climatológicas regionais, estudos relacionados a dispersão de poluentes e na previsão do tempo. Esta camada se estende desde a superfície da terra até uma altura de 1 a $2 \mathrm{~km}$. A camada limite convectiva (CLC) é dividida em:

- Camada superficial: é uma região muito próxima ao solo, correspondendo de 5 a $10 \%$ da CLC e caracterizada pela diminuição de umidade com altura. Tem uma distribuição quase constante de quantidades tais como temperatura potencial, velocidade do vento, umidade e concentração de poluentes devido à forte flutuabilidade gerada por turbulência convectiva.

- Camada mista: Corresponde de 35 a 80\% de CLC e é caracterizada por variáveis conservadas como temperatura potencial, velocidade do vento e umidade.

- Zona de entranhamento: pode ser bastante espessa, com média de cerca de $40 \%$ da profundidade da CLC. É a região de ar estaticamente estável no topo da camada mista, onde há arrasto do ar da atmosfera 
livre para baixo. Existem um aumento acentuado da temperatura potencial e da velocidade do vento, enquanto que a umidade tem uma queda acentuada e concentração de poluentes.

Como mostrado na Figura 31, a espessura da CLC tem um processo de crescimento dividido em 4 fases: (I) Formação de uma fina camada mista: Durante a madrugada a camada mista é superficial e sua profundidade aumenta lentamente devido à forte cobertura noturna de inversão estável. (II) Crescimento rápido: Ao final da manhã, o ar noturno frio foi aquecido a uma temperatura próxima à da camada residual, de modo que as térmicas sobem rapidamente durante essa fase. (III) Camada mista: Essa camada tem uma espessura quase constante, pois é quando as térmicas atingem a camada de inversão térmica no topo da camada residual e elas encontram resistência ao movimento vertical, fazendo com que a taxa de crescimento da camada mista diminua rapidamente. Durante esta terceira fase, que abrange a maior parte da tarde, a taxa de temperatura da CLC é de $1^{\circ} \mathrm{C} / 100 \mathrm{~m}$. (IV) Declínio: A turbulência gerada pela flutuabilidade que impulsiona a mistura decai após o pôr do sol e a CLC decai também (Stull, 1988).

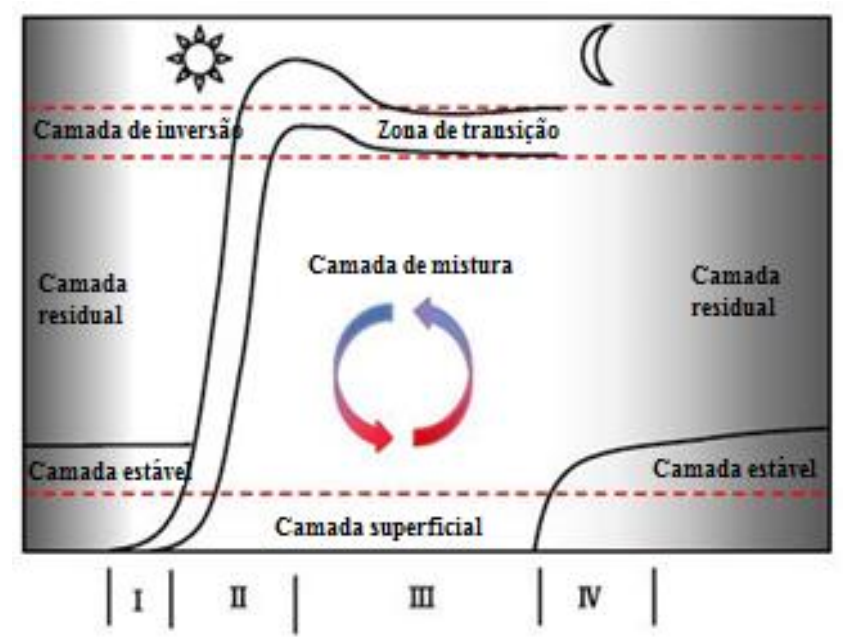

Figura 31. Evolução da camada limite convectiva (Adaptado de Stull, 1988)

\section{2 .}

\section{Estratificação térmica em túneis de vento}

A maioria das pesquisas em túneis de vento se realiza utilizando simulações de camada limite atmosférica em condições de estabilidade neutra, porém, em alguns casos deve ser considerada a estratificação atmosférica, requerendo um 
grande investimento de tempo e equipamento para seu desenvolvimento. Há diversas razões para simular a camada limite atmosférica estratificada em um túnel de vento, dentre elas, está a resolução de problemas ambientais, como a difusão de fontes de poluição do ar. A estabilidade da atmosfera, isto é, as características de estratificação, exibem uma grande variedade de fenômenos atmosféricos interessantes. $\mathrm{O}$ estudo dos efeitos da estratificação sobre o escoamento na CLA é importante para a compreensão e análise dos padrões de movimento do escoamento na proximidade do terreno e é um dos tópicos mais importantes da pesquisa na área de poluição atmosférica.

Os túneis de vento que foram projetados para produzir camadas ou estratificação contínua podem ter diferentes configurações. Alguns utilizam a passagem de ar através de um trocador de calor a montante, injeção de ar aquecido, ou ainda utiliza-se de uma camada limite térmica crescida sobre longas superfícies aquecidas ou resfriadas. Alguns trabalhos relacionados com estratificação térmica em túneis de vento incluem Hunt e Fernholz (1975), Cermak, (1982), Ohba et al. (1998), Meroney (1980), Meroney e Melbourne (1992).

O túnel de vento proposto por Schon e Mery (1971) foi usado para simular condições neutras e instáveis na parte inferior da camada limite atmosférica. Naquele túnel, a camada limite se desenvolve naturalmente sobre o chão aquecido do túnel a uma temperatura de aproximadamente $100{ }^{\circ} \mathrm{C}$, enquanto que a temperatura do teto do túnel é de cerca de $20{ }^{\circ} \mathrm{C}$. Já no túnel de vento de Cermak (1971), a temperatura do ar ambiente pode variar de $5^{\circ} \mathrm{C}$ até $95^{\circ} \mathrm{C}$ (Cermak e Takeda, 1985).

Para analisar a dispersão sob condições de estabilidade não-neutra Janssen, (1979), simulou, utilizando sempre escoamento isotérmico, condições nas quais a turbulência é mais alta e mais baixa que em uma simulação de um escoamento com estabilidade neutra. Para análise de dispersão, considera-se que estas condições se aproximam respectivamente a escoamentos atmosféricos mais estáveis e instáveis.

Debler, descreveu como um gradiente de temperatura estável constante foi montado em um túnel de vento por meio de tiras aquecidas na colmeia do túnel de vento. Seus resultados mostraram que um gradiente de temperatura estável em um escoamento turbulento atenua as flutuações da velocidade vertical, mas não tem muito efeito nos movimentos horizontais. Os espectros foram também medidos, mostrando um aumento das flutuações de temperatura a favor do vento. 
Hertig (1984), conseguiu simular escoamentos estratificados, incluindo condições de inversão térmica, mediante a utilização de vários canais nos quais a geração do escoamento e o aquecimento podem ser feitos individualmente com ventiladores e aquecedores múltiplos.

No Japão foi construído um túnel com ventiladores múltiplos controlados individualmente por meio de um computador para simular o vento atmosférico (Nishi e Miyagi, 1995). É possível obter as características requeridas do escoamento através de medições com anemômetro de fio quente e de comparações com os espectros atmosféricos.

Para simular casos de inversão térmica, em que a camada limite estratificada é considerada estável, frequentemente são utilizados tanques de água para realizar o experimento (Hunt; Snyder, 1980), pois nessa condição o gradiente térmico é grande (Wittwer, 2006). Já para o caso de estratificação instável, o caso crítico para aplicações práticas é o caso da camada de mistura. A turbulência da camada de mistura simula-se mediante uma rugosidade adequada, ou seja, para simular a camada de mistura utiliza-se um escoamento isotérmico (Plate, 1982; Wittwer, 2006). Dentre todas as possibilidades, a configuração escolhida para simular uma camada limite convectiva foi realizando aquecimento na parte inferior do túnel de vento.

\section{3. Montagem para realizar o aquecimento do túnel de vento}

A fim de simular a estratificação térmica da atmosfera, foram instaladas resistências térmicas embaixo do chão do túnel. Para se obter o perfil térmico desejado, foram necessárias 7 unidades de 750 W (com resistência de aproximadamente $65 \Omega$ ), com 1 metro de comprimento cada uma, instaladas desde a entrada da seção de testes. Uma chapa de $1 \mathrm{~m}^{2}$ possui 4 fileiras composta por fios de resistências com espaçamento de $15 \mathrm{~mm}$. Para garantir homogeneidade na geração de calor e máximo aproveitamento do calor dissipado, foram adicionadas, abaixo do chão do túnel e das resistências, camadas de isolante térmico lã de vidro seguidas de uma lâmina de madeira com resina celeron, que é altamente resistente a mudanças bruscas de temperatura e possui uma temperatura de combustão em 
torno de $140{ }^{\circ} \mathrm{C}$ (Isolaplast, 2016). A Figura 32 mostra as etapas dessa montagem no túnel de vento.

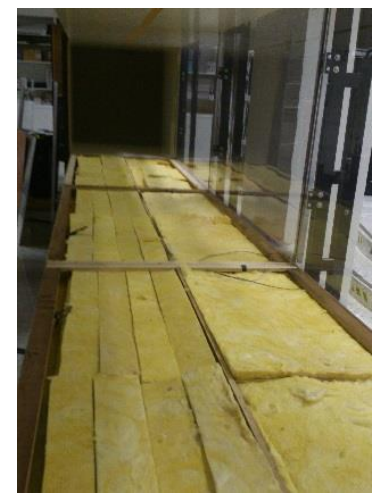

(a)

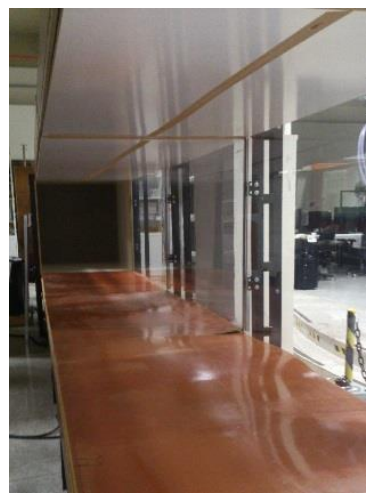

(b)

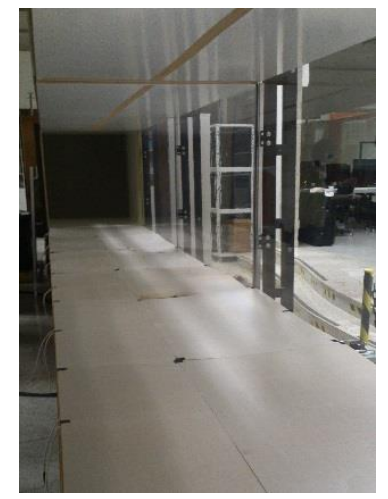

(c)

Figura 32. Montagem do sistema de aquecimento (a) Lã de vidro disposta em quatro camadas no interior do túnel de vento, (b) madeira disposta sobre a lã de vidro e (c) montagem das resistências sobre a madeira

O controle do calor dissipado e, consequentemente, da temperatura da superfície e do perfil térmico, foi realizado através da variação da tensão de alimentação das resistências. Um regulador de tensão Variac JNG (TSGC2 - 30), de $30 \mathrm{kVA}$, foi instalado entre a alimentação da rede e as resistências, as quais foram instaladas em paralelo. A potência dissipada foi monitorada fazendo-se leituras na tensão de saída do variac. A corrente de entrada no variac foi medida em 21,7 A com um amperímetro, e multiplicando-se pela tensão de entrada de $220 \mathrm{~V}$, obtêm-se a o valor de $4774 \mathrm{~W}$ de potência total dissipada. Essa potência total é dividida em 7 placas com as resistências, o que confere a cada placa $682 \mathrm{~W}$.

O instrumento utilizado para medição de temperatura no túnel de vento foi o termopare. Termopares são transdutores de temperatura utilizados em uma ampla gama de aplicações devido ao seu baixo custo, robustez e facilidade de operação. São compostos por dois diferentes metais unidos em uma das extremidades. O princípio de funcionamento baseia-se no surgimento de uma diferença de potencial quando há uma diferença de temperatura entre a extremidade unida e a extremidade livre. Os termopares utilizados para o presente trabalho são do tipo J (Ferro/Constantan), podendo abranger temperaturas de $0{ }^{\circ} \mathrm{C}$ até $750{ }^{\circ} \mathrm{C}$ (Omega, 2017). Como a estrutura do túnel de vento é feita em madeira naval, foi necessário realizar a instalação de termopares para monitoramento da temperatura em pontos 
próximos a essas estruturas, evitando, assim, pontos de superaquecimento. Deste modo, oito termopares calibrados foram instalados em diversos pontos das mantas de lã de vidro para monitoramento da temperatura.

A montagem dos termopares para adquirir o perfil de temperatura no túnel de vento envolveu 20 termopares, dispostos verticalmente na linha central do túnel, a uma distância de 7 metros da entrada da seção de testes e se deu da seguinte maneira: próximo ao chão do túnel foram colocados 6 termopares igualmente espaçados de $2 \mathrm{~cm}$ entre si, sendo que o primeiro está encostado no chão; a $10 \mathrm{~cm}$ do chão do túnel foram colocados 4 termopares com espaçamento de $4 \mathrm{~cm}$ entre si, e a partir de $26 \mathrm{~cm}$ do chão do túnel foram colocados os restantes 10 termopares com espaçamento de $7 \mathrm{~cm}$ entre eles. Preocupou-se em refinar os dados na parte inferior, uma vez que é esperado que a temperatura varie mais, nas proximidades da chapa aquecida.

Esses 20 termopares foram conectados a um módulo de um equipamento para aquisição dos dados, Agilent 34970A. Para visualização e obtenção dos dados de temperatura dos termopares foi utilizado um programa no software LabVIEW. Este programa realiza uma comunicação via GPIB com o equipamento de aquisição Agilent 34970A, e inserindo dados no LabVIEW como números de termopares que se deseja ativar, tempo entre medições e tipo de sensor, é possível fazer a aquisição dos dados de temperatura para posteriormente tratá-los. Através desse programa, é possível também realizar o monitoramento das temperaturas dos termopares colocados próximos à lã de vidro.

\subsection{1.}

\section{Calibração dos termopares}

Antes de serem instalados no túnel de vento, os termopares utilizados foram submetidos a calibração. Para isso, uma comparação entre os valores de temperatura dos termopares em calibração e um instrumento padrão em um banho termostático foi realizada.

O padrão de temperatura utilizado foi um termopar do tipo PT100 da marca Fluke calibrado, com incerteza abaixo de $0,01^{\circ} \mathrm{C}$. Um recipiente com isolamento térmico apropriado, sobre um agitador eletromagnético da marca BIOFOCO, 
modelo BF2AGM-E1, utilizado para minimizar os efeitos de gradiente térmico propiciou gerar um banho estável.

O líquido escolhido para o banho foi água destilada, a qual foi aquecida até o ponto de ebulição. A água destilada foi, então, inserida no recipiente, juntamente com os termopares e o medidor padrão. Todos os termopares foram inseridos à mesma altura no banho, para evitar efeitos do gradiente térmico vertical. O banho foi lentamente resfriando por várias horas, até atingir a temperatura ambiente, enquanto os valores de temperatura eram automaticamente aquisitados. Desta forma, pequenas incertezas devido à falta de sincronia entre a aquisição dos dados dos diversos sensores e o padrão foram minimizados.

O mesmo processo foi realizado com água resfriada, a qual foi sendo aquecida lentamente por trocas térmicas com o ambiente. Foram feitas 3 rodadas da calibração, tanto aquecendo quanto resfriando a água.

\subsection{2.}

Incerteza dos Termopares

O modelo matemático da calibração pode ser considerado como:

$$
T_{r}=T_{i}+C
$$

Onde $T_{r}$ é a temperatura de referência, $T_{i}$ é a temperatura indicada pelo sensor em calibração e $C$ é a constante de calibração. A temperatura de referência pode ser definida como:

$$
T_{r}=T_{P T 100}+\delta T_{g}+\delta T_{s}
$$

Onde $T_{P T 100}$ é a temperatura do padrão (PT100), $\delta T_{g}$ é a correção devido ao gradiente térmico e $\delta T_{s}$ é a correção devido à falta de sincronia entre as medidas do padrão e do sensor em calibração. O modelo completo fica:

$$
C=T_{P T 100}+\delta T_{g}+\delta T_{s}-T_{i}+\delta C
$$

Em que $\delta C$ é a repetibilidade, ou seja, o desvio padrão das diversas corridas. 
O valor de $T_{P T 100}$ é o valor lido diretamente dos registros do padrão, com incerteza expandida $U\left(T_{P T 100}\right)$ obtido do certificado de calibração.

Com o uso do agitador magnético e posicionando-se os sensores numa mesma altura no banho, $\delta T_{g}$ pôde ser desprezado. Para assegurar isto, foi feita uma varredura no banho, posicionando o sensor calibrado em diversas alturas e verificando a diferença de temperatura. Foi observado que a diferença é desprezível, de forma que $\delta T_{g} \approx U\left(\delta T_{g}\right)=0$.

Como não é possível determinar qual a diferença de tempo exata entre a medição do padrão e do sensor a ser calibrado, $\delta T_{s}$ foi considerado com valor nulo e sua incerteza foi estimada verificando-se a taxa de variação da temperatura com o tempo e determinando um valor máximo de defasagem entre a aquisição dos dois sinais. A taxa máxima de variação de temperatura durante as calibrações foi de $\partial T / \partial t=0.0023^{\circ} \mathrm{C}$ e máxima defasagem foi estimada em 10s. Desta forma, $U\left(\delta T_{s}\right)=0.023^{\circ} \mathrm{C}$.

$\mathrm{O}$ valor de $T_{i}$ é obtido diretamente dos valores registrados, com incerteza $U\left(T_{i}\right)=0.0005^{\circ} \mathrm{C}$, que é a incerteza devido a resolução dos termopares.

Os cálculos de incertezas foram realizados de acordo com o Guia para a expressão de incerteza de medição (ISO GUM, 2008), através da expressão:

$$
u_{c}(t)=\sqrt{\sum_{i=1}^{N}\left(\frac{\partial f}{\partial x_{i}}\right)^{2} u^{2}\left(x_{i}\right)}
$$

Em que $u_{c}(t)$ é a incerteza-padrão combinada, $f$ é a função que relaciona as grandezas que determinam o mensurando, cada $u\left(x_{i}\right)$ é uma incerteza-padrão tipo A ou tipo B.

Para cada termopar foi obtida uma curva de calibração com incertezas associadas. O gráfico da Figura 33 apresenta a curva de calibração para o termopar de número 4, como exemplo. 


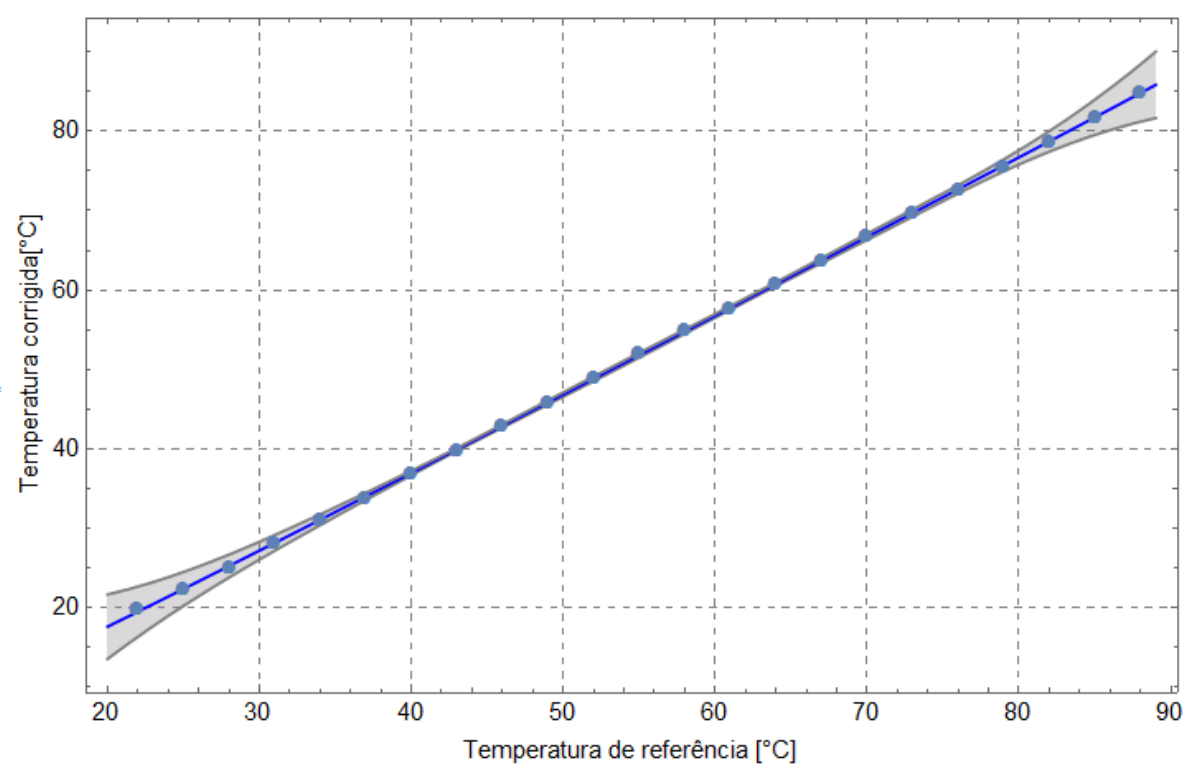

Figura 33. Curva de calibração de um termopar. A linha azul representa o valor corrigido e a área em cinza apresenta o intervalo de confiança de 95\%

O gráfico apresenta a temperatura corrigida em função da temperatura indicada, com os valores de incerteza associados para fator de abrangência de k=2 (intervalo de confiança de 95\%). Observa-se que os termopares apresentam uma incerteza maior para temperaturas menores, isso se deve à baixa repetibilidade dos termopares. Porém, foi realizado um estudo quanto ao grau de correlação entre os termopares e foi verificado que todos possuem um alto grau de correlação entre si. 


\section{7 \\ Resultados e discussões}

\section{1. Planejamento dos experimentos}

Primeiramente, foi necessário avaliar as características do perfil de velocidade no interior da seção de testes, realizando uma caracterização do túnel de vento. A caracterização é fundamental para se conhecer o perfil do escoamento e determinar a velocidade média de trabalho, parâmetro de entrada essencial para estudos realizados no túnel de vento. $\mathrm{Na}$ área da metrologia, a caracterização do túnel é extremamente importante para a calibração de instrumentos de medição de velocidade.

O processo de caracterização já havia sido iniciado (Farias et al., 2014). Com as medições realizadas no túnel vazio, foi possível analisar o comportamento do escoamento no interior da seção de testes em diversas alturas. Mais medições foram realizadas no início da seção de testes de modo a determinar quais velocidades seriam usadas nos experimentos.

Posteriormente, a reprodução da camada limite atmosférica descrita na seção 5.1.1 foi implementada e as características do perfil de velocidades e intensidade turbulenta foram analisadas. Foram realizados ensaios na condição do túnel vazio e com 3 e 4 spires, a uma distância de $4 \mathrm{~m}$ e $7 \mathrm{~m}$ da entrada do túnel. Para as medições de intensidade turbulenta e de variação de velocidade com simulação da CLA, foi utilizado o anemômetro de fio quente CTA da Dantec, com frequência de aquisição de $1 \mathrm{kHz}$. Com a CLA gerada, foram realizados ensaios utilizando o sistema de estratificação térmica montado no túnel.

Um protótipo de uma chaminé foi colocado na seção de testes, a 7 metros da entrada. Todos os estudos de dispersão da pluma foram analisados com a técnica PIV. Foram consideradas três velocidades diferentes de emissão da pluma, cada uma com duas temperaturas diferentes $\left(T_{w}\right)$, para condição do túnel de vento vazio e com a reprodução da CLA. As temperaturas de emissão da pluma possuíam uma 
diferença de temperatura $(\Delta T)$ de $10^{\circ} \mathrm{C}$ e $20^{\circ} \mathrm{C}$ em relação à temperatura ambiente no túnel de vento $\left(T_{t}\right)$. Como explicado anteriormente, tanto a velocidade, quanto a temperatura da pluma são controladas por um soprador térmico. Este soprador, ligado a um regulador de tensão variac, permite um ajuste fino da velocidade de saída e a temperatura pode ser modificada no próprio equipamento. Deste modo, foram realizados diversos testes para determinar três velocidades de emissão da pluma, $W_{0}$, entre 0,5 e $2,5 \mathrm{~m} / \mathrm{s}$. Assim, as tensões ajustadas no variac para atingir essas velocidades são 40, 50 e 60\% da tensão de entrada. Como a velocidade era ajustada variando-se a tensão fornecida pelo variac, a potência máxima disponível para o sistema também diminuía. Como o sistema de aquecimento do soprador tem controle em malha fechada, para garantir que haveria potência suficiente para que a velocidade desejada não fosse modificada, foram realizados testes medindo-se a velocidade do ar com um anemômetro de hélice da marca ICEL Manaus, modelo AN-4870 e verificou-se que o aumento de temperatura no soprador não ocasionou uma diminuição de velocidade.

\section{2.}

\section{Caracterização do túnel de vento}

Como explicado na seção 5.1.1, o método de simulação escolhido para promover a CLA no túnel de vento requer que o perfil de entrada, anterior aos spires, seja uniforme. Para isso foi necessário realizar medições na primeira seção do túnel de vento. Foram realizadas medições em 7 posições na disposição transversal do túnel (em $z=80,215,365,500,645,790,920 \mathrm{~mm}$ ), a fim de caracterizar toda a seção de entrada, para 6 diferentes velocidades do escoamento principal. Para cada posição, foram feitas medições em um total de 44 pontos na posição vertical. Nas proximidades do chão e do teto foi utilizado um passo de 1 mm, e no restante, 35 mm. Para essa caracterização, foi utilizado o AFQ, com 32768 amostras a $1 \mathrm{kHz}$.

O resultado apontado na Figura 34 mostra todos os perfis de velocidade plotados para as seguintes frequências do inversor de frequências $(f)$ que controla o ventilador do túnel: 5, 7, 9, 11, 13 e $15 \mathrm{~Hz}$. Sendo que para cada alteração na frequência do inversor, esperava-se um tempo para o escoamento estabilizar. 


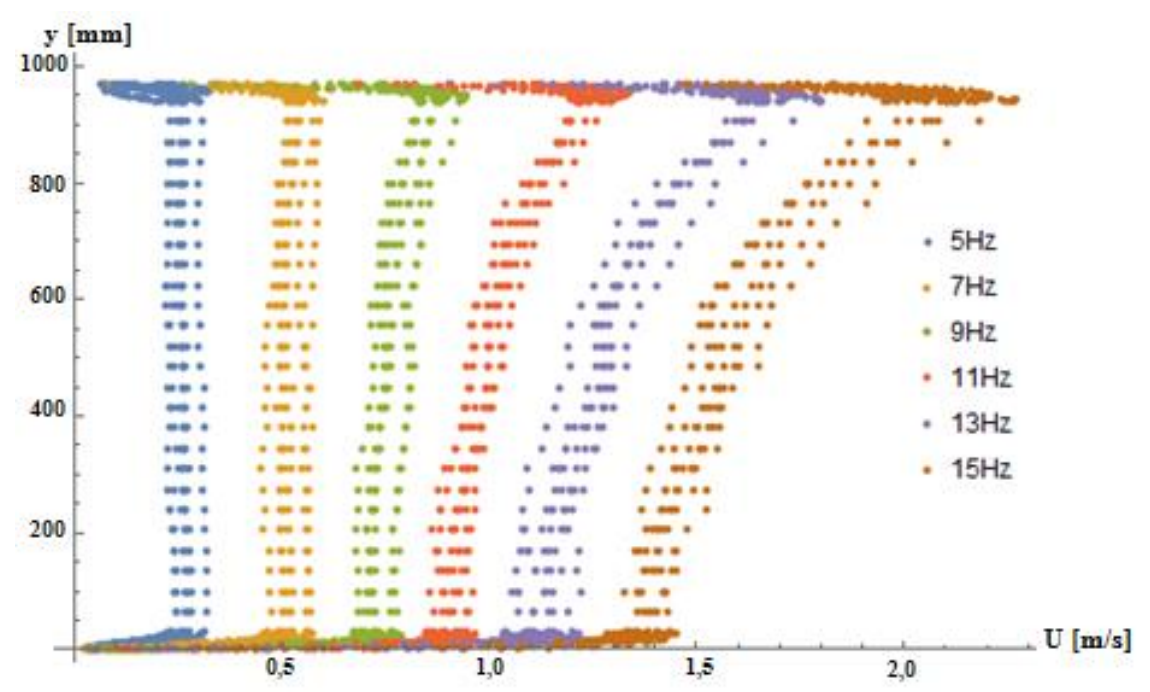

Figura 34. Perfis de velocidade obtidos com a técnica AFQ na entrada da seção de testes

O valor de velocidade máxima $\left(U_{\max }\right)$ para cada frequência ensaiada, no início da seção de testes, está apresentado na Tabela 5.

Tabela 5. Relação entre frequência do inversor e velocidade máxima no início da seção de testes

\begin{tabular}{c|cccccc}
$\begin{array}{c}\text { Frequência do } \\
\text { inversor (f) }\end{array}$ & $5 \mathrm{~Hz}$ & $7 \mathrm{~Hz}$ & $9 \mathrm{~Hz}$ & $11 \mathrm{~Hz}$ & $13 \mathrm{~Hz}$ & $15 \mathrm{~Hz}$ \\
\hline$U_{\max }(\mathrm{m} / \mathrm{s})$ & 0,31 & 0,59 & 0,93 & 1,34 & 1,79 & 2,26
\end{tabular}

No gráfico apresentado, percebe-se que os perfis de velocidade correspondentes às frequências acima de $11 \mathrm{~Hz}$ apresentam grande grau de nãohomogeneidade, que pode ser ocasionado pela seção de expansão, pela disposição das telas e colmeias e pelo tipo de ventilador. Observando-se o perfil da camada limite escolhida e o tipo de estudo a ser realizado, foram escolhidas as frequências de 7, 9 e $11 \mathrm{~Hz}$ para se realizar os estudos de dispersão da pluma. A frequência de $5 \mathrm{~Hz}$ foi descartada pois apresentou velocidades baixas para o estudo. A frequência de $11 \mathrm{~Hz}$, apesar de apresentar alterações maiores na velocidade próximo ao teto do túnel, foi escolhida para verificar se a teoria de Irwin se aplica bem à condição de perfil não uniforme anterior aos spires. 


\section{3. \\ Verificação da camada limite atmosférica gerada}

Após o projeto, construção e montagem dos spires, estes foram colocados a uma distância de $75 \mathrm{~mm}$ da posição onde o perfil de entrada foi verificado. Posteriormente foi realizada a caracterização do túnel para averiguar o efeito destas estruturas. As medidas do perfil de velocidade com os spires foram feitas às distâncias de $x=4$ metros e $x=7$ ( $x$ é o eixo longitudinal do túnel) metros da entrada do túnel para as três frequências escolhidas do inversor, citadas anteriormente. A posição de 4 metros foi escolhida pois, de acordo com a técnica de Irwin, é onde espera-se que o perfil da camada limite esteja formado a uma distância de $6 h_{s}$ dos spires, como visto na seção 5.1.1. Entretanto, como trabalho objetiva realizar também a parte de estratificação térmica do túnel de vento, os experimentos foram realizados a uma distância de 7 metros da entrada, possibilitando a instalação de uma quantidade suficiente de resistências para aquecimento do túnel. E para garantir que a CLA se mantinha a esta distância, foram realizadas novas medições. Os próximos gráficos mostram os resultados dessa caracterização com o túnel de vento vazio, com 3 e com 4 spires, comparados com a lei da potência, descrita pela equação (3-3), com os parâmetros para simular um terreno suburbano. Foram realizadas medidas do perfil de velocidade média e de intensidade turbulenta em 34 pontos no eixo vertical com o anemômetro de fio quente. Na região próxima ao solo do túnel (até $30 \mathrm{~mm}$ de altura), onde espera-se que o escoamento tenha maior variação na velocidade, foram feitas medições a cada $5 \mathrm{~mm}$, e de 65 a $975 \mathrm{~mm}$, a cada $35 \mathrm{~mm}$.

A Figura 35 mostra os perfis de velocidade para condição de $U_{\max }=0,59 \mathrm{~m} / \mathrm{s}$ no início da seção de testes em $\mathrm{x}=4 \mathrm{~m}$. O perfil de intensidade turbulenta para esses casos é mostrado na Figura 36. 


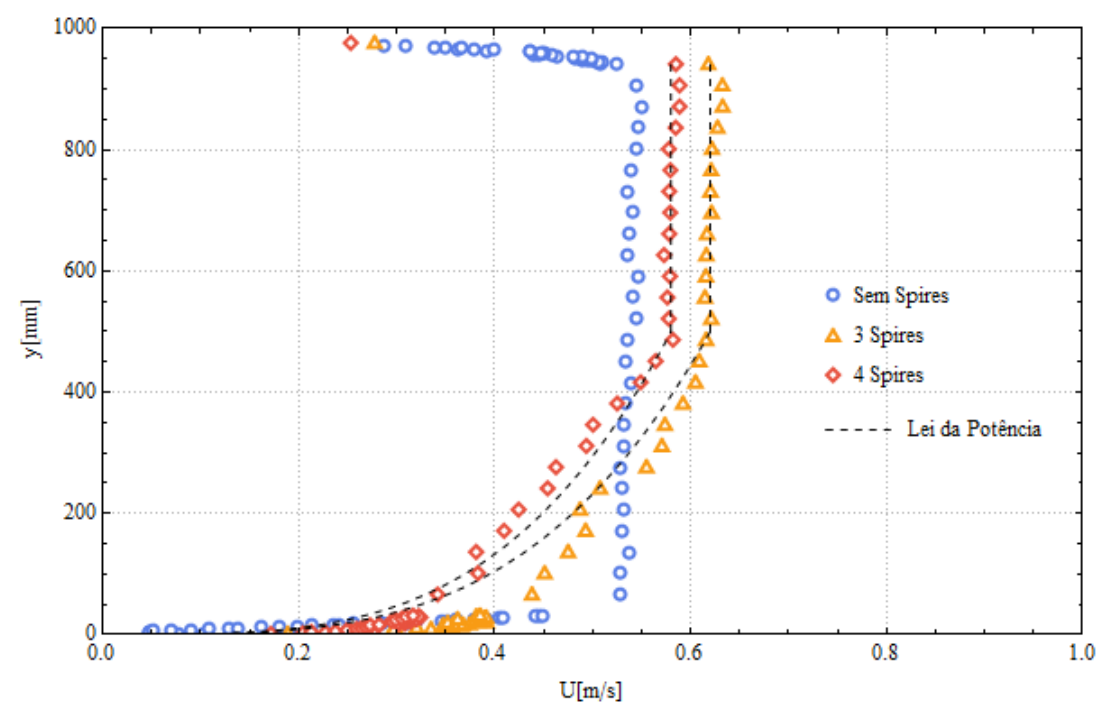

Figura 35. Perfil de velocidade para $U_{\max }=0,59 \mathrm{~m} / \mathrm{s}(f=7 \mathrm{~Hz})$ e $x=4 \mathrm{~m}$

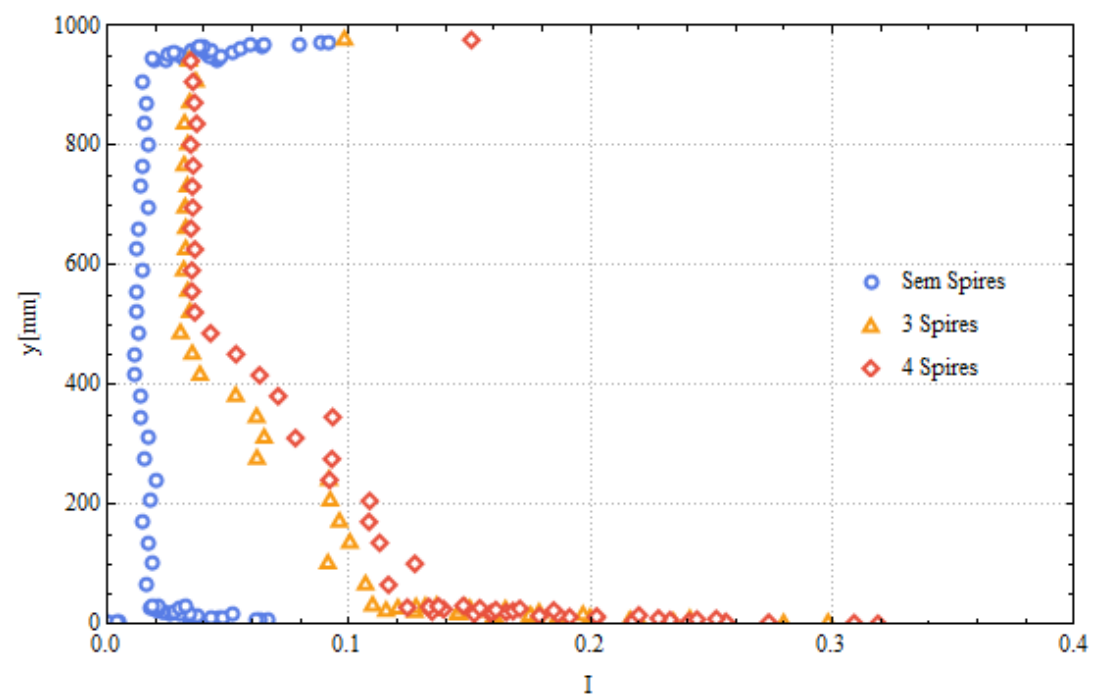

Figura 36. Intensidade turbulenta para $U_{\max }=0,59 \mathrm{~m} / \mathrm{s}(f=7 \mathrm{~Hz})$ e $x=4 \mathrm{~m}$

O gráfico da Figura 35, na distância de 4 metros da entrada do túnel, resulta em $U_{\max }=0,56 \mathrm{~m} / \mathrm{s}$ na condição de túnel sem spires, $U_{\max }=0,63 \mathrm{~m} / \mathrm{s}$ na condição de túnel com 3 spires e $U_{\max }=0,58 \mathrm{~m} / \mathrm{s}$ com 4 spires. A Figura 37 mostra os perfis de velocidade para $U_{\max }=0,93 \mathrm{~m} / \mathrm{s}$, em $x=4 \mathrm{~m}$. O perfil de intensidade turbulenta para esses casos é mostrado na Figura 38. 


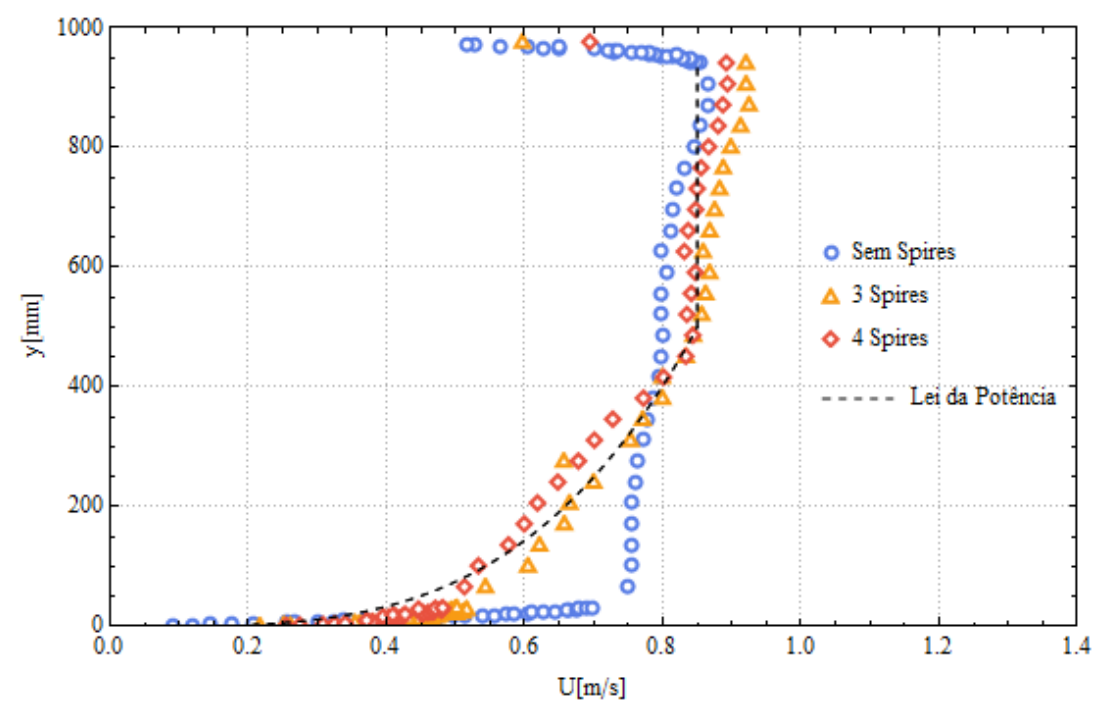

Figura 37. Perfil de velocidade para $U_{\max }=0,93 \mathrm{~m} / \mathrm{s}(f=9 \mathrm{~Hz})$ e $x=4 \mathrm{~m}$

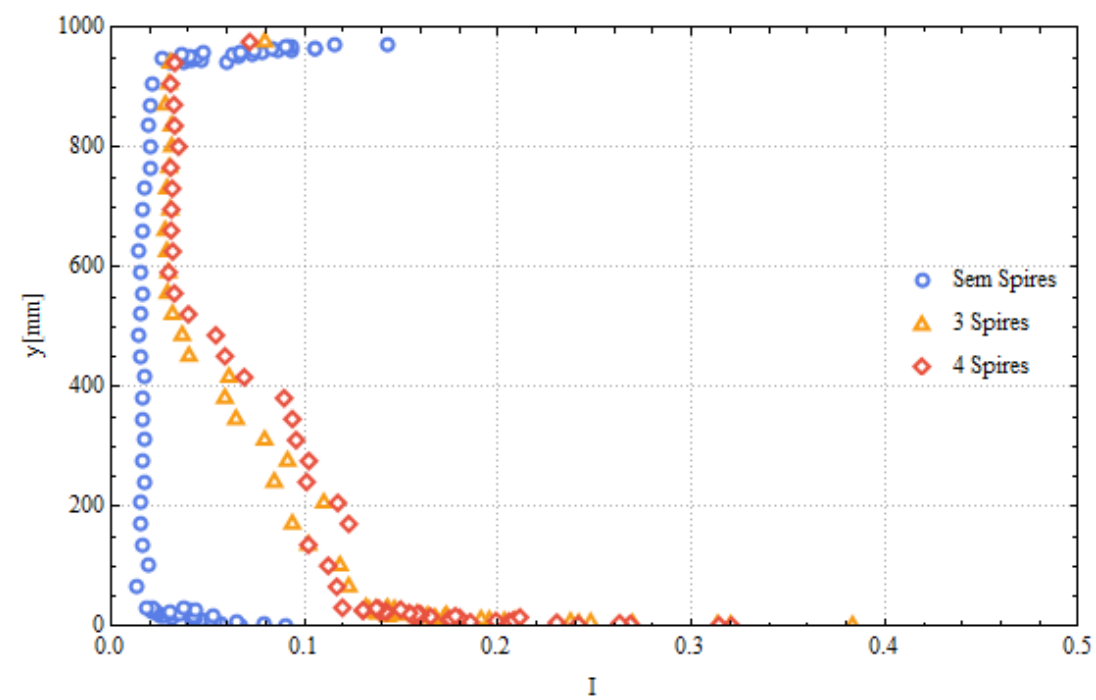

Figura 38. Intensidade turbulenta para $U_{\max }=0,93 \mathrm{~m} / \mathrm{s}(f=9 \mathrm{~Hz})$ e $x=4 \mathrm{~m}$

O gráfico da Figura 37 que resulta em $U_{\max }=0,89 \mathrm{~m} / \mathrm{s}$ na condição de túnel sem spires, $U_{\max }=0,93 \mathrm{~m} / \mathrm{s}$ na condição com 3 spires e $U_{\max }=0,86 \mathrm{~m} / \mathrm{s}$ com 4 spires. A Figura 39 mostra os perfis de velocidade para $U_{\max }=1,34 \mathrm{~m} / \mathrm{s}$, em $x=$ $4 \mathrm{~m}$. O perfil de intensidade turbulenta para esses casos é mostrado na Figura 40. 


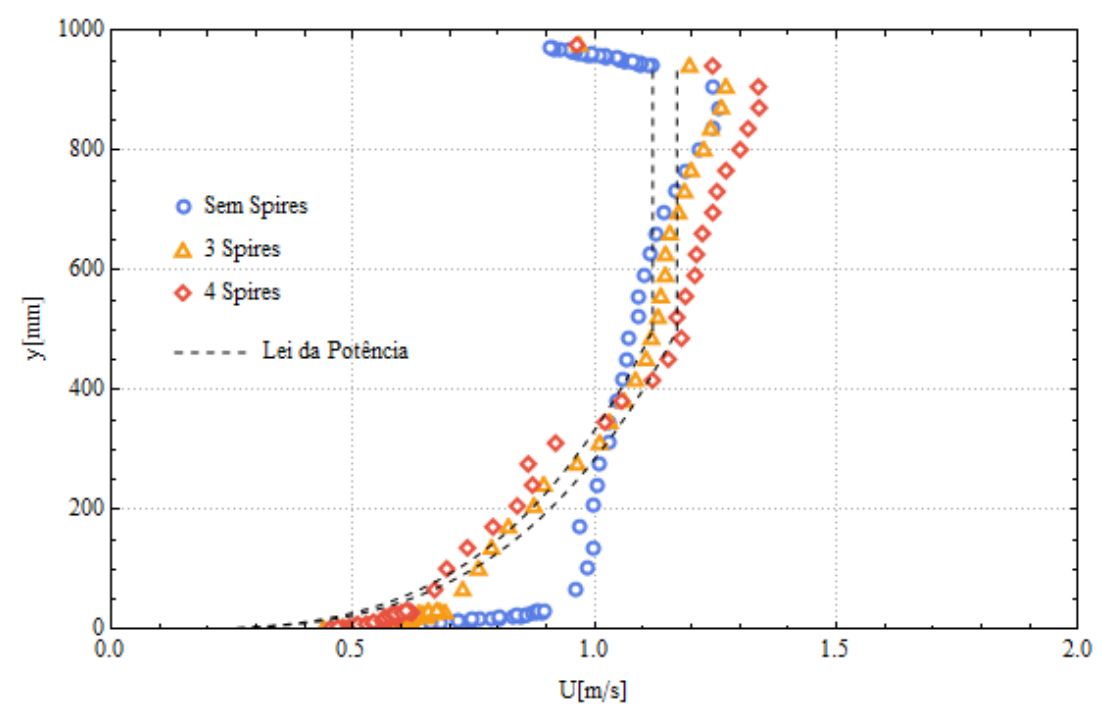

Figura 39. Perfil de velocidade para $U_{\max }=1,34 \mathrm{~m} / \mathrm{s}(f=11 \mathrm{~Hz})$ e $x=4 \mathrm{~m}$

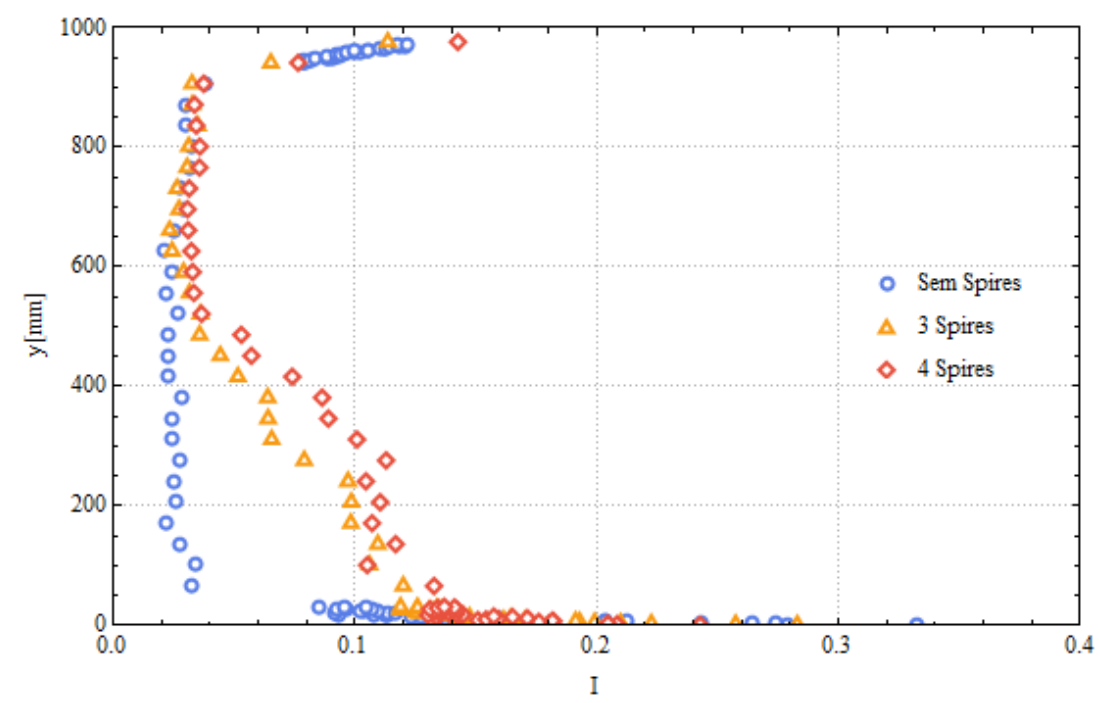

Figura 40. Intensidade turbulenta para $U_{\max }=1,34 \mathrm{~m} / \mathrm{s}(f=11 \mathrm{~Hz})$ e $x=4 \mathrm{~m}$

O gráfico da Figura 39 resulta em $U_{\max }=1,25 \mathrm{~m} / \mathrm{s}$ na condição de túnel sem spires, $U_{\max }=1,27 \mathrm{~m} / \mathrm{s}$ na condição com 3 spires e $U_{\max }=1,34 \mathrm{~m} / \mathrm{s}$ com 4 spires.

É possível observar que o perfil resultante tanto para 3 spires quanto para 4 spires, para todas as velocidades ensaiadas, apresentam uma boa concordância com a lei da potência (para $\alpha=0,28$ ). Porém, para as velocidades correspondentes às frequências de $9 \mathrm{~Hz}$ e $11 \mathrm{~Hz}$ do inversor, nota-se um aumento de velocidade na parte superior do perfil da camada limite. Isto já era esperado devido às questões estruturais do túnel de vento, conforme visto na seção 7.3. Nos gráficos de intensidade turbulenta, é expressiva a mudança de valores após a instalação dos 
spires. Os perfis com o túnel vazio apresentam nível de turbulência na ordem de $3 \%$, ao passo que a presença dos spires faz com que a turbulência ultrapasse um pouco mais de $10 \%$. O gráfico da Figura 39 comprova a eficácia da teoria de Irwin, onde, à distância $6 h_{s}$ dos spires $(x=4 \mathrm{~m})$, o perfil da camada limite atmosférica está bem desenvolvido.

Os gráficos apresentados desde a Figura 41 até a Figura 46, mostram a evolução da camada limite, do perfil de velocidades e intensidade turbulenta a uma distância de 7 metros da entrada no túnel. Conforme mencionado, isto foi necessário para que pudesse ser instalado o sistema de aquecimento do túnel de vento. A Figura 41 mostra os perfis de velocidade para $U_{\max }=0,59 \mathrm{~m} / \mathrm{s}$ no início da seção de testes, em $x=7 \mathrm{~m}$. O perfil de intensidade turbulenta para esses casos é mostrado na Figura 42 .

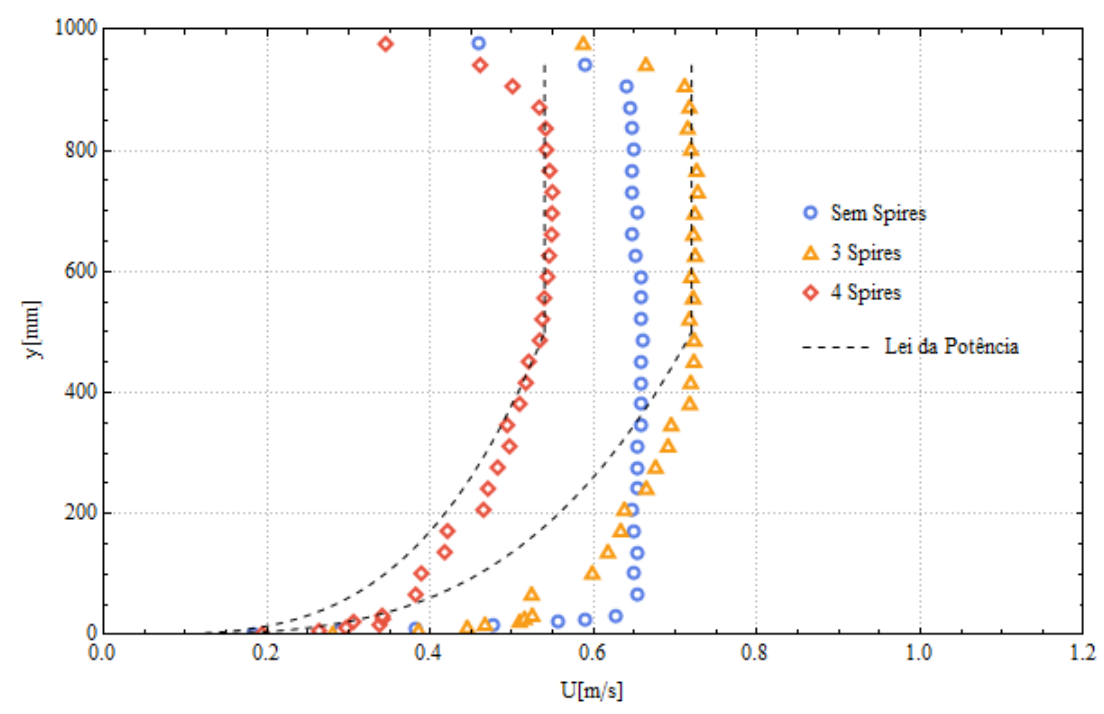

Figura 41. Perfil de velocidade para $U_{\max }=0,59 \mathrm{~m} / \mathrm{s}(f=7 \mathrm{~Hz})$ e $x=7 \mathrm{~m}$ 


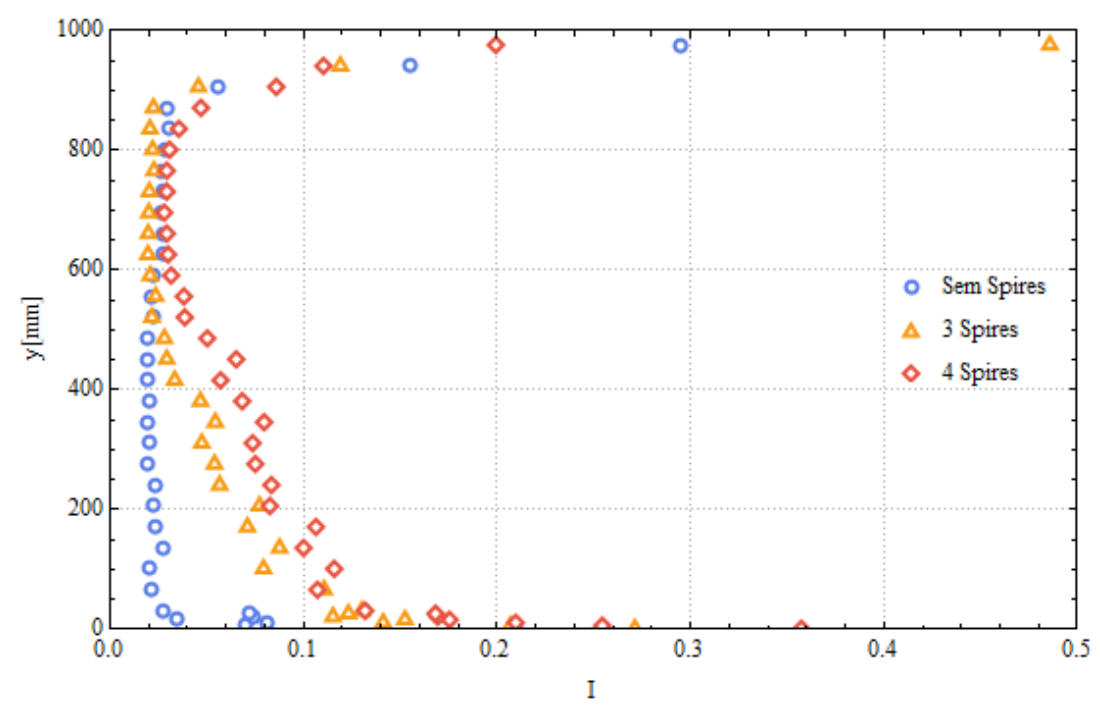

Figura 42. Intensidade turbulenta para $U_{\max }=0,59 \mathrm{~m} / \mathrm{s}(f=7 \mathrm{~Hz})$ e $x=7 \mathrm{~m}$

O gráfico da Figura 41 mostra $U_{\max }=0,66 \mathrm{~m} / \mathrm{s}$ na condição de túnel sem spires, $U_{\max }=0,73 \mathrm{~m} / \mathrm{s}$ na condição de túnel com 3 spires e $U_{\max }=0,55 \mathrm{~m} / \mathrm{s}$ com 4 spires. A Figura 43 mostra os perfis de velocidade para $U_{\max }=0,93 \mathrm{~m} / \mathrm{s}$ no início da seção de testes, em $x=7 \mathrm{~m}$. O perfil de intensidade turbulenta para esses casos é mostrado na Figura 44.

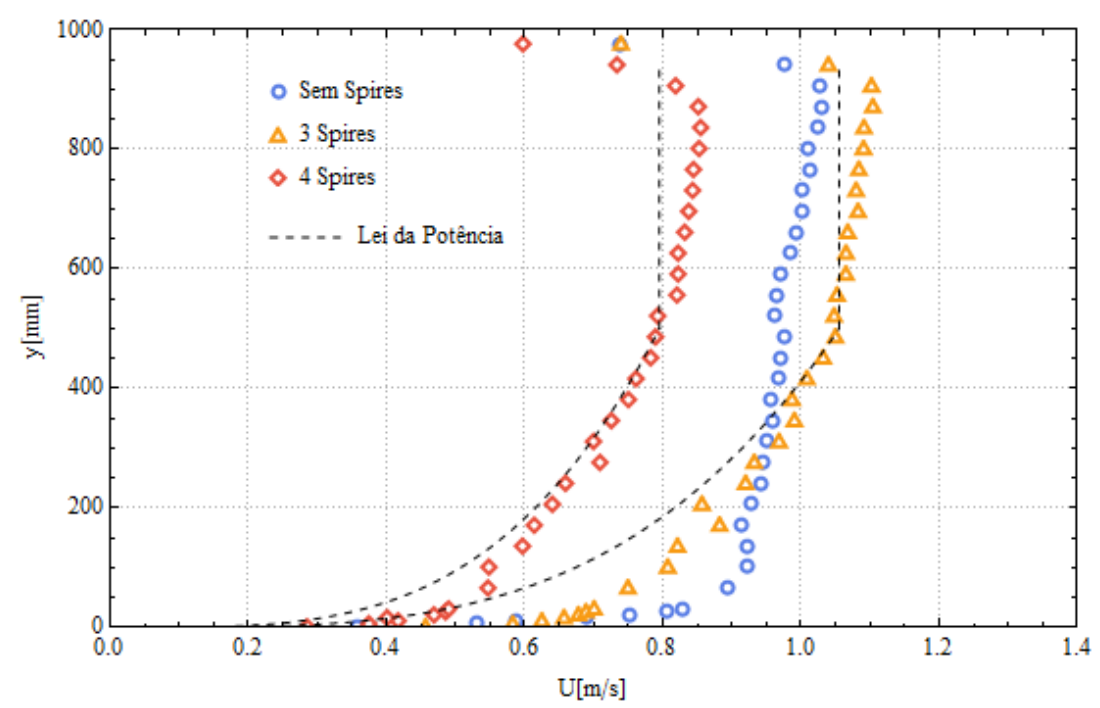

Figura 43. Perfil de velocidade para $U_{\max }=0,93 \mathrm{~m} / \mathrm{s}(f=9 \mathrm{~Hz})$ e $x=7 \mathrm{~m}$ 


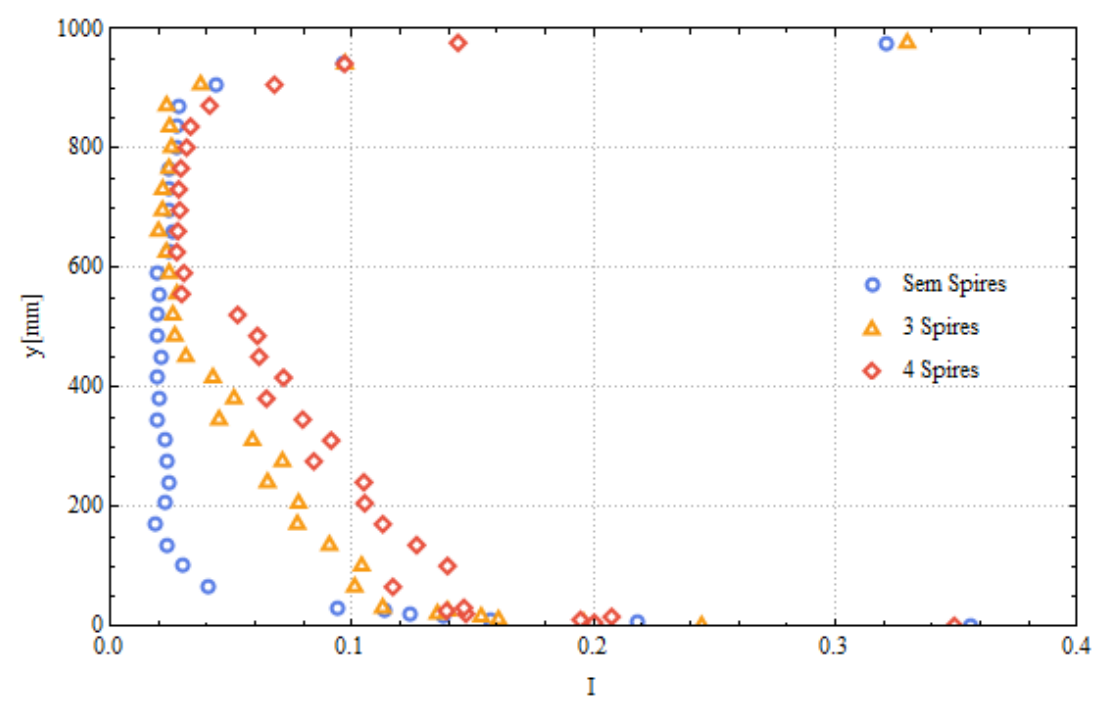

Figura 44. Intensidade turbulenta para $U_{\max }=0,93 \mathrm{~m} / \mathrm{s}(f=9 \mathrm{~Hz})$ e $x=7 \mathrm{~m}$

O gráfico da Figura 43 resulta em $U_{\max }=1,03 \mathrm{~m} / \mathrm{s}$ na condição de túnel sem

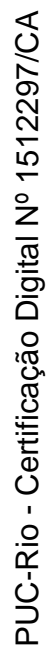
spires, $U_{\max }=1,11 \mathrm{~m} / \mathrm{s}$ na condição de túnel com 3 spires e $U_{\max }=0,86 \mathrm{~m} / \mathrm{s} \mathrm{com} 4$ spires. A Figura 45 mostra os perfis de velocidade para $U_{\max }=0,93 \mathrm{~m} / \mathrm{s}$ no início da seção de testes, em $x=7 \mathrm{~m}$. O perfil de intensidade turbulenta para esses casos é mostrado na Figura 46.

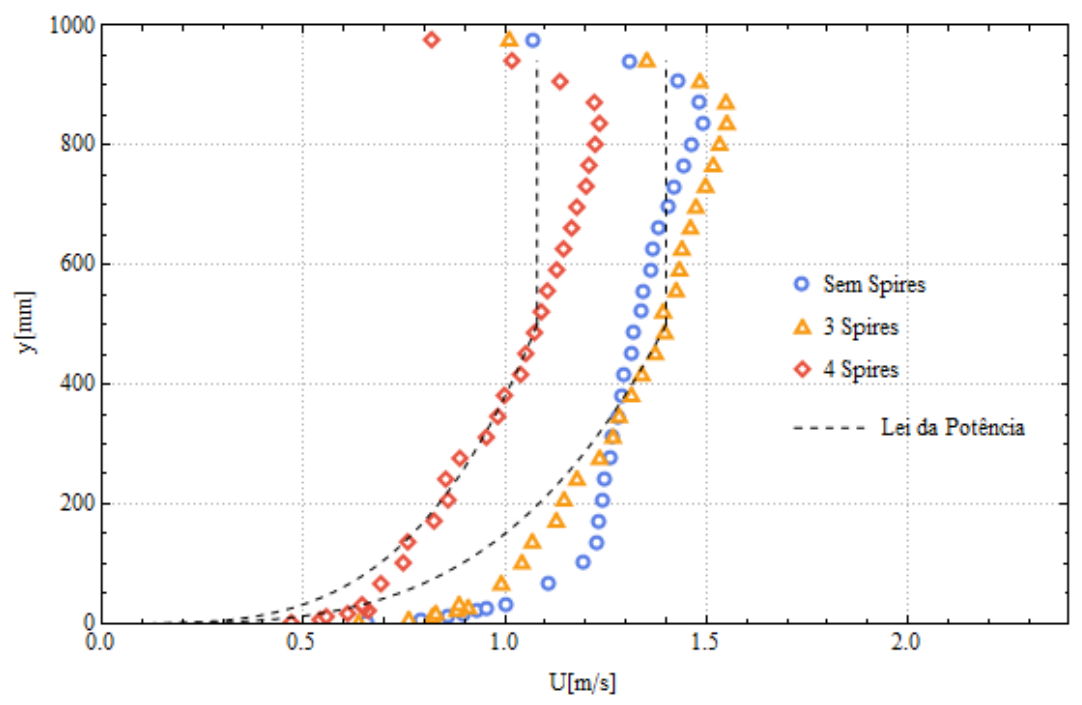

Figura 45. Perfil de velocidade para $U_{\max }=1,34 \mathrm{~m} / \mathrm{s}(f=11 \mathrm{~Hz})$ e $x=7 \mathrm{~m}$ 


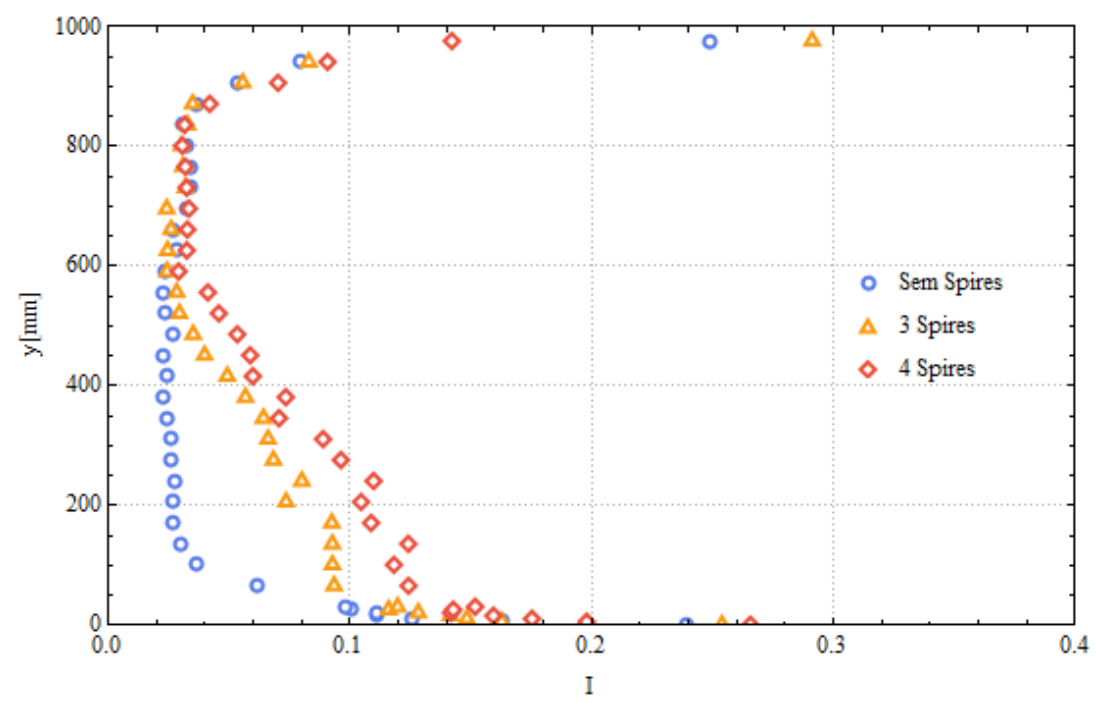

Figura 46. Intensidade turbulenta para $U_{\max }=1,34 \mathrm{~m} / \mathrm{s}(f=11 \mathrm{~Hz})$ e $x=7 \mathrm{~m}$

O gráfico da Figura 45 resulta em $U_{\max }=1,49 \mathrm{~m} / \mathrm{s}$ na condição de túnel sem spires, $U_{\max }=1,55 \mathrm{~m} / \mathrm{s}$ na condição de túnel com 3 spires e $U_{\max }=1,24 \mathrm{~m} / \mathrm{s}$ com 4 spires. A uma distância de $7 \mathrm{~m}$ da entrada do túnel, tanto para condição do túnel vazio quanto com spires, o perfil de velocidades sofreu certas modificações. Ainda é possível observar um aumento de velocidade na parte superior do túnel para velocidades mais altas, indicando que o problema estrutural do túnel produz reflexos no escoamento por um longo comprimento da seção de testes. Os perfis de velocidade em $x=7 \mathrm{~m}$, com o túnel vazio, tiveram um aumento em sua velocidade de cerca de 15 a $19 \%$ em relação a $\mathrm{x}=4 \mathrm{~m}$. Já para condição de 3 spires, esse aumento variou de 15 a 22\%. O arranjo de 4 spires foi o que gerou menos variação, ficando entre 5 e $7 \%$, sendo que para $U_{\max }=0,86 \mathrm{~m} / \mathrm{s}$, a velocidade se manteve. Por esse motivo, o perfil de velocidade com 4 spires sofreu uma certa defasagem em relação ao de 3 spires em todas as situações.

A Tabela 6 relaciona as frequências do inversor testadas com valores de velocidade máxima $\left(U_{\max }\right)$ apresentada para cada perfil, no centro do túnel de vento, para condição de túnel vazio, com 3 spires e com 4 spires. 
Tabela 6. Relação entre a frequência do inversor e valores de velocidade

\begin{tabular}{|c|c|c|c|}
\hline \multirow{2}{*}{$\begin{array}{l}\text { Frequência do } \\
\text { inversor }(f)\end{array}$} & \multicolumn{2}{|c|}{$\begin{array}{c}\text { Velocidade do escoamento } \\
\text { principal }\left(U_{\max }\right)(\mathrm{m} / \mathrm{s})\end{array}$} & \multirow{2}{*}{$\begin{array}{l}\text { Condição do túnel } \\
\text { de vento }\end{array}$} \\
\hline & $x=4 m$ & $x=7 m$ & \\
\hline \multirow{3}{*}{$7 \mathrm{~Hz}$} & 0,56 & 0,66 & Vazio \\
\hline & 0,63 & 0,73 & 3 spires \\
\hline & 0,58 & 0,55 & 4 spires \\
\hline \multirow{3}{*}{$9 \mathrm{~Hz}$} & 0,89 & 1,03 & Vazio \\
\hline & 0,93 & 1,11 & 3 spires \\
\hline & 0,86 & 0,86 & 4 spires \\
\hline \multirow{3}{*}{$11 \mathrm{~Hz}$} & 1,25 & 1,49 & Vazio \\
\hline & 1,27 & 1,55 & 3 spires \\
\hline & 1,34 & 1,24 & 4 spires \\
\hline
\end{tabular}

E em todos os casos, para $x=7 \mathrm{~m}$, o perfil que melhor se assemelhou à lei da potência $(\alpha=0,28)$ foi obtido com 4 spires. Portanto, essa foi a configuração utilizada para geração da camada limite atmosférica no túnel de vento nos estudos de dispersão. Os gráficos de intensidade turbulenta para $x=7 \mathrm{~m}$ demonstraram poucas alterações em relação a $x=4 \mathrm{~m}$. O nível de intensidade turbulenta com o túnel vazio se manteve em $3 \%$ e com a presença dos elementos de rugosidade se mantiveram em cerca de $10 \%$.

Uma simulação computacional foi realizada como modo de comparação com os resultados experimentais e os resultados estão apresentados na Figura 47.
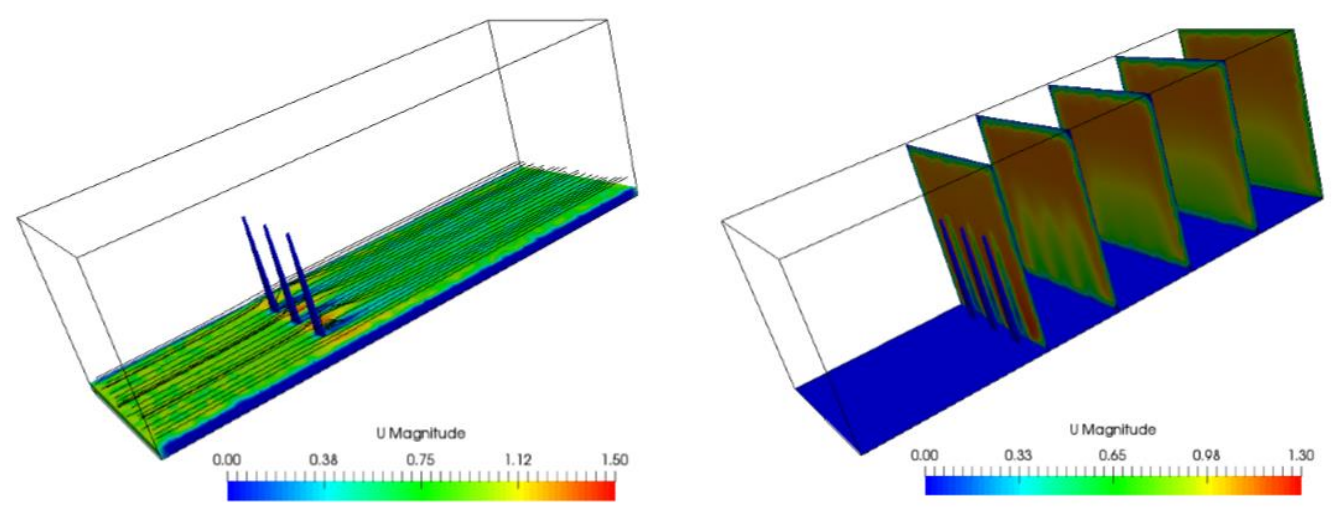

Figura 47. Desenvolvimento do escoamento na simulação computacional 
A Figura 48 mostra um caso de comparação entre a simulação computacional com o experimento, para condição de 4 spires, $U_{\max }=0,55 \mathrm{~m} / \mathrm{s}$ em $x=7 \mathrm{~m}$. É possível observar que a simulação se assemelha bem à lei da potência na parte inferior do túnel e apresenta valores coerentes com os dados experimentais.

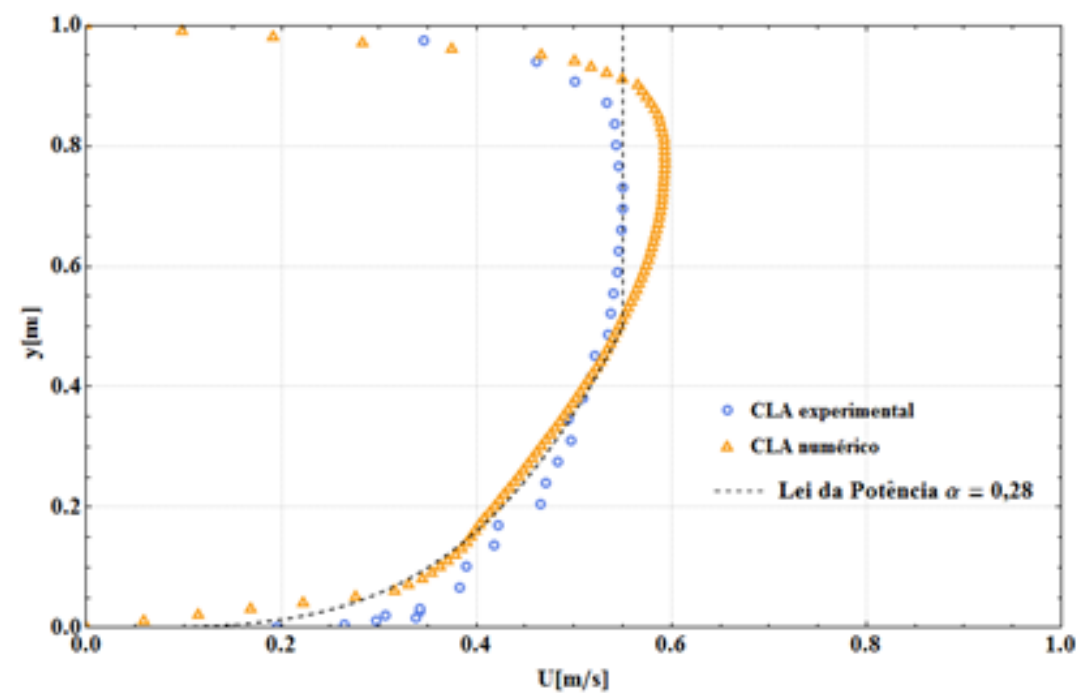

Figura 48. Comparação da simulação computacional com o experimento

É notória a interferência dos spires no resultado do perfil de velocidade e de intensidade turbulenta. $\mathrm{O}$ formato triangular dos spires, mais extensos na parte inferior, faz com que a velocidade diminua e a intensidade turbulenta aumente, uma vez que se tem um bloqueio maior nessa parte inferior do túnel.

\subsection{1.}

\section{Análise em frequência do túnel de vento}

Processos de dispersão de plumas em laboratório geralmente são analisados com baixas velocidades no escoamento principal. Assim, problemas mecânicos e estruturais do túnel podem interferir mais significativamente no perfil de velocidade. Portanto, foram feitos testes a fim de se avaliar a influência das variações de velocidade no túnel. Foram analisados 3 pontos ao longo da altura do túnel ( $y=170,500$ e $800 \mathrm{~mm}$ ) a uma distância de 7 metros da entrada da seção de testes, onde foram realizados os experimentos de dispersão da pluma. Foram capturadas 32768 amostras com o anemômetro de fio quente a uma taxa de aquisição de $1 \mathrm{KHz}$. Como os gráficos, nas três alturas analisadas, apresentam alto 
grau de semelhança, foram expostos somente os gráficos para $y=170 \mathrm{~mm}$, região dentro da CLA. A Figura 49 mostra os resultados de variação de velocidade com o tempo (a) e o espectro de frequência (b) para a condição de $U_{\max }=0,55 \mathrm{~m} / \mathrm{s}$.

(a)

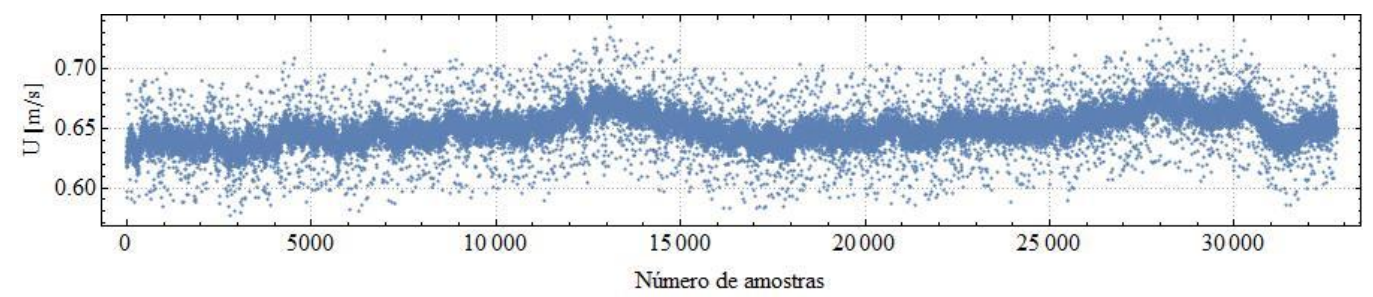

(b)

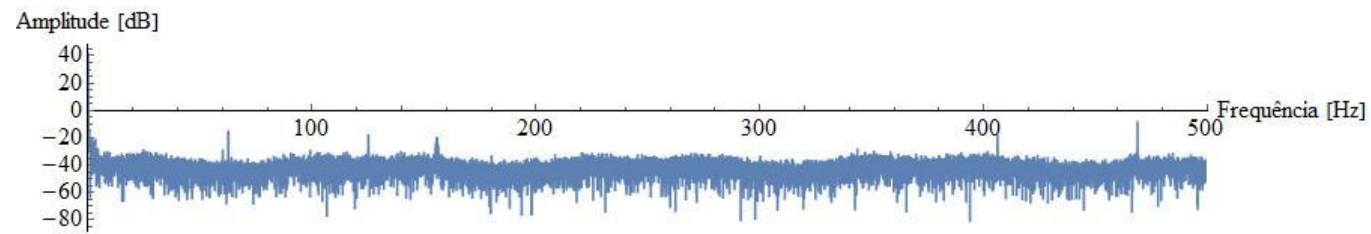

Figura 49. Resultados para $U_{\max }=0,55 \mathrm{~m} / \mathrm{s}$

A Figura 50 mostra os mesmos resultados para a condição de $U_{\max }=0,86 \mathrm{~m} / \mathrm{s}$.

(a)

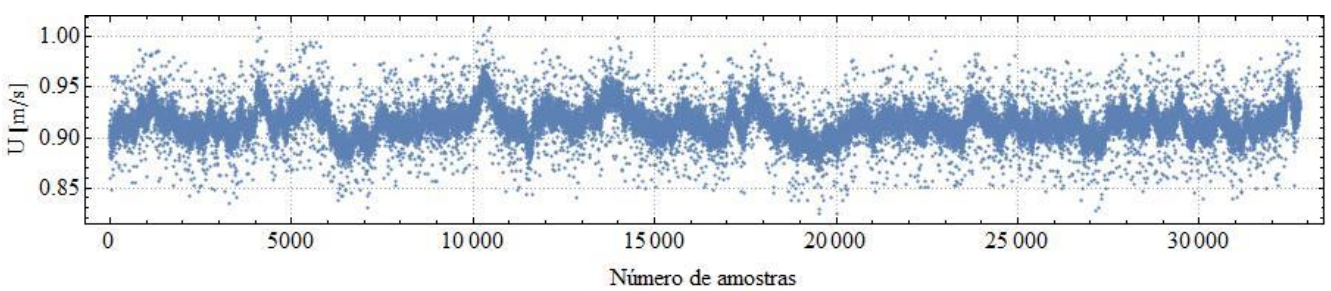

(b)

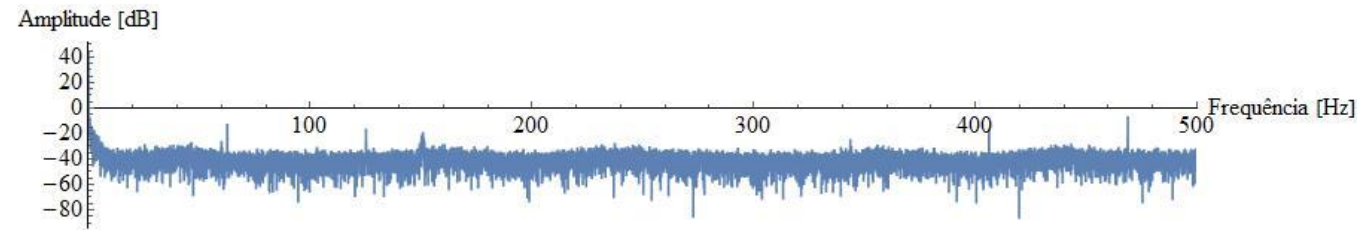

Figura 50. Resultados para $U_{\max }=0,86 \mathrm{~m} / \mathrm{s}$

Na Figura 51 são mostrados os resultados para $U_{\max }=1,24 \mathrm{~m} / \mathrm{s}$. 
(a)

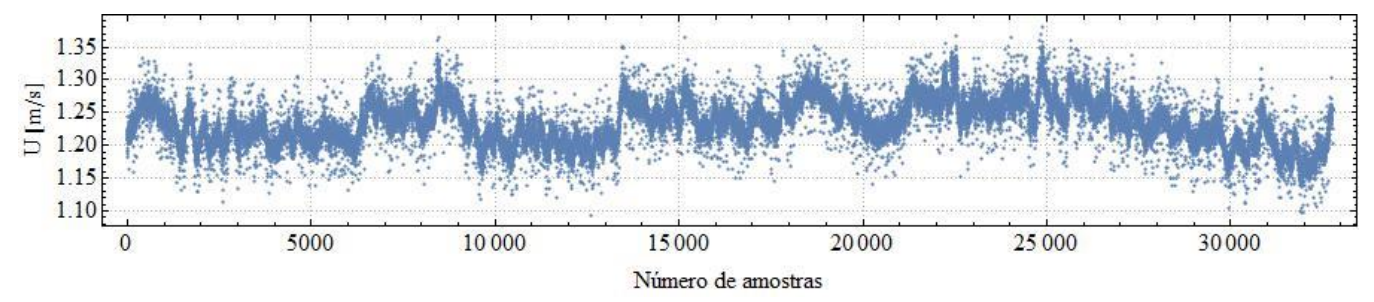

(b)

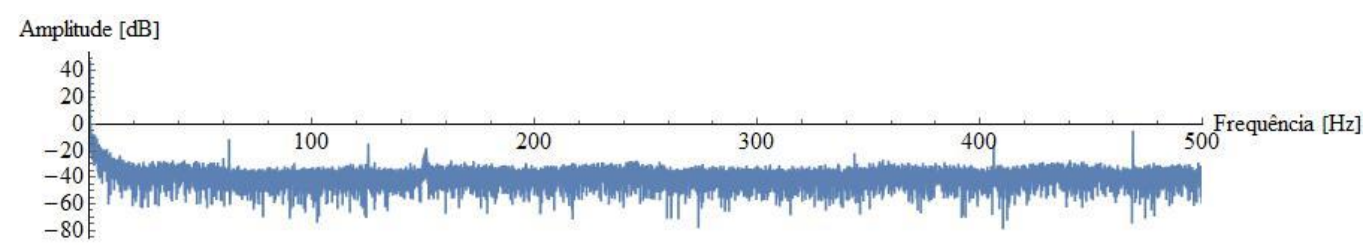

Figura 51. Resultados para $U_{\max }=1,24 \mathrm{~m} / \mathrm{s}$

Através desses resultados é possível observar que quanto maior a velocidade na entrada do túnel de vento, maior é a variação de velocidade ao longo da seção de testes. No primeiro caso, onde $U_{\max }=0,55 \mathrm{~m} / \mathrm{s}$, a faixa de velocidade fica entre 0,55 até, aproximadamente, $0,75 \mathrm{~m} / \mathrm{s}$, variando $0,2 \mathrm{~m} / \mathrm{s}$. No segundo caso, em que $U_{\max }=0,86 \mathrm{~m} / \mathrm{s}$, a variação da velocidade fica em média em $0,2 \mathrm{~m} / \mathrm{s}$; na terceira condição, em que $U_{\max }=1,24 \mathrm{~m} / \mathrm{s}$, ocorre a maior flutuação de velocidade, chegando a $0,25 \mathrm{~m} / \mathrm{s}$. Com os gráficos de espectro de frequências é possível notar o comportamento dominante em baixas frequências em todos os gráficos, o que é um bom comportamento para simular condições ambientais. É possível também notar que há um pico de frequência em $60 \mathrm{~Hz}$, representando ruídos e um harmônico em $120 \mathrm{~Hz}$.

\subsection{2.}

Medições do perfil de temperatura no túnel de vento atmosférico

Para realizar a simulação da camada limite convectiva, toda montagem do sistema de aquecimento, descrita na seção 6.3, foi realizada. A fim de se avaliar o perfil de temperatura desenvolvido no túnel, foram realizados experimentos utilizando-se 20 termopares na linha central do túnel de vento, como explicado na seção 6.3. Em todos os experimentos, a temperatura ambiente, umidade e pressão do laboratório foram monitoradas. O resultado do perfil térmico, com os valores de incerteza, depois de uma hora com o sistema de aquecimento ligado e na condição 
do túnel desligado (sem escoamento) está mostrado na Figura 52. Foi observado que depois de uma hora do sistema de aquecimento ligado, o perfil permanece praticamente constante, portanto, todas as medições foram feitas respeitando esse tempo de estabilização, sendo que o tempo de duração de cada medição foi de 30 minutos.

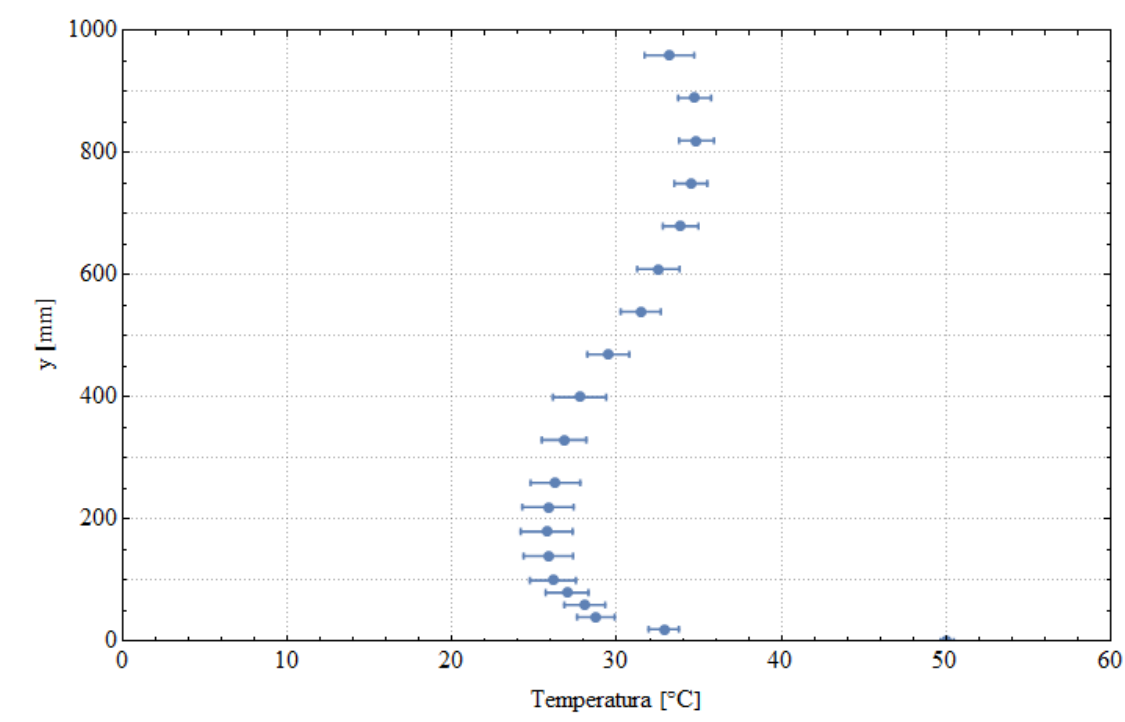

Figura 52. Perfil térmico depois de uma hora de aquecimento, sem presença de escoamento

$\mathrm{Na}$ Figura 53 são mostrados os três perfis térmicos, após uma hora de aquecimento, para as respectivas velocidades: $U_{\max }=0,66 \mathrm{~m} / \mathrm{s}, U_{\max }=1,03 \mathrm{~m} / \mathrm{s}$ e $U_{\max }=1,49 \mathrm{~m} / \mathrm{s}$ na condição de túnel vazio, ou seja, sem CLA, em $x=7 \mathrm{~m}$.

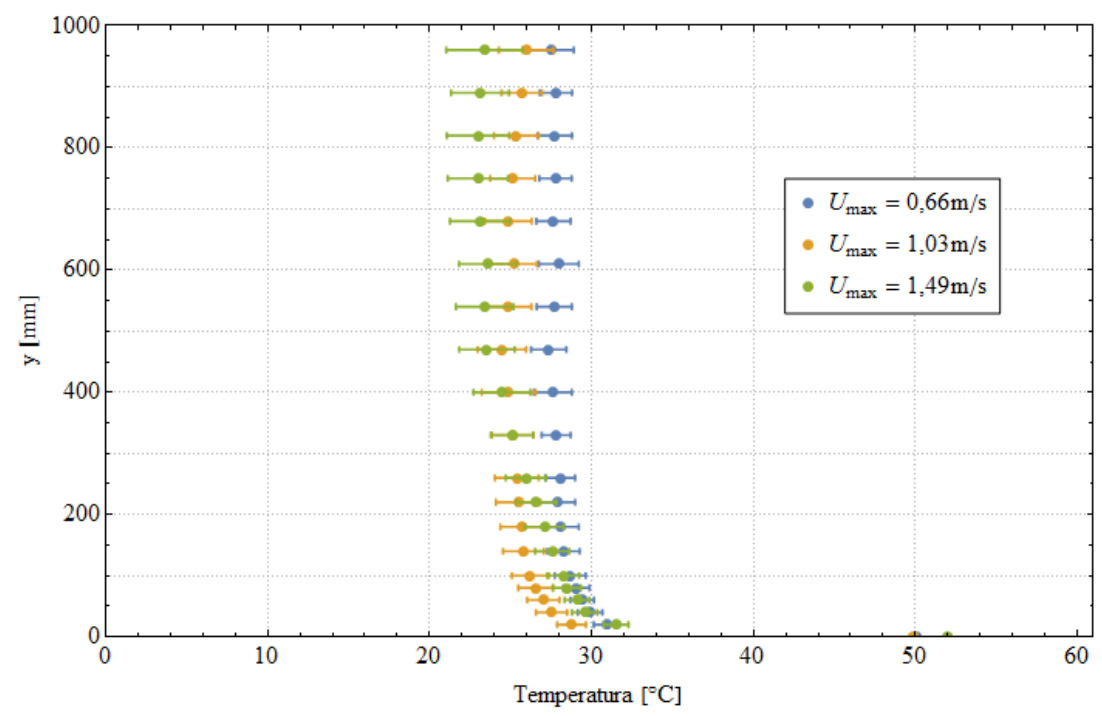

Figura 53. Perfil térmico para as três velocidades escolhidas sem CLA 
$\mathrm{Na}$ Figura 54 são mostrados os três perfis térmicos, após uma hora de aquecimento, para as respectivas velocidades: $U_{\max }=0,55 \mathrm{~m} / \mathrm{s}, U_{\max }=0,86 \mathrm{~m} / \mathrm{s} \mathrm{e}$ $U_{\max }=1,24 \mathrm{~m} / \mathrm{s}$ na condição de túnel com reprodução de CLA, em $x=7 \mathrm{~m}$.

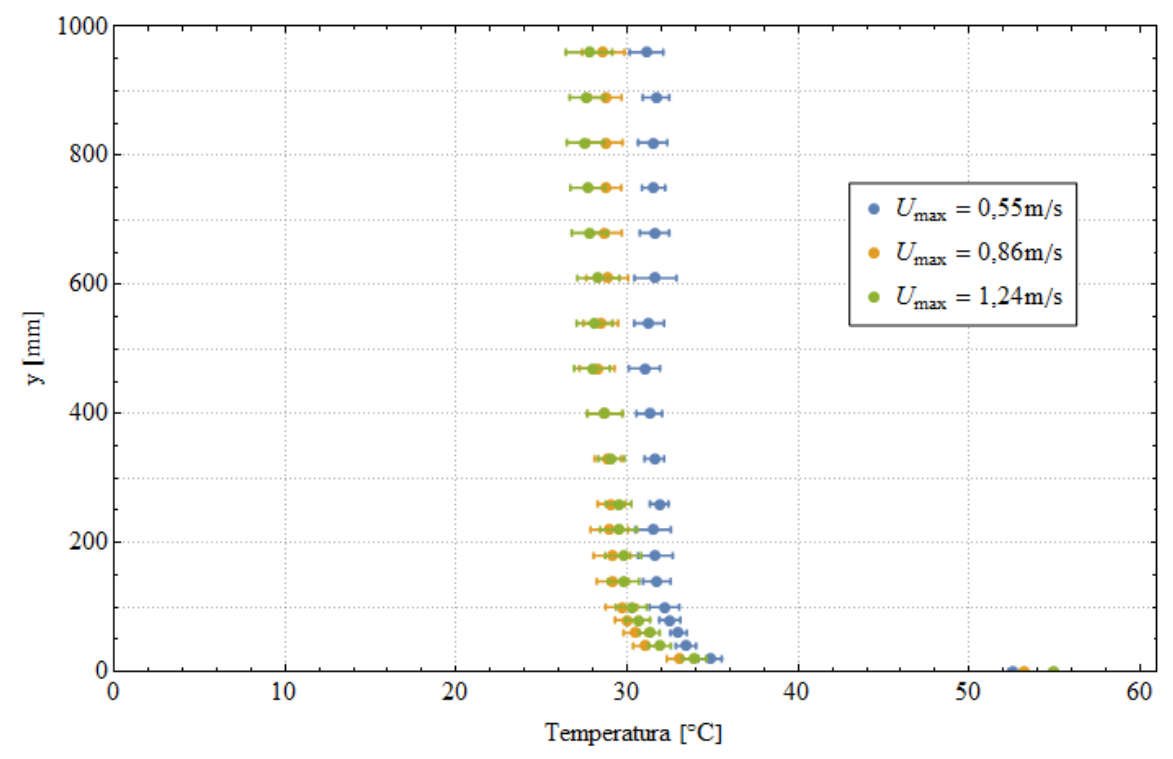

Figura 54. Perfil térmico para as três velocidades escolhidas com CLA

A Figura 52 mostra um processo de convecção natural, em que o fluido na parte central do túnel torna-se menos denso e sobe, devido ao aumento da temperatura. O fluido localizado nas laterais é então resfriado e desce, formando uma corrente de convecção. Esse processo transfere energia térmica da parte inferior para o topo da célula de convecção.

Como pode ser observado na Figura 53 e Figura 54, o perfil térmico se mostrou coerente com a literatura e nota-se que a presença de uma camada limite altera o perfil de temperatura. A presença dos spires faz com que a velocidade média do escoamento diminua, aumentando, assim, a temperatura.

Após verificação do perfil térmico, fez-se necessário reavaliar o perfil de velocidades com a reprodução da CLA, para modo de verificação. Porém, quando se utiliza da configuração do túnel com aquecimento, é criado um grande gradiente de temperatura no interior do túnel de vento, impossibilitando o uso da técnica de anemometria a fio quente, pois esse sistema pressupõe temperatura ambiente constante. Assim, outros métodos para medir o perfil de velocidades média foram testados. Inicialmente, um Tubo de Pitot foi testado; porém, devido às baixas 
velocidades do escoamento, especialmente próximo ao solo, tornam este equipamento igualmente inadequado. Posteriormente foi utilizado um anemômetro ultrassônico, que também não mostrou bons resultados, uma vez que as dimensões do volume de controle impossibilitam a medição com resolução dimensional adequada para camada limite.

Diante desses fatos, o perfil de velocidades foi então analisado com o sistema de velocimetria por imagem de partículas (PIV), que conseguiu reproduzir bem as velocidades médias. Um outro problema, no entanto, foi constatado. O perfil da camada limite atmosférica, reproduzido com os 4 spires não se mantém o mesmo quando o sistema de aquecimento do chão do túnel de vento é acionado, ou seja, quando existe um perfil térmico. Isto ocorre devido à interação entre o escoamento principal e as correntes convectivas geradas pelo gradiente térmico. As baixas faixas de velocidade configuradas no túnel de vento são fortemente influenciadas pelas velocidades ascendentes geradas no aquecimento, descaracterizando o perfil da camada limite. Um exemplo desse problema está relatado na Figura 55 e na Figura 56. Na Figura 55 é mostrado o perfil para condição de $U_{\max }=0,55 \mathrm{~m} / \mathrm{s}$ e sem aquecimento, e na Figura 56 é mostrado o perfil para mesma condição de $U_{\max }=$ $0,55 \mathrm{~m} / \mathrm{s}$ e com o túnel aquecido. Ambos os casos são comparados com a lei da potência para um ambiente suburbano.

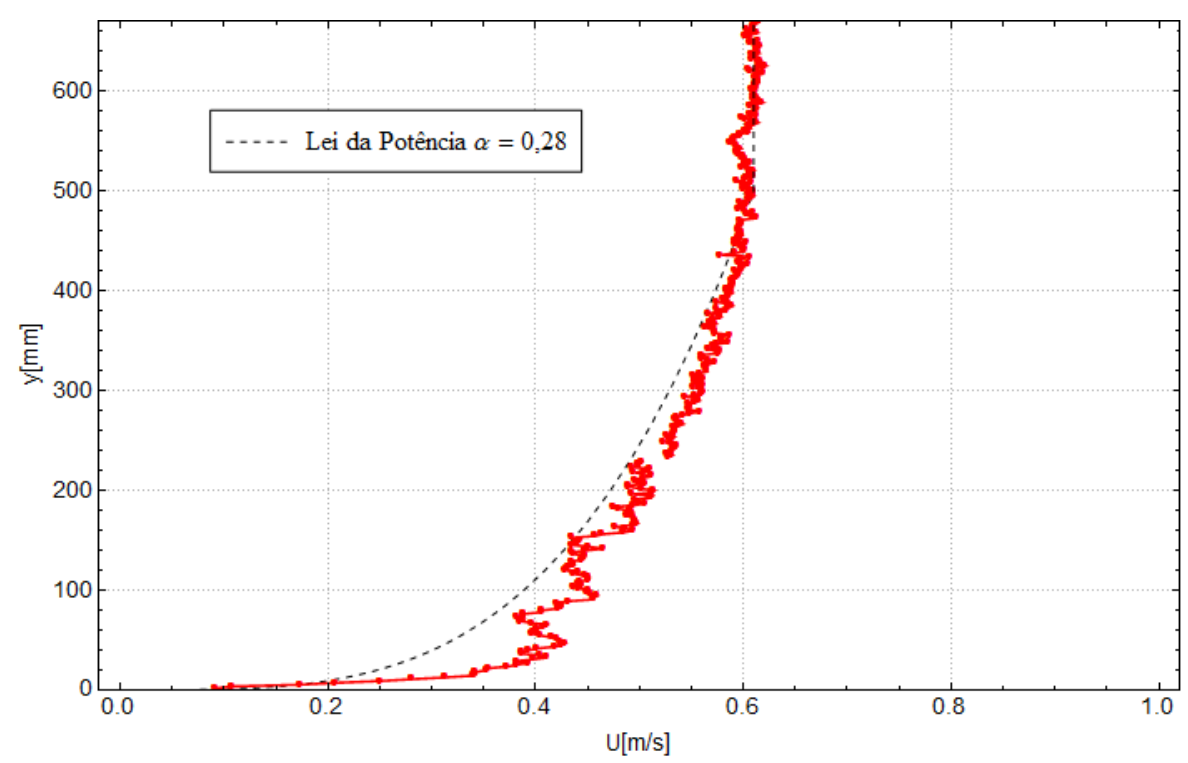

Figura 55. Perfil de velocidade para $U_{\max }=0,55 \mathrm{~m} / \mathrm{s}$ sem aquecimento 


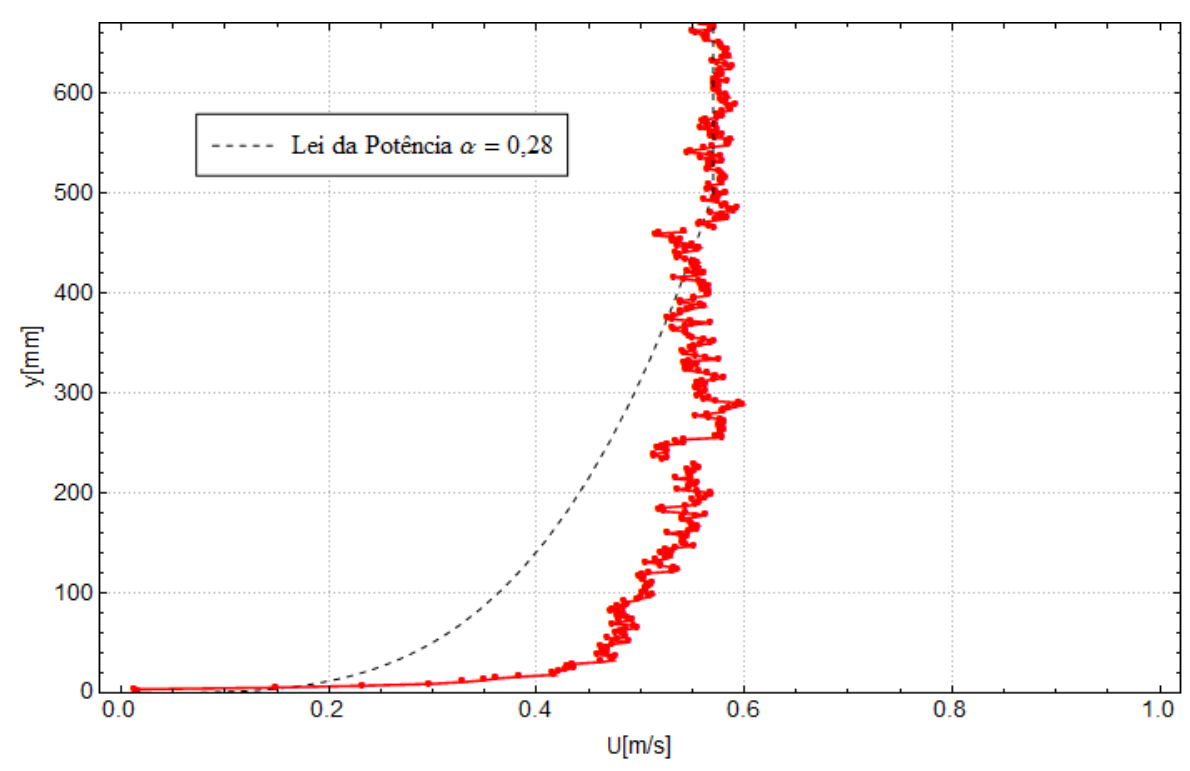

Figura 56. Perfil de velocidade para $U_{\max }=0,55 \mathrm{~m} / \mathrm{s}$ com aquecimento

Na literatura, simulações de camada limite com estratificação térmica são raras, e praticamente todos os experimentos, foram realizados de forma empírica, por meio de tentativa e erro. Devido ao fato de haver interferência do aquecimento na camada limite atmosférica, este trabalho não utilizará como condição experimental a camada limite convectiva, uma vez que demandaria um precioso tempo na tentativa de se conseguir um perfil de velocidades adequado para representar a CLA.

Entretanto, utilizou-se de toda a infraestrutura do sistema de aquecimento para observar um efeito importante que acontece numa pluma em ambiente convectivo, o efeito de looping. A Figura 17 demonstra a diferença no formato da pluma entre uma condição de atmosfera neutra e uma condição instável. E a Figura 57 demonstra esse efeito no experimento, para condição de $U_{\max }=0,55 \mathrm{~m} / \mathrm{s}$. 
(a)

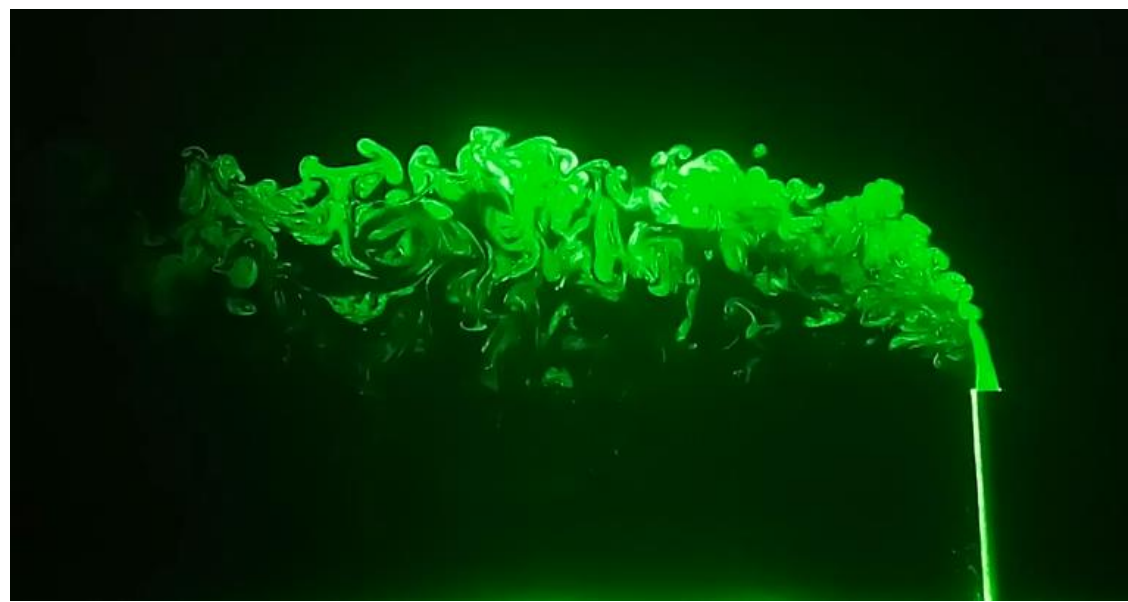

(b)

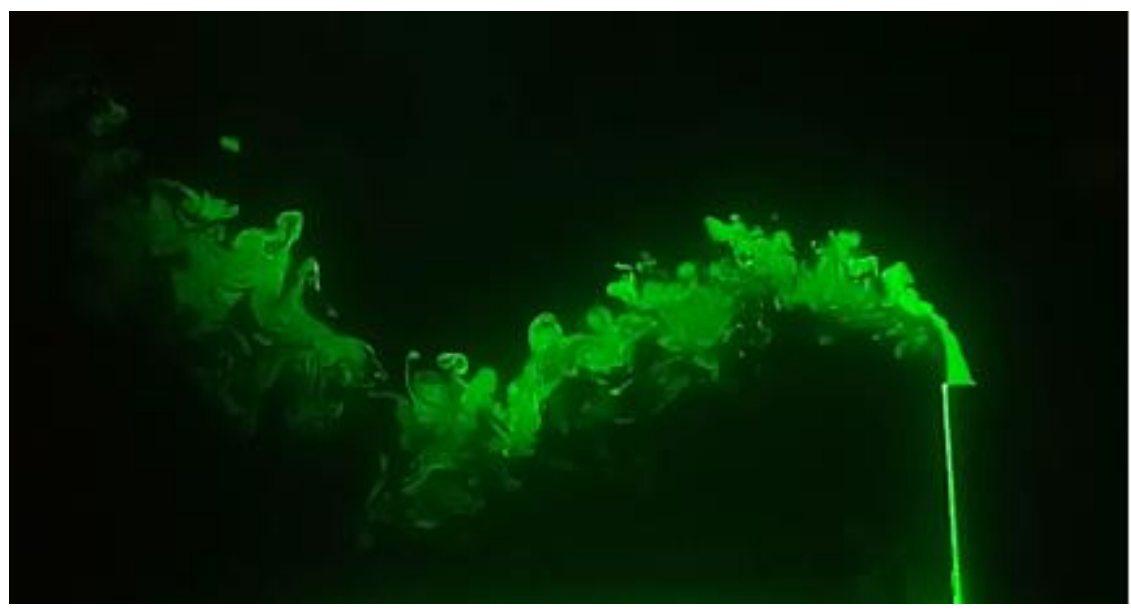

Figura 57. Visualização da pluma (a) sem aquecimento e (b) com aquecimento (efeito de looping)

Sendo assim, o perfil térmico foi descartado e, para conhecimento, foi levantado o perfil de temperatura para $x=7 \mathrm{~m}$, sem aquecimento. Foram utilizados os mesmos 20 termopares posicionados da mesma forma apresentada anteriormente. O perfil foi medido nas mesmas condições de velocidade para condição com presença de CLA (Figura 58) e sem a presença de CLA (Figura 59). 


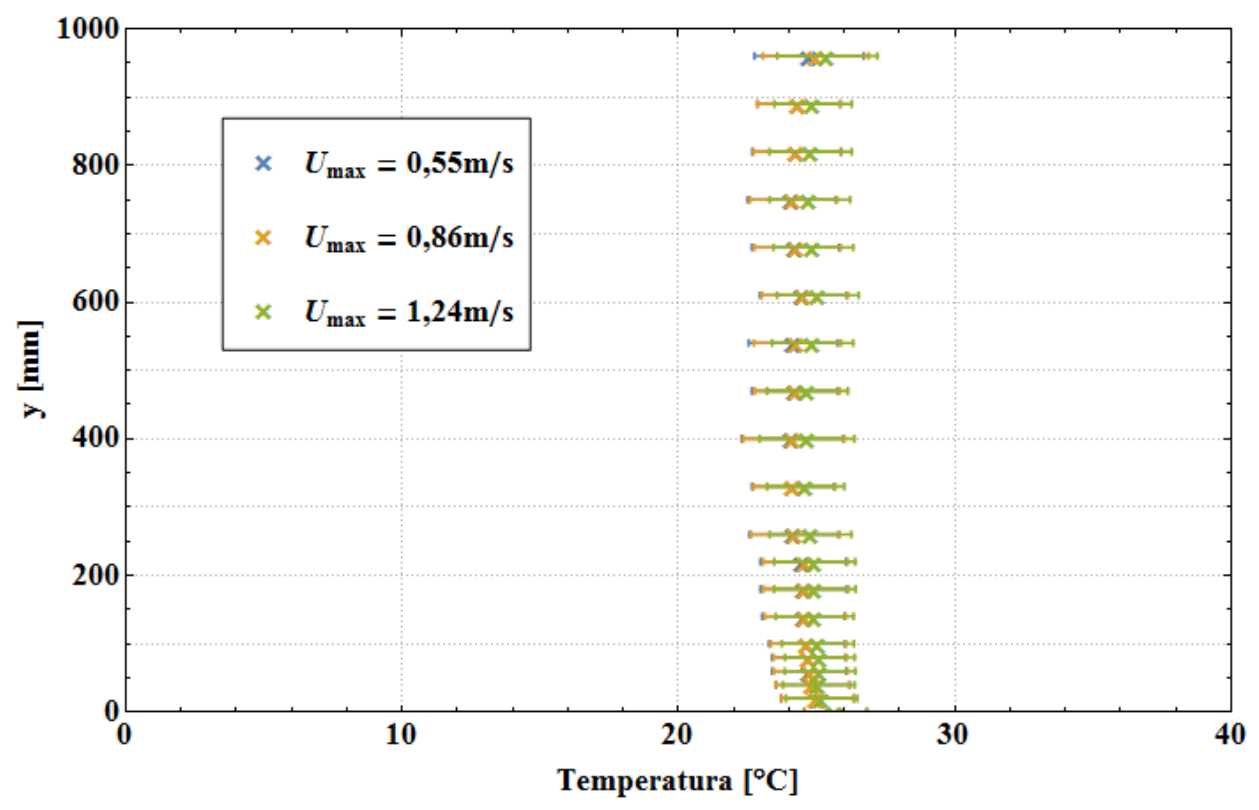

Figura 58. Perfil térmico sem aquecimento para as três velocidades escolhidas com CLA

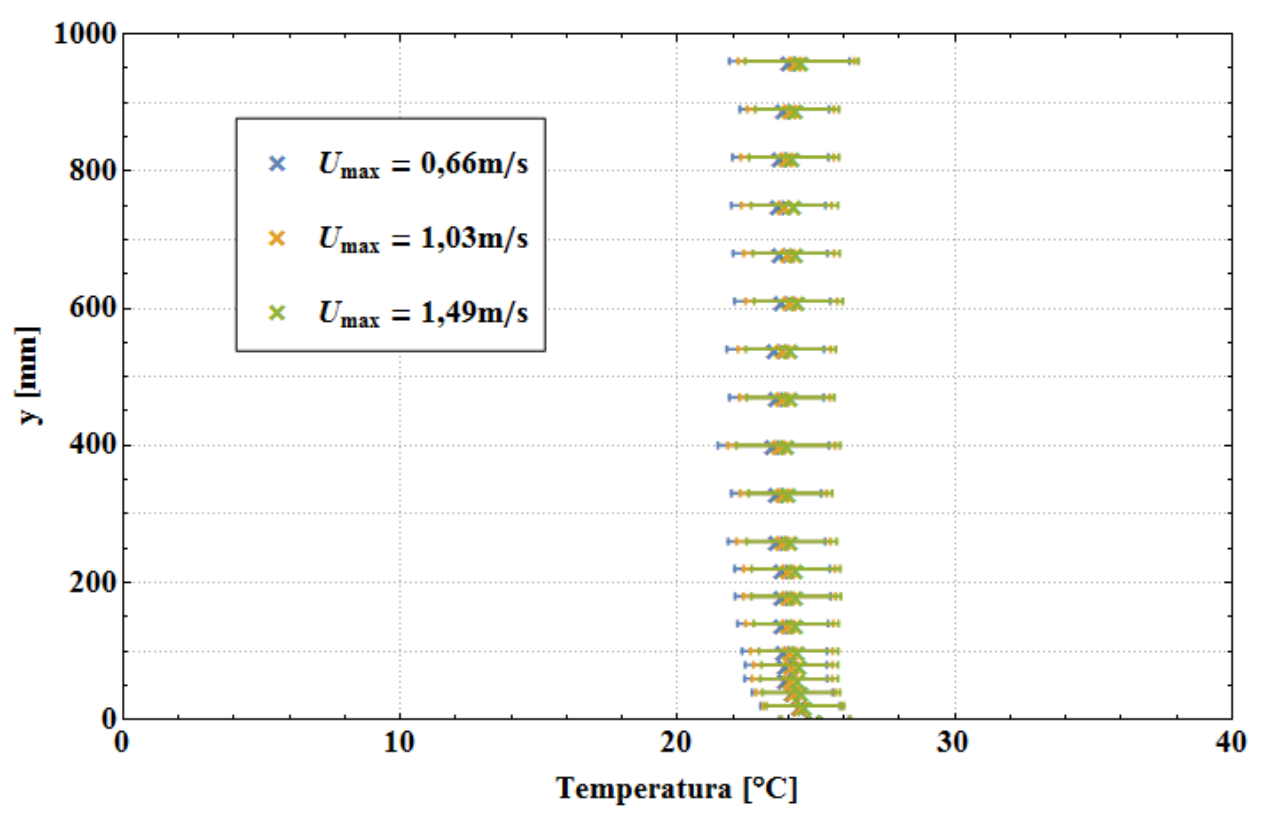

Figura 59. Perfil térmico sem aquecimento para as três velocidades escolhidas sem CLA

Observa-se que a presença da CLA não altera significativamente o perfil de temperatura, no interior do túnel de vento. Esse estudo foi necessário para avaliar as condições de temperatura em que a pluma estaria inserida, uma vez que um dos objetivos é avaliar a dispersão da pluma para diferenças de temperatura entre o 
escoamento principal e o escoamento da pluma. Portanto, pode-se definir esse ambiente como mostrando uma condição de estabilidade neutra (classe D Pasquill-Gifford).

\section{4. \\ Resultados do estudo do processo de dispersão da pluma}

Nesta seção são analisados experimentalmente os campos vetoriais de velocidade, perfis verticais de velocidade e intensidade turbulenta à jusante da chaminé. Foi possível realizar também um estudo de concentração da pluma, produto do processo de dispersão nas proximidades de uma fonte de emissão pontual. É feita também uma análise comparando-se o coeficiente de dispersão vertical $\left(\sigma_{y}\right)$ obtido no experimento com resultados conhecidos na literatura.

\subsection{1.}

\section{Análises do perfil do escoamento}

A chaminé, localizada a 7 m da entrada da seção de testes do túnel de vento, representa uma fonte pontual de emissão de poluentes que se dispersa em uma camada limite turbulenta com estabilidade neutra. Foram consideradas 3 condições de velocidade de emissão da pluma $\left(W_{0}\right)$, três velocidades do escoamento principal no túnel $\left(U_{\max }\right)$ e duas diferenças de temperatura, $\Delta T$, da pluma, $\left(T_{w}\right)$ em relação à temperatura ambiente no túnel $\left(T_{t}\right)$. O escoamento principal do túnel representa uma camada limite atmosférica neutra com expoente da lei da potência de $\alpha=0,28$. Foram feitos testes sem o perfil da camada limite atmosférica para comparação. A velocidade do vento, medida com a técnica PIV, foi variada de 0,92 até 1,79 m/s.

O modelo da chaminé construído por um tubo circular de $150 \mathrm{~mm}$ de altura, em concordância com a escala adotada para a reprodução da camada limite atmosférica, representa uma chaminé real de altura de $120 \mathrm{~m}$. A Tabela 7 mostra o programa dos ensaios. 
Tabela 7. Programa dos ensaios

\begin{tabular}{|c|c|c|c|c|c|c|}
\hline Caso & $\begin{array}{c}\text { Vel. do } \\
\text { escoamento } \\
\text { principal } \\
\left(U_{\max }\right)(\mathrm{m} / \mathrm{s})\end{array}$ & $\begin{array}{l}\text { Tensão } \\
(\%) \text { no } \\
\text { variac }\end{array}$ & $\begin{array}{c}\text { Vel. de } \\
\text { emissão na } \\
\text { chaminé } \\
\left(W_{0}\right) \\
(\mathrm{m} / \mathrm{s})\end{array}$ & $\begin{array}{c}\text { Temperatura } \\
\text { média do } \\
\text { escoamento } \\
\text { principal }\left(T_{t}\right)\end{array}$ & $\begin{array}{c}\text { Temperatura } \\
\text { na saída da } \\
\text { chaminé }\left(T_{w}\right)\end{array}$ & $\begin{array}{c}\Delta T \\
\left({ }^{\circ} C\right)\end{array}$ \\
\hline 1 & \multirow{2}{*}{0,92} & \multirow{4}{*}{40} & 1,08 & 25 & 35 & 10 \\
\hline 2 & & & 1,31 & 24 & 44 & 20 \\
\hline 3 & \multirow{2}{*}{1,08} & & 1,02 & 25 & 35 & 10 \\
\hline 4 & & & 1,43 & 24 & 44 & 20 \\
\hline 5 & \multirow{2}{*}{0,92} & \multirow{4}{*}{50} & 1,49 & 25 & 35 & 10 \\
\hline 6 & & & 1,67 & 24 & 44 & 20 \\
\hline 7 & \multirow{2}{*}{1,08} & & 1,64 & 25 & 35 & 10 \\
\hline 8 & & & 1,77 & 24 & 44 & 20 \\
\hline 9 & \multirow{2}{*}{0,92} & \multirow{4}{*}{60} & 1,77 & 25 & 35 & 10 \\
\hline 10 & & & 2,11 & 24 & 44 & 20 \\
\hline 11 & \multirow{2}{*}{1,08} & & 2,55 & 25 & 35 & 10 \\
\hline 12 & & & 3,27 & 24 & 44 & 20 \\
\hline 13 & \multirow{2}{*}{1,38} & \multirow{4}{*}{40} & 0,59 & 25 & 35 & 10 \\
\hline 14 & & & 0,90 & 24 & 44 & 20 \\
\hline 15 & \multirow{2}{*}{1,52} & & 0,90 & 25 & 35 & 10 \\
\hline 16 & & & 0,99 & 24 & 44 & 20 \\
\hline 17 & \multirow{2}{*}{1,38} & \multirow{4}{*}{50} & 1,24 & 26 & 36 & 10 \\
\hline 18 & & & 1,55 & 24 & 44 & 20 \\
\hline 19 & \multirow{2}{*}{1,52} & & 1,31 & 25 & 35 & 10 \\
\hline 20 & & & 1,62 & 24 & 44 & 20 \\
\hline 21 & \multirow{2}{*}{1,38} & \multirow{4}{*}{60} & 1,80 & 26 & 36 & 10 \\
\hline 22 & & & 1,95 & 24 & 44 & 20 \\
\hline 23 & \multirow{2}{*}{1,52} & & 2,25 & 25 & 35 & 10 \\
\hline 24 & & & 2,52 & 24 & 44 & 20 \\
\hline 25 & \multirow{2}{*}{1,79} & \multirow{4}{*}{40} & 0,80 & 26 & 36 & 10 \\
\hline 26 & & & 0,92 & 25 & 45 & 20 \\
\hline 27 & \multirow{2}{*}{1,85} & & 0,86 & 25 & 35 & 10 \\
\hline 28 & & & 1,18 & 25 & 45 & 20 \\
\hline 29 & \multirow{2}{*}{1,79} & \multirow{4}{*}{50} & 1,32 & 26 & 36 & 10 \\
\hline 30 & & & 1,42 & 24 & 44 & 20 \\
\hline 31 & \multirow{2}{*}{1,85} & & 1,15 & 25 & 35 & 10 \\
\hline 32 & & & 2,06 & 24 & 44 & 20 \\
\hline 33 & \multirow{2}{*}{1,79} & \multirow{4}{*}{60} & 1,64 & 25 & 35 & 10 \\
\hline 34 & & & 2,14 & 25 & 45 & 20 \\
\hline 35 & \multirow{2}{*}{1,85} & & 1,91 & 25 & 35 & 10 \\
\hline 36 & & & 2,67 & 25 & 45 & 20 \\
\hline
\end{tabular}


A técnica escolhida para medição e visualização do campo de dispersão da pluma foi o PIV. Para todos os experimentos foram realizados testes preliminares, no qual identificou-se que o tempo entre pulsos adequado à faixa de velocidades pretendida é de $150 \mu$ s. Foram aquisitadas 1000 imagens do escoamento, às quais foram aplicados uma sequência de processamento em que cada imagem foi subtraída a média das 1000 imagens para remoção do background. Para o cálculo dos campos instantâneos de velocidade foi utilizado o método de correlação adaptativa, no software Dynamic Studio (Dantec Dynamics). Em todas as medições, a temperatura, pressão e umidade ambiente foram monitorados. Para todas as medições esperou-se um tempo de alguns minutos para que o escoamento principal do túnel e da pluma estabilizassem. A Figura 60 mostra uma foto tirada da região da chaminé durante um experimento, com o laser do PIV acionado.

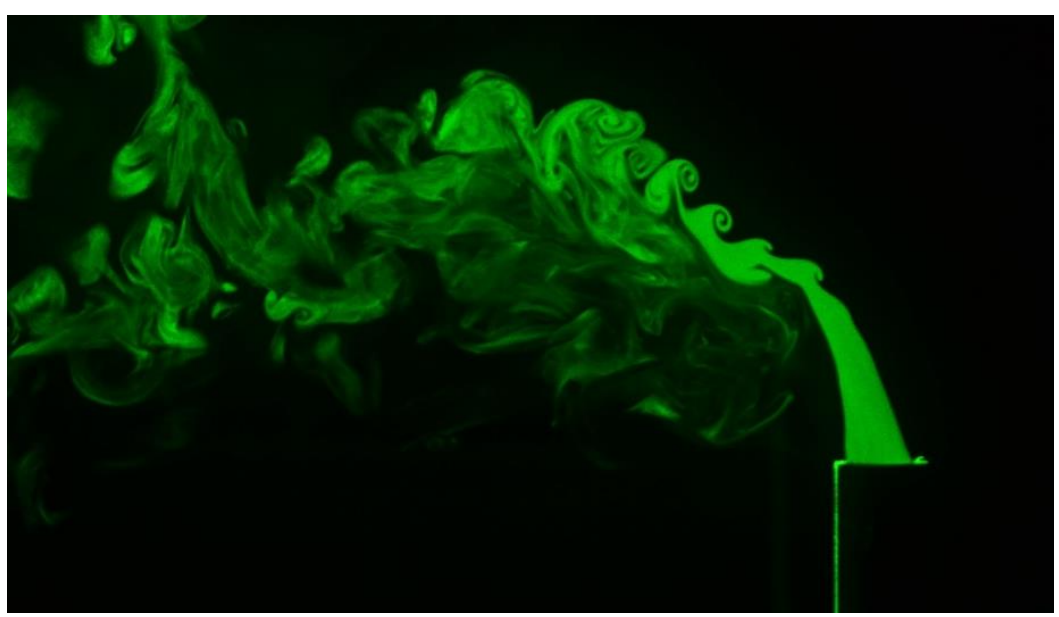

Figura 60. Foto tirada da pluma durante um experimento

Através do software do PIV foram analisados os campos vetoriais médios das velocidades instantâneas, para todas as condições ensaiadas, apresentados na Tabela 7. Nos gráficos de campo de velocidades, a legenda contém uma escala de cores representando a intensidade da componente horizontal de velocidade $(U)$. Os campos vetoriais foram calculados juntando as duas janelas de visualização, mostradas na seção 5.3.1.1. Para modo de comparação, foram apresentados os resultados dos campos vetoriais na condição do túnel de vento com reprodução da CLA, para condição de $\Delta T=10^{\circ} \mathrm{C}$ e $\Delta T=20^{\circ} \mathrm{C}$. A região em branco é uma zona de sombra, sendo que a região da chaminé é delimitada pela linha pontilhada preta. 
A Figura 61 até a Figura 66 mostram o campo de velocidades para os casos $1,2,5,6,9$ e 10 , respectivamente, em que a velocidade do escoamento principal é a menor ensaiada $\left(U_{\max }=0,92 \mathrm{~m} / \mathrm{s}\right)$. Foram variadas a velocidade de emissão da chaminé e a diferença de temperatura de emissão da pluma para o escoamento principal.

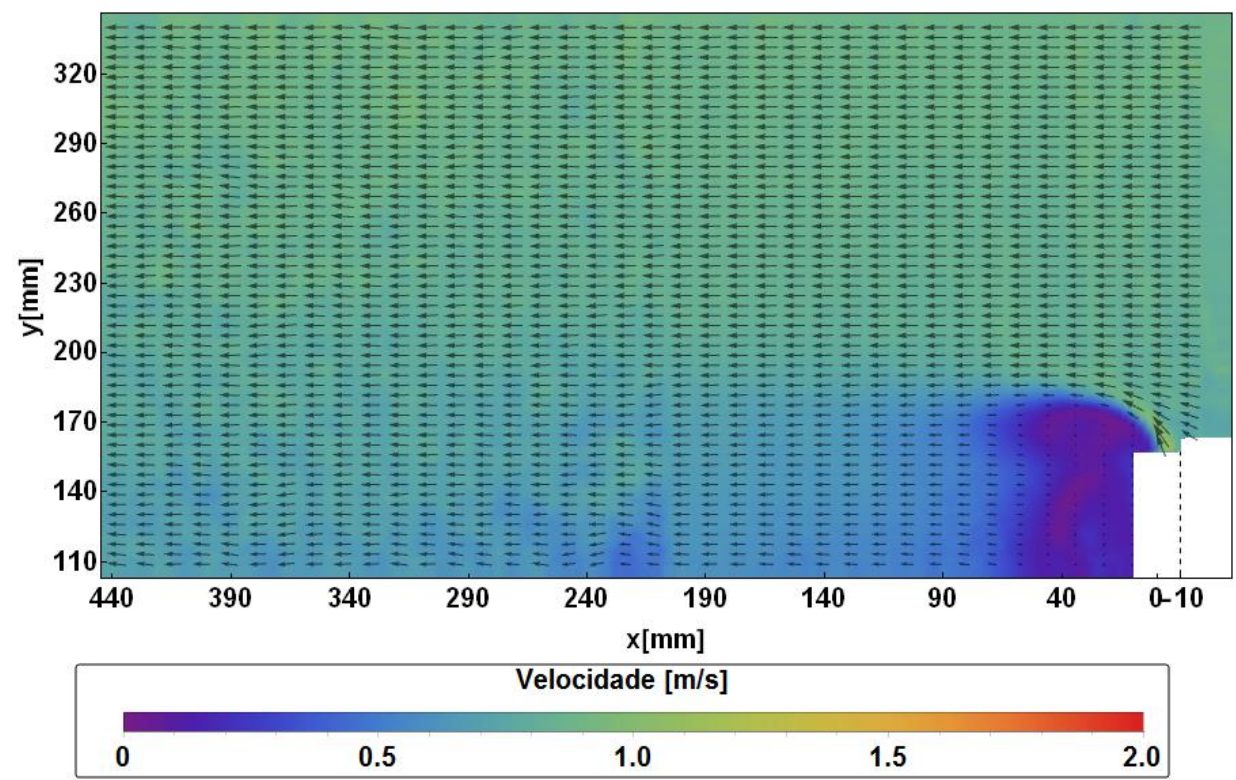

Figura 61. Campo de velocidades para $U_{\max }=0,92 \mathrm{~m} / \mathrm{s}, W_{0}=1,08 \mathrm{~m} / \mathrm{s}, T_{t}=$ $25^{\circ} \mathrm{C}$ e $T_{w}=35^{\circ} \mathrm{C}, \Delta T=10^{\circ} \mathrm{C}$

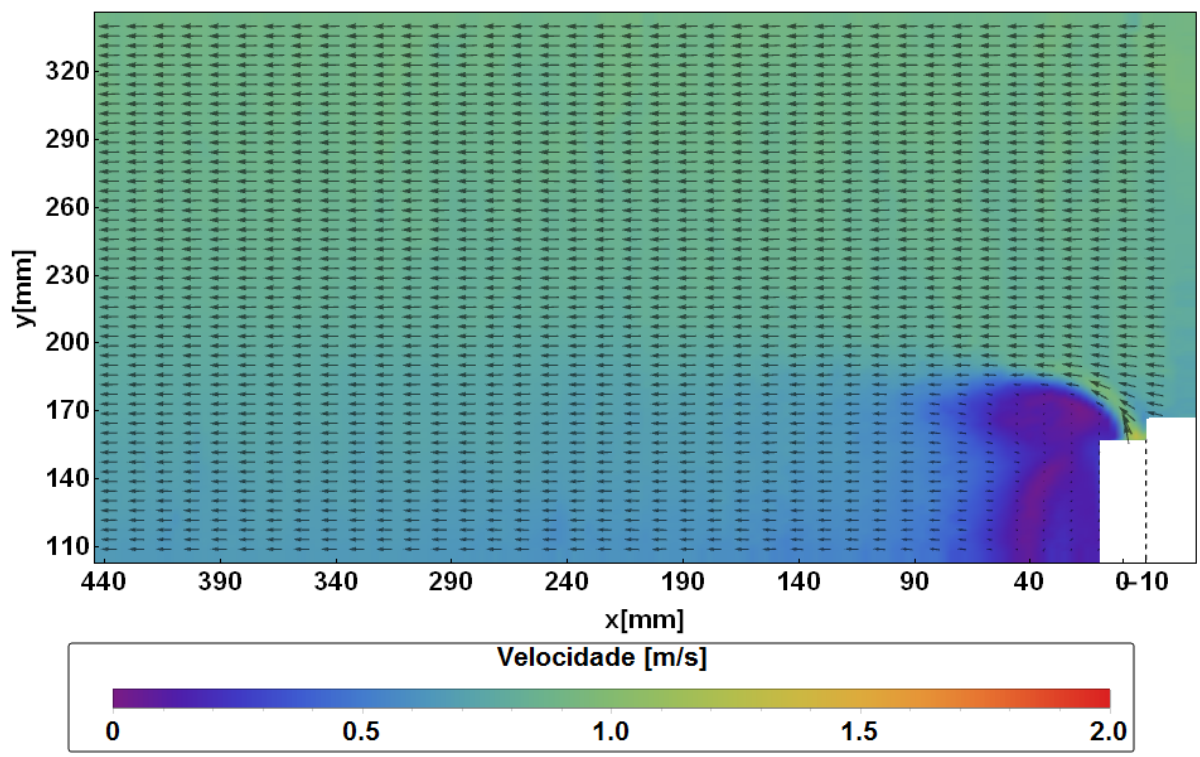

Figura 62. Campo de velocidades para $U_{\max }=0,92 \mathrm{~m} / \mathrm{s}, W_{0}=1,31 \mathrm{~m} / \mathrm{s}, T_{t}=$ $24^{\circ} \mathrm{C}$ e $T_{w}=44^{\circ} \mathrm{C}, \Delta T=20^{\circ} \mathrm{C}$ 


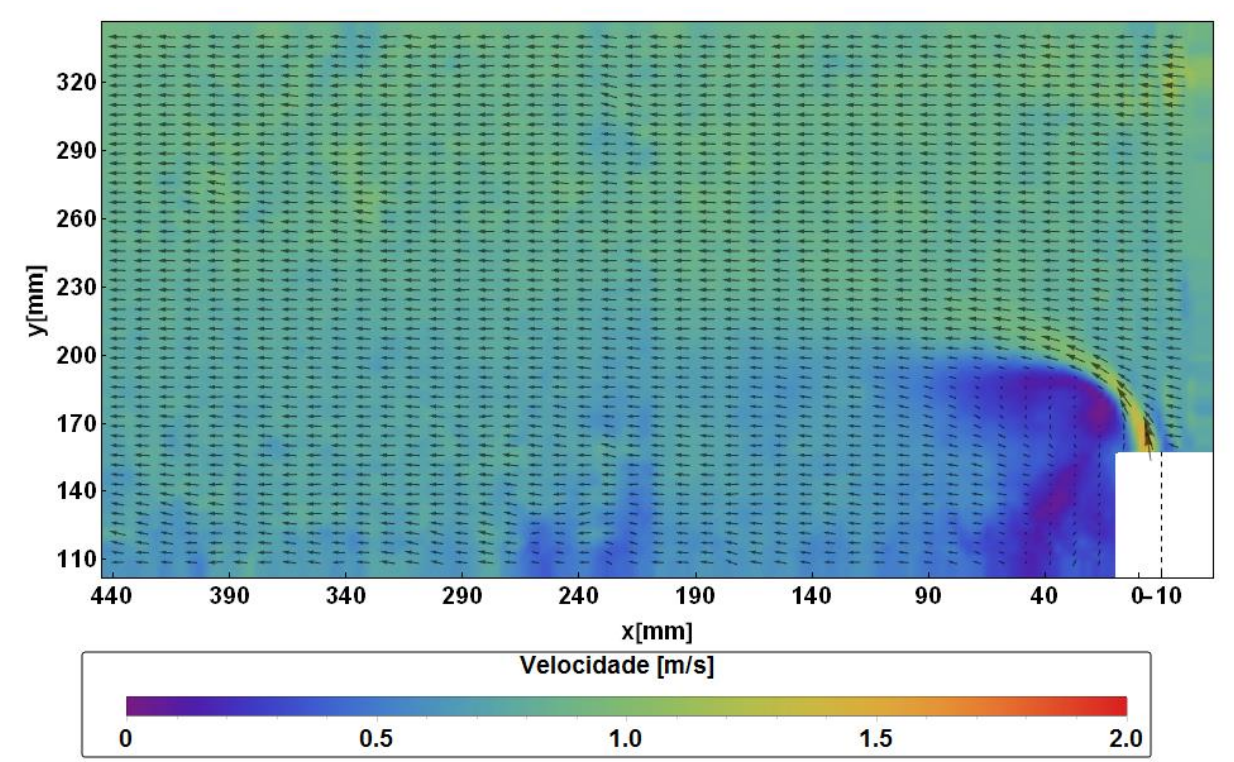

Figura 63. Campo de velocidades para $U_{\max }=0,92 \mathrm{~m} / \mathrm{s}, W_{0}=1,49 \mathrm{~m} / \mathrm{s}, T_{t}=$

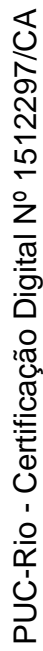
$25^{\circ} \mathrm{C}$ e $T_{w}=35^{\circ} \mathrm{C}, \Delta T=10^{\circ} \mathrm{C}$

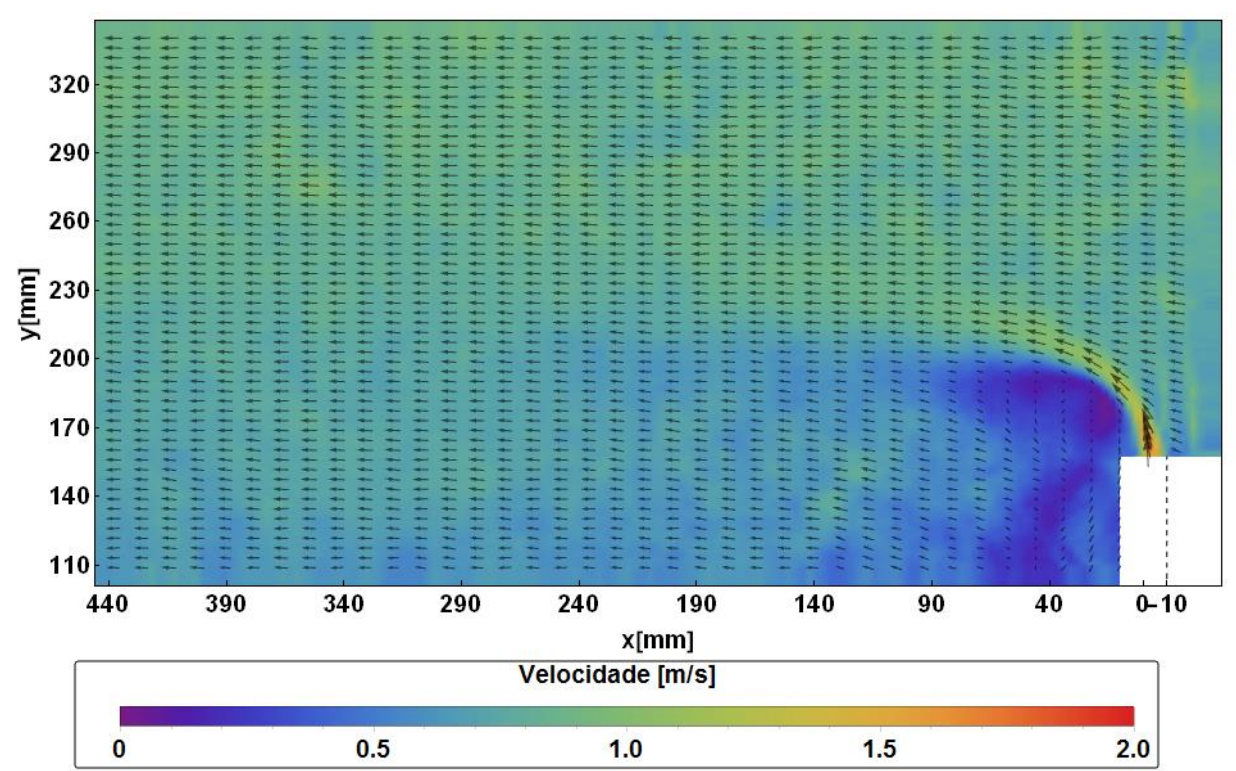

Figura 64. Campo de velocidades para $U_{\max }=0,92 \mathrm{~m} / \mathrm{s}, W_{0}=1,67 \mathrm{~m} / \mathrm{s}, T_{t}=$ $24^{\circ} \mathrm{C}$ e $T_{w}=44^{\circ} \mathrm{C}, \Delta T=20^{\circ} \mathrm{C}$ 


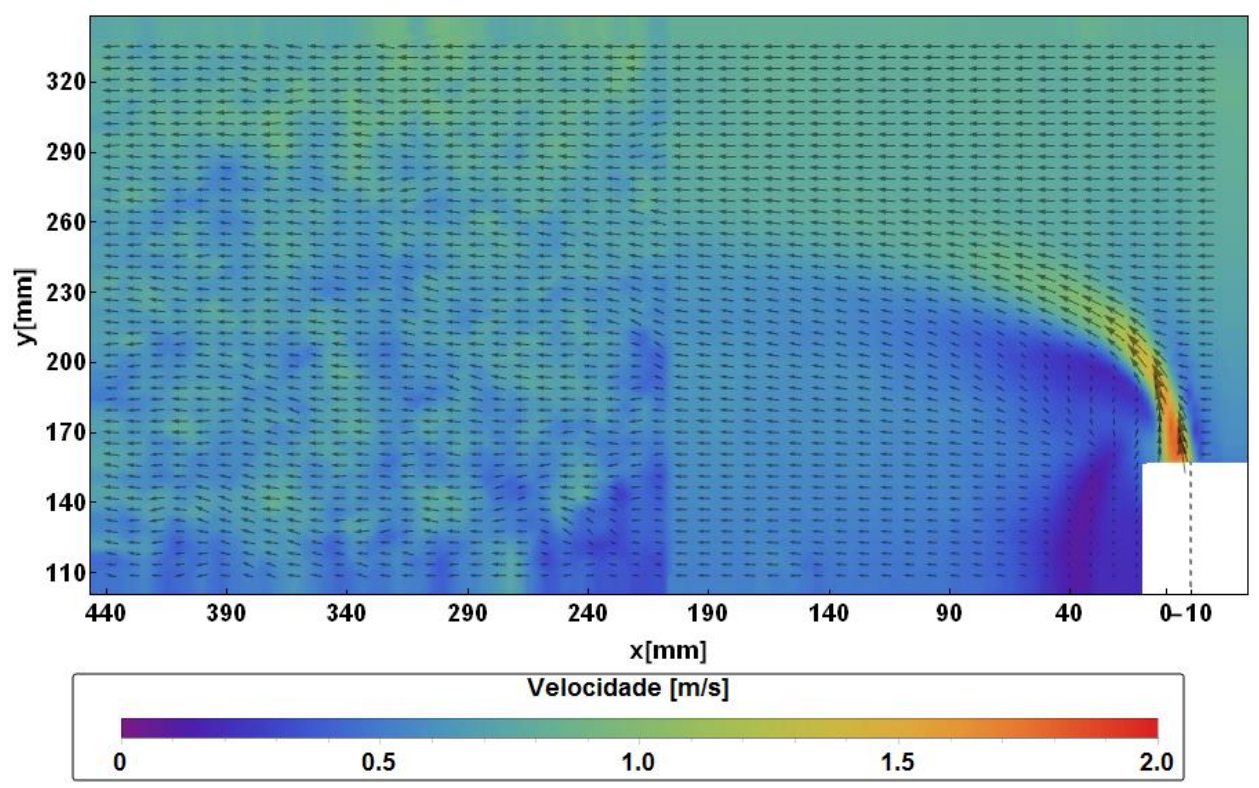

Figura 65. Campo de velocidades para $U_{\max }=0,92 \mathrm{~m} / \mathrm{s}, W_{0}=1,77 \mathrm{~m} / \mathrm{s}, T_{t}=$ $25^{\circ} \mathrm{C}$ e $T_{w}=35^{\circ} \mathrm{C}, \Delta T=10^{\circ} \mathrm{C}$

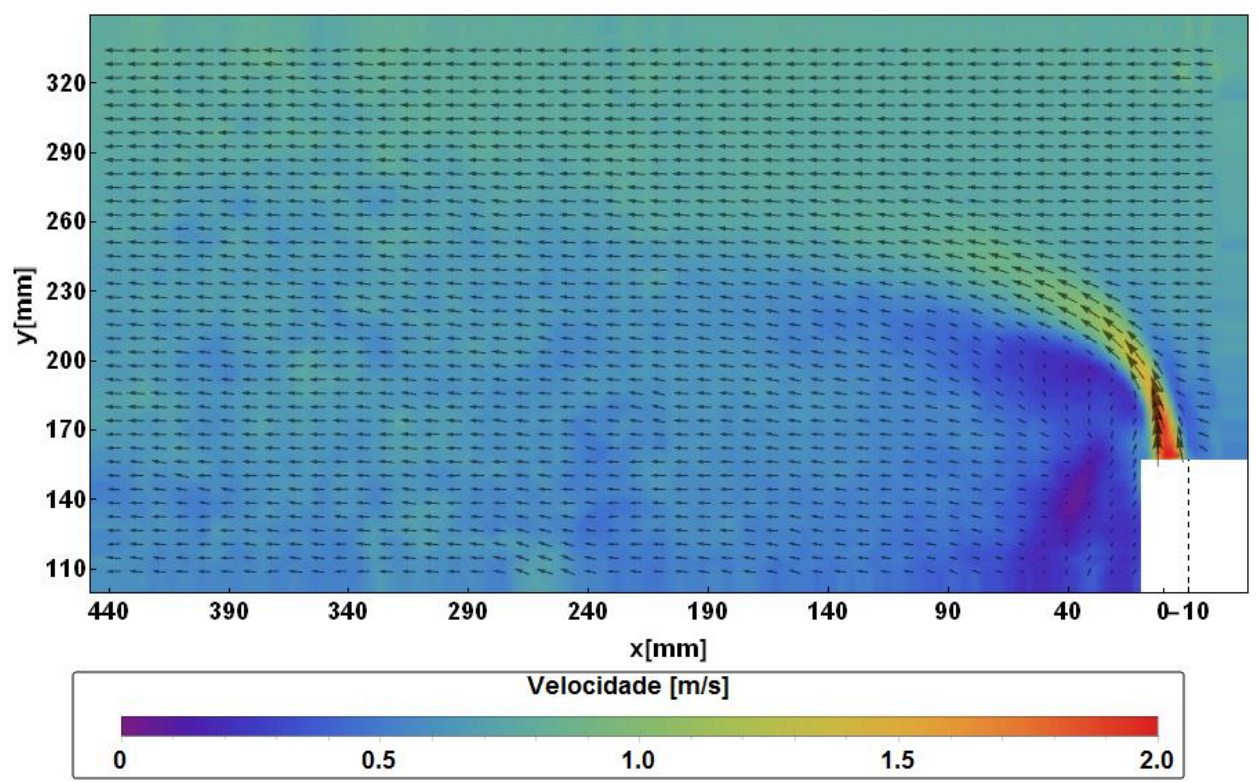

Figura 66. Campo de velocidades para $U_{\max }=0,92 \mathrm{~m} / \mathrm{s}, W_{0}=2,11 \mathrm{~m} / \mathrm{s}, T_{t}=$ $24^{\circ} \mathrm{C}$ e $T_{w}=44^{\circ} \mathrm{C}, \Delta T=20^{\circ} \mathrm{C}$

A Figura 67 até a Figura 72 mostram a mesma análise do campo vetorial para os casos 13, 14, 17, 18, 21 e 22, respectivamente, em que a velocidade do escoamento principal se mantêm em $U_{\max }=1,38 \mathrm{~m} / \mathrm{s}$. 


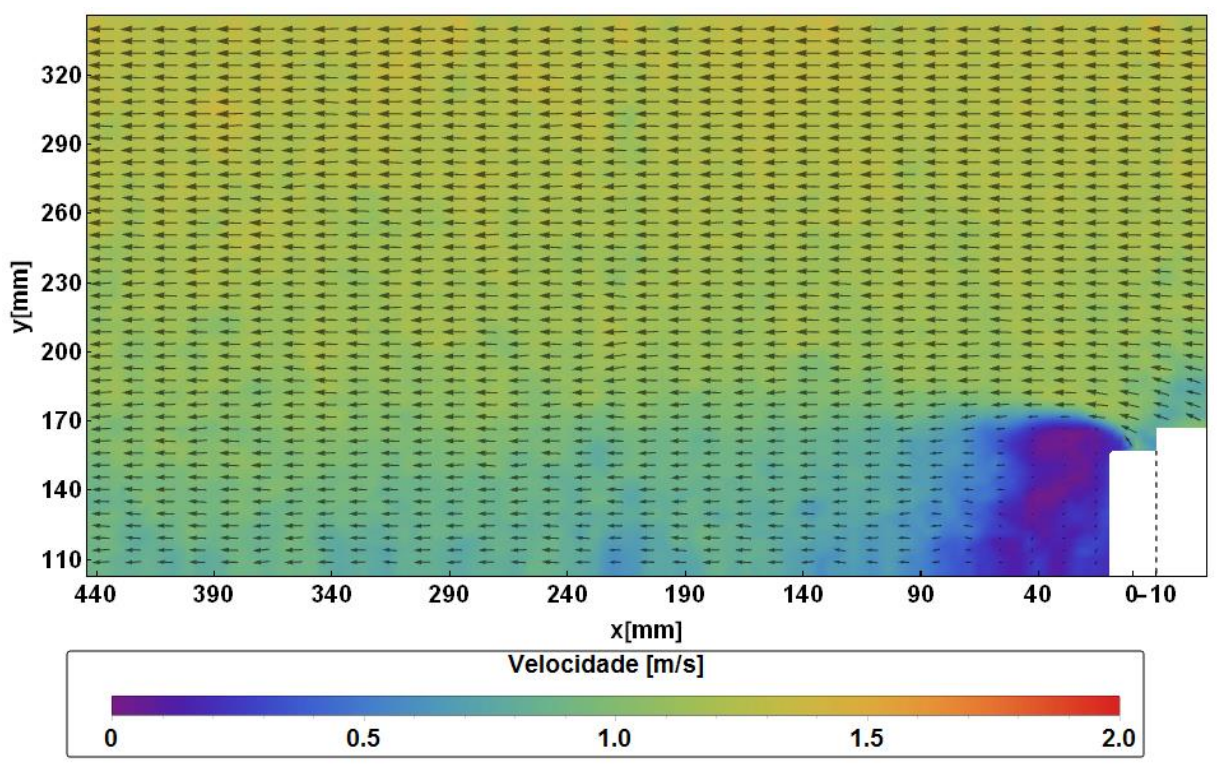

Figura 67. Campo de velocidades para $U_{\max }=1,38 \mathrm{~m} / \mathrm{s}, W_{0}=0,59 \mathrm{~m} / \mathrm{s}, T_{t}=$ $25^{\circ} \mathrm{C}$ e $T_{w}=35^{\circ} \mathrm{C}, \Delta T=10^{\circ} \mathrm{C}$

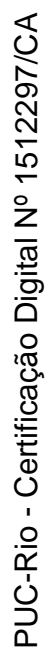

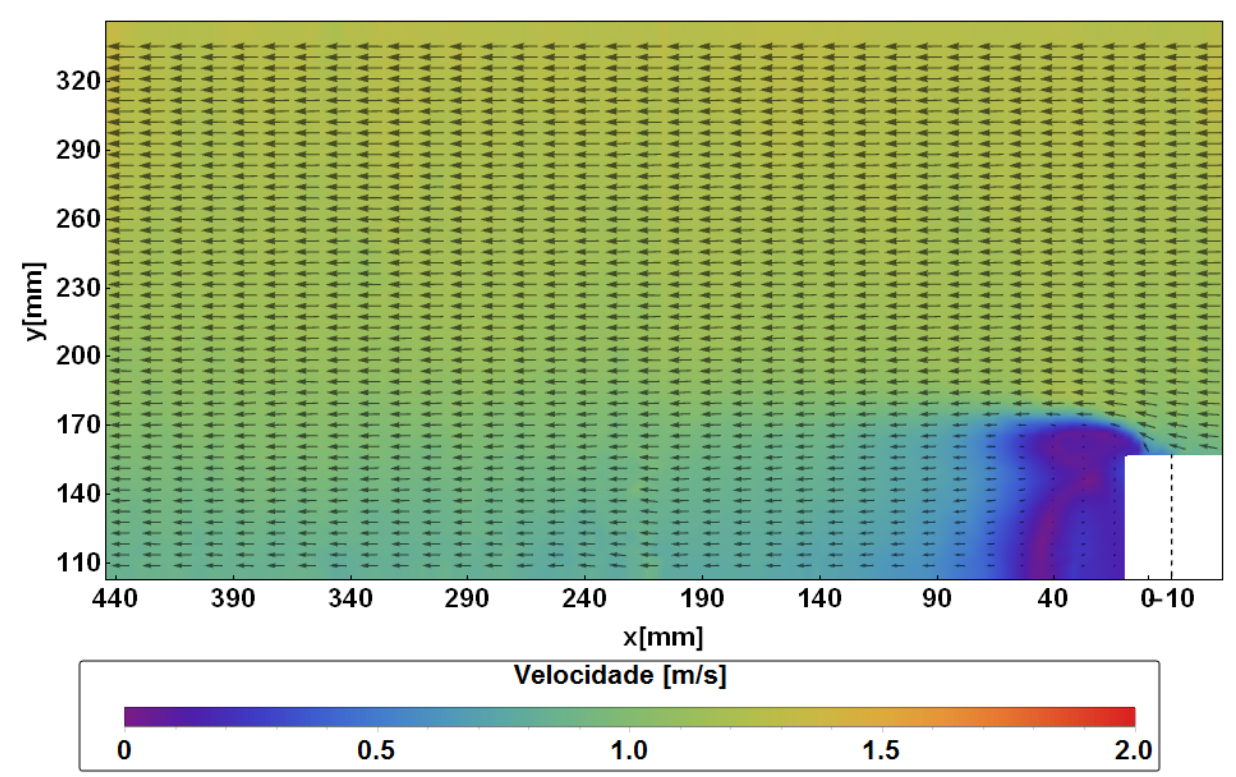

Figura 68. Campo de velocidades para $U_{\max }=1,38 \mathrm{~m} / \mathrm{s}, W_{0}=0,90 \mathrm{~m} / \mathrm{s}, T_{t}=$ $24^{\circ} \mathrm{C}$ e $T_{w}=44^{\circ} \mathrm{C}, \Delta T=20^{\circ} \mathrm{C}$ 


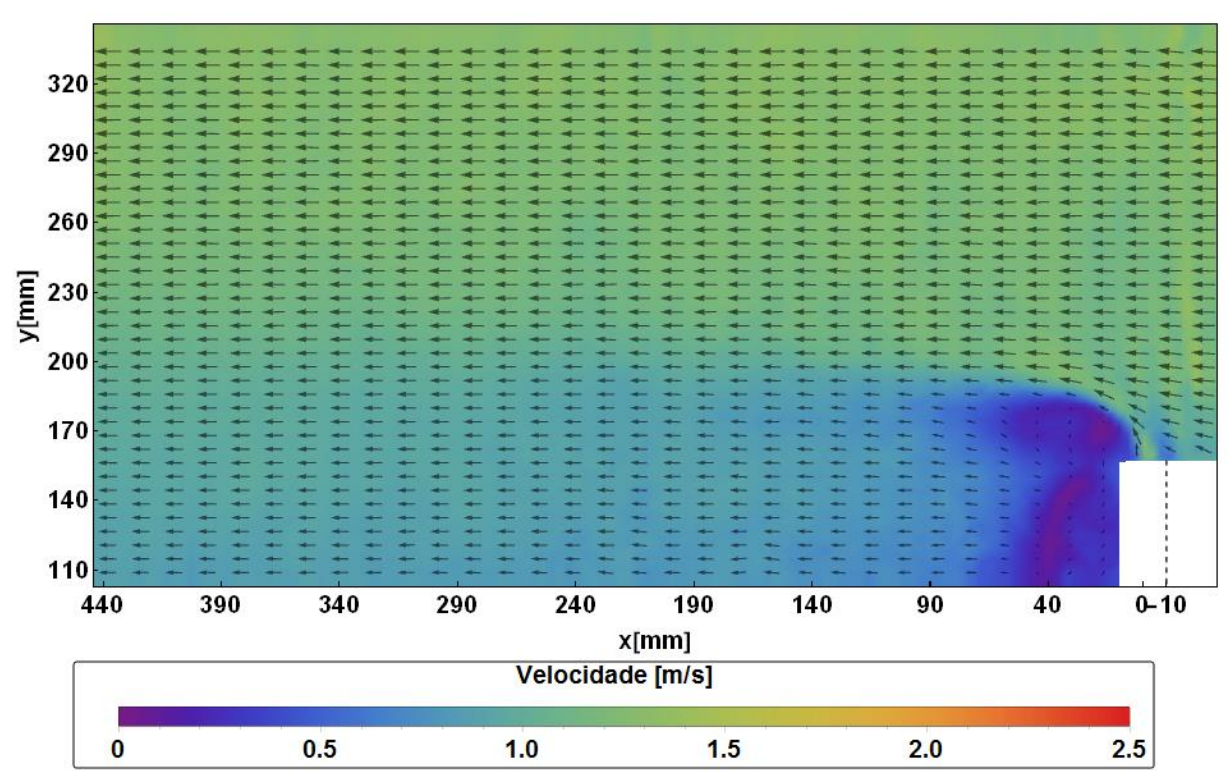

Figura 69. Campo de velocidades para $U_{\max }=1,38 \mathrm{~m} / \mathrm{s}, W_{0}=1,24 \mathrm{~m} / \mathrm{s}, T_{t}=$ $26^{\circ} \mathrm{C}$ e $T_{w}=36^{\circ} \mathrm{C}, \Delta T=10^{\circ} \mathrm{C}$

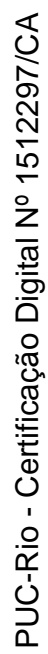

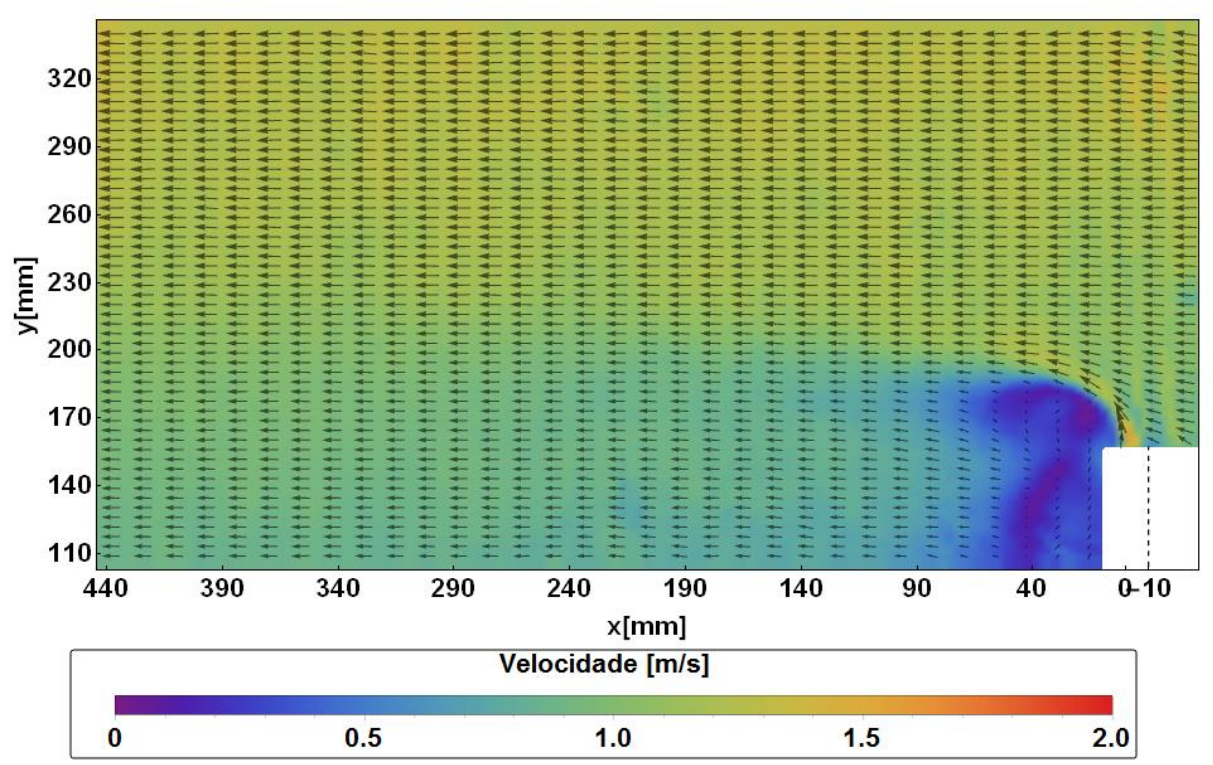

Figura 70. Campo de velocidades para $U_{\max }=1,38 \mathrm{~m} / \mathrm{s}, W_{0}=1,55 \mathrm{~m} / \mathrm{s}, T_{t}=$ $24^{\circ} \mathrm{C}$ e $T_{w}=44^{\circ} \mathrm{C}, \Delta T=20^{\circ} \mathrm{C}$ 


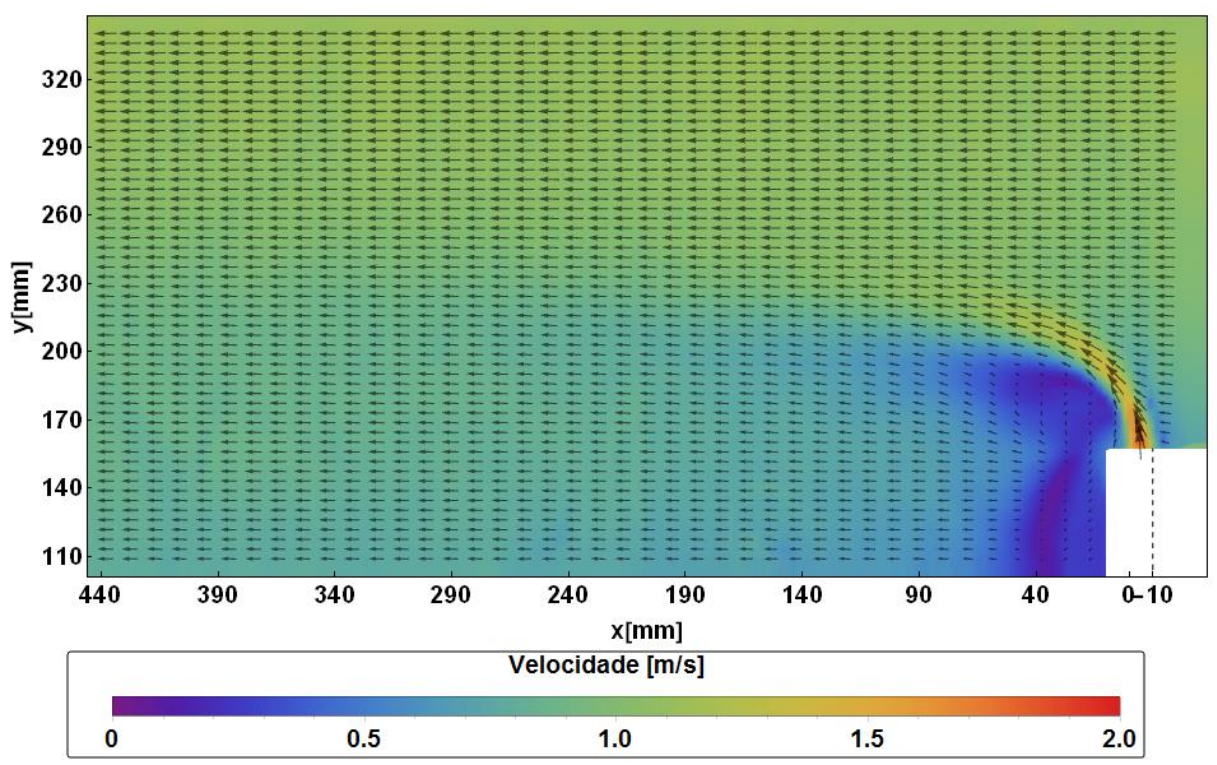

Figura 71. Campo de velocidades para $U_{\max }=1,38 \mathrm{~m} / \mathrm{s}, W_{0}=1,80 \mathrm{~m} / \mathrm{s}, T_{t}=$ $26^{\circ} \mathrm{C}$ e $T_{w}=36^{\circ} \mathrm{C}, \Delta T=10^{\circ} \mathrm{C}$

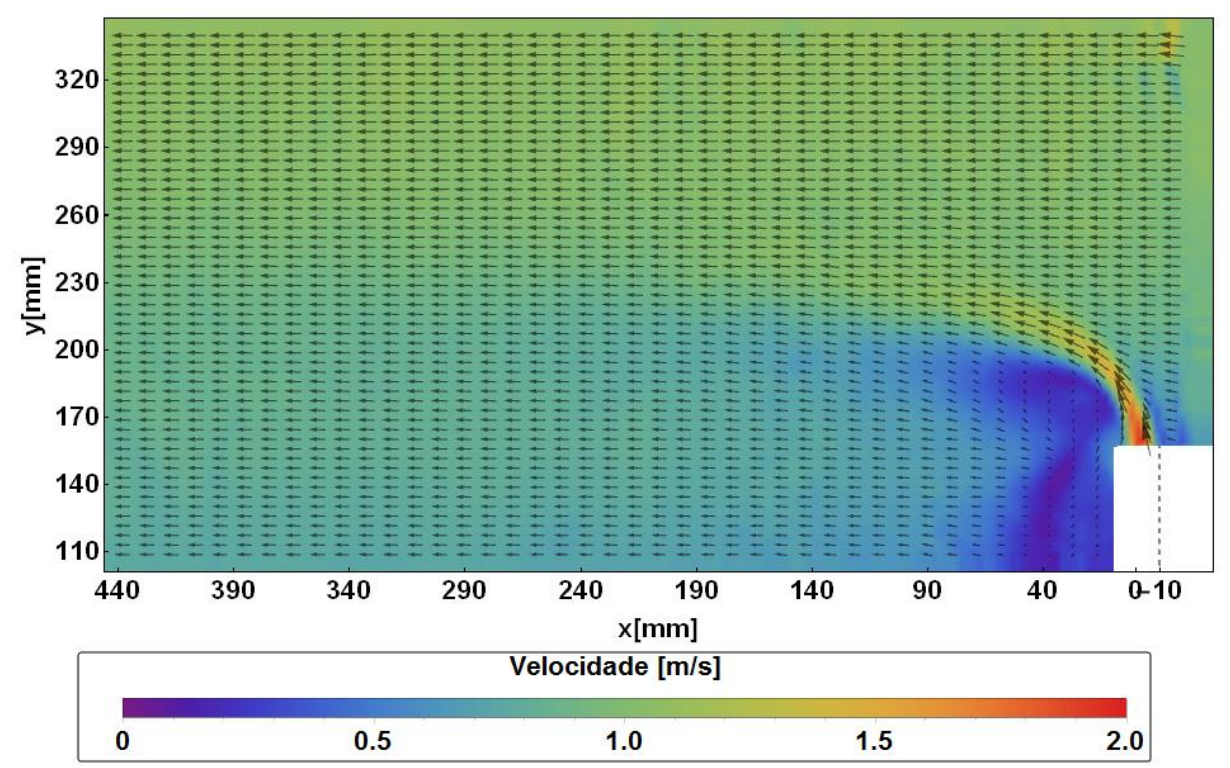

Figura 72. Campo de velocidades para $U_{\max }=1,38 \mathrm{~m} / \mathrm{s}, W_{0}=1,95 \mathrm{~m} / \mathrm{s}, T_{t}=$ $24^{\circ} \mathrm{C}$ e $T_{w}=44^{\circ} \mathrm{C}, \Delta T=20^{\circ} \mathrm{C}$

A Figura 73 até a Figura 78 mostram os resultados do campo vetorial para os casos $25,26,29,30,33$ e 34, respectivamente, em que a velocidade do escoamento principal se mantêm em $U_{\max }=1,79 \mathrm{~m} / \mathrm{s}$. 


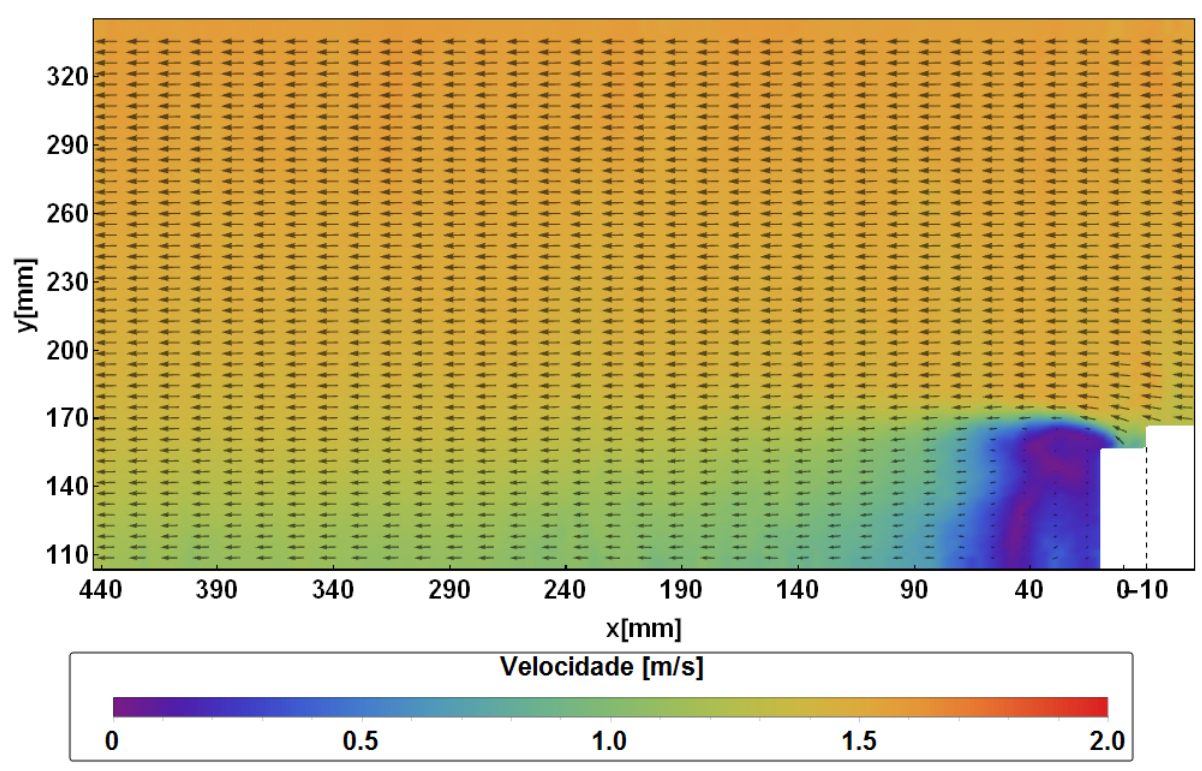

Figura 73. Campo de velocidades para $U_{\max }=1,79 \mathrm{~m} / \mathrm{s}, W_{0}=0,80 \mathrm{~m} / \mathrm{s}, T_{t}=$ $26^{\circ} \mathrm{C}$ e $T_{w}=36^{\circ} \mathrm{C}, \Delta T=10^{\circ} \mathrm{C}$

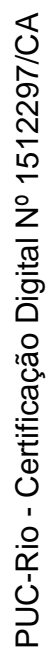

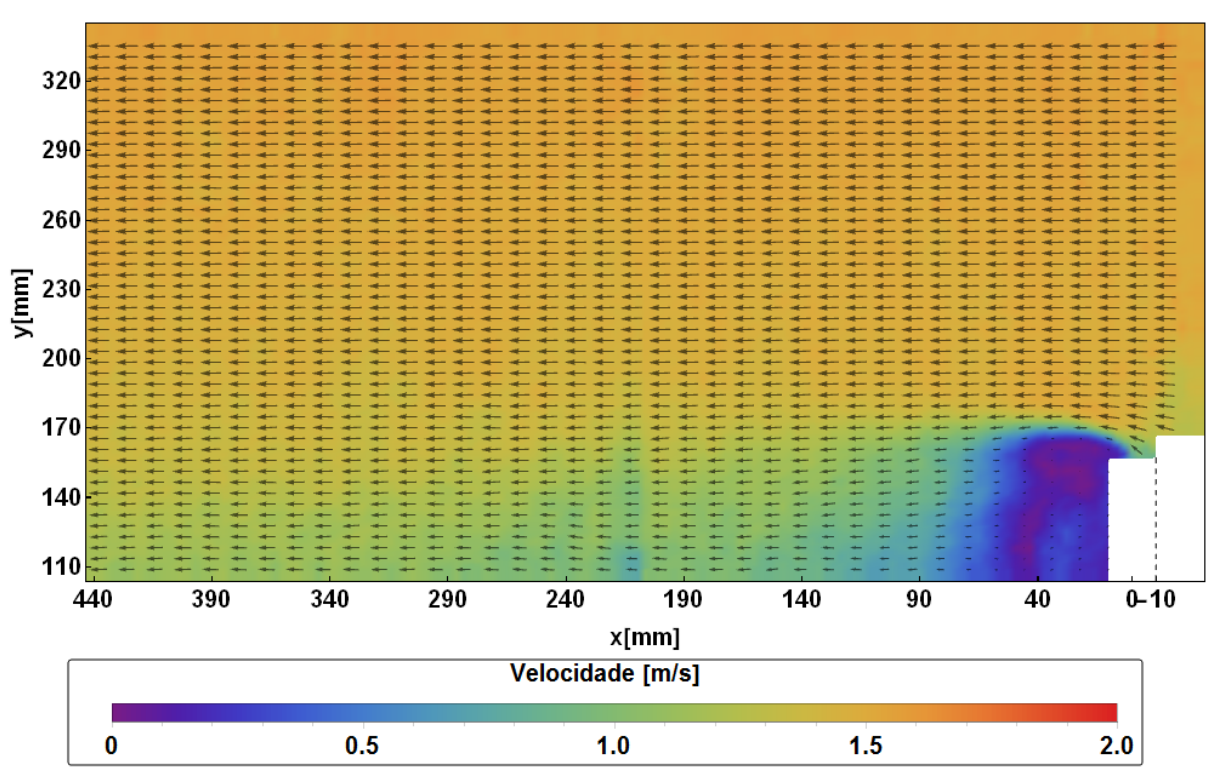

Figura 74. Campo de velocidades para $U_{\max }=1,79 \mathrm{~m} / \mathrm{s}, W_{0}=0,92 \mathrm{~m} / \mathrm{s}, T_{t}=$ $25^{\circ} \mathrm{C}$ e $T_{w}=45^{\circ} \mathrm{C}, \Delta T=20^{\circ} \mathrm{C}$ 


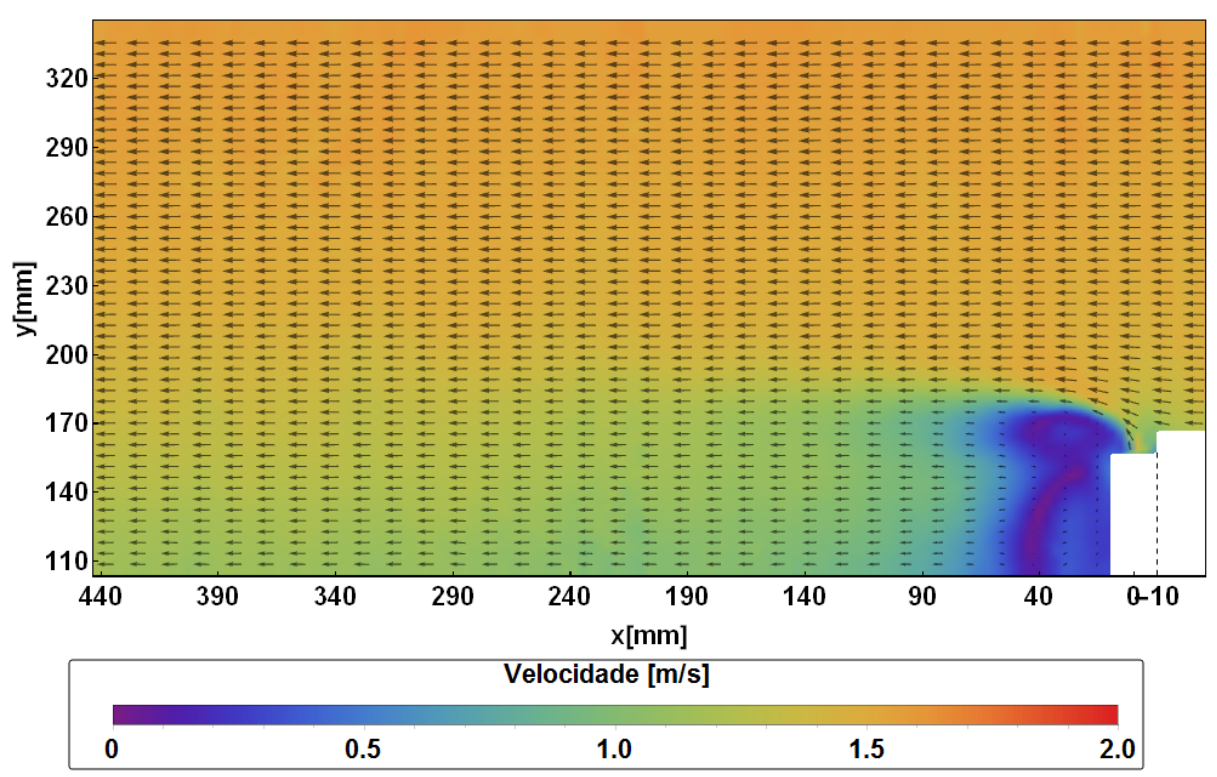

Figura 75. Campo de velocidades para $U_{\max }=1,79 \mathrm{~m} / \mathrm{s}, W_{0}=1,32 \mathrm{~m} / \mathrm{s}, T_{t}=$ $26^{\circ} \mathrm{C}$ e $T_{w}=36^{\circ} \mathrm{C}, \Delta T=10^{\circ} \mathrm{C}$

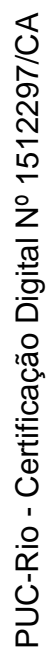

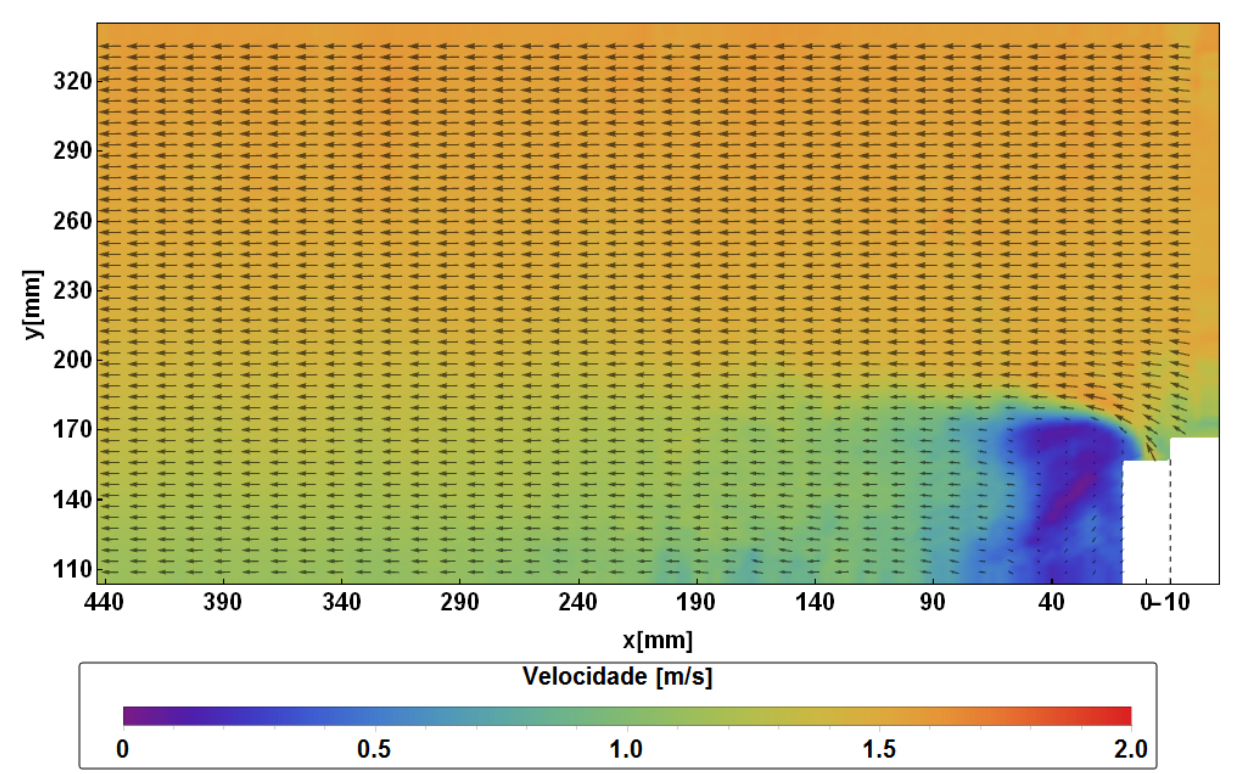

Figura 76. Campo de velocidades para $U_{\max }=1,79 \mathrm{~m} / \mathrm{s}, W_{0}=1,42 \mathrm{~m} / \mathrm{s}, T_{t}=$ $24^{\circ} \mathrm{C}$ e $T_{w}=44^{\circ} \mathrm{C}, \Delta T=20^{\circ} \mathrm{C}$ 


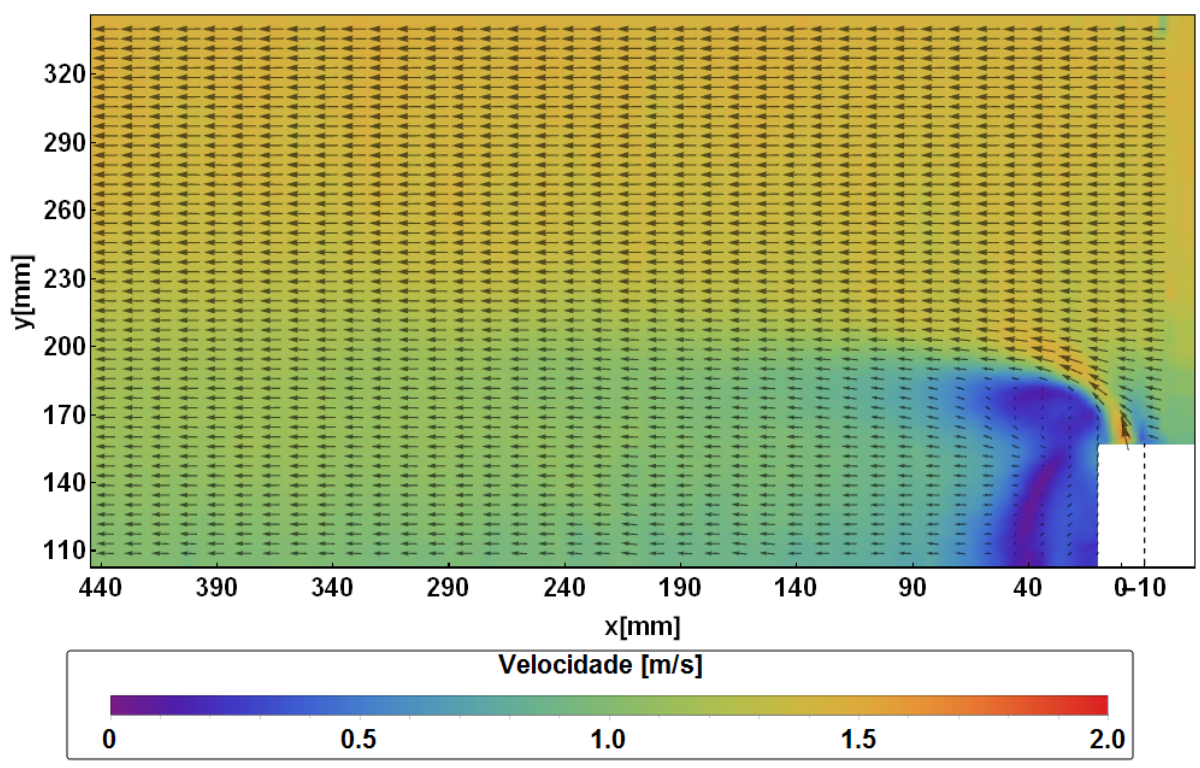

Figura 77. Campo de velocidades para $U_{\max }=1,79 \mathrm{~m} / \mathrm{s}, W_{0}=1,64 \mathrm{~m} / \mathrm{s}, T_{t}=$ $25^{\circ} \mathrm{C}$ e $T_{w}=35^{\circ} \mathrm{C}, \Delta T=10^{\circ} \mathrm{C}$

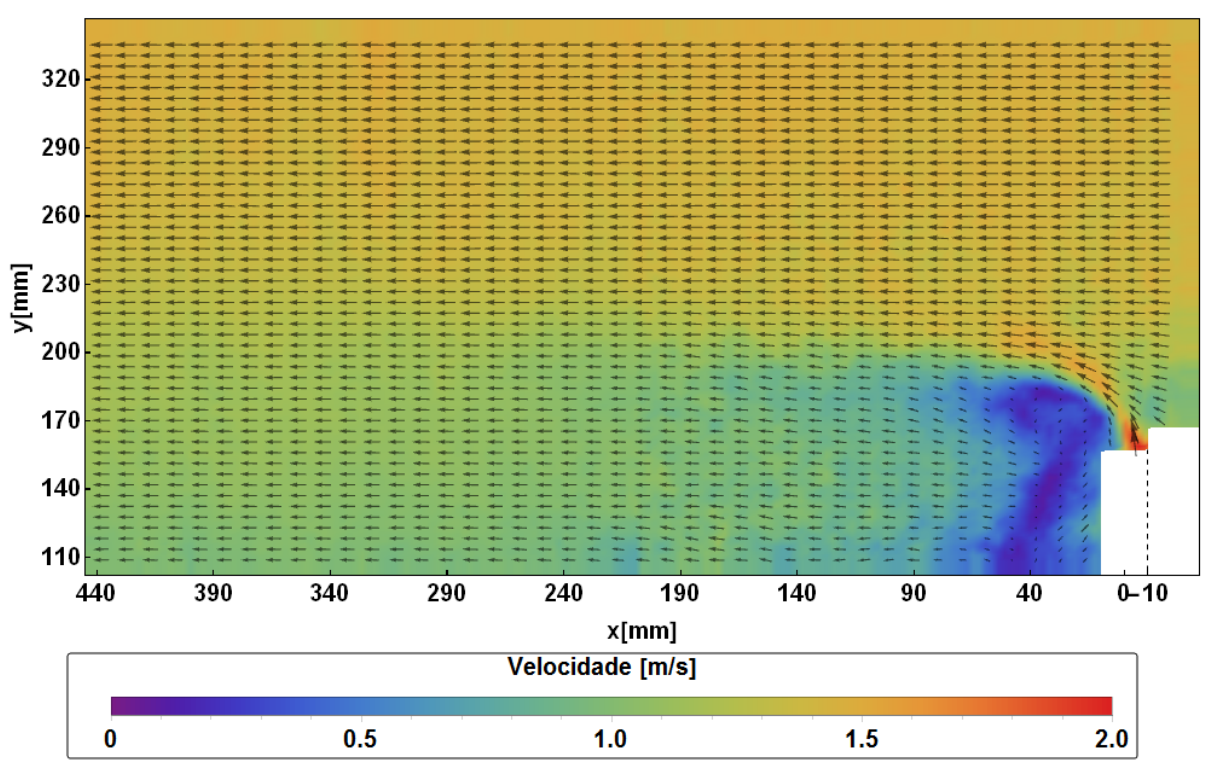

Figura 78. Campo de velocidades para $U_{\max }=1,79 \mathrm{~m} / \mathrm{s}, W_{0}=2,14 \mathrm{~m} / \mathrm{s}, T_{t}=$ $25^{\circ} \mathrm{C}$ e $T_{w}=45^{\circ} \mathrm{C}, \Delta T=20^{\circ} \mathrm{C}$

Através dos campos de velocidades é possível realizar uma análise qualitativa do comportamento da pluma. Em todos os campos vetoriais, os vetores seguem o escoamento de maneira semelhante. Porém, na região da pluma e anteriormente à chaminé, os vetores apresentam uma inclinação que prevalece até certa distância. A presença da pluma é mais marcante quanto maior é sua velocidade de emissão. 
Comparando os casos 1, 5 e 9, que possuem as menores velocidades de emissão da pluma e a menor velocidade do escoamento principal $\left(U_{\max }=0,92 \mathrm{~m} / \mathrm{s}\right)$, com os casos 25,29 e 33, que possuem a menor velocidade de emissão e a maior velocidade ensaiada do escoamento principal, $\left(U_{\max }=1,79 \mathrm{~m} / \mathrm{s}\right)$, é possível visualizar que a velocidade do escoamento altera significativamente a inclinação da pluma. Isso é mostrado na Figura 79, em que para mesma condição de injeção, a inclinação da pluma é modificada pela velocidade do escoamento no túnel.

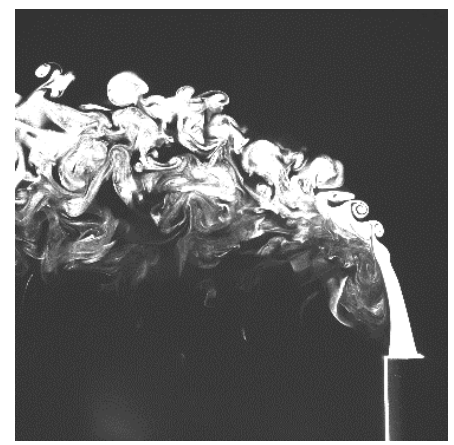

(a)

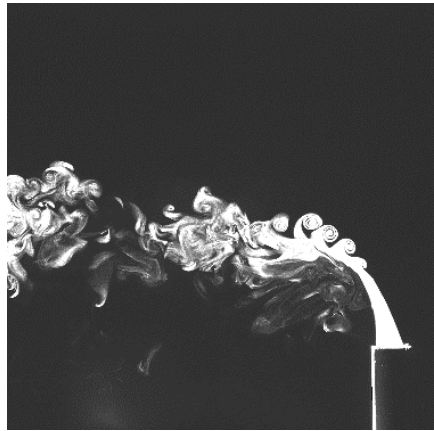

(b)

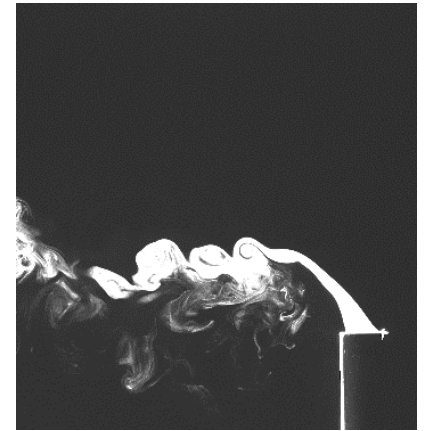

(c)

Figura 79. Condições de dispersão da pluma para mesma condição de injeção e diferentes velocidades do escoamento principal do túnel (a) $U_{\max }=0,92$ $\mathrm{m} / \mathrm{s} ;$ (b) $U_{\max }=1,38 \mathrm{~m} / \mathrm{s} \mathrm{e}(\mathrm{c}) U_{\max }=1,79 \mathrm{~m} / \mathrm{s}$

Para uma mesma velocidade do escoamento principal no túnel de vento e diferentes velocidades de emissão da pluma, é possível visualizar também diferenças quanto à presença e inclinação da pluma. Comparando os casos 1,5 e 9 , em que a velocidade do escoamento principal se mantém em $U_{\max }=0,92 \mathrm{~m} / \mathrm{s}$ e $\Delta T$ $=10^{\circ} \mathrm{C}$, é possível perceber que a inclinação da pluma fica mais positiva quanto maior a velocidade de emissão. Isso ocorre também para os casos 13, 17 e 21 em que $U_{\max }=1,38 \mathrm{~m} / \mathrm{s}$ e para os casos 25,29 e 33 em que $U_{\max }=1,79 \mathrm{~m} / \mathrm{s}$, todos para $\Delta T=10^{\circ} \mathrm{C}$.

A diferença de temperatura entre o escoamento principal e a saída da chaminé é um fator importante de influência na velocidade de saída. Em alguns casos fica notável a diferença entre $\Delta T=10^{\circ} \mathrm{C}$ e $\Delta T=20^{\circ} \mathrm{C}$. Na Figura 65 , em que $T_{t}=25^{\circ} \mathrm{C}$ e $T_{w}=35^{\circ} \mathrm{C}$, é possível comparar com a Figura 66 , em que $T_{t}=24^{\circ} \mathrm{C}$ e $T_{w}=44^{\circ} \mathrm{C}$, e notar que a magnitude dos vetores resultantes na saída da chaminé alterou onde a velocidade de saída obteve um aumento de $W_{0}=1,77 \mathrm{~m} / \mathrm{s}$ para $W_{0}=2,11 \mathrm{~m} / \mathrm{s}$. Isso 
é perceptível também para as Figura 69 e Figura 70, Figura 71 e Figura 72 e Figura 77 e Figura 78.

Outra observação importante e perceptível em todas as imagens é a nítida presença de uma região de recirculação do escoamento próxima à chaminé. Isso se deve à presença de uma obstrução (chaminé) inserido no escoamento, criando uma região de esteira à jusante da chaminé. Nessa região é possível observar um gradiente de velocidade ao longo do comprimento da janela de visualização, sendo que a velocidade tende a aumentar quanto mais afastada da chaminé. O Número de Reynolds referente ao escoamento ao redor do cilindro (chaminé) varia entre 4600 a 12500, caracterizando os vórtices como do tipo de Von Karman. Já o Número de Reynolds da chaminé fica entre 6700 a 275000 , enquanto que o Reynolds do túnel de vento fica entre 36387 a 98577.

Também foram realizados experimentos sem a reprodução da CLA para efeito de comparação e observação da influência da CLA na velocidade de emissão da chaminé. Para uma análise mais detalhada do escoamento na saída da chaminé, os próximos gráficos apresentam essa região ampliada para as condições de escoamento com e sem CLA, às mesmas condições de emissão da pluma. A Figura 80 mostra o campo vetorial dessa região para os casos 1 e 3 .

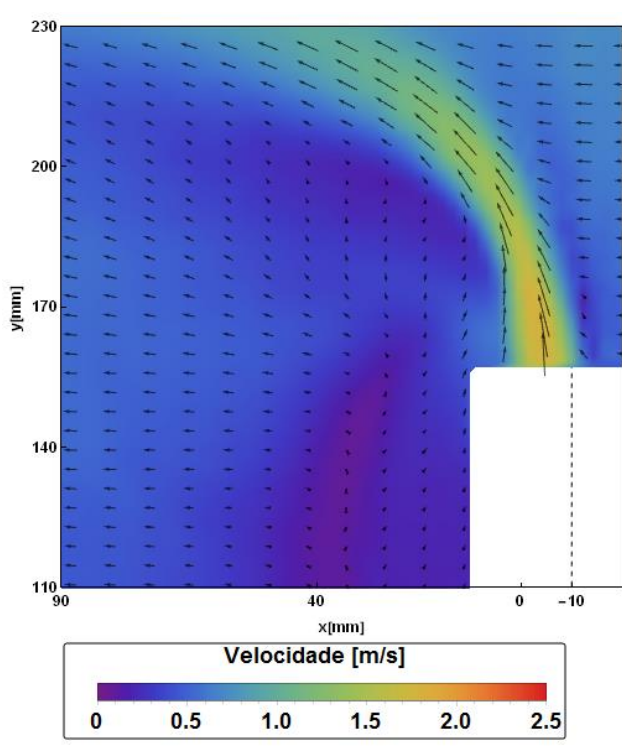

(a)

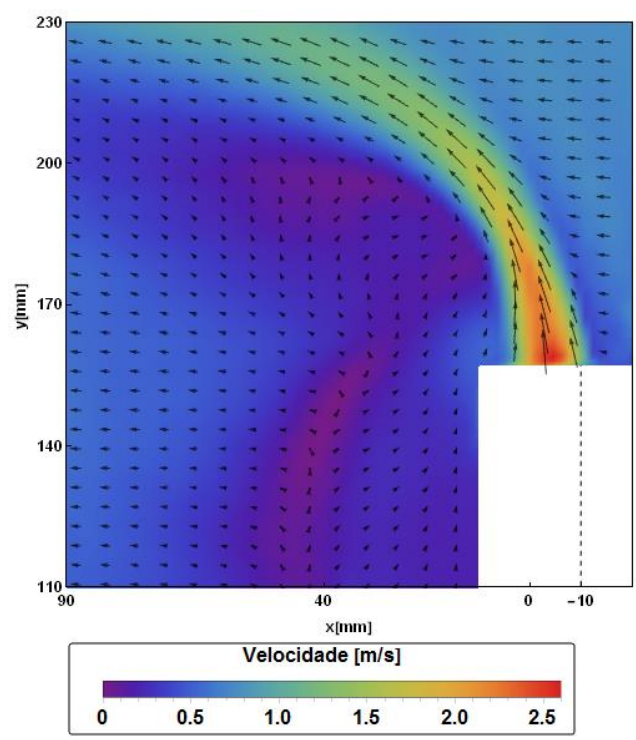

(b)

Figura 80. Campo vetorial para (a) $U_{\max }=0,92 \mathrm{~m} / \mathrm{s}$ com CLA, $W_{0}=1,08 \mathrm{~m} / \mathrm{s}, T_{t}=$ $25^{\circ} \mathrm{C}$ e $T_{w}=35^{\circ} \mathrm{C}, \Delta T=10^{\circ} \mathrm{C}$ e (b) $U_{\max }=1,08 \mathrm{~m} / \mathrm{s} \mathrm{sem} \mathrm{CLA}, W_{0}=1,31 \mathrm{~m} / \mathrm{s}, T_{t}=$ $24^{\circ} \mathrm{C}$ e $T_{w}=34^{\circ} \mathrm{C}, \Delta T=10^{\circ} \mathrm{C}$ 
A Figura 81 mostra o campo vetorial para os casos 13 e 15.

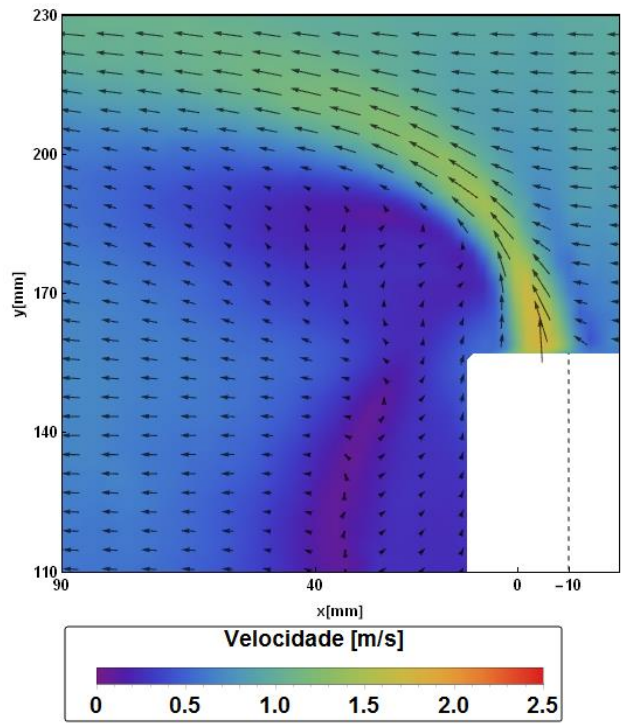

(a)

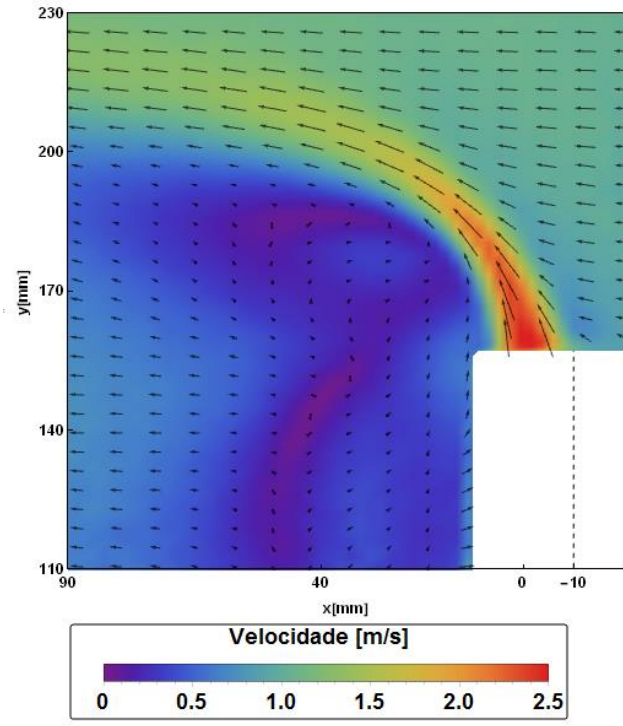

(b)

Figura 81. Campo vetorial para (a) $U_{\max }=1,38 \mathrm{~m} / \mathrm{s} \operatorname{com}$ CLA, $W_{0}=0,59 \mathrm{~m} / \mathrm{s}, T_{t}=$ $25^{\circ} \mathrm{C}$ e $T_{w}=35^{\circ} \mathrm{C}, \Delta T=10^{\circ} \mathrm{C}$ e (b) $U_{\max }=1,52 \mathrm{~m} / \mathrm{s}$ sem CLA, $W_{0}=0,90 \mathrm{~m} / \mathrm{s}, T_{t}=$ $25^{\circ} \mathrm{C}$ e $T_{w}=35^{\circ} \mathrm{C}, \Delta T=10^{\circ} \mathrm{C}$

A Figura 82 mostra o campo vetorial da região próxima à chaminé para os casos 25 e 27.

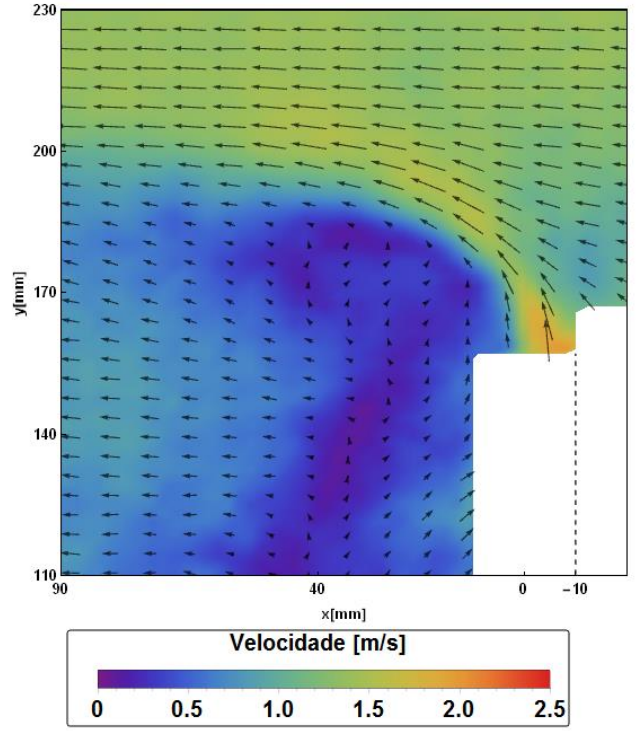

(a)

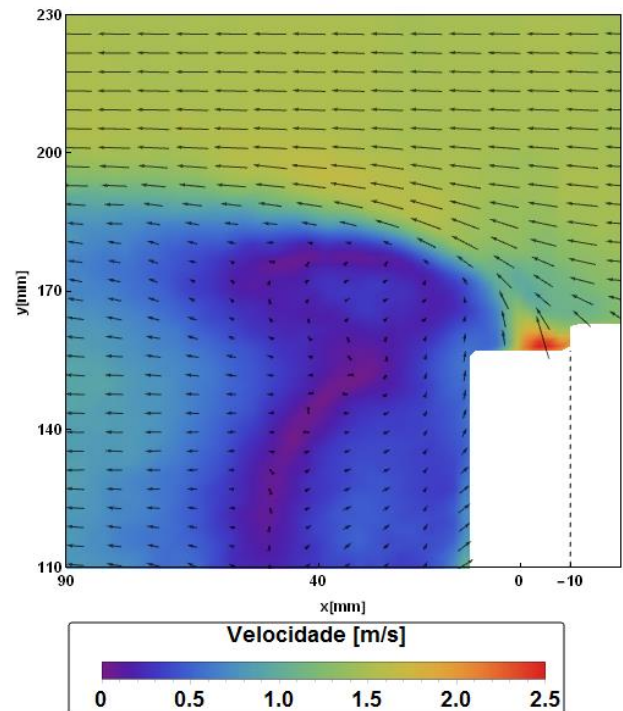

(b)

Figura 82. Campo vetorial para (a) $U_{\max }=1,79 \mathrm{~m} / \mathrm{s}$ com CLA, $W_{0}=0,80 \mathrm{~m} / \mathrm{s}, T_{t}=$ $26^{\circ} \mathrm{C}$ e $T_{w}=36^{\circ} \mathrm{C}, \Delta T=10^{\circ} \mathrm{C}$ e (b) $U_{\max }=1,85 \mathrm{~m} / \mathrm{s}$ sem CLA, $W_{0}=0,86 \mathrm{~m} / \mathrm{s}, T_{t}=$ $25^{\circ} \mathrm{C}$ e $T_{w}=35^{\circ} \mathrm{C}, \Delta T=10^{\circ} \mathrm{C}$ 
Em todas as três comparações é possível observar que a velocidade do escoamento na saída da chaminé diminui quando a velocidade do escoamento principal é maior. Isso se deve ao fato de que uma maior velocidade acarreta em menor pressão na saída da chaminé, aumentando a vazão. Isso acontece também para os outros casos estudados, como se pode ver na Tabela 7.

Na região de emissão da chaminé, foi observado um típico padrão de transição chamado instabilidades de Kelvin-Helmholtz, que ocorre quando há uma camada cisalhante livre em um único fluido contínuo, ou onde há uma diferença de velocidade através da interface entre dois fluidos. Esta instabilidade conduz à formação de um vórtice dentro da zona de mistura entre os dois fluidos. Dependendo da razão de velocidade do vento, estes padrões giram no sentido horário ou anti-horário, como pode ser observado na Figura 83.

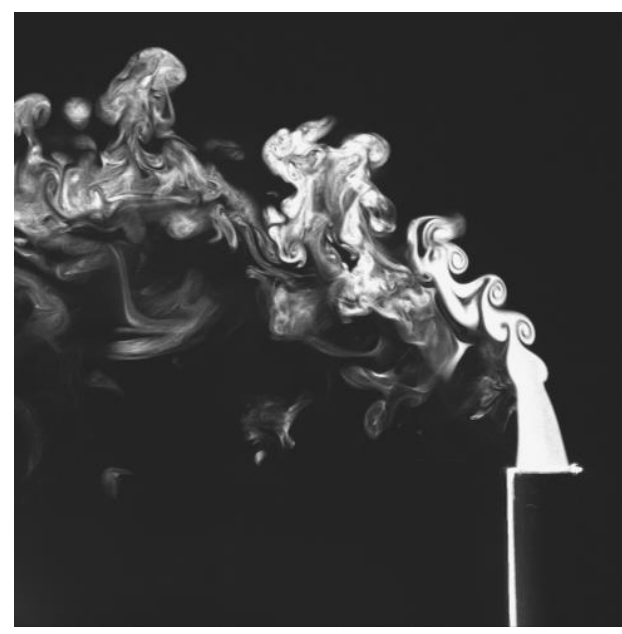

(a)

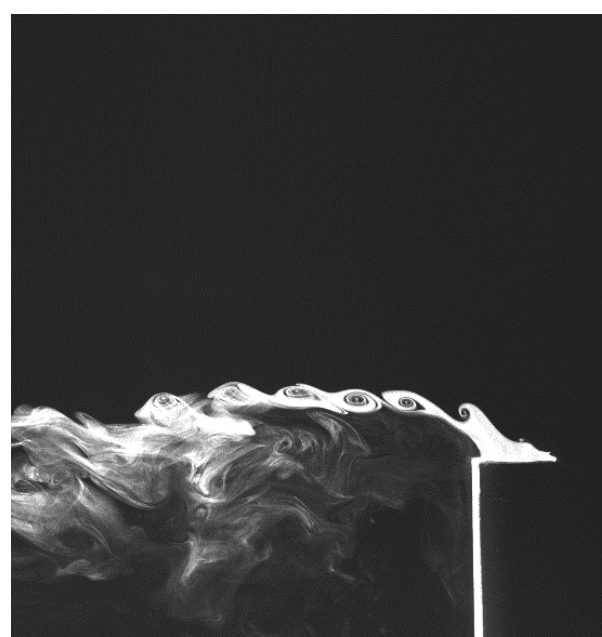

(b)

Figura 83. Instabilidade de Kelvin-Helmholtz para condição de (a) $\boldsymbol{U}_{\boldsymbol{m a x}}=0,92$ $\mathrm{m} / \mathrm{s}$ e $W_{0}=1,77 \mathrm{~m} / \mathrm{s}$ e (b) $\boldsymbol{U}_{\boldsymbol{m a x}}=1,79 \mathrm{~m} / \mathrm{s}$ e $W_{0}=1,64 \mathrm{~m} / \mathrm{s}$

A Figura 84 mostra a componente vertical de velocidade (v) na saída da chaminé para os casos 1, 2, 5, 69 e 10, em que é mantida a velocidade do escoamento principal em $U_{\max }=0,92 \mathrm{~m} / \mathrm{s}$, e varia-se as velocidades de saída e a diferença de temperatura. 


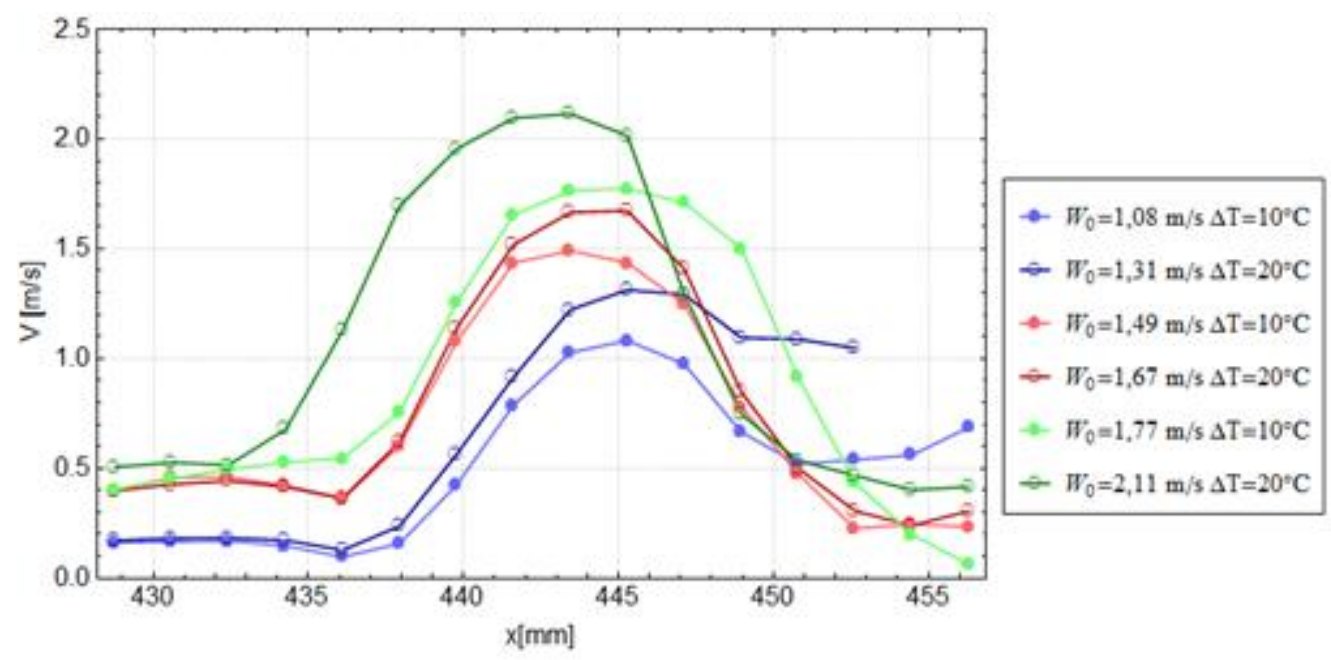

Figura 84. Perfil de velocidade $v(\mathrm{~m} / \mathrm{s})$ para $U_{\max }=0,92 \mathrm{~m} / \mathrm{s}$

Percebe-se que o perfil de velocidade possui um formato parabólico e uma não simetria. Isso se deve ao fato da chaminé ser um corpo rombudo, sujeito à formação de vórtices, que deformam o perfil de saída. Fica também evidenciado o efeito do aumento da temperatura sobre a velocidade de emissão; a condição de $\Delta T$ $=20^{\circ} \mathrm{C}$ possui um aumento na componente vertical de velocidade $(V)$ em relação à de $\Delta T=10^{\circ} \mathrm{C}$.

A questão do aumento da diferença de temperatura pode ser melhor analisada através de um estudo da inclinação da linha central da pluma, obtida através da análise dos perfis gaussianos de concentração. Uma regressão linear foi realizada com diversos pontos da altura da pluma, da qual se tem os valores da inclinação da pluma $(\Delta y / \Delta x)$. Assim, pode-se definir essa regressão linear da linha central como a taxa média de ascensão da pluma, cujos valores estão apresentados na Tabela 8. 
Tabela 8. Inclinação da pluma $(\Delta y / \Delta x)$

\begin{tabular}{|c|c|c|c|c|c|c|c|}
\hline \multirow[b]{2}{*}{$C L A$} & \multirow{2}{*}{$\begin{array}{l}U_{\max } \\
(\mathrm{m} / \mathrm{s})\end{array}$} & \multicolumn{6}{|c|}{$\Delta y / \Delta x$ com valores de $W_{0}$ entre parênteses } \\
\hline & & $\Delta T=10^{\circ} \mathrm{C}$ & $\Delta T=20^{\circ} \mathrm{C}$ & $\Delta T=10^{\circ} \mathrm{C}$ & $\Delta T=20^{\circ} \mathrm{C}$ & $\Delta T=10^{\circ} \mathrm{C}$ & $\Delta T=20^{\circ} \mathrm{C}$ \\
\hline \multirow{3}{*}{$\checkmark$} & $\mathbf{0 , 9 2}$ & $\begin{array}{c}-0,074 \\
(1,02 \mathrm{~m} / \mathrm{s})\end{array}$ & $\begin{array}{c}-0,017 \\
(1,43 \mathrm{~m} / \mathrm{s})\end{array}$ & $\begin{array}{c}0,013 \\
(1,64 \mathrm{~m} / \mathrm{s})\end{array}$ & $\begin{array}{c}0,049 \\
(1,77 \mathrm{~m} / \mathrm{s})\end{array}$ & $\begin{array}{c}0,111 \\
(2,55 \mathrm{~m} / \mathrm{s})\end{array}$ & $\begin{array}{c}0,123 \\
(3,27 \mathrm{~m} / \mathrm{s})\end{array}$ \\
\hline & 1,38 & $\begin{array}{c}-0,077 \\
(0,90 \mathrm{~m} / \mathrm{s})\end{array}$ & $\begin{array}{c}-0,001 \\
(0,99 \mathrm{~m} / \mathrm{s})\end{array}$ & $\begin{array}{c}-0,012 \\
(1,31 \mathrm{~m} / \mathrm{s})\end{array}$ & $\begin{array}{c}0,012 \\
(1,62 \mathrm{~m} / \mathrm{s})\end{array}$ & $\begin{array}{c}0,018 \\
(2,25 \mathrm{~m} / \mathrm{s})\end{array}$ & $\begin{array}{c}0,059 \\
(2,52 \mathrm{~m} / \mathrm{s})\end{array}$ \\
\hline & 1,79 & $\begin{array}{c}-0,083 \\
(0,86 \mathrm{~m} / \mathrm{s})\end{array}$ & $\begin{array}{c}-0,106 \\
(1,18 \mathrm{~m} / \mathrm{s})\end{array}$ & $\begin{array}{c}-0,027 \\
(1,15 \mathrm{~m} / \mathrm{s})\end{array}$ & $\begin{array}{c}-0,023 \\
(2,06 \mathrm{~m} / \mathrm{s})\end{array}$ & $\begin{array}{c}-0,002 \\
(1,91 \mathrm{~m} / \mathrm{s})\end{array}$ & $\begin{array}{c}-0,001 \\
(2,67 \mathrm{~m} / \mathrm{s})\end{array}$ \\
\hline & $\mathbf{1 , 0 8}$ & $\begin{array}{c}-0,055 \\
(1,08 \mathrm{~m} / \mathrm{s})\end{array}$ & $\begin{array}{c}-0,032 \\
(1,31 \mathrm{~m} / \mathrm{s})\end{array}$ & $\begin{array}{c}0,007 \\
(1,49 \mathrm{~m} / \mathrm{s})\end{array}$ & $\begin{array}{c}0,037 \\
(1,67 \mathrm{~m} / \mathrm{s})\end{array}$ & $\begin{array}{c}0,015 \\
(1,77 \mathrm{~m} / \mathrm{s})\end{array}$ & $\begin{array}{c}0,039 \\
(2,11 \mathrm{~m} / \mathrm{s})\end{array}$ \\
\hline & 1,52 & $\begin{array}{c}-0,077 \\
(0,59 \mathrm{~m} / \mathrm{s})\end{array}$ & $\begin{array}{c}-0,070 \\
(0,90 \mathrm{~m} / \mathrm{s})\end{array}$ & $\begin{array}{c}-0,008 \\
(1,24 \mathrm{~m} / \mathrm{s})\end{array}$ & $\begin{array}{c}-0,002 \\
(1,55 \mathrm{~m} / \mathrm{s})\end{array}$ & $\begin{array}{c}-0,007 \\
(1,80 \mathrm{~m} / \mathrm{s})\end{array}$ & $\begin{array}{c}0,030 \\
(1,95 \mathrm{~m} / \mathrm{s})\end{array}$ \\
\hline & $\mathbf{1 , 8 5}$ & $\begin{array}{c}-0,084 \\
(0,80 \mathrm{~m} / \mathrm{s})\end{array}$ & $\begin{array}{c}-0,082 \\
(0,92 \mathrm{~m} / \mathrm{s})\end{array}$ & $\begin{array}{c}-0,007 \\
(1,32 \mathrm{~m} / \mathrm{s})\end{array}$ & $\begin{array}{c}-0,016 \\
(1,42 \mathrm{~m} / \mathrm{s})\end{array}$ & $\begin{array}{c}-0,019 \\
(1,64 \mathrm{~m} / \mathrm{s})\end{array}$ & $\begin{array}{c}-0,003 \\
(2,14 \mathrm{~m} / \mathrm{s})\end{array}$ \\
\hline
\end{tabular}

Uma maior temperatura da pluma faz com que a força de empuxo, devido à menor densidade, seja maior, levando a uma inclinação mais positiva e aumentando sua elevação. Assim, para temperaturas mais altas, onde $\Delta T=20^{\circ} \mathrm{C}$, a pluma tende a elevar em relação a temperaturas mais baixas, com $\Delta T=10^{\circ} \mathrm{C}$. Isso pode ser visualizado na Tabela 8 , observando que os valores de $\Delta y / \Delta x$ aumentam de $\Delta T=$ $10^{\circ} \mathrm{C}$ para $\Delta T=20^{\circ} \mathrm{C}$.

Através desta tabela é possível realizar também uma análise da inclinação da pluma em relação à velocidade do escoamento principal. $O$ valor da inclinação tende a diminuir quanto maior a velocidade do escoamento principal, uma vez que a relação entre as velocidades vertical e axial diminui. Isso é exemplificado na Figura 85, em que se percebe que, mantida a condição de emissão, para uma velocidade de escoamento principal mais alta $\left(U_{\max }=1,79 \mathrm{~m} / \mathrm{s}\right)$, a pluma abaixa em relação à velocidade mais baixa $\left(U_{\max }=0,92 \mathrm{~m} / \mathrm{s}\right)$. O efeito da temperatura também é percebido neste gráfico; para $\Delta T=20^{\circ} \mathrm{C}$, os pontos da linha central estão acima dos pontos para $\Delta T=10^{\circ} \mathrm{C}$. Alguns casos para velocidades mais baixas, na condição sem CLA apresentaram certos erros que podem ser atribuídos ao procedimento experimental. 


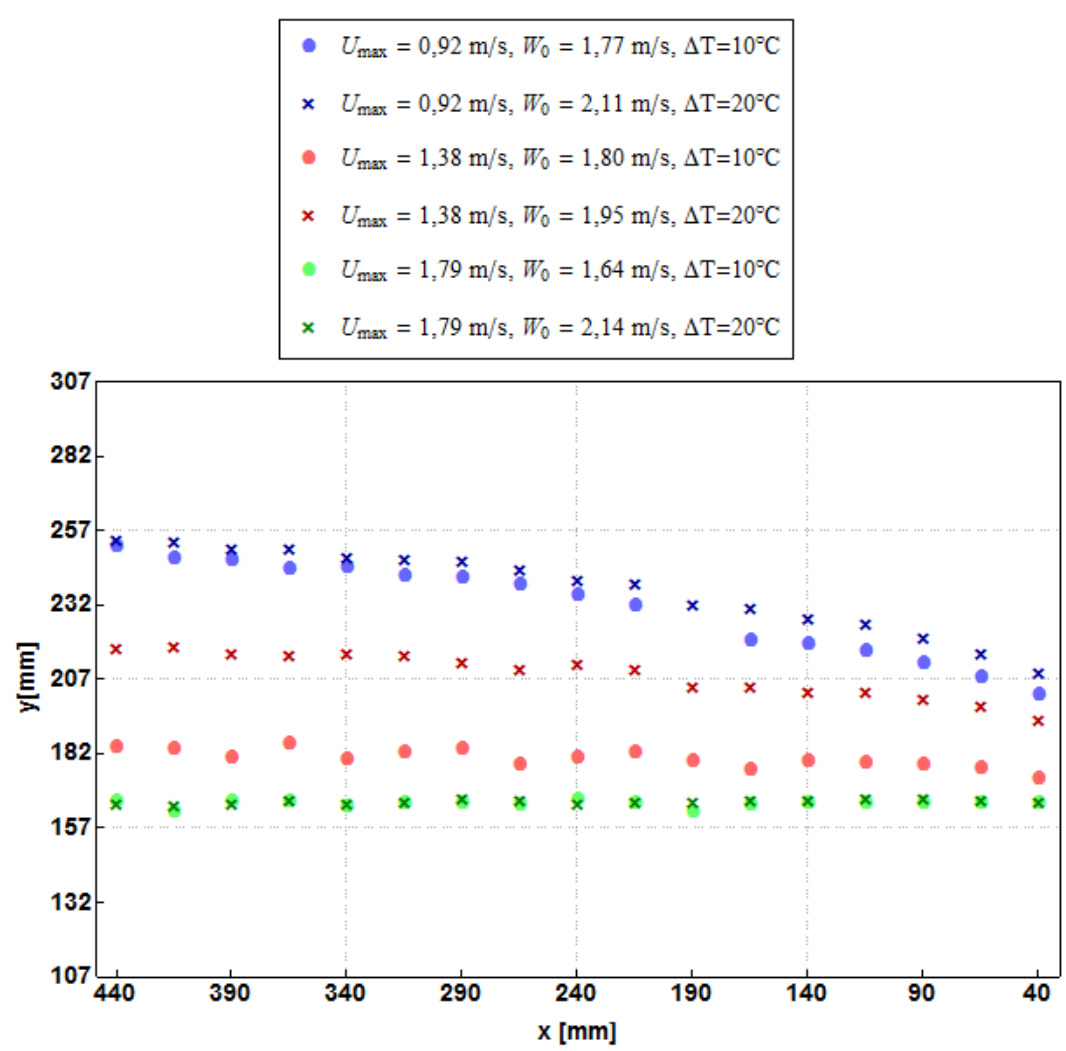

Figura 85. Inclinação da pluma para diferentes velocidades do escoamento principal e diferentes temperaturas de emissão

Os gráficos a seguir foram obtidos através de uma análise dos dados do PIV e mostram o perfil da componente horizontal de velocidade e flutuações de velocidade em diversas posições a jusante da pluma. Em $x=20 \mathrm{~mm}$ está representado o perfil mais próximo à chaminé e em $x=420 \mathrm{~mm}$, o perfil mais longe. As linhas pretas pontilhadas, em ambos os gráficos, apresentam os perfis de velocidade e turbulência nas posições anteriores à chaminé. A análise foi realizada para todos os casos, porém foram expostos somente os resultados, com reprodução da CLA, de:

- Menor velocidade do escoamento principal e menor velocidade de emissão da chaminé para $\Delta T=10^{\circ} \mathrm{C}$ e $\Delta T=20^{\circ} \mathrm{C}-$ Caso 1 e caso 2

- Menor velocidade do escoamento principal e maior velocidade de emissão da chaminé para $\Delta T=10^{\circ} \mathrm{C}$ e $\Delta T=20^{\circ} \mathrm{C}-$ Caso 9 e caso 10

- Maior velocidade do escoamento principal e menor velocidade de emissão da chaminé para $\Delta T=10^{\circ} \mathrm{C}$ e $\Delta T=20^{\circ} \mathrm{C}-$ Caso 25 e caso 26

- Maior velocidade do escoamento principal e maior velocidade de emissão da chaminé para $\Delta T=10^{\circ} \mathrm{C}$ e $\Delta T=20^{\circ} \mathrm{C}-$ Caso 33 e caso 34 
A Figura 86 e a Figura 87 mostram, respectivamente, os perfis da componente horizontal de velocidade e flutuações para o caso 1. A Figura 88 mostra uma ampliação da região em que os perfis de flutuação estão mais concentrados para o caso 1.

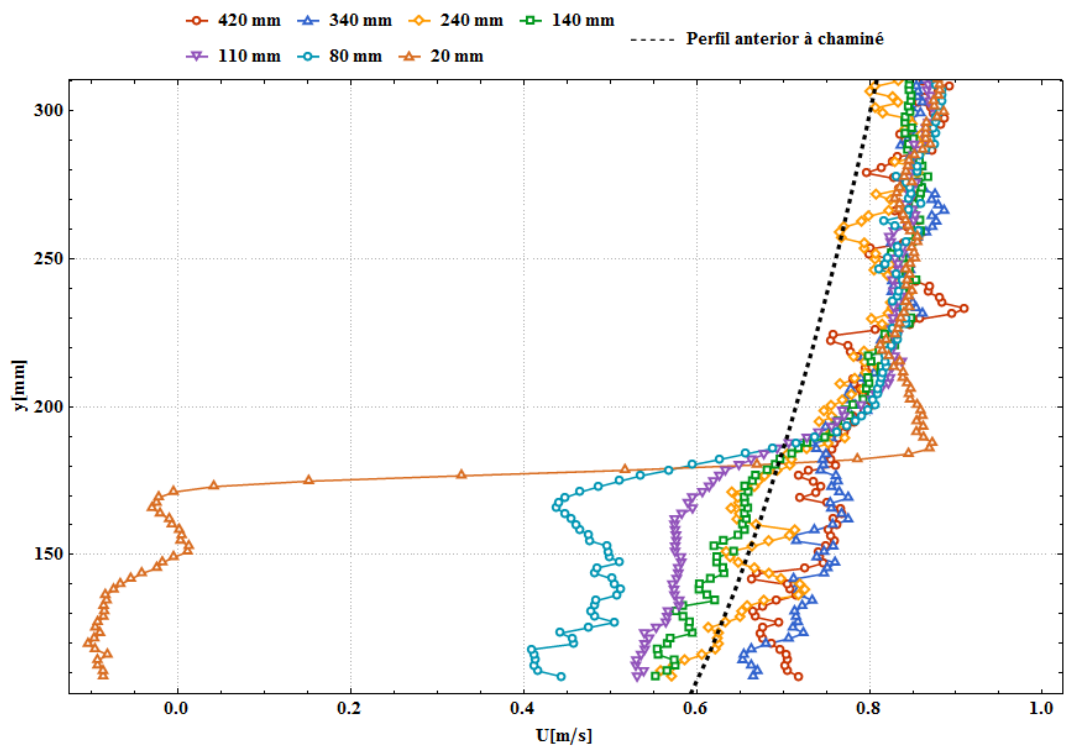

Figura 86. Perfil de velocidade para diversas posições em $x$ para $U_{\max }=0,92$ $\mathrm{m} / \mathrm{s}, W_{0}=1,08 \mathrm{~m} / \mathrm{s}, T_{t}=25^{\circ} \mathrm{C}$ e $T_{w}=35^{\circ} \mathrm{C}, \Delta T=10^{\circ} \mathrm{C}$

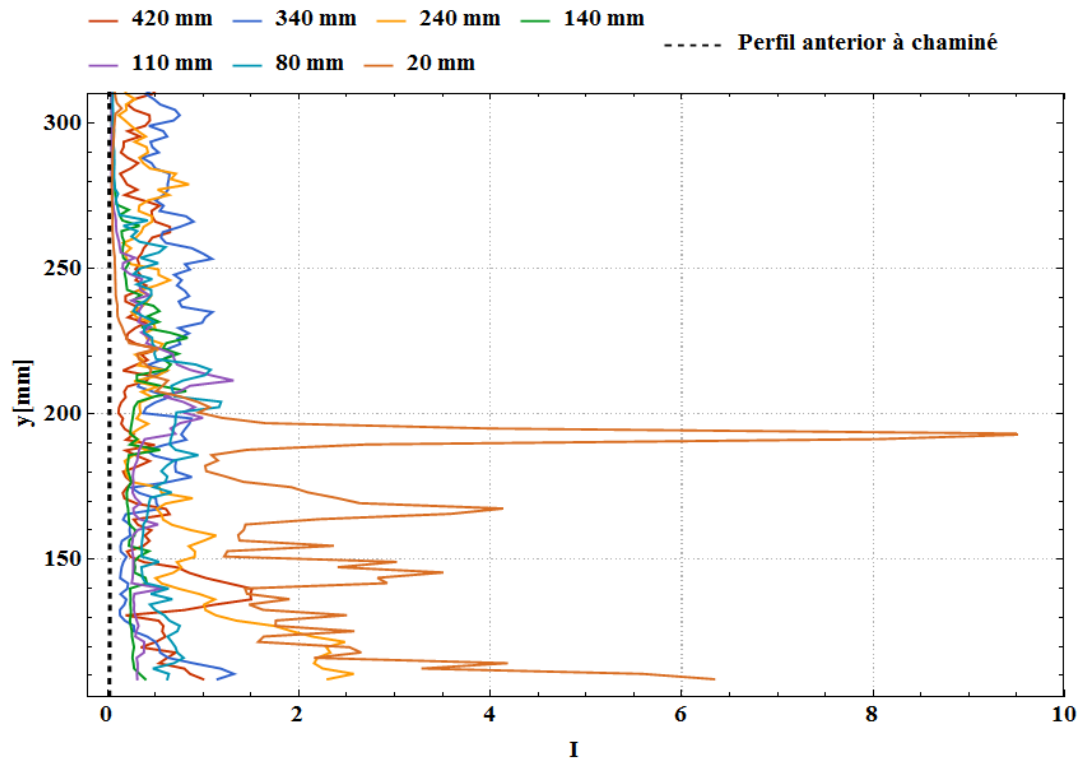

Figura 87. Perfil de flutuações de $U$ para diversas posições em $x$ para $U_{\max }=$ $0,92 \mathrm{~m} / \mathrm{s}, W_{0}=1,08 \mathrm{~m} / \mathrm{s}, T_{t}=25^{\circ} \mathrm{C}$ e $T_{w}=35^{\circ} \mathrm{C}, \Delta T=10^{\circ} \mathrm{C}$ 


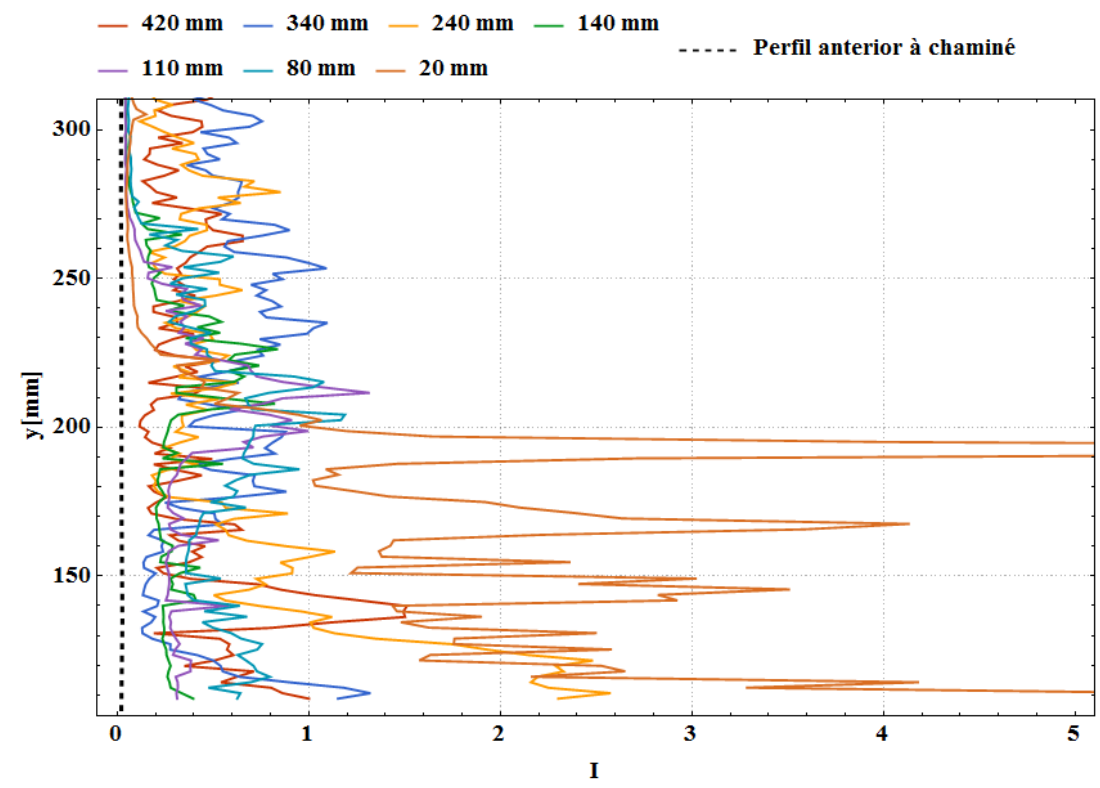

Figura 88. Ampliação do perfil de flutuações de $U$ para diversas posições em $x$ para $U_{\max }=0,92 \mathrm{~m} / \mathrm{s}, W_{0}=1,08 \mathrm{~m} / \mathrm{s}, T_{t}=25^{\circ} \mathrm{C}$ e $T_{w}=35^{\circ} \mathrm{C}, \Delta T=10^{\circ} \mathrm{C}$

Como é possível ver na Figura 87, o valor de máxima flutuação do gráfico é de aproximadamente $950 \%$. Como o perfil de flutuação próxima à chaminé ( $x=20$ $\mathrm{mm}$ ) apresenta valores muito altos, devido às baixas velocidades média, a visualização do gráfico fica comprometida pela extensão do eixo $x$. Por esse motivo, nos próximos gráficos, que apresentam valores de flutuações extremamente altos na região próxima à chaminé, foram expostos somente a ampliação da região em que os perfis estão mais concentrados. No texto é indicado qual o valor da máxima flutuação para cada caso.

A Figura 89 e a Figura 90 mostram, respectivamente, os perfis de velocidade e flutuação para o caso 2 . 


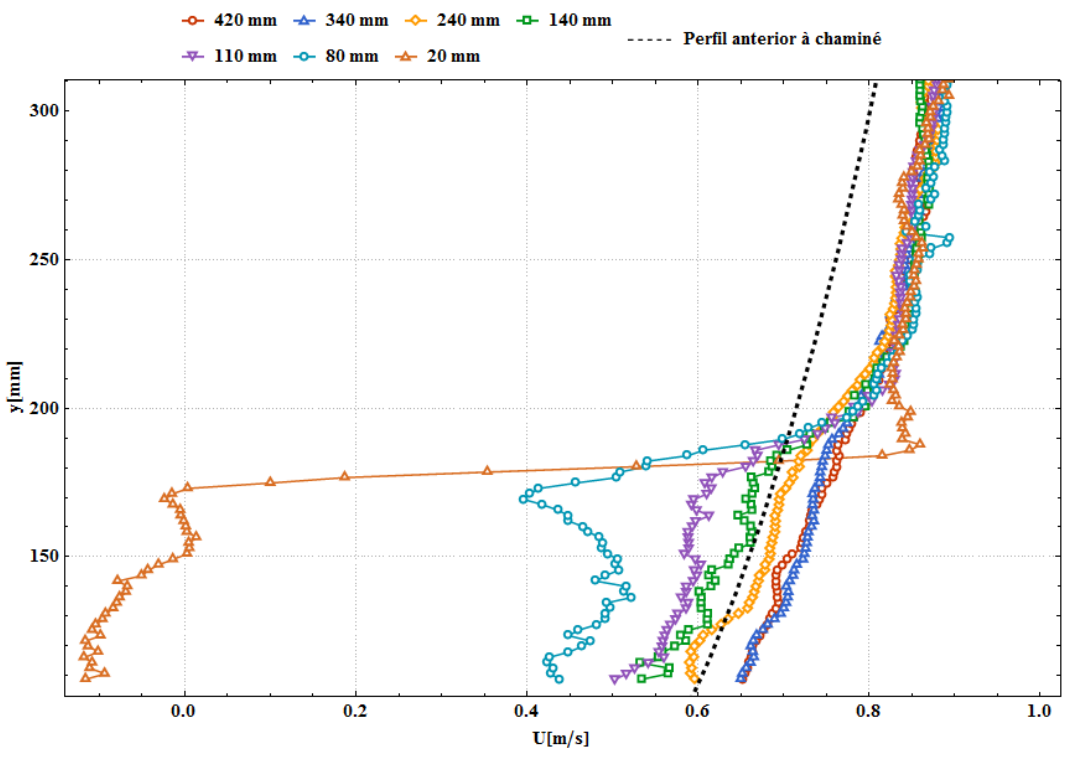

Figura 89. Perfil de velocidade para diversas posições em $x$ para $U_{\max }=0,92$ $\mathrm{m} / \mathrm{s}, W_{0}=1,31 \mathrm{~m} / \mathrm{s}, T_{t}=24^{\circ} \mathrm{C}$ e $T_{w}=44^{\circ} \mathrm{C}, \Delta T=20^{\circ} \mathrm{C}$

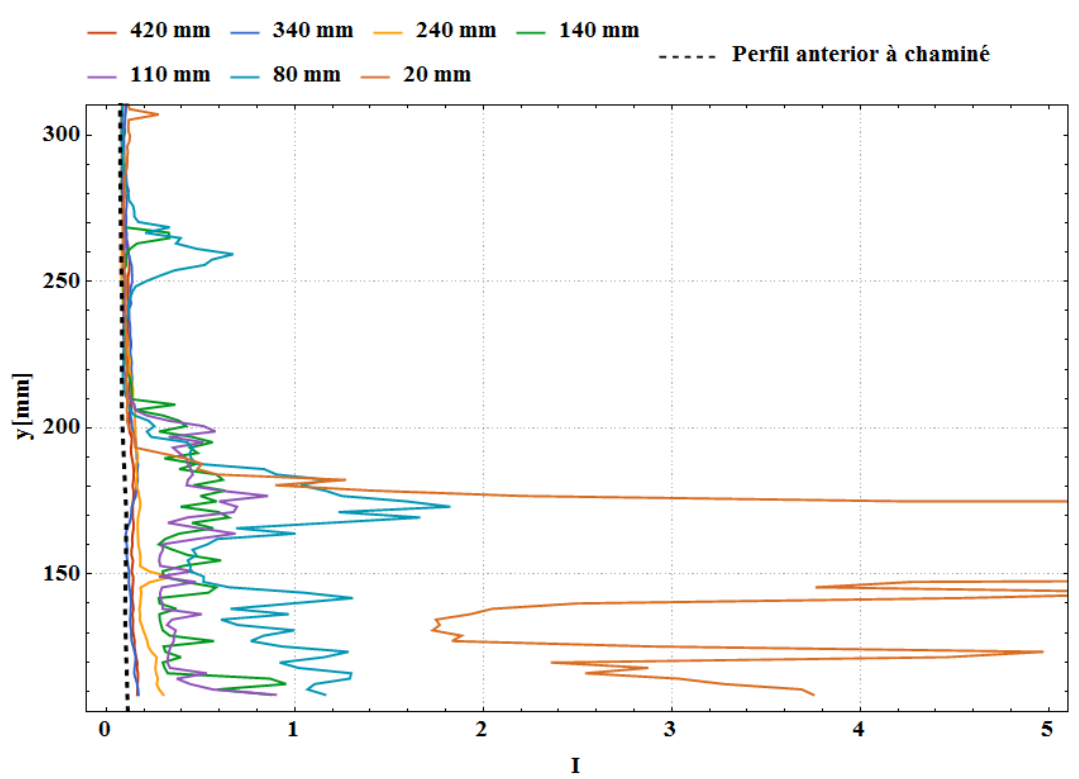

Figura 90. Ampliação do perfil de flutuação de $U$ para diversas posições em $x$ para $U_{\max }=0,92 \mathrm{~m} / \mathrm{s}, W_{0}=1,31 \mathrm{~m} / \mathrm{s}, T_{t}=24^{\circ} \mathrm{C}$ e $T_{w}=44^{\circ} \mathrm{C}, \Delta T=20^{\circ} \mathrm{C}$

O valor de máxima flutuação do gráfico da Figura 90 é de $870 \%$. A Figura 91 e a Figura 92 mostram, respectivamente, os perfis de velocidade e flutuação para o caso 9. 


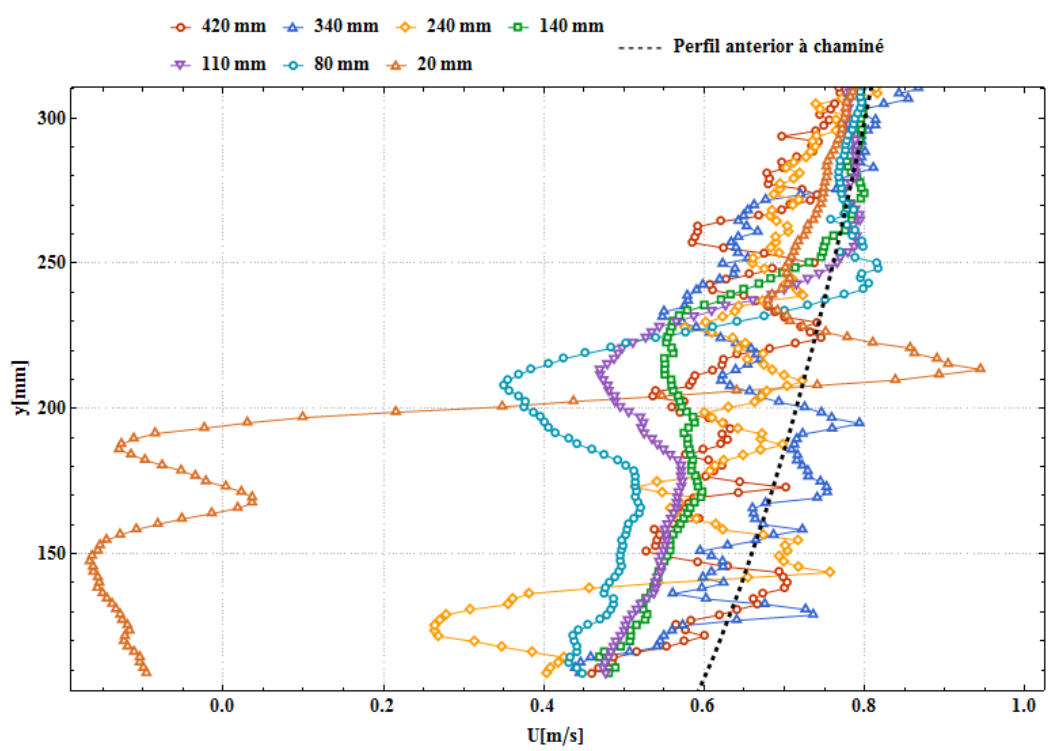

Figura 91. Perfil de velocidade para diversas posições em $x$ para $U_{\max }=0,92$ $\mathrm{m} / \mathrm{s}, W_{0}=1,77 \mathrm{~m} / \mathrm{s}, T_{t}=25^{\circ} \mathrm{C}$ e $T_{w}=35^{\circ} \mathrm{C}, \Delta T=10^{\circ} \mathrm{C}$

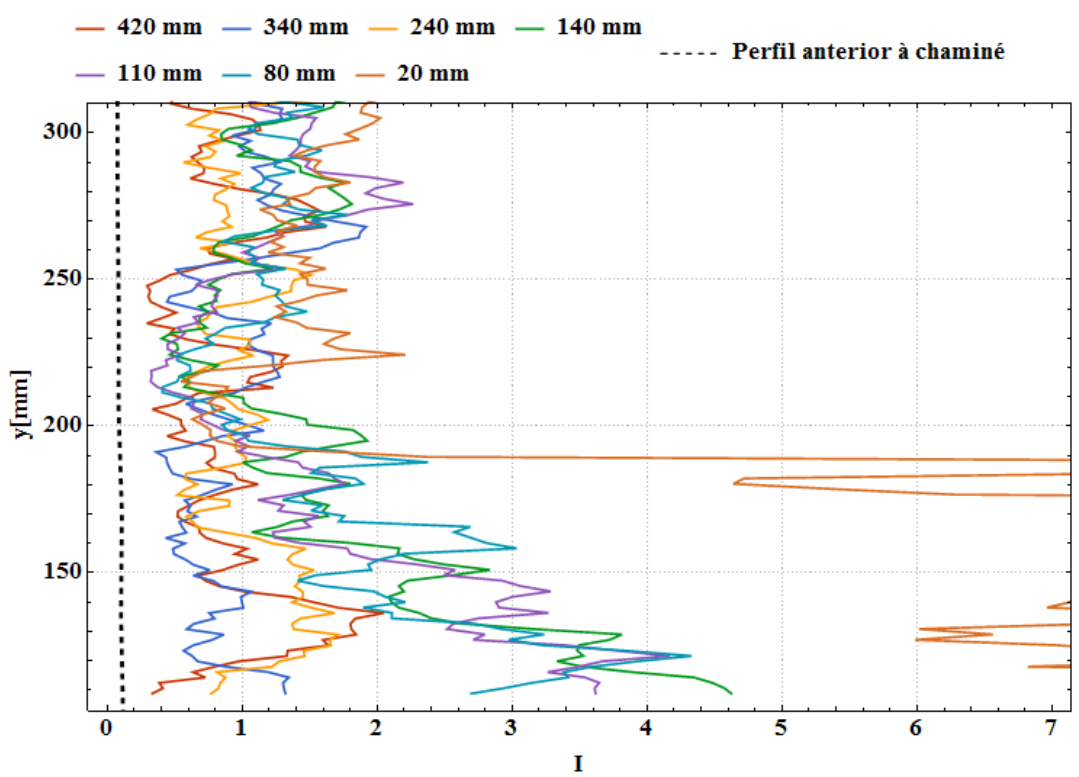

Figura 92. Perfil de flutuação de $U$ para diversas posições em $x$ para $U_{\max }=$ $0,92 \mathrm{~m} / \mathrm{s}, W_{0}=1,77 \mathrm{~m} / \mathrm{s}, T_{t}=25^{\circ} \mathrm{C}$ e $T_{w}=35^{\circ} \mathrm{C}, \Delta T=10^{\circ} \mathrm{C}$

O valor de máxima flutuação do gráfico da Figura 92 é de $800 \%$. A Figura 93 e a Figura 94 mostram, respectivamente, os perfis de velocidade e flutuação para o caso 10. 


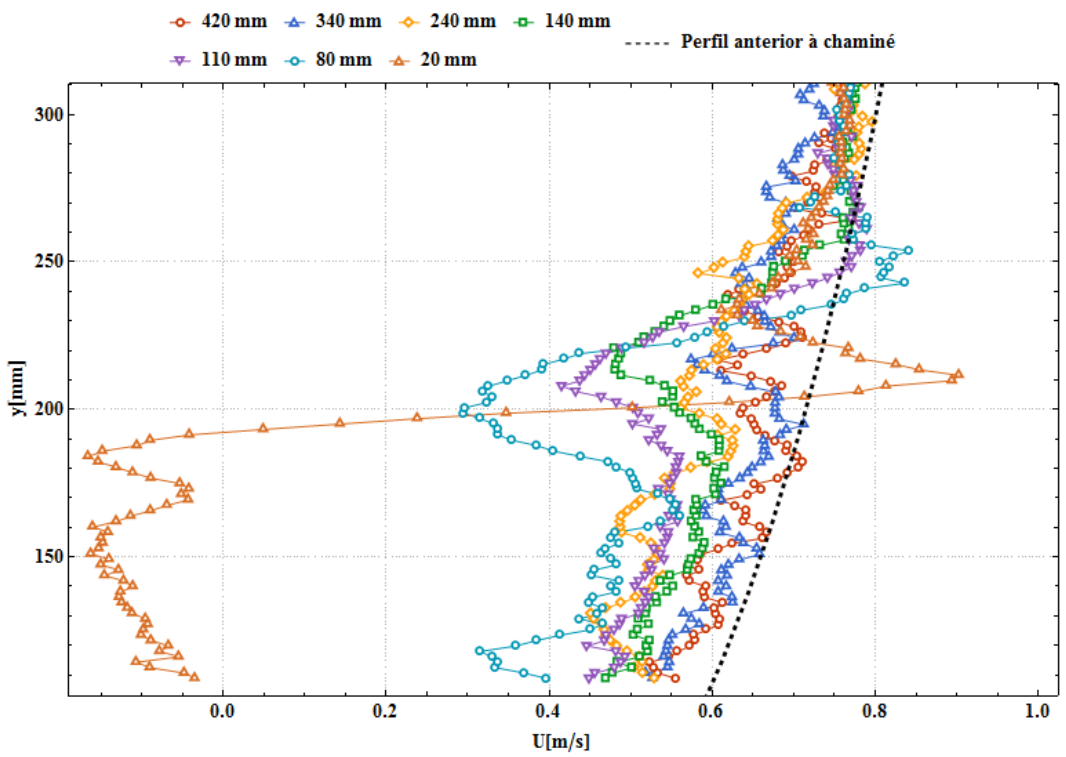

Figura 93. Perfil de velocidade para diversas posições em $x$ para $U_{\max }=0,92$ $\mathrm{m} / \mathrm{s}, W_{0}=2,11 \mathrm{~m} / \mathrm{s}, T_{t}=24^{\circ} \mathrm{C}$ e $T_{w}=44^{\circ} \mathrm{C}, \Delta T=20^{\circ} \mathrm{C}$

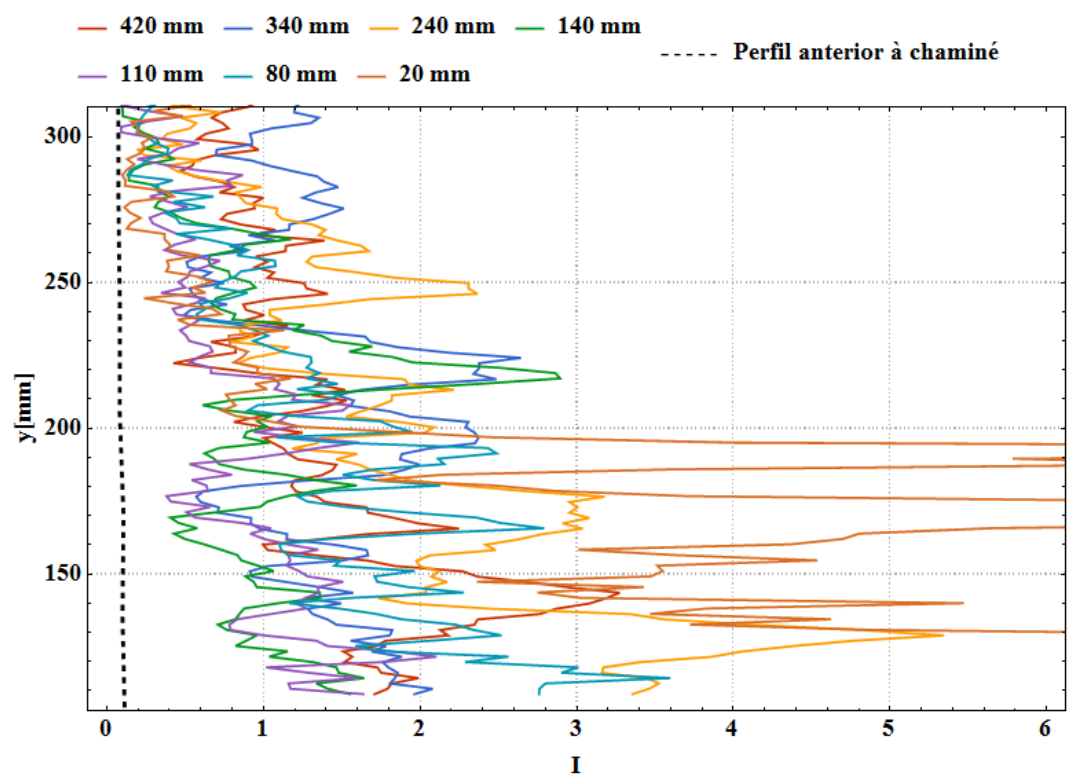

Figura 94. Perfil de flutuação de $U$ para diversas posições em $x$ para $U_{\max }=$ $0,92 \mathrm{~m} / \mathrm{s}, W_{0}=2,11 \mathrm{~m} / \mathrm{s}, T_{t}=24^{\circ} \mathrm{C}$ e $T_{w}=44^{\circ} \mathrm{C}, \Delta T=20^{\circ} \mathrm{C}$

O valor de máxima flutuação do gráfico da Figura 94 é de $740 \%$. As Figura 95 e Figura 96 mostram, respectivamente, os perfis de velocidade e flutuação para o caso 25 . 


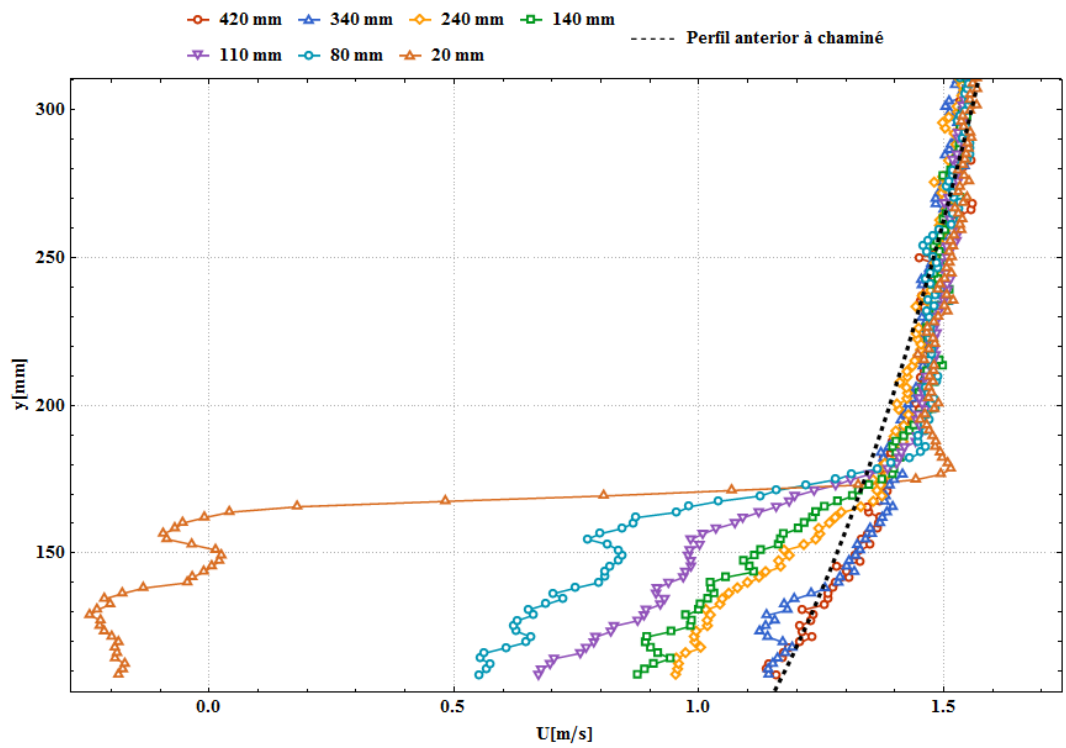

Figura 95. Perfil de velocidade para diversas posições em $x$ para $U_{\max }=1,79$ $\mathrm{m} / \mathrm{s}, W_{0}=0,80 \mathrm{~m} / \mathrm{s}, T_{t}=26^{\circ} \mathrm{C}$ e $T_{w}=36^{\circ} \mathrm{C}, \Delta T=10^{\circ} \mathrm{C}$

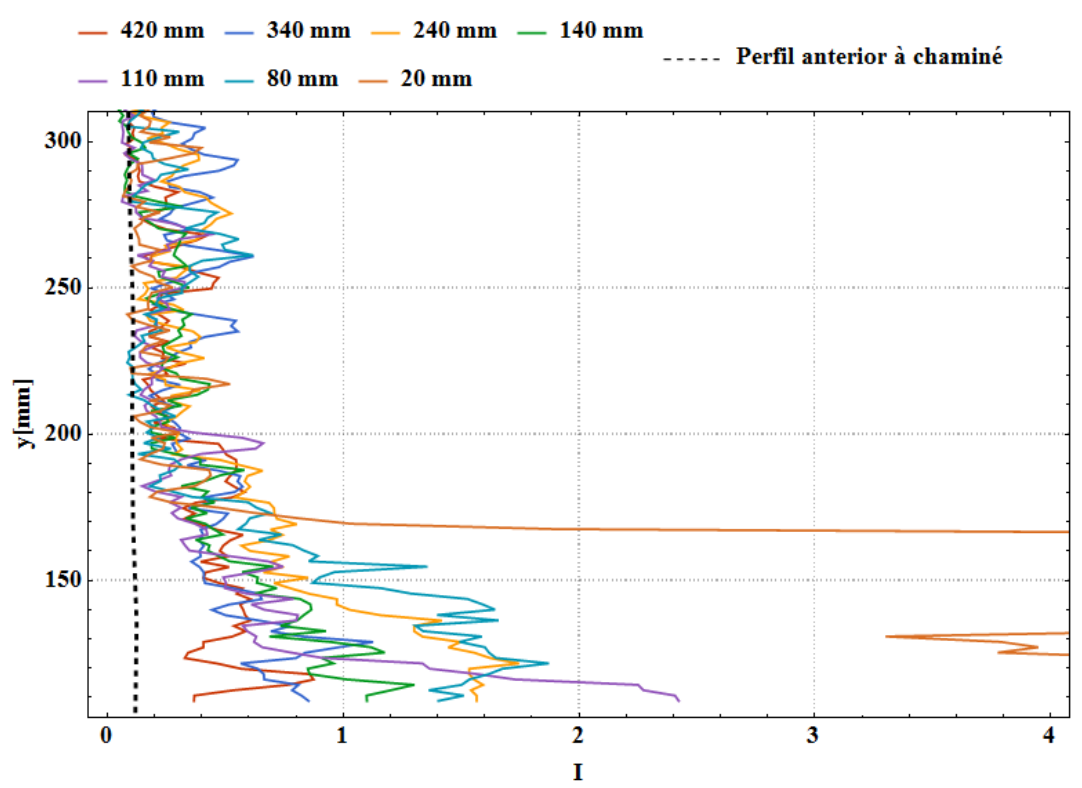

Figura 96. Ampliação do perfil de flutuação de $U$ para diversas posições em $x$ para $U_{\max }=1,79 \mathrm{~m} / \mathrm{s}, W_{0}=0,80 \mathrm{~m} / \mathrm{s}, T_{t}=26^{\circ} \mathrm{C}$ e $T_{w}=36^{\circ} \mathrm{C}, \Delta T=10^{\circ} \mathrm{C}$

O valor de máxima flutuação do gráfico da Figura 96 é de 520\%. A Figura 97 e a Figura 98 mostram, respectivamente, os perfis de velocidade e flutuação para o caso 26 . 


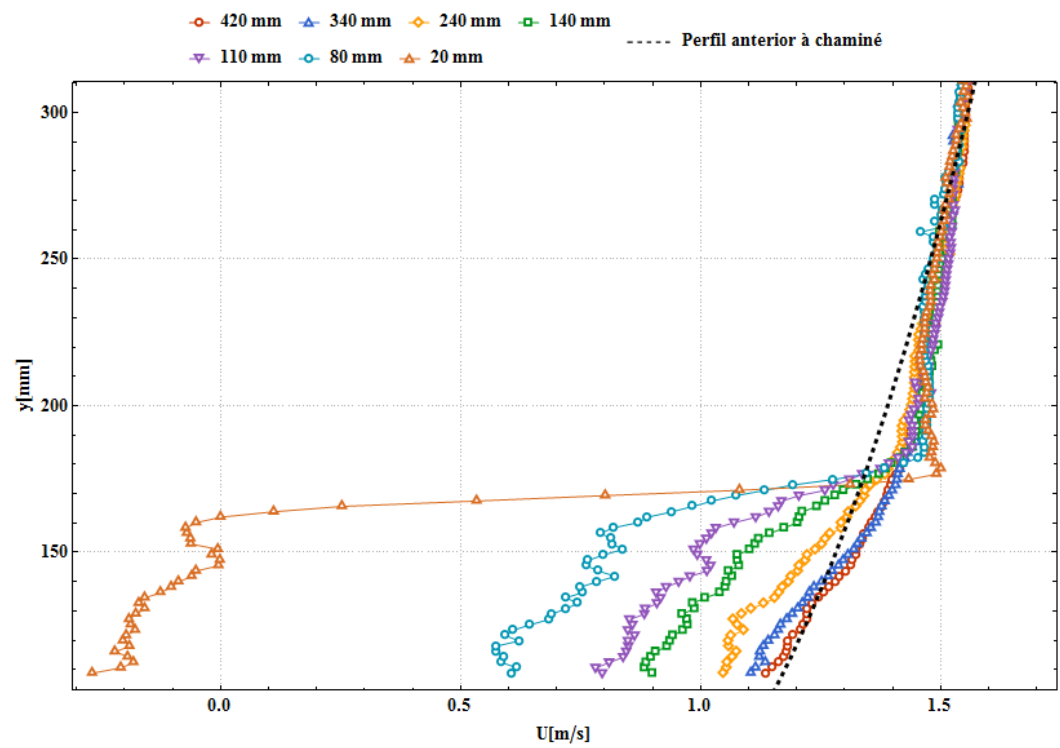

Figura 97. Perfil de velocidade para diversas posições em $x$ para $U_{\max }=1,79$ $\mathrm{m} / \mathrm{s}, W_{0}=0,92 \mathrm{~m} / \mathrm{s}, T_{t}=25^{\circ} \mathrm{C}$ e $T_{w}=45^{\circ} \mathrm{C}, \Delta T=20^{\circ} \mathrm{C}$

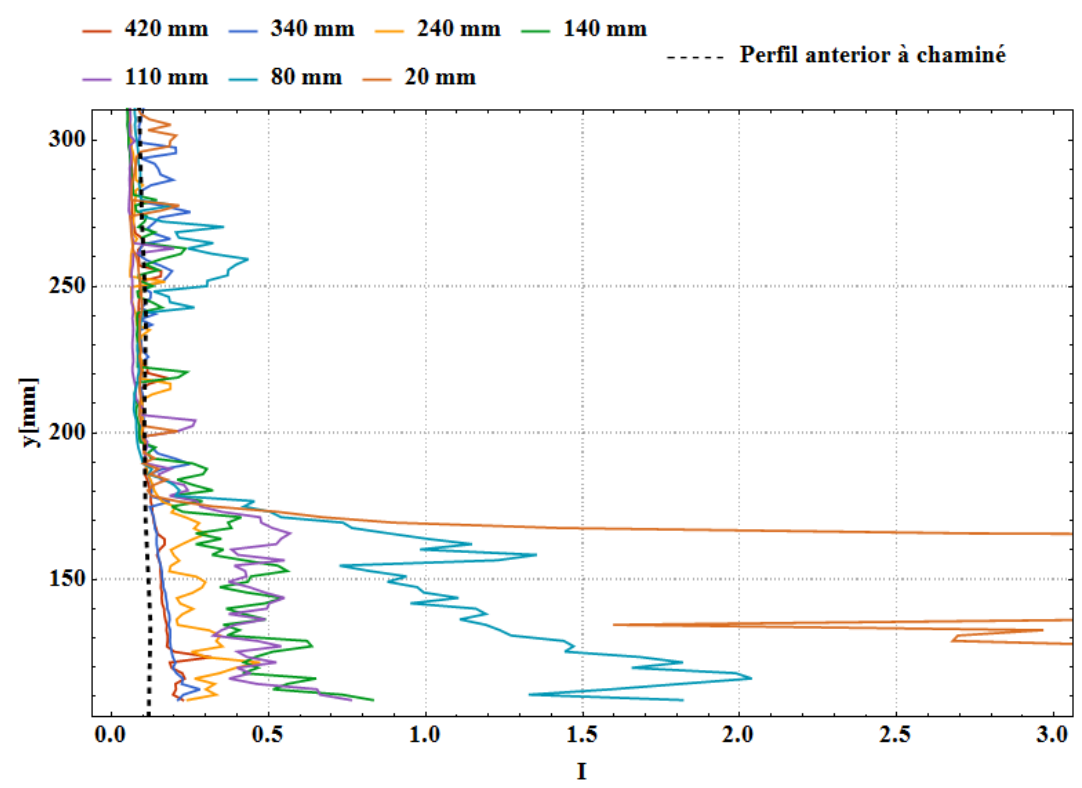

Figura 98. Ampliação do perfil de flutuação de $U$ para diversas posições em $x$ para $U_{\max }=1,79 \mathrm{~m} / \mathrm{s}, W_{0}=0,92 \mathrm{~m} / \mathrm{s}, T_{t}=25^{\circ} \mathrm{C}$ e $T_{w}=45^{\circ} \mathrm{C}, \Delta T=20^{\circ} \mathrm{C}$

O valor de máxima flutuação do gráfico da Figura 98 é de aproximadamente 500\%. A Figura 99 e a Figura 100 mostram, respectivamente, os perfis de velocidade e flutuação para o caso 33. 


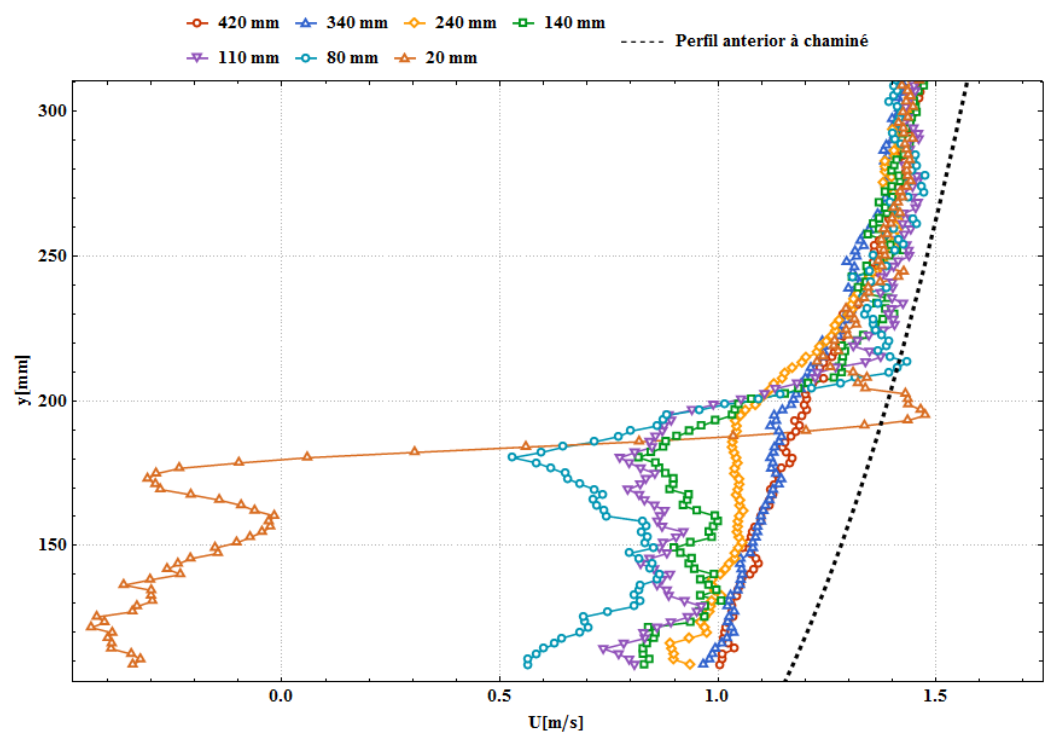

Figura 99. Perfil de velocidade para diversas posições em $x$ para $U_{\max }=1,79$ $\mathrm{m} / \mathrm{s}, W_{0}=1,64 \mathrm{~m} / \mathrm{s}, T_{t}=25^{\circ} \mathrm{C}$ e $T_{w}=35^{\circ} \mathrm{C}, \Delta T=10^{\circ} \mathrm{C}$

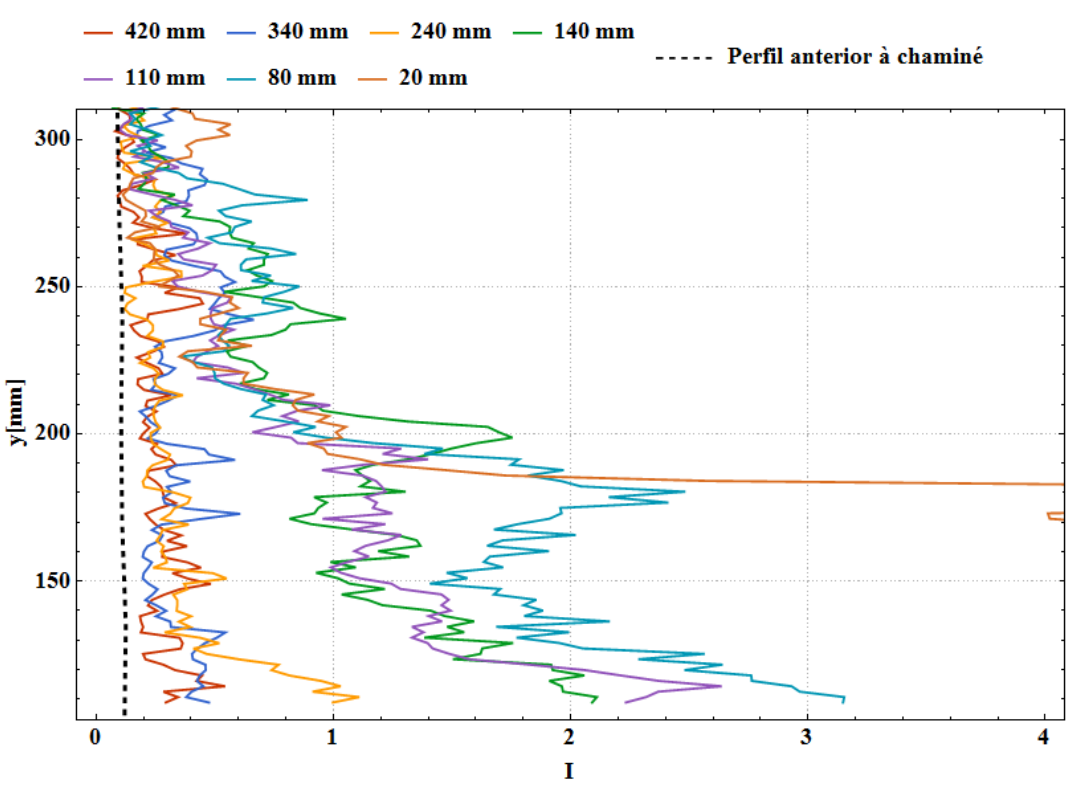

Figura 100. Ampliação do perfil de flutuação de $U$ para diversas posições em $x$ para $U_{\max }=1,79 \mathrm{~m} / \mathrm{s}, W_{0}=1,64 \mathrm{~m} / \mathrm{s}, T_{t}=25^{\circ} \mathrm{C}$ e $T_{w}=35^{\circ} \mathrm{C}, \Delta T=10^{\circ} \mathrm{C}$

O valor de máxima flutuação do gráfico da Figura 100 é de $480 \%$. A Figura 101 e a Figura 102 mostram, respectivamente, os perfis de velocidade e flutuação para o caso 34. 


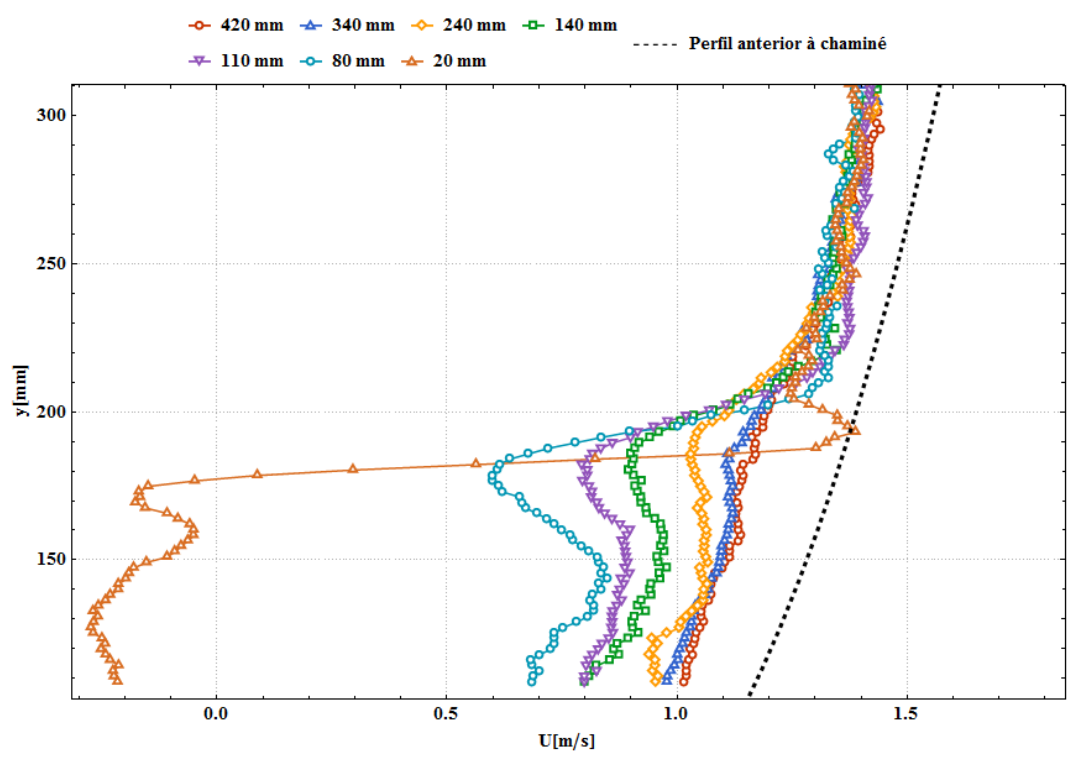

Figura 101. Perfil de velocidade para diversas posições em $x$ para $U_{\max }=$ $1,79 \mathrm{~m} / \mathrm{s}, W_{0}=2,14 \mathrm{~m} / \mathrm{s}, T_{t}=25^{\circ} \mathrm{C}$ e $T_{w}=45^{\circ} \mathrm{C}, \Delta T=20^{\circ} \mathrm{C}$

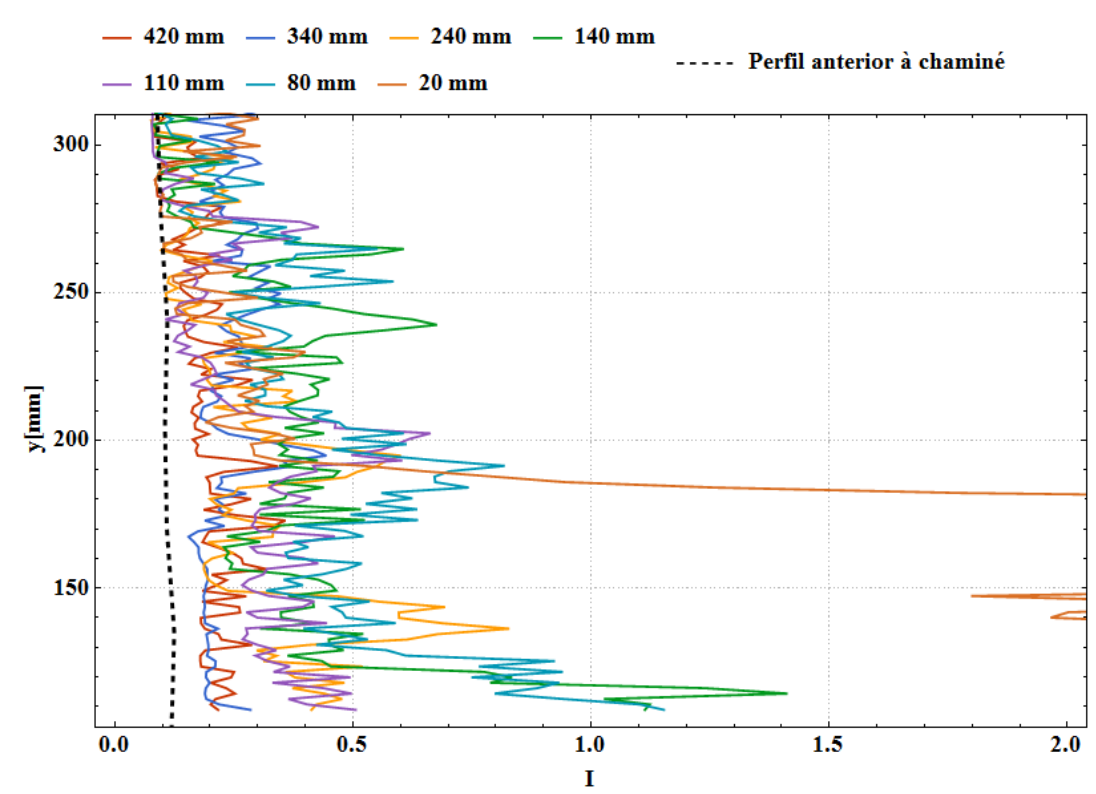

Figura 102. Perfil de flutuação de $U$ para diversas posições em $x$ para $U_{\max }=$

$$
1,79 \mathrm{~m} / \mathrm{s}, W_{0}=2,14 \mathrm{~m} / \mathrm{s}, T_{t}=25^{\circ} \mathrm{C} \text { e } T_{w}=45^{\circ} \mathrm{C}, \Delta T=20^{\circ} \mathrm{C}
$$

O valor de máxima flutuação do gráfico da Figura 102 é de 410\%. Com os gráficos dos perfis velocidade apresentados, é possível notar que o ponto mais próximo à chaminé $(x=20 \mathrm{~mm})$ apresenta os menores valores de velocidade (havendo valores, negativos, inclusive), devido à região de esteira da chaminé. Essa região apresenta esse déficit de velocidade pois possivelmente, o escoamento foi 
direcionado lateralmente, gerando uma deficiência de quantidade de movimento. À medida que se afasta da chaminé, esse efeito torna-se menos intenso e o perfil tende a ficar constante para todas as posições.

É possível observar também a delimitação da interface inferior da pluma com o escoamento principal. Analisando os perfis de velocidade para os casos 9, 10, 33 e 34, que possuem as maiores velocidades de emissão, percebe-se que há um ponto próximo ao centro do perfil em que há uma redução abrupta de velocidade. Esses pontos, que estão coerentes com a delimitação da pluma, tem uma tendência de subir à medida que se afastam da chaminé, indicando que a pluma possui inclinação positiva. Já para os casos 1, 2, 25 e 26, em que as velocidades de emissão são menores, há uma suave tendência de que esses pontos decaiam, indicando que a pluma está se inclinando para baixo. Para essas velocidades mais baixas existe também uma maior interferência do obstáculo no escoamento. Analisando o perfil mais afastado da chaminé, é possível visualizar que este perfil tende a ter uma forma muito parecida com o perfil obtido na região anterior à chaminé.

Já os gráficos que demostram os perfis de flutuação, analisados de acordo com a equação (3-2), percebe-se que na região inferior, dentro da CLA, os valores são maiores em relação à região superior. O perfil mais próximo à região da chaminé apresenta valores de flutuação de 410 a 950\%, na região de recirculação. Já para o próximo perfil analisado $(x=80 \mathrm{~mm})$, os valores decaem abruptamente de 420 para $80 \%$. O perfil de flutuação na região mais afastada se assemelha ao perfil encontrado na região anterior à chaminé para alguns casos, porém, com uma intensidade maior. Pode-se perceber também que a flutuação é maior na parte inferior, que compreende a região de recirculação e a região da pluma.

O gráfico da Figura 100 pode ser comparado com um experimento nas mesmas condições, porém, sem a reprodução da CLA (caso 35), mostrado na Figura 103. Percebe-se que o nível de flutuação diminuiu aproximadamente $38 \%$, devido à ausência de spires na entrada da seção de testes. 


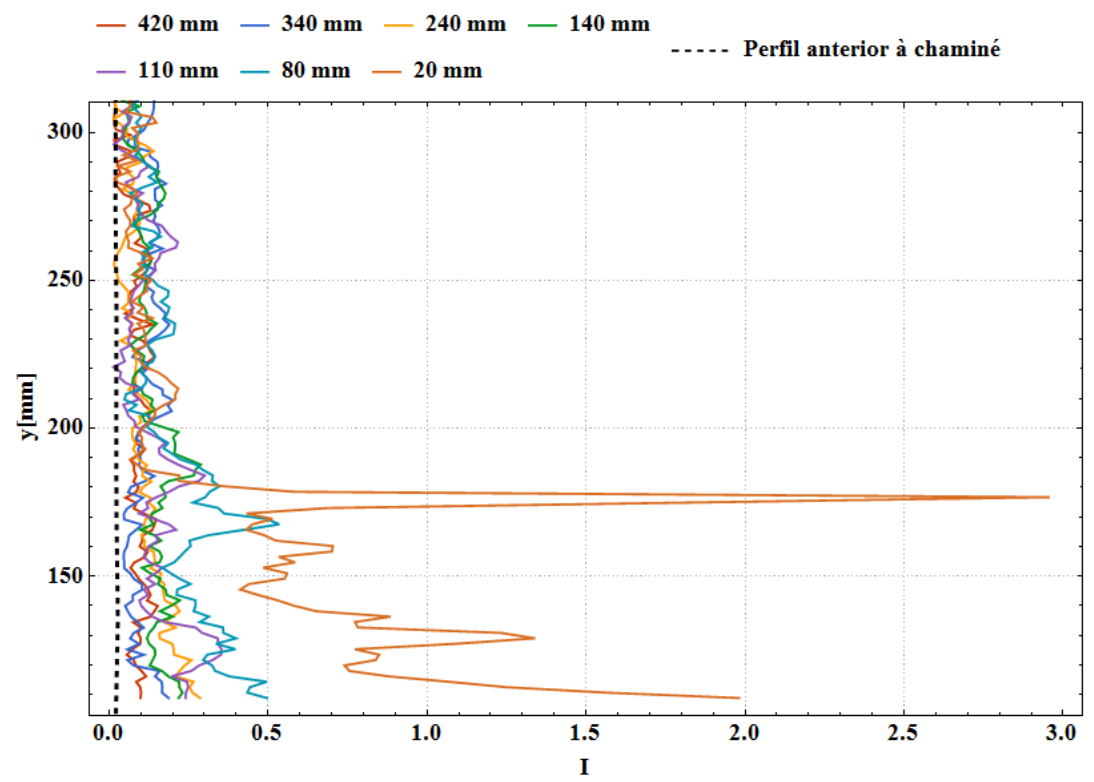

Figura 103. Perfil de flutuação de $U$ para diversas posições em $x$ para $U_{\max }=$

$$
1,85 \mathrm{~m} / \mathrm{s}, W_{0}=1,91 \mathrm{~m} / \mathrm{s}, T_{t}=25^{\circ} \mathrm{C} \text { e } T_{w}=35^{\circ} \mathrm{C}, \Delta T=10^{\circ} \mathrm{C}
$$

Uma outra análise dos dados de flutuações foi realizada. Agora, o perfil foi feito no sentido horizontal, a fim de se analisar a região fora e dentro da pluma. Em todos os experimentos, os resultados seguem uma mesma tendência. Os próximos gráficos foram plotados para condição de maior velocidade do escoamento principal, com menor e maior velocidades de emissão, correspondendo aos casos 25 e 33 , respectivamente.

A Figura 104 e Figura 105 mostram o perfil de flutuação para três posições no eixo $y$, que foram escolhidas de acordo com a presença da pluma na janela de visualização. 


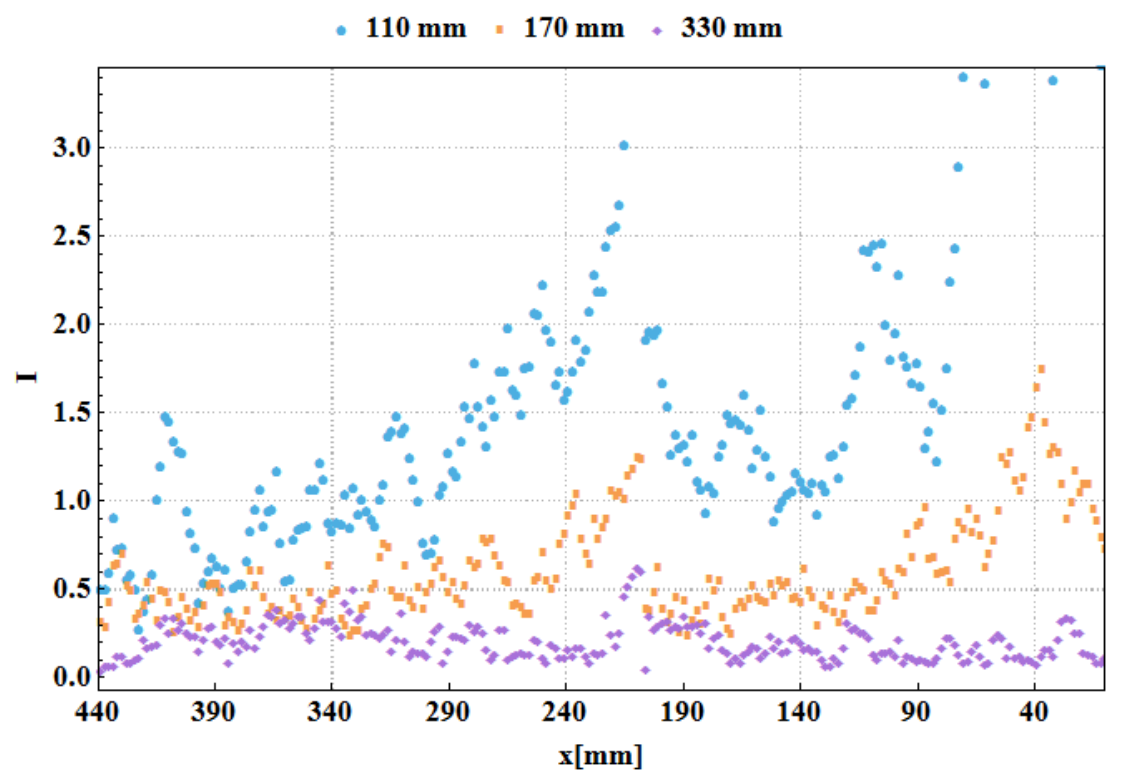

Figura 104. Perfil de flutuação de $U$ para diversas posições em $y$ para $U_{\max }=$ $1,79 \mathrm{~m} / \mathrm{s}, W_{0}=0,80 \mathrm{~m} / \mathrm{s}, T_{t}=26^{\circ} \mathrm{C}$ e $T_{w}=36^{\circ} \mathrm{C}, \Delta T=10^{\circ} \mathrm{C}$

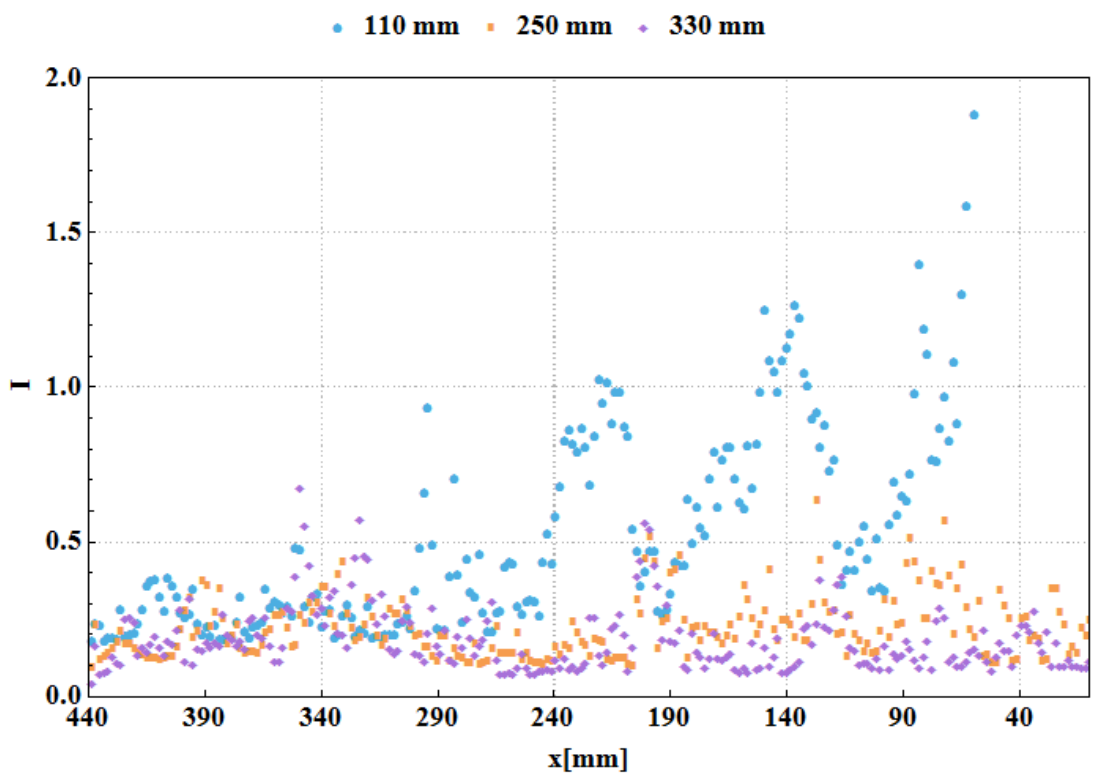

Figura 105. Perfil de flutuação de $U$ para diversas posições em $y$ para $U_{\max }=$ $1,79 \mathrm{~m} / \mathrm{s}, W_{0}=1,64 \mathrm{~m} / \mathrm{s}, T_{t}=25^{\circ} \mathrm{C}$ e $T_{w}=35^{\circ} \mathrm{C}, \Delta T=10^{\circ} \mathrm{C}$

Com os gráficos plotados, é possível apontar a região de maior flutuação em $y=110 \mathrm{~mm}$. Em ambos os gráficos, devido à presença da região da esteira da chaminé, a flutuação tem valores mais elevados nos primeiros $200 \mathrm{~mm}$ e, à medida que se afasta da chaminé, esse valor decai. No primeiro gráfico, na região da pluma, $y=170 \mathrm{~mm}$, o nível de flutuação varia de $170 \%$ na região mais próxima da esteira 
para $75 \%$, na região mais afastada da chaminé. Já no segundo gráfico, em $y=250$ mm, na região da pluma, o nível de flutuação tem máximo em 190\% na região mais próxima e $40 \%$ na região mais afastada. À altura $y=330 \mathrm{~mm}$ fica em $25 \% \mathrm{em}$ ambos os gráficos.

\section{5.}

\section{Análise de concentração da pluma}

Foram analisados os perfis de concentração da pluma considerando diferentes velocidades do escoamento principal do túnel de vento e diferentes condições de emissão ao longo de diversas posições a sotavento. Para essa análise foi criado um procedimento no software Wolfram Mathematica que determina os perfis de concentração através das imagens médias obtidas através do software do PIV, analisando a intensidade luminosa das imagens média. A concentração relativa em cada perfil foi calculada dividindo a concentração $C$ num dado ponto, pelo ponto de concentração máxima $C_{0}$, encontrada na saída da chaminé.

O perfil de concentração vertical da pluma $\left(\sigma_{z}\right)$ é definido pelos parâmetros de média, que também define a altura da pluma e pelo desvio padrão $(\sigma)$, que determina o quanto a pluma dispersa. Nas próximas figuras são mostrados os gráficos de intensidade luminosa (dados brutos) e o ajuste de uma curva gaussiana. O eixo vertical representa a intensidade luminosa (para dados brutos) ou concentração relativa (para os dados ajustados). A curva foi ajustada de acordo com a equação a seguir:

$$
I_{0}+k \frac{e^{-\frac{(y-\mu y)^{2}}{2 \sigma_{z}^{2}}}}{\sqrt{2 \pi} \sigma_{z}}
$$

Onde $I_{0}$ é a intensidade luminosa do background e $k$ é uma constante para ajustar o pico da curva, visto que a curva normal tem integral unitária, $\mu$ y é a altura da pluma e $\sigma_{y}$ é a dispersão da pluma. A Figura 106, Figura 107, Figura 108 e Figura 109 mostram os resultados para os casos 1, 2, 9 e 10 respectivamente. 
(a)

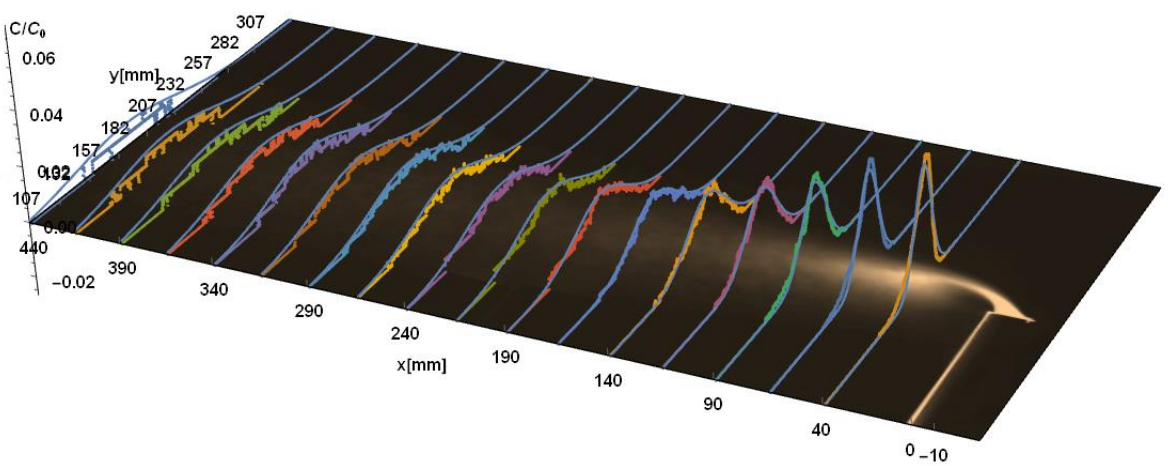

(b)

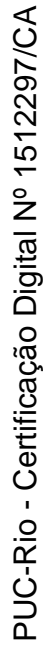

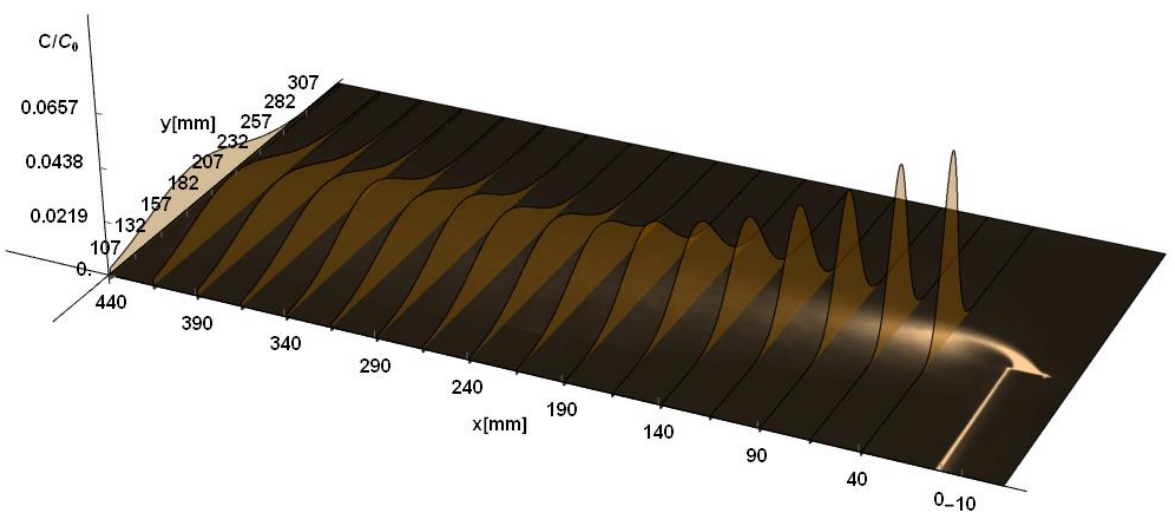

Figura 106. Perfil de concentração na condição $U_{\max }=0,92 \mathrm{~m} / \mathrm{s}, W_{0}=1,08 \mathrm{~m} / \mathrm{s}, T_{t}$ $=25^{\circ} \mathrm{C}$ e $T_{w}=35^{\circ} \mathrm{C}, \Delta T=10^{\circ} \mathrm{C}$

(a)

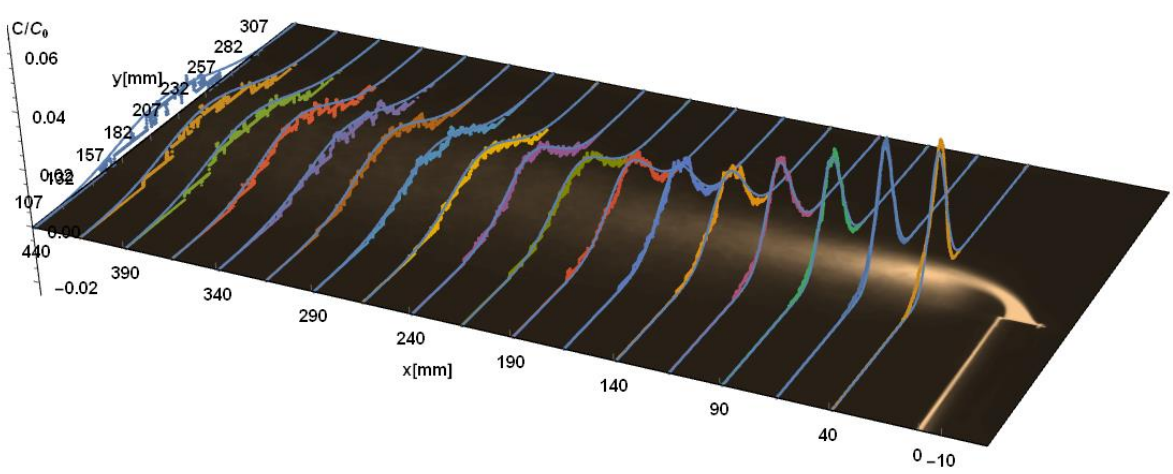


(b)

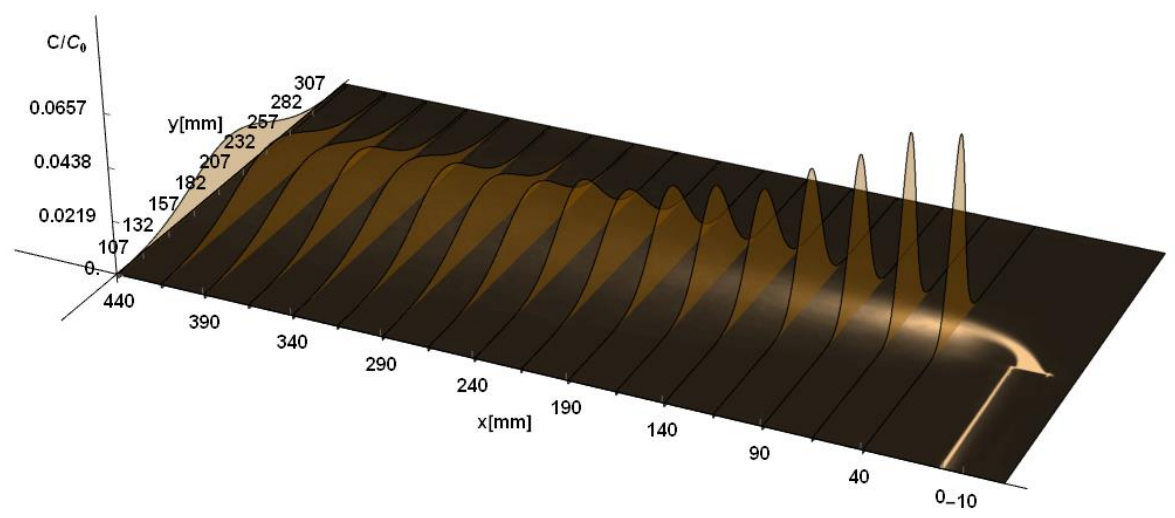

Figura 107. Perfil de concentração na condição $U_{\max }=0,92 \mathrm{~m} / \mathrm{s}, W_{0}=1,31 \mathrm{~m} / \mathrm{s}, T_{t}$

$$
=24^{\circ} \mathrm{C} \text { e } T_{w}=44^{\circ} \mathrm{C}, \Delta T=20^{\circ} \mathrm{C}
$$

(a)

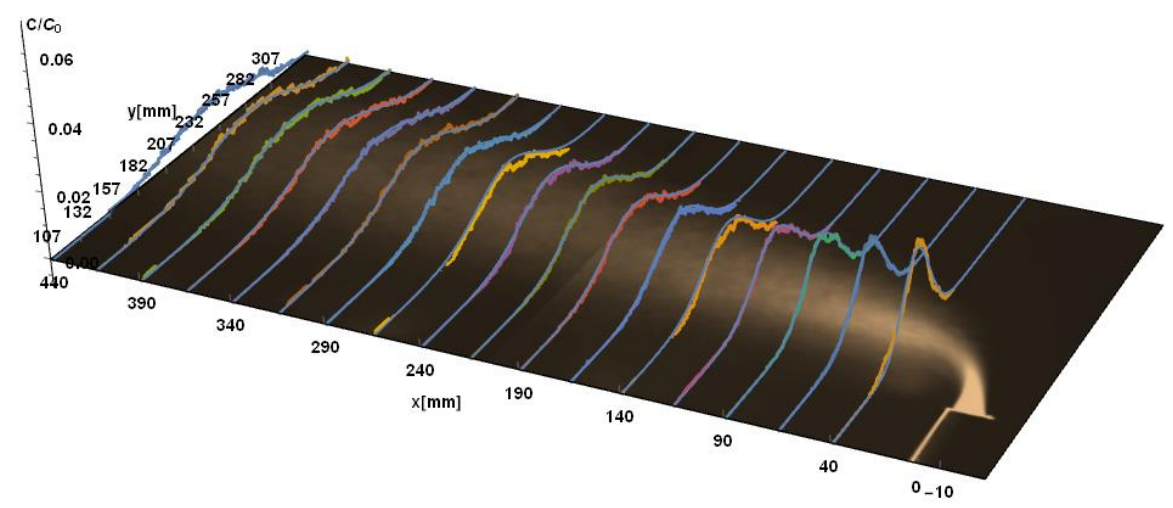

(b)

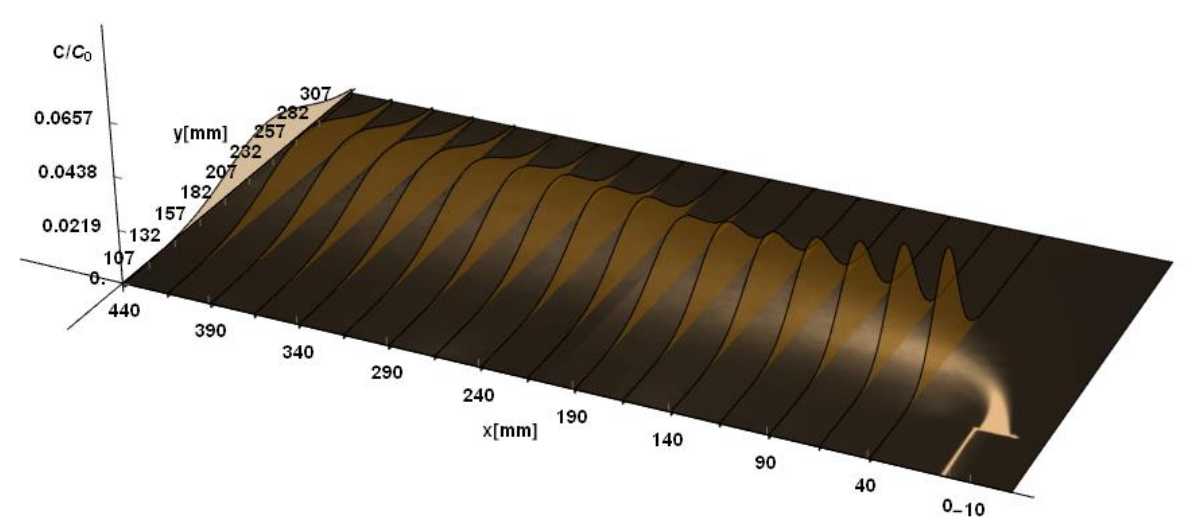

Figura 108. Perfil de concentração na condição $U_{\max }=0,92 \mathrm{~m} / \mathrm{s}, W_{0}=1,77 \mathrm{~m} / \mathrm{s}, T_{t}$

$$
=25^{\circ} \mathrm{C} \text { e } T_{w}=35^{\circ} \mathrm{C}, \Delta T=10^{\circ} \mathrm{C}
$$


(a)

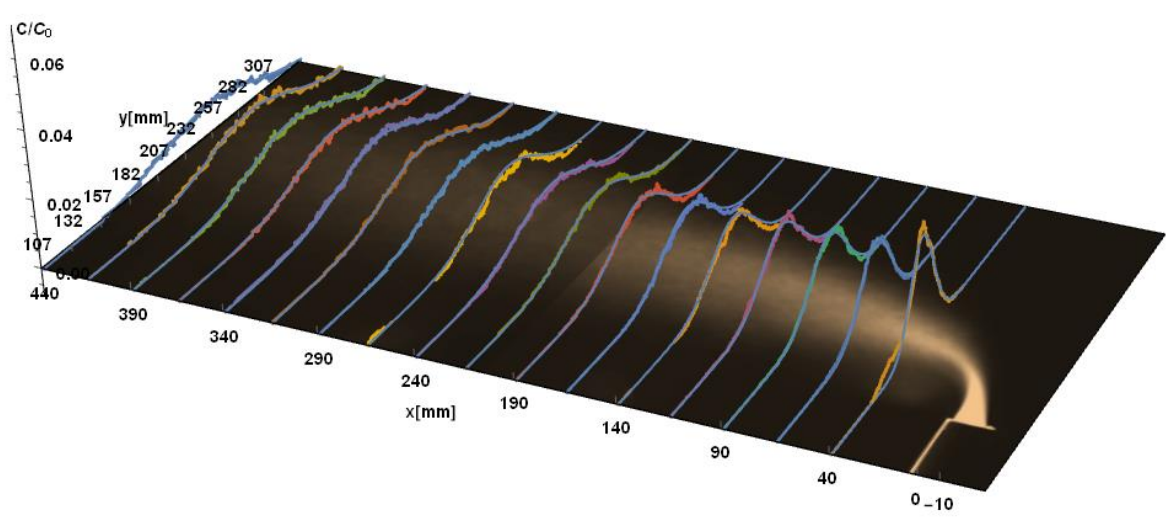

(b)

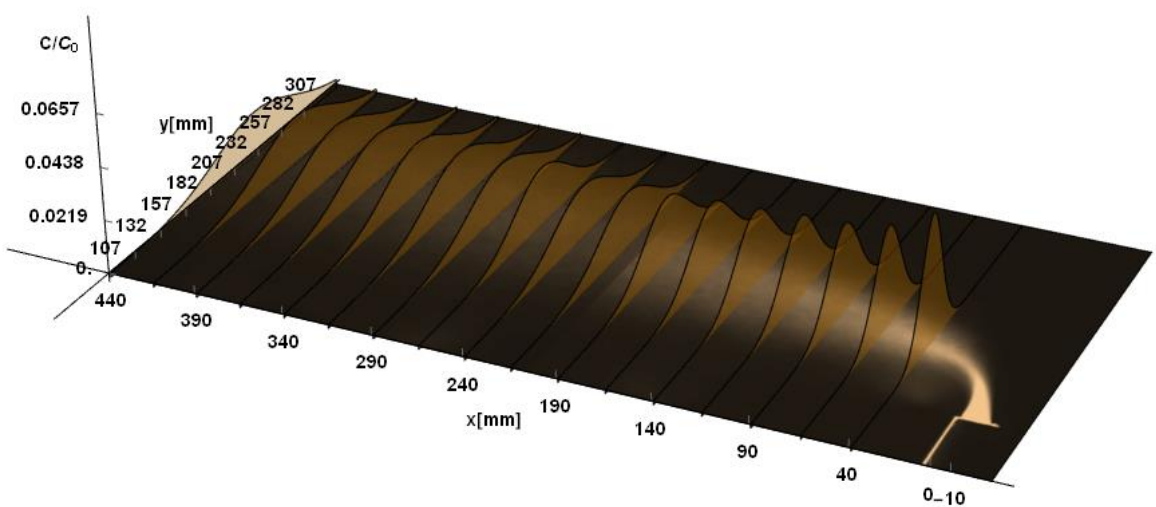

Figura 109. Perfil de concentração na condição $U_{\max }=0,92 \mathrm{~m} / \mathrm{s}, W_{0}=2,11 \mathrm{~m} / \mathrm{s}, T_{t}$

$$
=24^{\circ} \mathrm{C} \text { e } T_{w}=44^{\circ} \mathrm{C}, \Delta T=20^{\circ} \mathrm{C}
$$

A Figura 110, Figura 111, Figura 112 e Figura 113 mostram o perfil de concentração para o casos 25, 26, 33 e 34 , respectivamente.

(a)

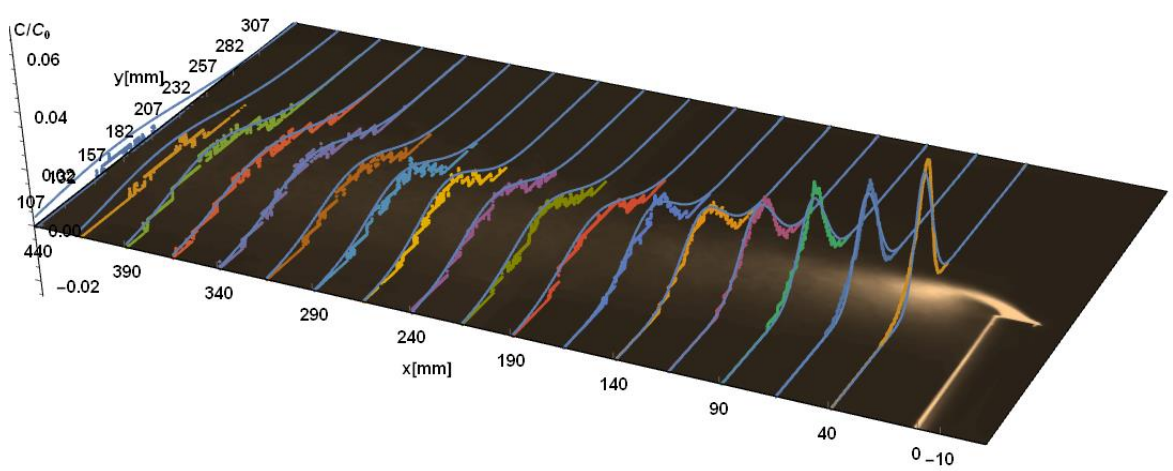


(b)

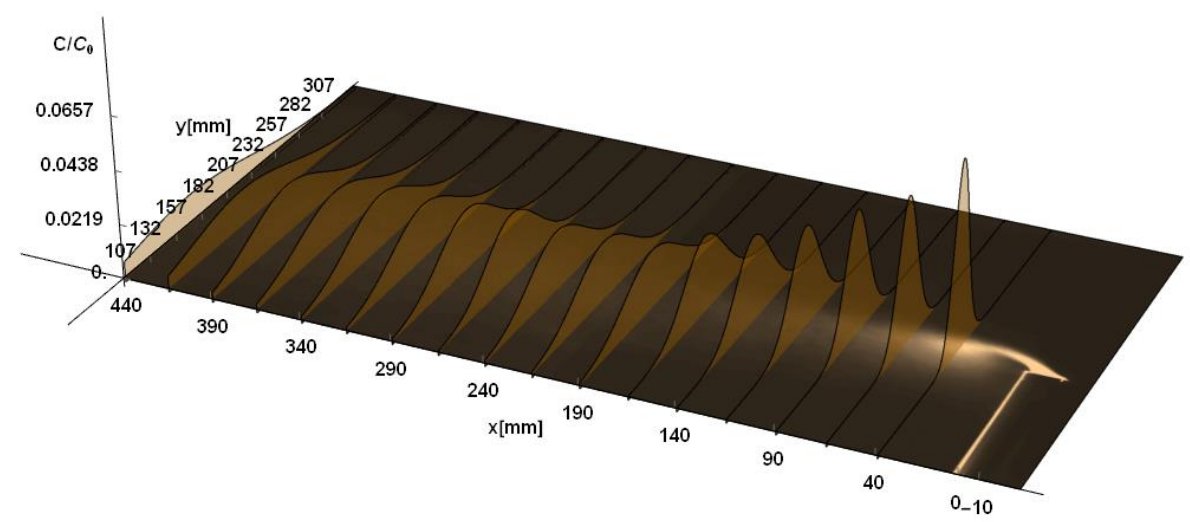

Figura 110. Perfil de concentração na condição $U_{\max }=1,79 \mathrm{~m} / \mathrm{s}, W_{0}=0,80 \mathrm{~m} / \mathrm{s}, T_{t}$

$$
=26^{\circ} \mathrm{C} \text { e } T_{w}=36^{\circ} \mathrm{C}, \Delta T=10^{\circ} \mathrm{C}
$$

(a)

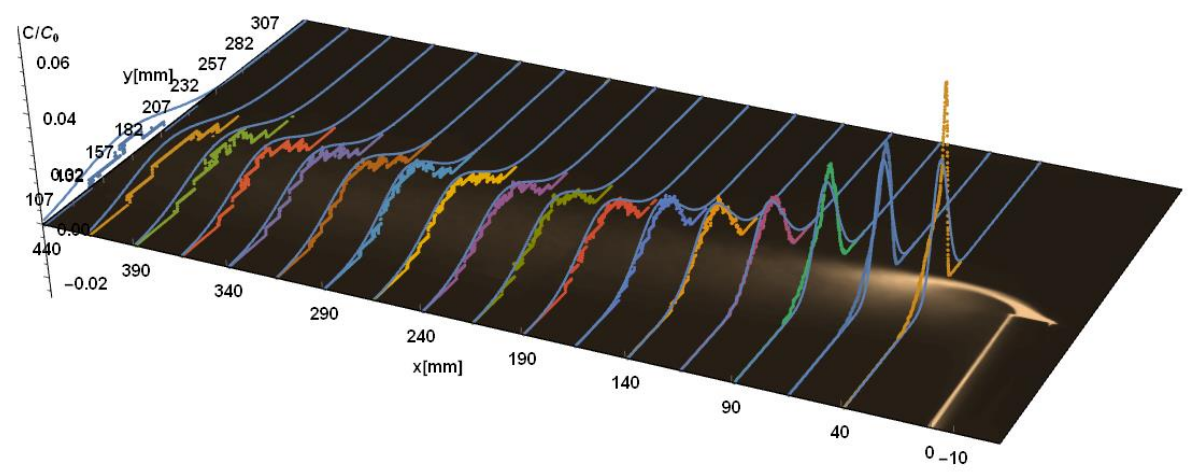

(b)

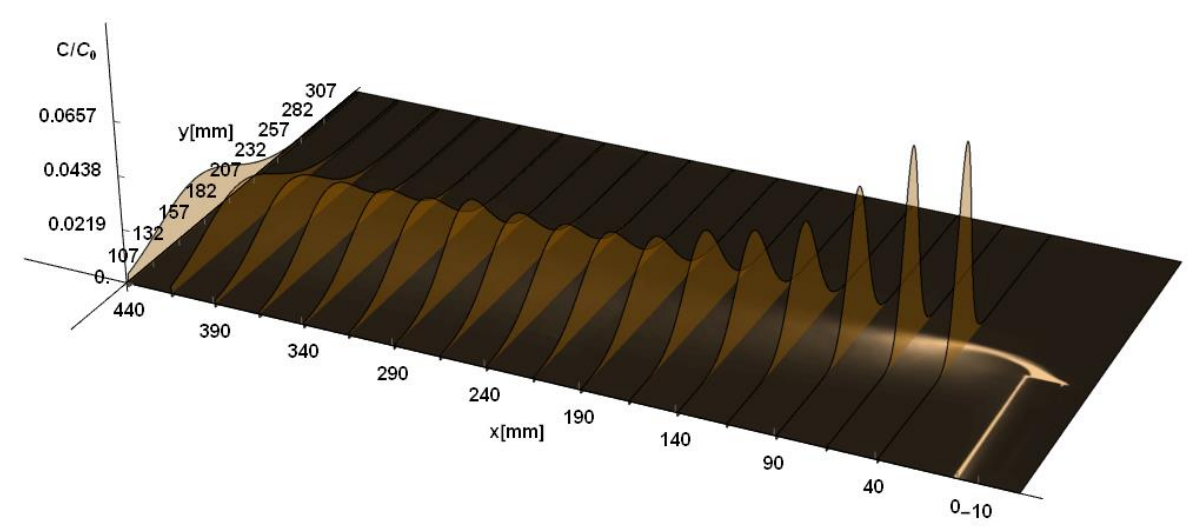

Figura 111. Perfil de concentração na condição $U_{\max }=1,79 \mathrm{~m} / \mathrm{s}, W_{0}=0,92 \mathrm{~m} / \mathrm{s}, T_{t}$

$$
=25^{\circ} \mathrm{C} \text { e } T_{w}=45^{\circ} \mathrm{C}, \Delta T=20^{\circ} \mathrm{C}
$$


(a)

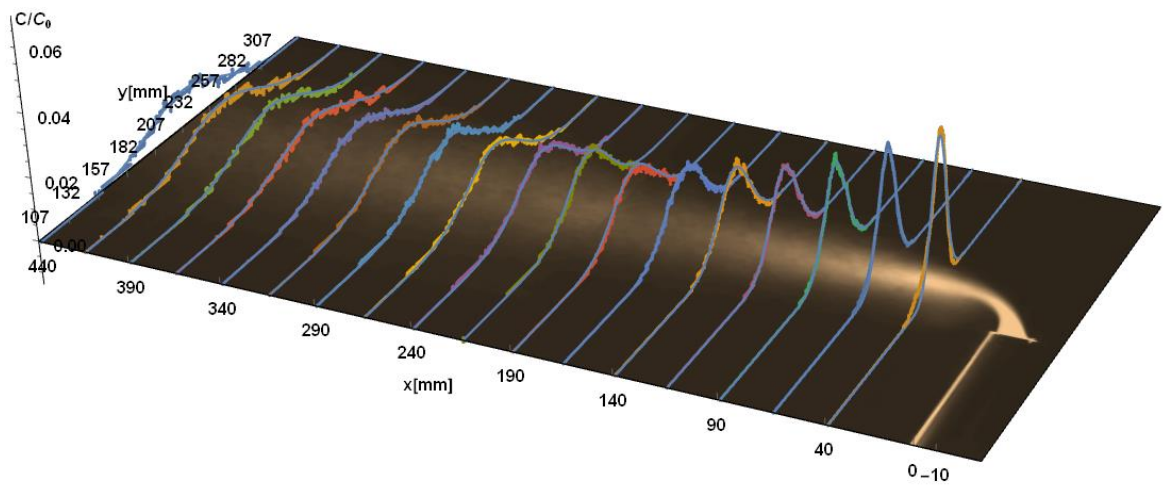

(b)

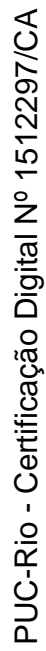

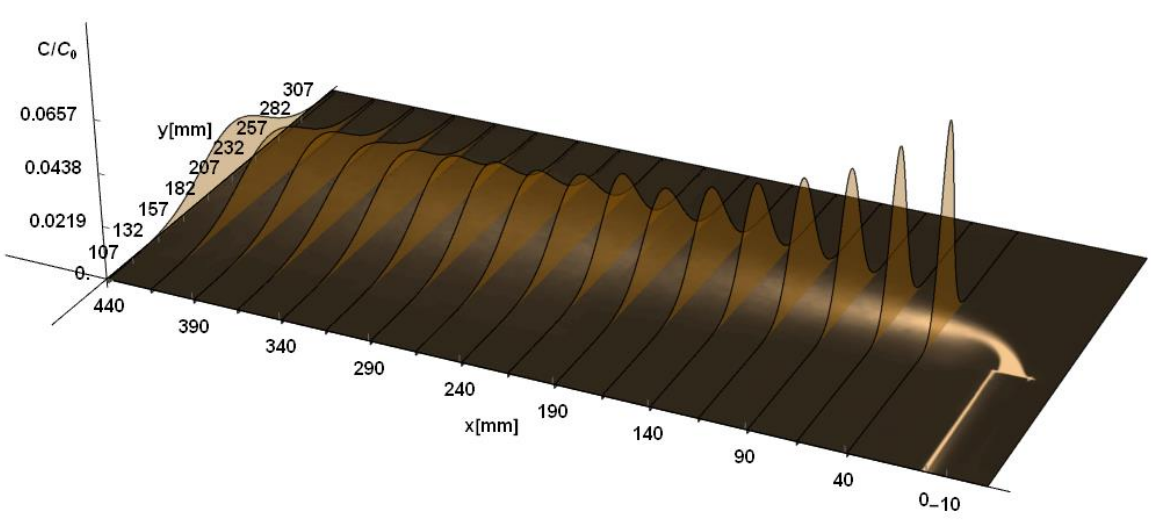

Figura 112. Perfil de concentração na condição $U_{\max }=1,79 \mathrm{~m} / \mathrm{s}, W_{0}=1,64 \mathrm{~m} / \mathrm{s}, T_{t}$ $=25^{\circ} \mathrm{C}$ e $T_{w}=35^{\circ} \mathrm{C}, \Delta T=10^{\circ} \mathrm{C}$

(a)

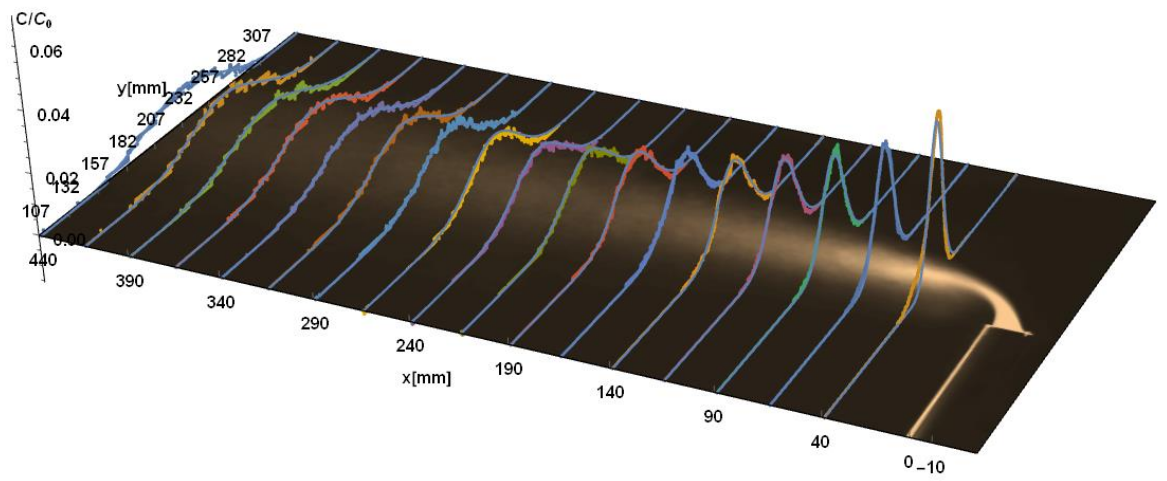


(b)

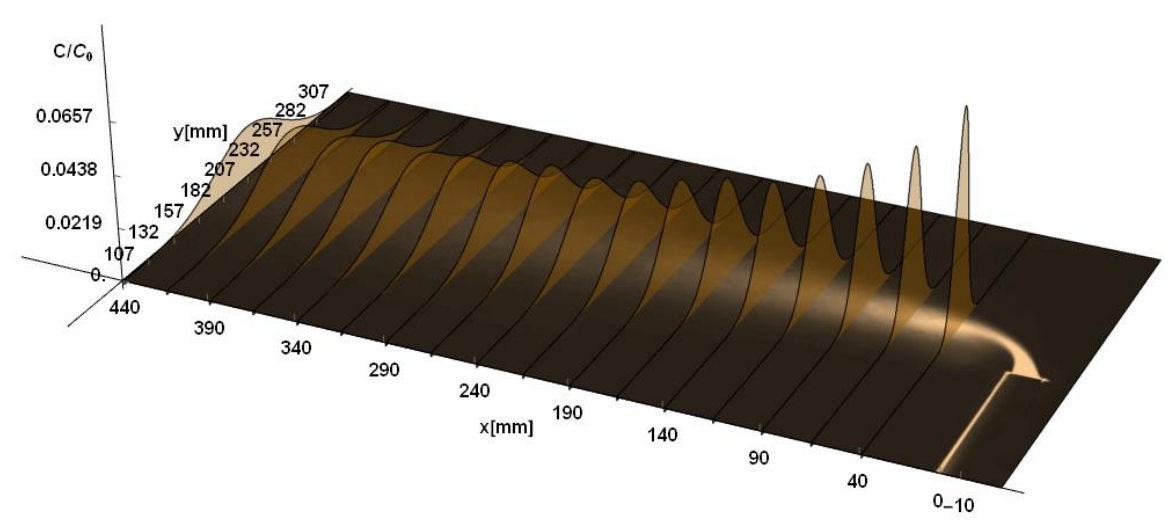

Figura 113. Perfil de concentração na condição $U_{\max }=1,79 \mathrm{~m} / \mathrm{s}, W_{0}=2,14 \mathrm{~m} / \mathrm{s}, T_{t}$

$$
=25^{\circ} \mathrm{C} \text { e } T_{w}=45^{\circ} \mathrm{C}, \Delta T=20^{\circ} \mathrm{C}
$$

Analisando os gráficos, que mostram a evolução da pluma, é possível notar que a distribuição de concentração segue um modelo de concentração gaussiano (Figura 18). O ponto de máximo da curva delimita a linha central da pluma, definindo sua altura. Observa-se também que a intensidade luminosa, bem como o valor máximo de concentração relativa, diminui à medida que se afasta da chaminé, devido à dispersão.

Há diversos fatores que influenciaram a elevação da pluma. Primeiramente, é possível comparar visualmente a altura observando os casos onde $U_{\max }=0,92 \mathrm{~m} / \mathrm{s}$ ou $U_{\max }=1,79 \mathrm{~m} / \mathrm{s}$, na menor velocidade de emissão, ocorre uma inclinação da pluma muito maior do que na maior velocidade de emissão.

Outra comparação é feita com diferentes velocidades de emissão para uma mesma velocidade do escoamento principal. Como era de se esperar, a diminuição da velocidade do escoamento principal causou um aumento da altura de elevação da pluma, o que é nitidamente visível se comparar os gráficos da Figura 112, em que $U_{\max }=1,79 \mathrm{~m} / \mathrm{s}$ e da Figura 108 , em que $U_{\max }=0,92 \mathrm{~m} / \mathrm{s}$. Esse aumento é devido à maior quantidade de movimento da pluma.

É possível ver também que na condição de velocidade mais baixa de emissão, a pluma tente a perder altura, inclinando para parte inferior. Já para maior velocidade de emissão, à medida que a pluma se dispersa, aumenta também sua inclinação. 
O perfil de temperatura ao longo do túnel é isotérmico, ou seja, a estabilidade atmosférica simulada foi a neutra. Assim, é possível notar que a pluma obteve um formato tipo cônico (Figura 17), característico desse tipo de ambiente.

\subsection{1.}

\section{Flutuações de concentração da pluma}

Foram avaliadas as flutuações de concentração da pluma, analisando 500 imagens instantâneas obtidas com o software do PIV. A Figura 114 mostra um exemplo de uma imagem instantânea obtida com o PIV, da janela 1, para o caso 1 .

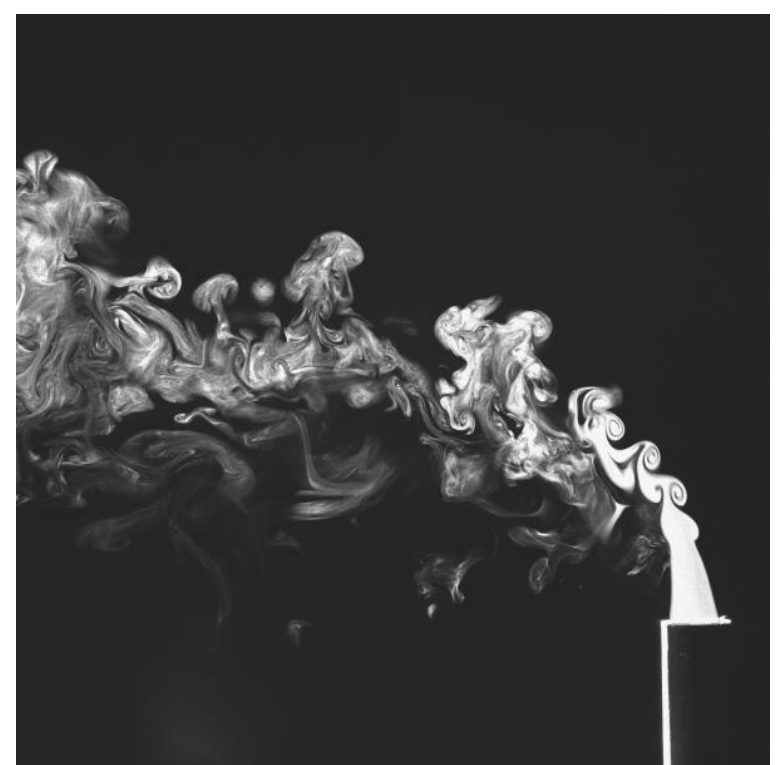

Figura 114. Exemplo de uma imagem instantânea obtida com o PIV

Para análise das flutuações de concentração, foram escolhidas duas distâncias no eixo $x$, a $125 \mathrm{~mm}$ e a $345 \mathrm{~mm}$ da chaminé, cada uma com 5 pontos diferentes para análise. O ponto central, chamado de $\sigma y$, é onde se encontra o ponto de máximo do perfil gaussiano de concentração, ou seja, a linha central da pluma. A partir desse ponto, são pegos dois pontos acima e dois abaixo de $\sigma y$, espaçados em $\pm 1 \sigma$ e $\pm 2 \sigma$, como mostrado na Figura 115. 


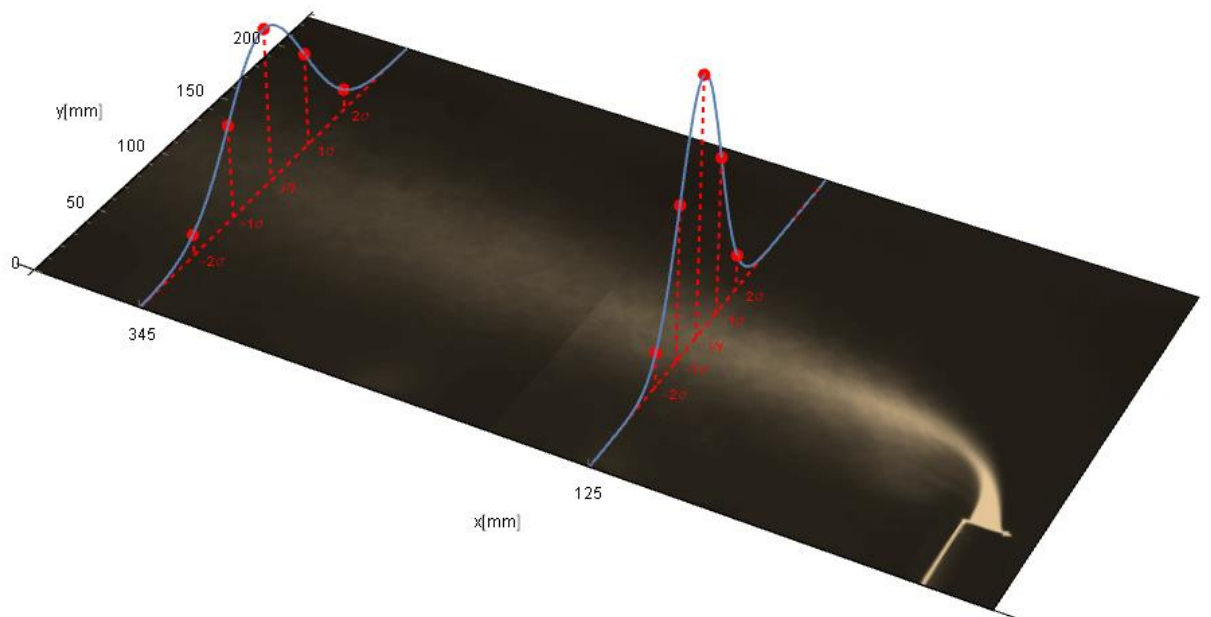

Figura 115. Distribuição dos pontos de análise de flutuação de concentração

Foi feita uma análise do caso 33, para situação com maior velocidade do escoamento principal no túnel e da chaminé, do comportamento da concentração ao longo do tempo. O resultado para distância de 125 e $345 \mathrm{~mm}$ da chaminé é mostrado nas Figura 116 e Figura 117, respectivamente.

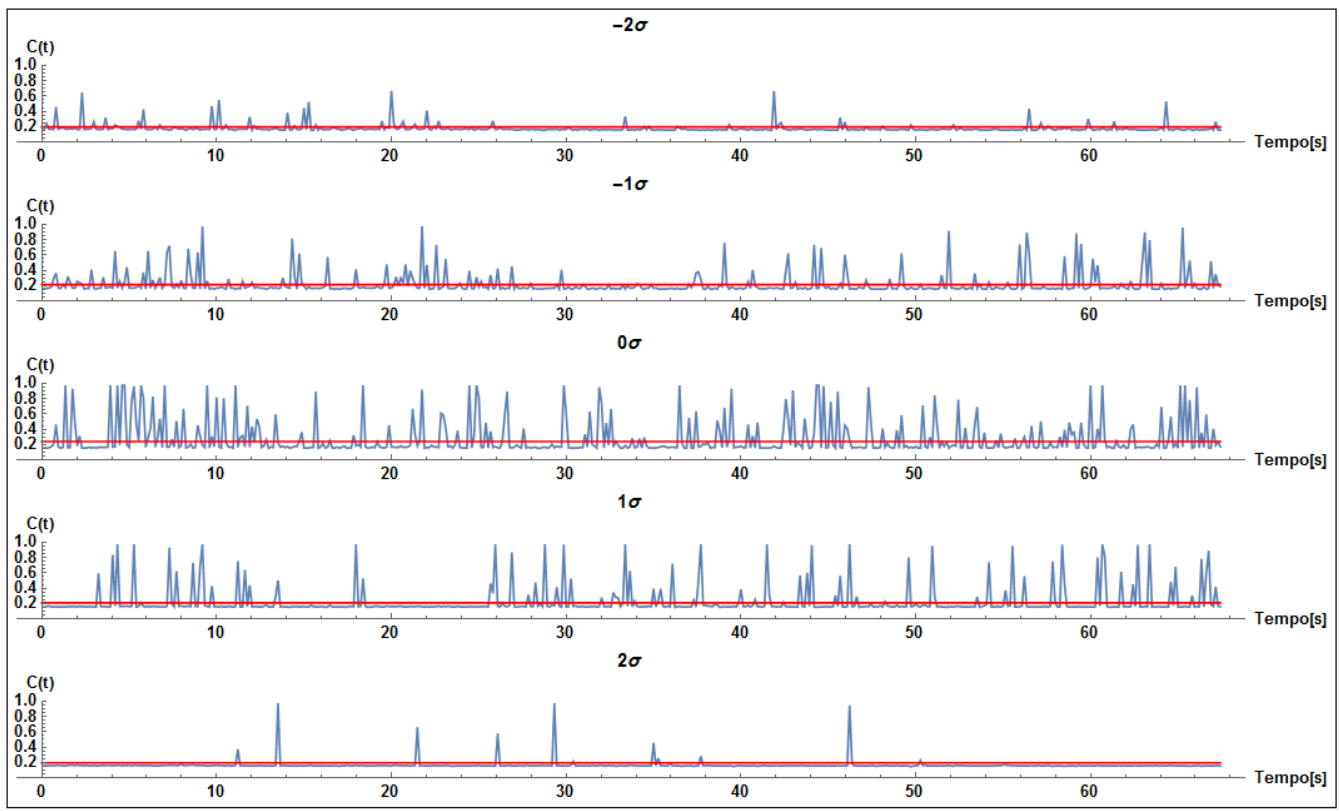

Figura 116. Gráficos de variação de concentração ao longo do tempo para as 5 posições analisadas em $x=125 \mathrm{~mm}$ 


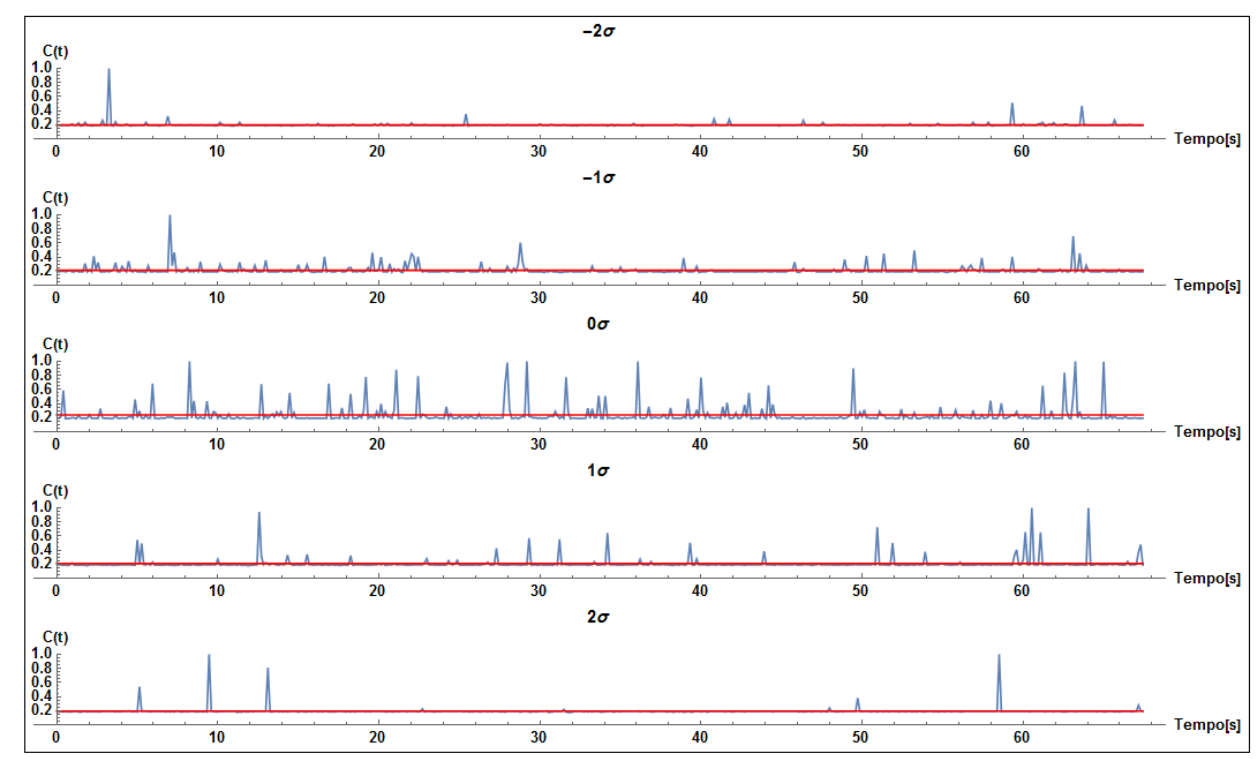

Figura 117. Gráficos de variação de concentração ao longo do tempo para as 5 posições analisadas em $x=345 \mathrm{~mm}$

Nos gráficos apresentados nas figuras é possível comparar o ponto central $(0 \sigma)$ com os pontos mais afastados e notar a diminuição de eventos com valores mais altos de concentração nas duas linhas verticais analisadas. Isso é esperado uma vez que na parte central a concentração de traçadores é maior, enquanto que nas regiões mais afastadas há um maior efeito de dispersão. É notável também que há uma significativa diferença de variação de concentração da posição mais próxima à pluma, $x=125 \mathrm{~mm}$, em relação à posição mais afastada, $x=345 \mathrm{~mm}$. A posição mais próxima abrange uma concentração de fumaça maior próxima à chaminé, enquanto que na região mais afastada, o nível de concentrações é bem menor, indicando um efeito de diluição nas concentrações. Esse efeito também se manifesta no aumento do coeficiente de dispersão vertical da pluma.

Fazendo uma análise dos eventos de concentração, pode-se obter histogramas para se determinar qual o comportamento que melhor os descreve estatisticamente. Os histogramas foram obtidos determinando-se intervalos de concentração e suas respectivas quantidades de eventos. Como é possível observar, essa distribuição de eventos não segue uma distribuição normal, como pode ser visto na Figura 118, dos histogramas para os 5 gráficos das posições analisadas em $x=125 \mathrm{~mm}$. 

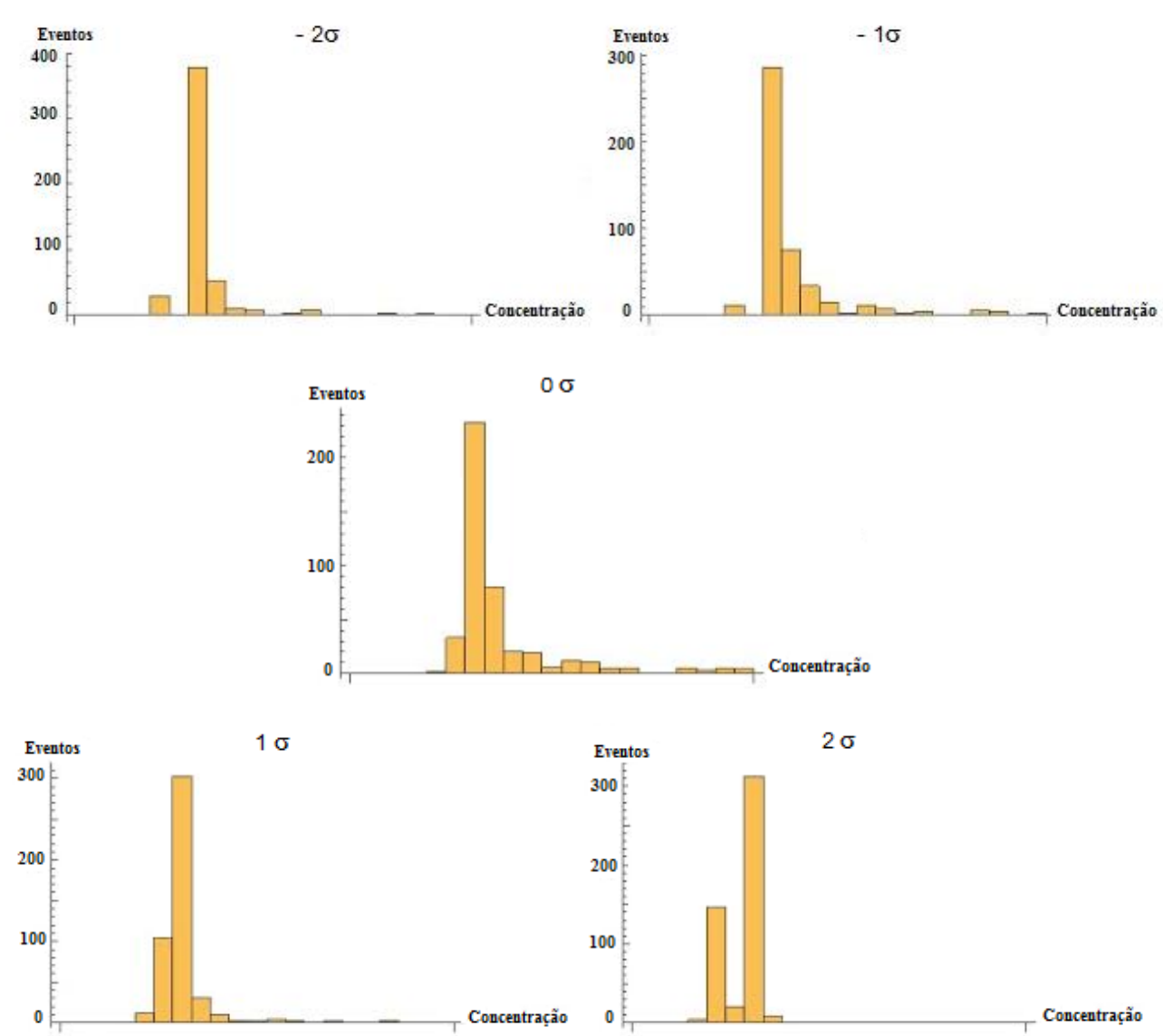

Figura 118. Histogramas dos eventos de concentração para as 5 posições analisadas em $x=125 \mathrm{~mm}$

Deste modo, apesar da pluma ter um comportamento médio gaussiano, as oscilações de concentração não se comportam de maneira a permitir essa análise. Isso pode ser atribuído ao efeito de turbulência, que não se comporta de forma homogênea e estacionária, permitindo esse tratamento estatístico. Outro fator importante é que o sistema PIV possui baixa frequência de aquisição, ou seja, as frequências mais altas não são identificadas e capturadas.

\section{6.}

\section{Análise da dispersão vertical $\left(\sigma_{z}\right)$ da pluma}

O modelo mais conhecido e utilizado para estudo de concentração de plumas é o modelo de dispersão gaussiano, mostrado na seção 4.1.1. Um ponto importante desse estudo é o cálculo do coeficiente de dispersão vertical e horizontal. Para este trabalho, foram feitas medidas somente no plano central da pluma, permitindo análises da dispersão vertical (adotado como eixo y neste trabalho; a leitura 
tradicional, no entanto, adota a letra $z$ como direção vertical). Assim, a partir das medições de concentração, foi possível realizar um estudo do coeficiente de dispersão vertical (no entanto, foi mantido a nomenclatura $\sigma_{z}$ para o coeficiente de dispersão vertical). Todos os resultados de $\sigma_{z}$ obtidos no experimento foram analisados. Um ajuste linear dos coeficientes de dispersão calculados em função da distância em relação à fonte foi feito para melhor entendimento do comportamento da dispersão. A Tabela 9 apresenta valores do coeficiente angular da curva ajustada $\left(\Delta \sigma_{z} / \Delta x\right)$.

Tabela 9. Valores de $\Delta \sigma_{z} / \Delta \mathrm{x}$

\begin{tabular}{|c|c|c|c|c|c|c|c|}
\hline \multirow[b]{2}{*}{$C L A$} & \multirow{2}{*}{$\begin{array}{l}U_{\max } \\
(\mathrm{m} / \mathrm{s})\end{array}$} & \multicolumn{6}{|c|}{$\Delta \sigma_{z} / \Delta x$ com valores de $W_{0}$ entre parênteses } \\
\hline & & $\Delta T=10^{\circ} \mathrm{C}$ & $\Delta T=20^{\circ} \mathrm{C}$ & $\Delta T=10^{\circ} \mathrm{C}$ & $\Delta T=20^{\circ} \mathrm{C}$ & $\Delta T=10^{\circ} \mathrm{C}$ & $\Delta T=20^{\circ} \mathrm{C}$ \\
\hline & $\mathbf{0 , 9 2}$ & $\begin{array}{c}8,45 \\
(1,02 \mathrm{~m} / \mathrm{s})\end{array}$ & $\begin{array}{c}5,32 \\
(1,43 \mathrm{~m} / \mathrm{s})\end{array}$ & $\begin{array}{c}8,99 \\
(1,64 \mathrm{~m} / \mathrm{s})\end{array}$ & $\begin{array}{c}11,32 \\
(1,77 \mathrm{~m} / \mathrm{s})\end{array}$ & $\begin{array}{c}15,04 \\
(2,55 \mathrm{~m} / \mathrm{s})\end{array}$ & $\begin{array}{c}14,41 \\
(3,27 \mathrm{~m} / \mathrm{s})\end{array}$ \\
\hline$\checkmark$ & 1,38 & 10,11 & 4,05 & 6,87 & 6,95 & 14,57 & 11,90 \\
\hline & & $(0,90 \mathrm{~m} / \mathrm{s})$ & $(0,99 \mathrm{~m} / \mathrm{s})$ & $(1,31 \mathrm{~m} / \mathrm{s})$ & $(1,62 \mathrm{~m} / \mathrm{s})$ & $(2,25 \mathrm{~m} / \mathrm{s})$ & $(2,52 \mathrm{~m} / \mathrm{s})$ \\
\hline & 1,79 & $\begin{array}{c}9,41 \\
(0,86 \mathrm{~m} / \mathrm{s})\end{array}$ & $\begin{array}{c}12,22 \\
(1,18 \mathrm{~m} / \mathrm{s})\end{array}$ & $\begin{array}{c}5,80 \\
(1,15 \mathrm{~m} / \mathrm{s})\end{array}$ & $\begin{array}{c}5,63 \\
(2,06 \mathrm{~m} / \mathrm{s})\end{array}$ & $\begin{array}{c}7,93 \\
(1,91 \mathrm{~m} / \mathrm{s})\end{array}$ & $\begin{array}{c}7,35 \\
(2,67 \mathrm{~m} / \mathrm{s})\end{array}$ \\
\hline & 1,08 & $\begin{array}{c}5,45 \\
(1,08 \mathrm{~m} / \mathrm{s})\end{array}$ & $\begin{array}{c}4,07 \\
(1,31 \mathrm{~m} / \mathrm{s})\end{array}$ & $\begin{array}{c}8,04 \\
(1,49 \mathrm{~m} / \mathrm{s})\end{array}$ & $\begin{array}{c}9,50 \\
(1,67 \mathrm{~m} / \mathrm{s})\end{array}$ & $\begin{array}{c}14,24 \\
(1,77 \mathrm{~m} / \mathrm{s})\end{array}$ & $\begin{array}{c}15,65 \\
(2,11 \mathrm{~m} / \mathrm{s})\end{array}$ \\
\hline$x$ & 1,52 & $\begin{array}{c}9,76 \\
(0,59 \mathrm{~m} / \mathrm{s})\end{array}$ & $\begin{array}{c}6,98 \\
(0,90 \mathrm{~m} / \mathrm{s})\end{array}$ & $\begin{array}{c}6,81 \\
(1,24 \mathrm{~m} / \mathrm{s})\end{array}$ & $\begin{array}{c}9,01 \\
(1,55 \mathrm{~m} / \mathrm{s})\end{array}$ & $\begin{array}{c}7,82 \\
(1,80 \mathrm{~m} / \mathrm{s})\end{array}$ & $\begin{array}{c}10,70 \\
(1,95 \mathrm{~m} / \mathrm{s})\end{array}$ \\
\hline & 1,85 & $\begin{array}{c}8,06 \\
(0,80 \mathrm{~m} / \mathrm{s})\end{array}$ & $\begin{array}{c}7,29 \\
(0,92 \mathrm{~m} / \mathrm{s})\end{array}$ & $\begin{array}{c}8,62 \\
(1,32 \mathrm{~m} / \mathrm{s})\end{array}$ & $\begin{array}{c}8,50 \\
(1,42 \mathrm{~m} / \mathrm{s})\end{array}$ & $\begin{array}{c}6,32 \\
(1,64 \mathrm{~m} / \mathrm{s})\end{array}$ & $\begin{array}{c}7,14 \\
(2,14 \mathrm{~m} / \mathrm{s})\end{array}$ \\
\hline
\end{tabular}

Com esses resultados percebe-se que quanto maior a velocidade do escoamento principal, menor é o valor de $\Delta \sigma_{z} / \Delta x$, exceto para baixas velocidades de emissão. Para essas baixas velocidades de emissão, a pluma é mais influenciada pela zona de esteira e efeitos tridimensionais, que modificam essa tendência. Notase que a partir de uma certa velocidade de saída, a tendência é que ocorra uma menor dispersão para velocidades mais altas, como era de se esperar.

Os valores obtidos experimentalmente foram comparados com valores da literatura obtidos em medições em campo. Uma das bibliografias escolhidas para comparação foram as curvas de Pasquill-Gifford (P-G) apresentadas na equação (4- 
3) em conjunto com a Tabela 1, para classe de estabilidade D. As curvas PG são as curvas de coeficientes de dispersão mais conhecidas e utilizadas, inclusive pela Sociedade Americana de Meteorologia e nos modelos dos organismos reguladores. Outras literaturas escolhidas foram as expressões de Briggs (Hanna et al., 1981), para condição de estabilidade atmosférica neutra (D) em terreno urbano, cuja expressão está mostrada na Tabela 3 e expressões de Smith, mostradas na equação (4-4), com os parâmetros da Tabela 2.

O modelo gaussiano da pluma é sugerido para uma região mais afastada da fonte de emissão. Como neste trabalho foi realizado um estudo de campo próximo à fonte de emissão, é proposto uma adequação do coeficiente de dispersão vertical para essas áreas mais próximas. Certamente, deve ser elaborada uma modelagem matemática completa; o esperado, porém, é que $\sigma_{z}$ tenha uma forte relação com o diâmetro da chaminé e que siga uma tendência exponencial, como nas curvas da literatura. A equação abaixo representa o modelo proposto:

$$
\sigma_{z}(x)=\frac{D}{2}+a x^{b}
$$

Em que D é o diâmetro da chaminé. Foi realizada uma análise abordando todos os valores de $\sigma_{z}$ obtidos nos experimentos, para se obter uma condição média e traçar uma linha de tendência (um ajuste dos dados experimentais), onde D/2 é o termo constante.

Todas as expressões empíricas citadas anteriormente e a linha de tendência de $\sigma_{z}$ proposta foram analisadas na escala de 1:800, mesma escala utilizada para geração da CLA no túnel de vento. O gráfico da Figura 119 mostra essas curvas com todos os dados $\sigma_{z}$ obtidos, para todos os experimentos realizados, em função da distância $x$. 


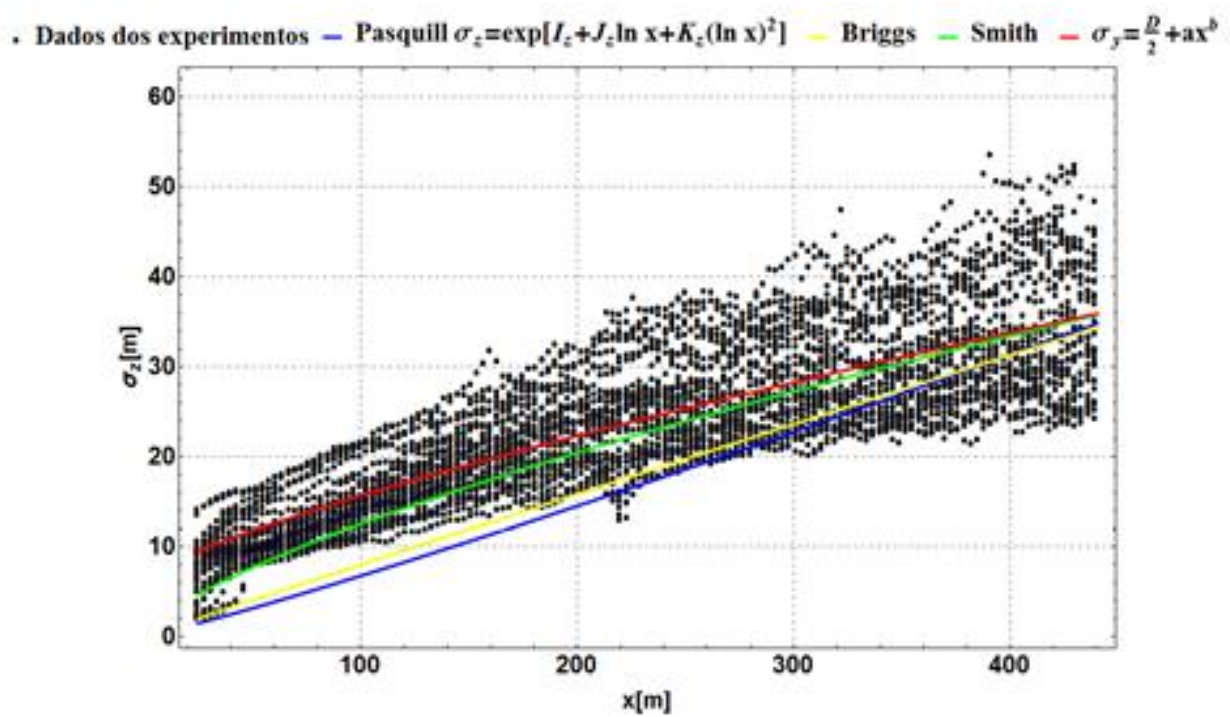

Figura 119. Dados dos experimentos comparados com valores literários e a curva de tendência proposta

O gráfico apresentado mostra que os dados experimentais tendem a ser maiores que as curvas obtidas de acordo com a literatura na região próxima à fonte e à medida que vão se afastando, se aproximam da teoria. Isso acontece pois a solução da pluma gaussiana e dos dados da literatura sobre $\sigma_{z}$ não são aplicáveis à campos próximos.

A curva proposta para regiões mais próximas à fonte de emissão seguiu a mesma tendência das curvas literárias e se mostrou bem coerente com a bibliografia de Smith. Os valores das constantes obtidas de acordo com o ajuste linear estão mostradas na equação completa abaixo:

$$
\sigma_{z}(x)=5,08+0,372 x^{0,724}
$$

Extrapolando-se a curva obtida com a modelagem proposta, foi verificado que, para longas distâncias, há uma tendência de que as curvas se aproximem. 


\section{8 Conclusões}

O presente trabalho teve como objetivo geral reproduzir escoamentos atmosféricos e estudar o processo de dispersão de uma pluma emitida por uma chaminé em um ambiente com formação de camada limite atmosférica.

A fim de se criar uma simulação mais realista possível, a camada limite atmosférica foi desenvolvida no túnel de vento do Laboratório de Caracterização de Escoamentos de Fluidos, no Inmetro. Através da metodologia de Irwin, foram dimensionados e construídos 4 spires para alocar no início da seção de testes, a fim de simular um ambiente suburbano $(\alpha=0,28)$ com espessura de $500 \mathrm{~mm}$. Mesmo para perfis de entrada não homogêneos, requisito desta metodologia, o resultado foi considerado apropriado. $\mathrm{O}$ perfil de velocidades média foi verificado com a técnica de AFQ e a CLA alcançada obteve uma boa concordância com a lei da potência para $\alpha=0,28$. Em seguida, todo um sistema de aquecimento do chão do túnel foi montado com resistências, a fim de se criar uma estratificação térmica no túnel de vento. O perfil térmico foi medido com termopares, que foram calibrados e realizados cálculo de incerteza. Esse perfil térmico se mostrou coerente, simulando um ambiente instável, porém, percebeu-se que o perfil de velocidades da CLA era totalmente alterado pelas correntes convectivas geradas pelo gradiente térmico. Como a solução deste problema demandaria tempo, visto que teria de ser feita de maneira empírica, a estratificação térmica não foi considerada neste trabalho. $\mathrm{O}$ túnel de vento, então, consegue simular um ambiente suburbano na classe de estabilidade neutra.

Os ensaios realizados para simular a dispersão de uma pluma de contaminantes emitida por uma chaminé foram possíveis através da técnica de PIV e apresentaram, qualitativamente e quantitativamente, resultados satisfatórios. Verificou-se que a inclinação da pluma é influenciada por diversos fatores. Para uma mesma condição de emissão, quanto maior a velocidade do escoamento principal no túnel, maior sua inclinação. O contrário também foi observado: a diferença de temperatura da pluma emitida e do escoamento principal foi variada 
em $10^{\circ} \mathrm{C}$ e $20^{\circ} \mathrm{C}$, e como esperado, houve um aumento de velocidade de emissão da pluma para uma temperatura maior de emissão. Essas características foram analisadas através de uma regressão linear da altura da pluma e observando as inclinações. Foram feitas também análises do perfil médio de velocidades e flutuações em diversas posições afastadas da chaminé. Observou-se uma grande região de recirculação do escoamento próximo à região da chaminé, a qual possui também os maiores valores de intensidade turbulenta. Verificou-se que esse escoamento é bastante complexo devido à sua natureza tridimensional e às interações da pluma com as várias regiões do escoamento principal. Observou-se também mudanças nos parâmetros de velocidade, em relação a um ambiente sem formação de CLA, constatando influência deste parâmetro e a importância de sua reprodução em laboratório.

$\mathrm{Na}$ análise de concentração foi utilizada uma rotina no software Wolfram Mathematica, que, levando em conta as imagens médias obtidas com a técnica PIV, avalia o perfil de concentração através da intensidade luminosa dos pixels. A distribuição de concentração obteve um comportamento gaussiano, modelo amplamente utilizado para estudos de dispersão de plumas.

Por fim, foi realizada uma análise da dispersão vertical $\left(\sigma_{z}\right)$ da pluma comparando os dados obtidos no experimento com diversas literaturas conhecidas, na qual conseguiu-se resultados coerentes. Como o modelo gaussiano é proposto para distâncias mais afastadas da fonte de emissão, foi proposta uma curva de $\sigma_{z}$ que se adequasse ao estudo de campo próximo. Todas as comparações, tanto as equações obtidas na literatura, quando a curva proposta, se mostraram bem coerentes com os dados dos experimentos.

Existem diversos pontos a serem analisados e estudados no que tange estudos de dispersão de plumas. Portanto, algumas sugestões de trabalhos futuros são estudar o processo de dispersão de plumas em ambientes com estratificação de temperatura e utilização de gases para simular os poluentes. Outra sugestão é a variação da altura da chaminé e verificar a influência da CLA.

Finalmente, o conhecimento gerado neste trabalho tem o intuito de contribuir para o desenvolvimento de modelos atualizados para análise de dispersão em campo próximo, contemplando os efeitos da vizinhança e contribuir também para o Inmetro, na consolidação do conhecimento na linha de pesquisa na área ambiental. 


\section{9 Referências bibliográficas}

ADAIR, D. Numerical calculations of aerial dispersion from elevated sources. BMT Fluid Mechanics Ltd, Research Engineering. Teddington, Middlesex, UK, 1990.

AL-NEHARI, H. A., ALI K. A., NASSIB, A. E. and SHAFEY, H. M. Design and Construction of a Wind Tunnel for Environmental Flow Studies. Cairo 11th International Conference on Energy and Environment, Hurghada, Egypt - March 15-18, 2010.

BEYCHOK, M. R. Fundamentals of Stack Gas Dispersion (4th ed.). authorpublished. ISBN 0-9644588-0-2, 2005.

BLESSMANN, J. O Vento na Engenharia Estrutural. Porto Alegre: Editora da Universidade, 1995. 166p, 1995.

BLESSMANN, J. The Boundary Layer Wind Tunnel of UFRGS; Journal of Wind Engineering and Industrial Aerodynamics, 10. pp. 231-248, 1982.

BRAY, G. C. A family of wind-tunnel simulations.

BRINGFELT, B. Plume rise measurements at industrial chimneys. Atmospheric Environment, Pergamon Press 1968. Vol 2, pp 575-598, 1968.

BRIGGS, G. A. Diffusion Estimation for Small Emissions. ATDL contribution File No. 79. Atmospheric Turbulence and Diffusion Laboratory, 1973. 
BRUUN, H. H. Hot-Wire Anemometry: Principles and signal analysis. Oxford Science Publications, 1995.

CARRAS, J. N. e WILLIAMS, D. J. Experimental studies of plume dispersion in convective conditions - II. Horizontal plume dispersion. Atmospheric Environment, Pergamon Journals Ltd. 1986. Vol 20, № 12, pp 2307-2314, 1986.

CERMAK, J. E. Laboratory simulation of the atmospheric boundary layer. AIAA Journal, Vol. 9, No. 9, 1971.

CERMAK, J. E. Wind tunnel testing of structures. Proceedings of the American Society of Civil Engineers, Engineering Mechanics Division, 1977, 1031125 1140, 1977.

CERMAK, J. E. Physical modeling of the atmospheric boundary layer in long boundary-layer wind tunnels. Wind Tunnel Modeling for Civil Engineering Applications. (Ed: Reinhold 1 A), pp.97-125. Cambridge, Cambridge University Press, 1982.

CERMAK, J. E., TAKEDA, K. Physical modeling of urban air-pollutant transport. Journal of Wind Engineering and Industrial Aerodynamics, 21, 51-67, 1985.

CHATZIPANAGIOTIDIS, A., e OLIVARI, D. Pollutant dispersal downstream of a hill in different wind conditions. Journal of Wind Engineering and Industrial Aerodynamics, 64, 233-248, 1996.

CHEUNG, J. C. K. e Melbourne, W. H. Building downwash of plumes and plume interactions. J Wind Eng Industr Aerodyn 54(55):543-548, 1995.

COOK, N. J. On simulating the lower third of the urban adiabatic boundary layer in a wind tunnel. Atmospheric Environment, 1973, 7 691-705, 1973. 
COOK, N. J. Wind-tunnel simulation of the adiabatic atmospheric boundary layer by roughness, barrier and mixing-device methods. Journal of Industrial Aerodynamics, 1978, 3 157-176, 1978.

COOK, N. J. Simulation techniques for short test-section wind tunnels; roughness, barrier and mixing-device methods. Wind Tunnel Modeling for Civil Engineering Applications. (Ed: Reinhold T A), pp. 126- 136. Cambridge, Cambridge University Press, 1982.

COUNIHAN, J. An Improved method of Simulating an Atmospheric Boundary Layer in a Wind Tunnel, Atmospheric Environment, Vol. 3, pp. 197-214, 1969.

COUNIHAN, J. Simulation of an adiabatic urban boundary layer in a wind tunnel. Atmospheric Environment, 1973, 7 673-689, 1973.

DANTEC DYNAMICS. Fluid Mechanics. Web site, 2013. Disponível em: <http://www.dantecdynamics.com/fluid-mechanics>. Acesso em 06 dez. 2016, 2013

DAVENPORT, A. G. The buffeting of large superficial structures by atmospheric turbulence, Annals of the New York Academy of Sciences, New York, June, Vol. 116, pp.135-159, 1964.

DAVENPORT, A. G., ISYUMOV, N. The Application of The Boundary Layer Wind Tunnel to the Prediction of Wind Loading. In: Proceedings of the International Research Seminar: Wind Effects on Buildings and Structures. Ottawa, Canada. September 11-15. Vol. 1. Pp. 201-230, 1967.

DAVIS, M., CORNWELL, D. Introduction to Environmental Engineering. Third Edition, Mc Graw-Hill, 1998.

DEBLER, W. Wind-tunnel measurements of turbulence decay in a stratified fluid. 
DYE, F. C. R. Investigation of profile simulation in short lengths by its effect on model results.

DRAXLER, R. R. Determination of Atmospheric Diffusion Parameters. Atmos. Environ. Vol.10. 363-372, 1976.

ELDER J. W. Steady flow through non-uniform gauzes of arbitrary shape. Journal of Fluid Mechanics, 1957, 5 355-368, 1957.

EPA. User's Manual for Single Source (CRSTER) Model, EPA-450/2-77-013, US EPA, Research Triangle Park, North Carolina, 1977.

FARIAS, M. H., SANTOS, A. M., SOUZA, D. B., FERREIRA, L. L. R., MASSARI, P. de L.; MASSARI, P. L., GARCIA, D. A.; COSTA, F. O. Characterization of low speed atmospheric wind tunnel. $3^{\text {rd }}$ International Congress on Mechanical Metrology, CIMMEC 2014, Gramado, Brazil, October $14^{\text {th }}-16^{\text {th }}, 2014$.

FLOW MANAGER. Flow Manager software and introduction to PIV instrumentation. Dantec Dynamics A/S, Fifth Edition, 2000.

GANDEMER, J. Wind-tunnel simulation of the atmospheric boundary layer at C.S.T.B, 1979.

GIFFORD, F. A. Use of Routine Meteorological Observations for Estimating Atmospheric Dispersion. Nud. Safety 2(4), pp. 47-51, 1961.

GIRARDI, R. M. e CATARINA, M. F. S. Desenvolvimento de um escoamento tipo camada limite atmosférica em túnel de vento com pequenas dimensões. Instituto Tecnológico de Aeronáutica (ITA). CONEM, 2000.

GOLDSTEIN, R. J. Fluid Mechanics Meaurement. 2nd Ed., Taylor and Francis, 1996. 
GUIMARÃES, J. H. D., dos Santos, S. J. F., Jr., Su, J. e Silva Freire, A. P. Large artificially generated turbulent boundary layers for the study of atmospheric flows. Proceedings of the 15th Brazilian Congress of Mechanical Engineering (COBEM 99), Águas de Lindóia, 1999.

HANNA, S. R., BRIGGS, G. A., DEARDORFF, J. W., EGAN, B. A., GIFFORD, F. A., and PASQUILL, F. AMS Workshop on Stability Classification Schemes and Sigma Curves -Summary of Recommendations. Bull. Amer. Meteorol. Soc. 58, pp. 1305-1309, 1981.

HANNA, S. R. Concentration fluctuations in a smoke plume. Atmospheric Environment, vol. 18, No. 6, pp. 1091-1106, 1984.

HANSEN, G. D. Indivisible labor and the business cycle. Journal of Monetary Economics. 16. November: 309-27, 1985.

HARTMANN, D. L. Global physical climatology. San Diego: Academic Press, 1994. 411 p, 1994.

HERTIG, J. A. A Stratified Boundary Layer Wind Tunnel Designed for Wind Engineering and Diffusion Studies. Journal of Wind Engineering and Industrial Aerodynamics, 16, 265-278, 1984.

HIGSON, H. L., GRIFFITHS, R. F., JONES, C. D., HALL, D. J. Concentration measurements around an isolated building: a comparison between wind tunnel and field data. Atmos Environ 28(11):1827-1836, 1994.

HUBER, A.H., SNYDER, W.H. Building wake effects on short stack effluents. Preprints, Third Symposium on Atmospheric Turbulence, Diffusion, and Air Quality. 19-22 October 1976, Raleigh, NC, American Meteorological Society, Boston, MA, pp. 235-242, 1976. 
HUBER, A.H. The influence of building width and orientation on plume dispersion in the wake of building. Atmospheric Environment 23 (10), 21092116, 1989.

HUBER, A. H. Wind tunnel and Gaussian plume modelling of building wake dispersion. Atmos Environ 25A:1237-1249, 1991.

HUNT, J. C. R.; POULTONE, E. C.; MUMFORD, J. C. The effects of wind on people; new criteria based on wind tunnel experiments. Submitted to Building Sci, 1975.

HUNT, J. C. R. e FERNHOLZ, H. Wind tunnel simulation of the atmospheric boundary layer; a report on Euromech 50. Journal Fluid Mechanics, Londres, 70 (3): 543-59, Aug, 1975.

HUNT, J. C. R., SNYDER, W. H. Experiments on stably and neutrally stratified flow over a model three-dimensional hill. J. Fluid Mech., vol.96, part 4, pp. 671704, 1980.

IRWIN, J. S. Schemes for Estimating Dispersion Parameters as a Function of Release Height. EPA-600/4-79-062. US EPA,Washington. DC, 1979.

IRWIN, H.P.A.H. The design of spires for wind simulation. Journal of Wind Engineering and Industrial Aerodynamics, 7, pp. 361-366, 1981.

ISO GUM. Avaliação de dados de Medição - Guia para a expressão de incerteza de medição. $1^{\text {a }}$ edição brasileira, 2008.

ISOLAPLAST. Isolaplast: O Perfil da Qualidade. Disponível em: < http://www.isolaplast.com.br/index.php?option=com_content $\& v i e w=\operatorname{article} \& i d=9$ 4\&Itemid=146>. Acesso em 24 jul., 2016.

ISYMOV, N., TANAKA, H. Wind tunnel modelling of stack gas dispersion Difficulties and aproximations. Wind Engineering, Proceedings of the fifth 
International Conference, Fort Collins, Colorado, USA, Ed. by J. E. Cermak, Pergamon Press Ltd, 1980.

JANSSEN, L. A. M. Wind Tunnel Modelling of Dispersion of Odours in the Neighborhood of Pig houses. Journal of Industrial Aerodynamics, vol. 4, pp. 391398, 1979.

JEGEDE, O. O., FOKEN, T. A study of the internal boundary layer due to a roughness change in neutral conditions observed during the LINEX field campaigns. Theoretical and Applied Climatology, v. 62, p. 31-41, 1998.

LAZARIDIS, M. First principles of meteorology and air pollution. Vol 19, Springer, 2010.

LORA, E. E. S. Prevenção e controle da poluição nos setores energético, industrial e de transporte. 2 ed. Rio de Janeiro: Interciência, 2002.

LORD, G. R., LEUTHEUSSER, H. J. Wind tunnel modelling of stack discharge. Man and his environment, vol. 1, M. A. Ward, Editor, Pergamon Press Inc., 1970.

LOREDO SOUZA, A. M., SCHETTINI, E. B. C., PALUCH, M. J. Simulação da camada limite atmosférica em túnel de vento. In: Möller, S. V., Silvestrini, J. H. Turbulência. Porto Alegre: Associação Brasileira de Ciências e Engenharia Mecânica, 2004, vol.4, p.137-164, 2004.

MASSARI, P. de L., GOMES, M. S. P., FARIAS, M. H., TEIXEIRA, R. Numerical and experimental study of the generation of atmospheric boundary layer profile in wind tunnel. $16^{\text {th }}$ Brazilian Congress of Thermal Sciences and Engineering. 07 - 10 Novembro. Vitória - Espírito Santo, 2016.

MAVROIDIS, I., GRIFFITHS, R. F., HALL, D. J. Field and wind tunnel investigations of plume dispersion around single surface obstacles. Atmospheric Environment. Vol. 37, pp. 2903-2918, 2003. 
MIRZAI, M.H., HARVEY, J.K., JONES, C.D. Wind tunnel investigation of dispersion of pollutants due to wind flow around a small building. Atmospheric Environment 28 (11),1819-1826, 1994.

MÖLLER, S. V., SILVESTRINI, J. H. Turbulência: Fundamentos. In: Möller, S.V., Silvestrini, J. H. Turbulência. Porto Alegre: Associação Brasileira de Ciências e Engenharia Mecânica, 2004, vol.4, p.1-32, 2004.

MERONEY, R., NEFF, D. Laboratory simulation of liquid natural gas vapour dispersion over land or water. Wind Engineering, Proceedings of the fifth International Conference, Fort Collins, Colorado, USA, 2, pp. 1139-1149, Ed. by J. Cermak, Pergamon Press Ltd., 1980.

MERONEY, R. N., MELBOURNE, W. H. Operating ranges of metrological wind tunnels for the simulation of convective boundary layer phenomena. Boundary Layer Metrological, 1992.

MORAES, O. L. L., ACEVEDO, O. Fluxos turbulentos na atmosfera. In: Moreira, D. M., Carvalho, J. C., Vilhena, M. T. Tópicos em Turbulência e Modelagem da Dispersão de Poluentes na Camada Limite Planetária. Porto Alegre: Universidade Federal do Rio Grande do Sul, 2005, p. 17-29, 2005.

NISHI, A., MIYAGI, H. Computer-controlled wind tunnel for wind engineering applications. Journal of Wind Engineering and Industrial Aerodynamics, 54/55, 493-504, 1995.

OHBA, R.; SHAO, Y.; KOUCHI, A. A wind tunnel and numerical investigation of turbulent dispersion in coastal atmospheric boundary layers. Boundary Layer Meteorology, v.87, n.3, p. 255-273, 1998.

OMEGA. Omega: Your Source for Process measurement \& Control. Disponível em: < http://www.omega.com/prodinfo/thermocouples.html\#learn>. Acesso em 18 out. 2016. Omega, 2017. 
OWEN, P. R. e ZIENKIEWICZ, H. K. The production of uniform shear flow in a wind tunnel. Journal of Fluid Mechanics, 1957, 2 521—531, 1957.

PARKER, A. Industrial air pollution handbook. Mc Graw-Hill Book Company (UK) Limited, London, 1977.

PASQUILL, F. Atmospheric Diffusion. 2nd ed., John Wiley and Sons, New York, 1974.

PETERSEN, R. L. Effect of homogeneous and heterogeneous surface roughness on heavier-than-air gas dispersion. Journal of Wind Engineering and Industrial Aerodynamics, Vol.36, pp. 643-652, 1990.

PLATE, E. Aerodynamic characteristics of atmospheric boundary layers. U.S. Atomic Energy Commission, Ofice of Information Services (T.I.D. - 25465), 1971.

PLATE, E. J. Wind tunnel modelling of wind effects in engineering. Engineering Meteorology, Ed. by E. J. Plate, Elsevier Scientific Publishing Company, Amsterdam, 1982.

POREH, M., KACHERGINSKY, A. Simulation of plume rise using small wind tunnel models. Journal of Wind Engineering and Industrial Aerodynamics, 7, 114, 1981.

RAMSAY, S. Air Pollution. Notas de Aula. Mimeografado, 1992.

ROBINS, A. G. Experimental model techniques for the investigation of the dispersion of chimney plumes. Proc. Inst. Mech. Engrs, 189, 44, 1975.

RUSCHEWEYH, H., FISHER, K. Aerodinamic effects of large natural-draught cooling towers on the atmospheric dispersion from a stack, Journal of Industrial Aerodynamics, 4, 399-413, 1979. 
SAÏD, N. M., MHIRI, H., LE PALEC, G., BOURNOT, P. Experimental and numerical analysis of pollutant dispersion from a chimney. Atmospheric Environment. Vol. 39, pp. 1727-1738, 2004.

SAÏD, N. M., MHIRI, H., LE PALEC, G., BOURNOT, P., BAOUABE, I. B. Experimental and numerical analysis of the jet dispersion from a bent chimney around an obstacle. Heat Mass Transfer. Vol. 47, pp. 323-342, 2010.

SANTA CATARINA, M. F. Avaliação do escoamento no Centro de Lançamento de Foguetes de Alcântara: estudo em túnel de vento. 1999, p. 72. Relatório Final de Atividades de Iniciação Cientifica, Instituto Tecnológico de Aeronáutica (ITA), São José dos Campos, 1999.

SCHON, P. J., MERY, P. A Preliminary Study of the Simulation of Neutral Atmospheric Boundary Layer using air injection in a wind tunnel. Atmospheric Enviromental Pergamon Press. Vol. 5, pp. 299-311. Great Britain, 1971.

SEINFELD, J. H. e PANDIS, S. N. Atmospheric Chemistry and Physics: from air pollution to climate change. $2^{\text {nd }}$ ed. John Wiley \& Sons, INC, 1963.

SEINFELD, J. H., PANDIS, S. N. Atmospheric chemistry and physics: from air pollution to climate change. [S.I.]: Ed. John Wiley \& Sons, 1326p., 1998.

SHOJAEE, S. M. N.; UZOL, O.; KURC, Ö. Atmospheric boundary layer simulation in a short wind tunnel. Int. J. Environ. Sci. Technol. (2014) Vol. 11, pp. 59-68, 2013.

SHUTTERSTOCK. Shutterstock. Disponível em: < https://www.shutterstock.com/de/video/clip-2953126-stock-footage-industrialplant-with-smoke-air-pollution-concept.html>. Acesso em 12 set. 2016. Shutterstock, 2017. 
SILVEIRA, A. N. Fundamentos de turbulência nos fluidos. III Escola de Primavera em Transição \& Turbulência (Mini-cursos), UFSC, Florianópolis/SC, Edit. C. Deschamps e J. Barbosa, UFSC, pp. 1-52, 2002.

SIMIU, E. e SCANLAN, R. Wind effects on structures, 2nd ed. Wiley, New York, 1986.

SMITH, F. B. Atmospheric Structure: Proceedings of "Air Pollution Modelling for Environmental Impact Assessment". International Centre for Theoretical Physics, Trieste, June, 1990.

SOUZA, L. M. A., Schettini, C. B. E., Paluch, J. M. Simulação da Camada Limite Atmosférica em Túnel de Vento. Associação Brasileira de Engenharia e Ciências Mecânicas. IV Escola de Primavera de Transição e Turbulência. Porto Alegre, Rio Grande do Sul, 2004.

STATHOPOULOS, T. Design and Fabrication of a Wind Tunnel for Building Aerodynamics. Journal of Wind Engineering and Industrial Aerodynamics, 16, pp. 361-376, 1984.

STULL, R. B. An Introduction to boundary layer meteorology. Dordrecht: Kluwer Academic Publishers, 1997.

STULL, R. B. An introduction to boundary layer meteorology. Kluwer Academic Publishers, 1998.

SUTTON, O. G. Micrometeorology. McGraw-Hill, pp. 333, 1953.

THERMOPEDIA. Thermopedia: A-to-Z Guide to Thermodynamics, Heat \& Mass Transfer, and Fluids Engineering. Disponível em: <http://www.thermopedia.com/content/853/>. Acesso em 16 jan. 2017. Thermopedia, 2016. 
THOMPSON, R. S. Building amplification factors for sources near buildings: a wind tunnel study. Atmospheric Environment. Vol. 27A, $\mathrm{N}^{\circ} 15$, pp. 2313-2325, 1993.

TEMPLEMAN, B., et al. Analysis of vertical dispersion and relative concentration of an elevated plume in the tropical boundary layer video digitization. Atmospheric Environment, Pergamon Press, 1990. Vol 24A, № 4, pp 853-858, 1989.

TEnneKeS, H. e Lumley, J. L. A First Course in Turbulence. The M.I.T. Press, Cambridge, 1994.

TURNER, D. B. Workbook of Atmospheric Dispersion Estimates, Washington, D.C., HEW, 1969.

WHITE, B. R. Wind tunnel wake measurements of heavier than air gas dispersion near a two dimensional obstacle. Boundary- Layer Meteorol 38:105124, 1987.

WILLS, B. A. J. A method of atmospheric boundary layer simulation.

WISE, E. F. A. Effects due to groups of buildings. Phil. Trans, pp.469, 1971.

WITTWER, A. R. Simulação do vento atmosférico e dos Processos de dispersão de poluentes em túnel de vento. Universidade Federal do Rio Grande do Sul. Escola de Engenharia. Programa de Pós-Graduação em Engenharia Civil - PPGEC. Tese de Doutorado. Porto Alegre, Rio Grande do Sul, 2006.

ZANNetTI, P. The Problem: Air Pollution. In: Zannetti, Paolo. Air Pollution Modeling: Theories, Computational Methods and Available Software. New York: Computational Mechanics Publications, p. 41-55, 1990. 